\title{
DOMESTIC SUPPLY TO GLOBAL DEMAND: REFRAMING THE CHALLENGE OF CANADIAN ENGLISH-LANGUAGE TELEVISION DRAMA
}

\author{
by \\ Irene S. Berkowitz \\ A dissertation \\ presented to Ryerson University and York University \\ in partial fulfillment of the \\ requirements for the degree of \\ Doctorate of Philosophy \\ in the Joint Graduate Program in \\ Communication and Culture
}

Toronto, Ontario, Canada, 2016

(C) Irene S. Berkowitz 2016 


\section{AUTHOR'S DECLARATION FOR ELECTRONIC SUBMISSION OF A DISSERTATION}

I hereby declare that I am the sole author of this dissertation. This is a true copy of the dissertation, including any required final revisions, as accepted by my examiners.

I authorize Ryerson University to lend this dissertation to other institutions or individuals for the purpose of scholarly research.

I further authorize Ryerson University to reproduce this dissertation by photocopying or by other means, in total or in part, at the request of other institutions or individuals for the purpose of scholarly research.

I understand that my dissertation may be made electronically available to the public. 


\title{
Abstract \\ DOMESTIC SUPPLY TO GLOBAL DEMAND: \\ REFRAMING THE CHALLENGE OF \\ CANADIAN ENGLISH-LANGUAGE TELEVISION DRAMA
}

\author{
DOCTOR OF PHILOSOPHY, 2016 \\ IRENE S. BERKOWITZ \\ COMMUNICATION AND CULTURE \\ RYERSON UNIVERSITY AND YORK UNIVERSITY
}

As online TV delivery disrupts conventional TV broadcasting and unbundles TV cable channels, allowing consumers to choose programs and TV brands more directly, hit content is "king" more than ever before. This dissertation offers a new analysis of Canadian English-language TV drama content's failure to mature into a popular genre or robust economic sector since its introduction in the 1960s, and suggests ways that the Canadian English-language TV drama value chain might be strategically adjusted in response to global market disruption, by strengthening the development phase. The problem is approached with two methodologies: value chain analysis and qualitative field research. Findings identify weak links in the value chain and propose that the Canadian English-language TV drama content model is structurally flawed and has inhibited maturation of the sector. The study theorizes a TV drama value chain composed of 3 functional segments (develop, produce, distribute) and identifies the root of the Canadian drama problem as the creation phase, known in TV as development, analogous to the R\&D phase in other industries. The theorization explains why decades of policy attention and subsidies targeted to the production phase have not substantially improved domestic or global market performance of Canadian English-language TV drama. Moreover, the reframing reveals that development and distribution are functionally linked, while the production phase is the most separate. Theorization and field research concur that a strong imperative for financial returns is essential for successful creative results, from the earliest moments of development. Conversely, a weak link to monetization negatively impacts asset creation, impairing the development phase and, in the case of Canadian English-language TV drama, inhibits its capability to compete effectively in a 21 st-century drama attention economy that increasingly rewards creative excellence. Interviews with stakeholders occupying elite development positions in the Canadian and Hollywood TV drama industry confirm an urgency to upgrade development to foster transformation of Canada's TV drama model, from one purposed for domestic supply to one driven by global demand, and in so doing, future-proof Canadian TV drama for the digital age. Against the backdrop of Canada's unique geo-cultural position vis a vis the U.S., characterized by brain drain of high-performing Canadian TV drama creators to Hollywood and attempts by Canadian English-language TV drama to compete with Hollywood hits, this research contributes to debates on cluster upgrading, local-global linkages, and economic diasporas that focus on 
value capture of highly skilled professionals who seek career acceleration in global escalator regions. Findings are applicable to any nation upgrading domestic creative industries which, like TV drama, are characterized by an imperative for innovation excellence in R\&D-intensive global value chains.

Keywords: brain drain, broadcasting policy, Canadian television, cluster upgrading, creative industries, economic diasporas, global value chains, Hollywood, local-global linkages, prime time television, showrunners, television development, television disruption, value chain, value chain evolution (VCE) 


\section{Acknowledgments}

I am profoundly grateful for the support of so many distinguished individuals in the Ryerson and York University communities, as well as for the entirety of the Communication and Culture program and purpose. The dedication of my Research Supervisor, Dr. Charles H. Davis (Associate Dean, Scholarly Research and Creative Activities; E.S. Rogers Sr. Research Chair in Media Management and Entrepreneurship; Professor, RTA School of Media, Ryerson University), whose title indicates the array of demands on his time, was unfailing in the provision of guidance, encouragement, and wisdom from the moment this project took shape, kicking off with an award-winning essay. My equally esteemed Committee, Dr. Greg Elmer (Ryerson University Bell Globe Media Research Chair and Professor of Communication and Culture/Radio and Television Arts, RTA School of Media) and Peter S. Grant (Canada's foremost telecommunications and entertainment lawyer, distinguished media author, and York University Professor) have been most generous and invaluable contributors to this process. Dr. Paul S. Moore, Director of the Ryerson University Joint Program in Communication and Culture, provided remarkable, timely encouragement, as did Interim Director Izabella Pruska-Oldenhof. Each of my Professors in preliminary course work, including Dr. Wendy Cukier (Vice-President, Research and Innovation, Ryerson University); Dr. Joy Cohnstaedt; Professor Trina McQueen (Adjunct Professor, Schulich School of Business, former President and COO, CTV); Professor Ken Engelhart (Senior VP, Regulatory, Rogers Media); Professor Liora Salter (Professor, York University, Osgoode Hall Law School); and Dr. Michael Murphy (Professor, RTA School of Media and York-Ryerson Joint Graduate Program in Communication and Culture) each and all illuminated arenas of knowledge crucial to achieving this goal. The consultations of Ryerson University colleagues, including Dr. Kim Bates (MBA Program Director, Ted Rogers School of Management) and Emilia Zboralski (PhD Candidate, Communication and Culture), have been so important to this journey. I am indebted to Margaret Kennedy (retired CRTC officer) and Pip Wedge (Executive Director, Canadian Communications Foundation, former Vice President, CTV Television Network) who, on the recommendation of Ken Engelhart (Adjunct Professor, York University Osgoode Hall Law School and former Senior VP, Rogers Communications Inc.), generously provided time and expertise regarding the origin of simultaneous substitution. Jay Wolofsky (Communication and Culture Research Librarian) and Natalya Androsova (Dissertation Boot Camp Leader) imparted new skills, precisely when they became essential. Without the support and expertise of the Ryerson University Public Relations Department, including Michael Forbes, Kate Marshall, and Suelyn Toye, I would not have been able to respond to requests to publicize this research. Without the administrative excellence of Jo Ann Mackie and Mark Poulin, this dissertation would not have been completed. Many others in the Ryerson University community, who helped along the way, go unmentioned; I thank each of you. Outside of Ryerson, and in addition to media outlets, 
which requested my perspectives in recent months, I would like to thank Cher Jones (Socially Active), David Zitzerman (Goodmans LLP), as well as professionals at the Canada Media Fund and the Canadian Media Production Association, who graciously responded to my requests for information and documents. I also thank a number of Canadian Radio-television and Telecommunications Commission (CRTC) professionals, who expressed interest in this research, especially during the 2014 Let's Talk TV proceedings. Profound thanks to CRTC, for recognition of observations included in this thesis, on March 12, 2015, in Broadcast Regulatory Policy 2015-86. On a personal level, I would like to thank certain friends, especially Sandy, Rhonda, and Elise, without whose constant encouragement this effort would not have been completed. Finally, and above all, to each member of my precious family, thank you for your unfailing support and (often tested) patience: Mom, Dad, Stuart, Bob, Eileen, Rebecca, Andrew, Julie, Rory, Emily, Matthew, Dylan, Lucas, Lily and Charlie. You are my daily blessings and my divine inspiration. 


\section{Dedication}

"So what you're doing, you are now trailblazing." (Respondent, Canadian, A-list Hollywood showrunner)

This dissertation is dedicated to each and all of the informants. You are the stars of this story. Each of you was incredibly generous with your precious time, brilliant insights, compelling perspective, and passion for the topic of TV drama development. Each of you works at an elite level in this complex and often hidden arena. Many of you are Canadian creators who have ascended to eminence in Hollywood, through a combination of extraordinary talent and unimaginable levels of dedication, discipline, and hard work. As well, profound thanks are extended to your exceptionally gracious Agents and Assistants. When I started this project, I never dreamed you would speak with me, much less address the issues with such candour and engagement. As per your talents, you told me quite a story.

Fate delivered a timely opportunity to take your story to the Canadian government and to the Canadian public, namely the CRTC's 2014 inquiry into the future of Canadian TV, Let's Talk TV. During this process, the CRTC listened to a remarkable tale. A result, as of March 12, 2015, is that your views appear to have made history. They've helped to shift the future of Canadian English-language TV drama, by reframing its goal from domestic supply to global demand, and have helped guide the sector into the era of online TV delivery. I hope the following pages, which relate your perspectives at length, honour your stories with the quality of telling they deserve. Thank you. 


\section{Table of Contents}

Page

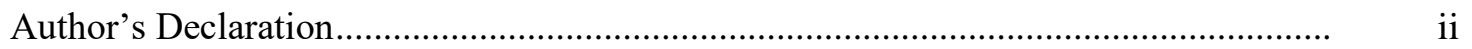

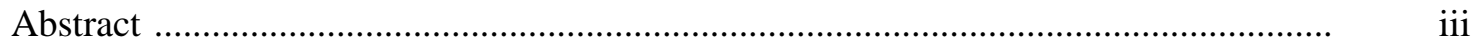

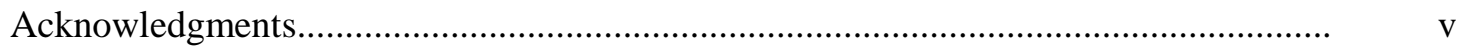

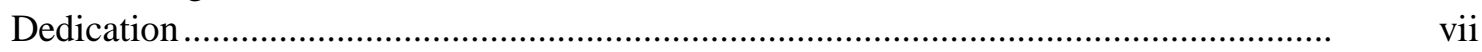

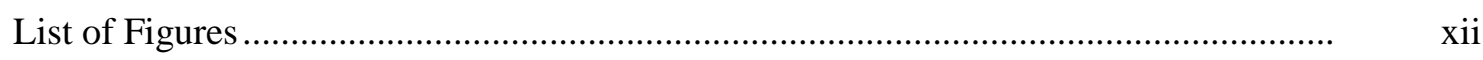

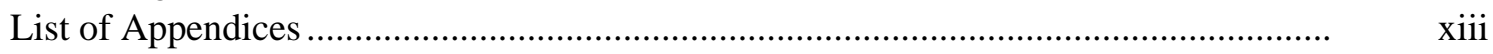

CHAPTER 1: THE DRAMA OF CANADIAN, ENGLISH-LANGUAGE PRIME TIME

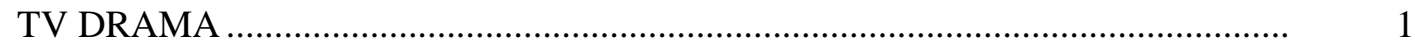

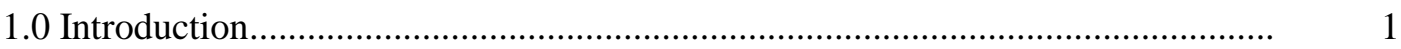

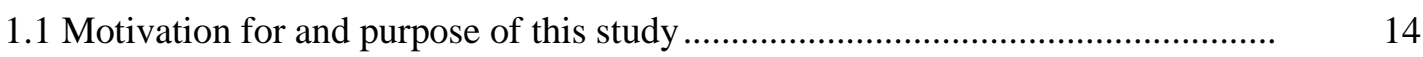

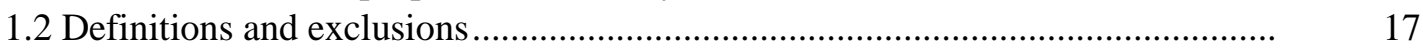

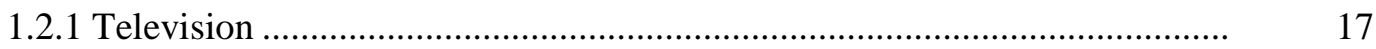

1.2.2 Development; production; distribution ................................................... 17

1.2.3 Network; broadcaster; studio ................................................................. 17

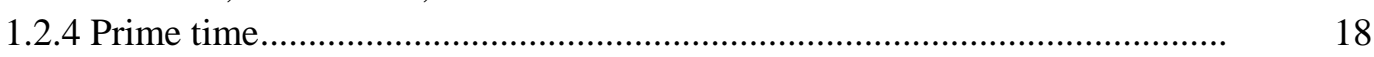

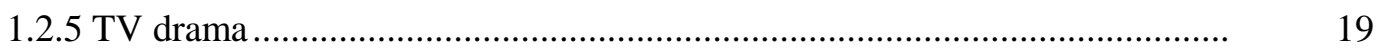

1.2.6 Canadian English-language prime time TV drama....................................... 19

1.2.7 Showrunner....................................................................................... 20

1.2.8 A list, B list ....................................................................................... 20

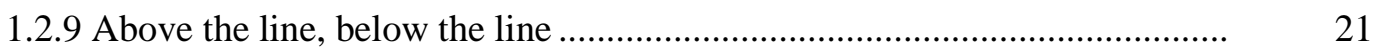

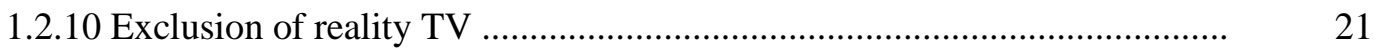

1.2.11 Exclusion of Canadian French-language TV ......................................... 21

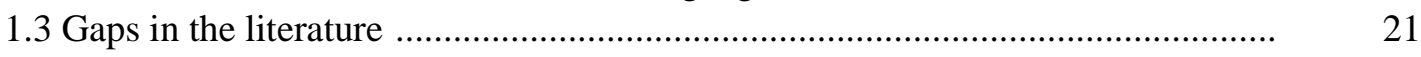

1.3.1 Gap: Overview of Hollywood and Canadian TV drama ............................ 23

1.3.2 Gap: Policy review of Canada-U.S TV relationship.................................. 24

1.3.3 Gap: Value chains and global value chains .............................................. 24

1.3.4 Gap: Cluster upgrading, local-global linkages, economic diasporas............... $\quad 25$

1.4 Research questions and hypotheses ............................................................. 27

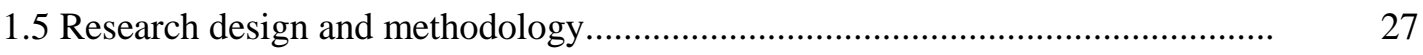

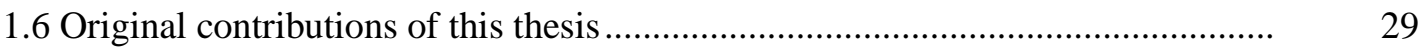

1.6.1 Contribution to theory.......................................................................... 29

1.6.2 Contribution to field research ............................................................... 29

1.6.3 Contribution to cluster upgrading studies ............................................... 30

1.6.4 Contribution to economic diaspora studies.............................................. $\quad 30$

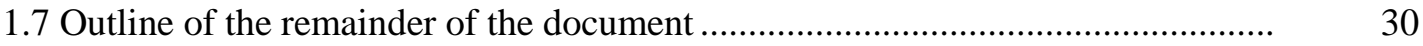

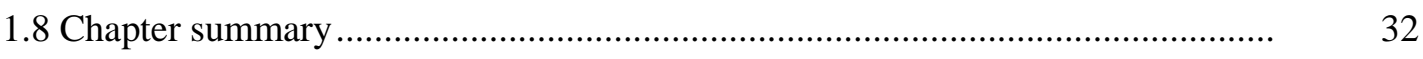

CHAPTER 2: GLOBAL DEMAND VERSUS DOMESTIC SUPPLY ......................... 33

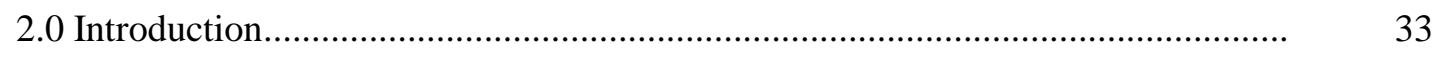

2.1 Foundational concepts: Hits, popularity, and brand ….................................... $\quad 35$

2.1.1 Hit content is king............................................................................ 35

2.1.2 Popularity versus quality .................................................................... 40

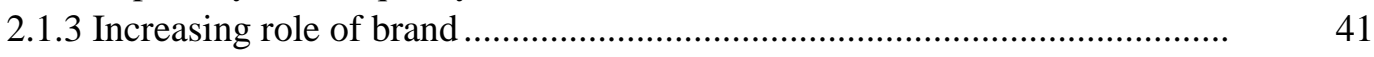




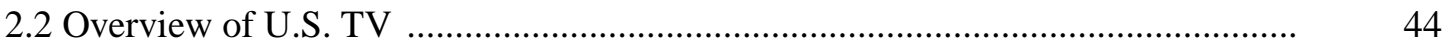

2.2.1 Hollywood TV drama development .................................................... 46

2.3 Overview of Canadian English-language TV .................................................. 52

2.3.1 Canadian content ........................................................................................ $\quad 60$

2.3.1.1 Canadian English-language TV drama ............................................. 64

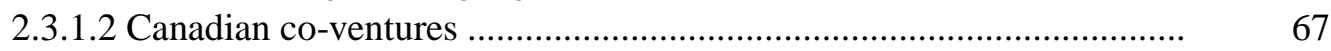

2.3.1.3 Canadian international treaty co-productions ....................................... 68

2.3.2 Canadian English-language TV drama development ............................... 68

2.3.3 Canadian brain drain to Hollywood............................................................ 71

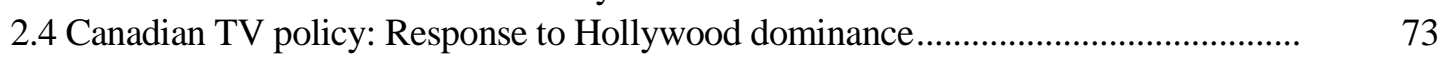

2.4.1 Canada-U.S. media relationship ............................................................ 73

2.4.2 Timeline of Canadian response to Hollywood dominance .......................... $\quad 75$

2.4.2.1-1929: Aird Commission................................................................. $\quad 75$

2.4.2.2-1949-1951: Royal Commission on National Development in the

Arts, Letters, and Sciences (Massey Commission) .................................. $\quad 75$

2.4.2.3-1968: Broadcasting Act and creation of CRTC ............................... 77

2.4.2.4-1959: Canadian content .................................................................. $\quad 78$

2.4.2.5 - 1970-1971: Simultaneous substitution ....................................... 78

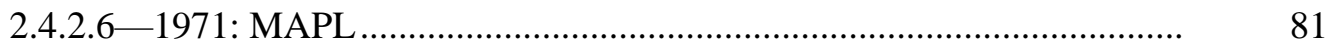

2.4.2.7-1983: Canadian content funding models ....................................... $\quad 82$

2.4.2.8 - 1986: Will technology be the ultimate de-regulator? ...................... $\quad 82$

2.4.2.9-1988: Free-trade......................................................................... 83

2.4.2.10 - 1999: Online exemption ........................................................ 84

2.4.2.11-2003: Our cultural sovereignty …............................................ 84

2.4.2.12 -2003: Drama crisis ................................................................ 85

2.4.2.13 - 2011: Programs of National Interest (PNI).................................. 86

2.4.2.14-2014: CRTC's Let's Talk TV ....................................................... 86

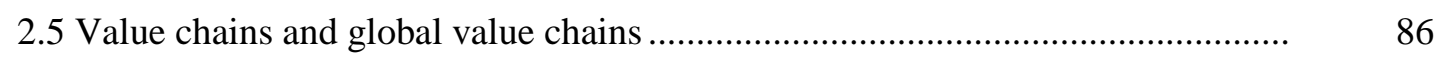

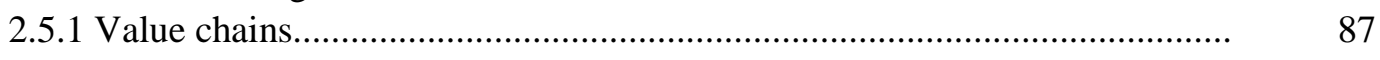

2.5.2 Global value chains......................................................................... 89

2.6 Cluster upgrading, local-global linkages, and economic diasporas ..................... $\quad 90$

2.6.1 Cluster upgrading................................................................................. $\quad 90$

2.6.2 Local-global linkages ....................................................................... 94

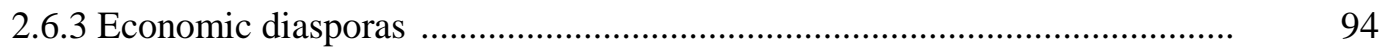

2.6.4 Two important studies ..................................................................... 96

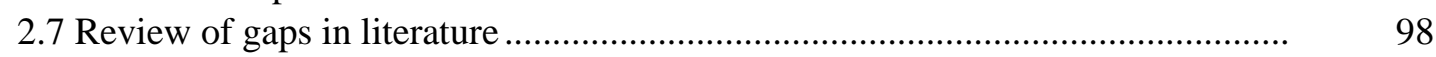

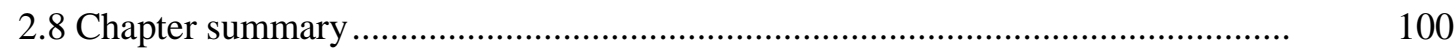

CHAPTER 3: A BRIDGE TO NOWHERE: THEORETICALLY REFRAMING

CANADIAN ENGLISH-LANGUAGE TV DRAMA …...................................... 101

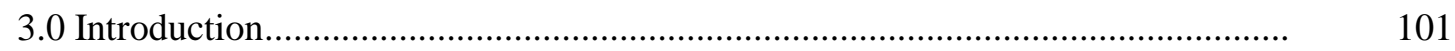

3.1 Reframing the Canada-U.S. TV relationship as 3Ps ......................................... 104

3.2 Reframing TV drama value ...................................................................... 106

3.3 Reframing the Canadian TV drama value chain: Bridge to nowhere ................... 109

3.3.1 Monetization phase of Canadian TV drama: Weakest link ......................... 111

3.3.2 Manufacturing phase of Canadian TV drama: World-class ......................... 117

3.3.3 Development phase of Canadian TV drama: Warped ................................ 120 
3.4 Reframing local-global linkages in Canadian TV drama: Follow the money.......

CHAPTER 4: METHODOLOGY OF THE FIELD RESEARCH …............................. 127

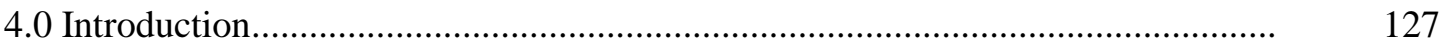

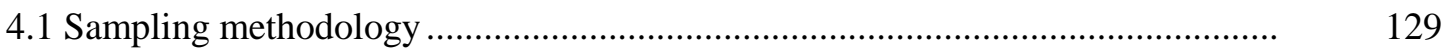

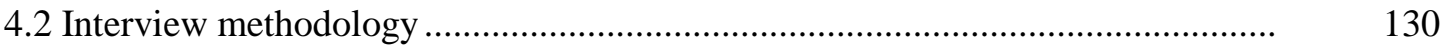

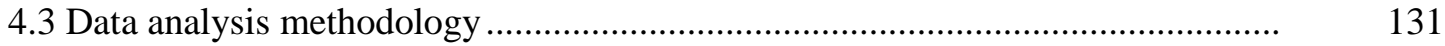

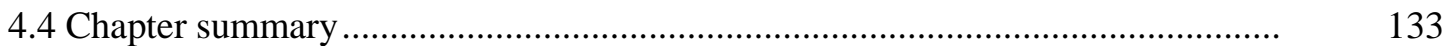

CHAPTER 5: FINDINGS, PART 1-HIT CONTENT IS KING: ROLE OF

DEVELOPMENT IN CANADIAN TV DRAMA ................................................... 134

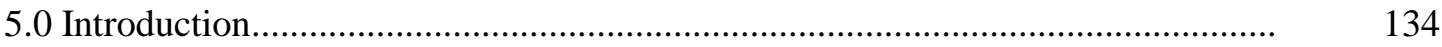

5.1 Role of development in the TV drama value chain ............................................. 134

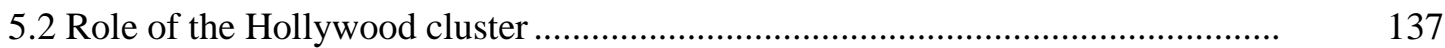

5.3 Comparing TV drama development in Canada and Hollywood ........................... 139

5.4 Canadian TV drama brand ........................................................................... 142

5.5 Current challenges in Canadian TV drama development .................................... 143

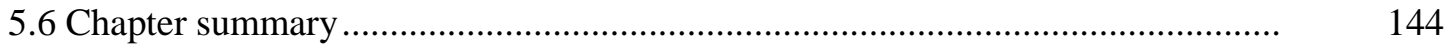

CHAPTER 6: FINDINGS, PART 2-FOLLOW THE MONEY: WEAKEST LINK IN

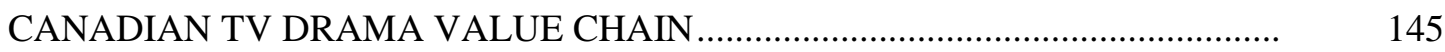

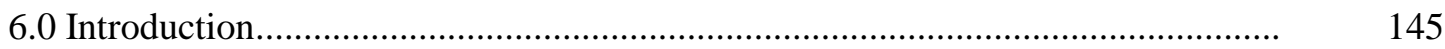

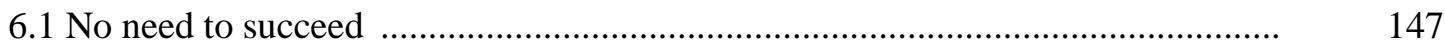

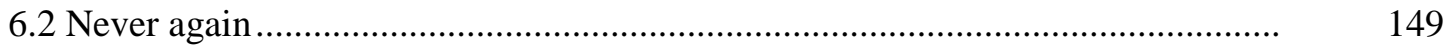

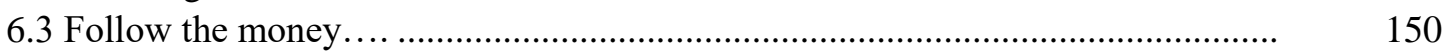

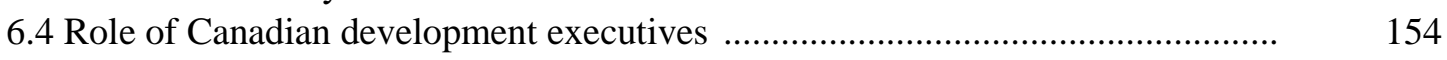

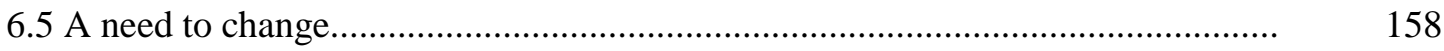

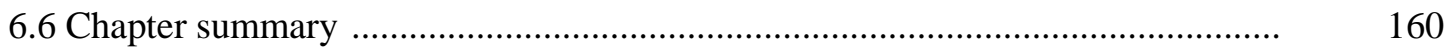

CHAPTER 7: FINDINGS, PART 3-BRAIN DRAIN TO BRAIN GAIN:

ROLE OF LOCAL-GLOBAL LINKAGES IN CANADIAN TV DRAMA …......... 161

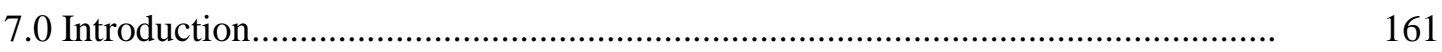

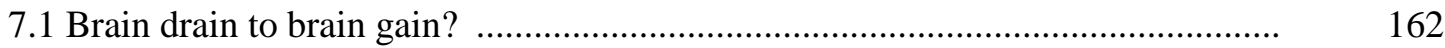

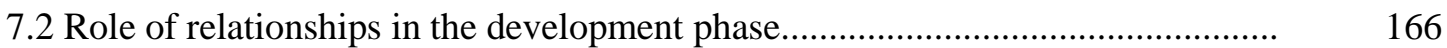

7.3 Reframing writer supply and training as local-global linkage opportunity ......... 168

7.4 Impact of Canadian rules and regulations on local-global linkages..................... 172

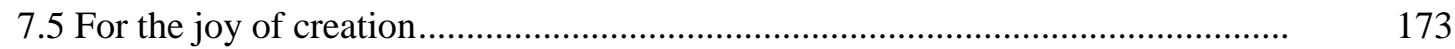

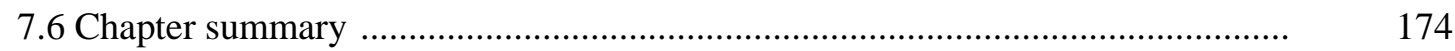

CHAPTER 8: FINDINGS, PART 4—THE WAY FORWARD: INVESTMENT

TO RETURN ON INVESTMENT .................................................................... 175

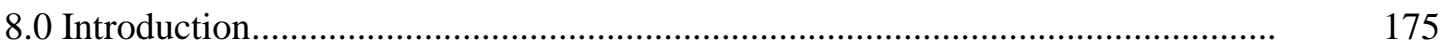

8.1 Responses to $L E A F$, a trial ROI instrument ................................................... 176

8.2 Responses to digital directory of Canadian creators in Hollywood ...................... 179

8.3 Responses to harmonizing TV drama development terms and schedules ............. 181

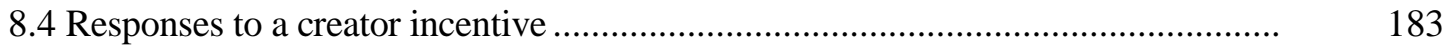

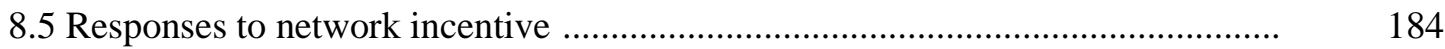

8.6 Other responses: Other countries' competitive advantage................................... 186 
8.7 Final answer: Strongest player to weakest link................................................. 189

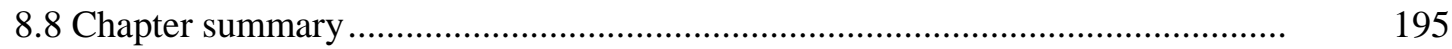

CHAPTER 9: DOMESTIC SUPPLY TO GLOBAL DEMAND: FUTUREPROOFING CANADIAN ENGLISH-LANGUAGE TV DRAMA .......................... 197

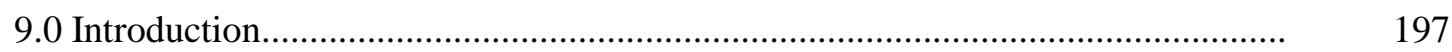

9.1 Review of original contributions of this dissertation ......................................... 200

9.2 Implications of this dissertation for policy and industry..................................... 201

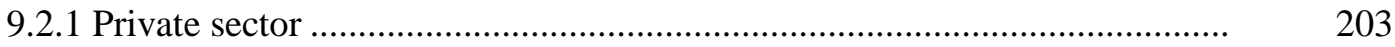

9.2.1.1 VCE: Value chain evolution............................................................. 203

9.2.1.2 Cluster upgrading: Canada-Hollywood linkages ................................ 204

9.2.1.3 RVP: Resources, processes, and values.............................................. 206

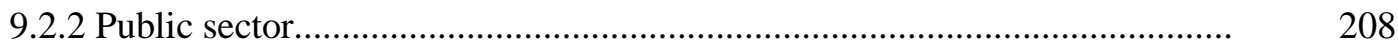

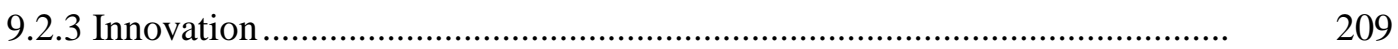

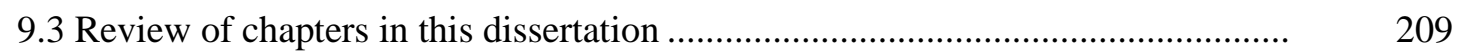

9.4 Limitations of this study and suggestions for future research ........................... 210

9.5 Epilogue: Connecting to the 2014-2015 CRTC public process, Let's Talk TV........ 212

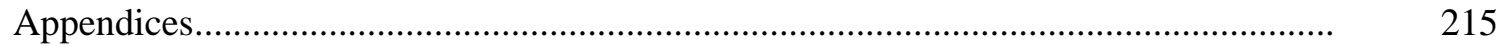

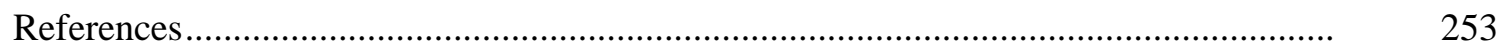

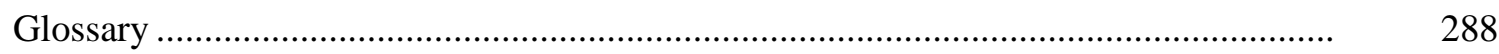




\section{List of Figures}

$\begin{array}{lll}\text { Figure } & \text { Page }\end{array}$

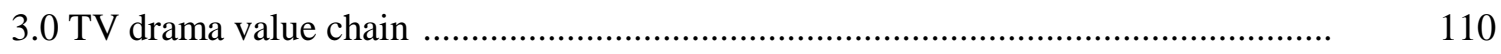

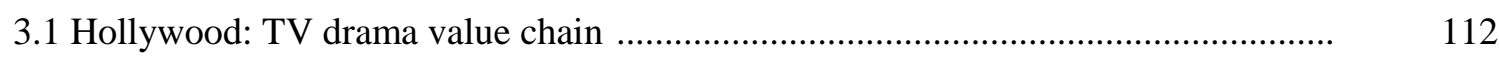

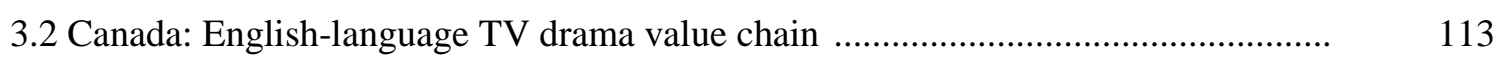

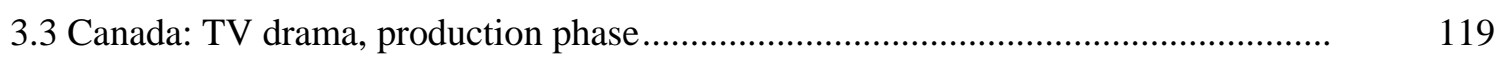

3.4 Hollywood: TV drama value chain, alignment of financial interests, development phase .................................................................................................... 122

3.5 Canada: English-language TV drama value chain, alignment of financial interests,

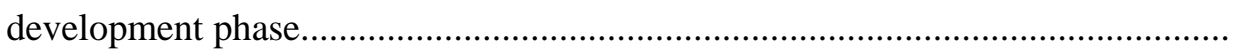

122 


\section{List of Appendices}

$\begin{array}{lll}\text { Appendix } & \text { Page }\end{array}$

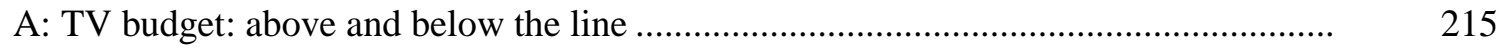

B: U.S.: Top 50 TV programs 2013-2014 .................................................................. 216

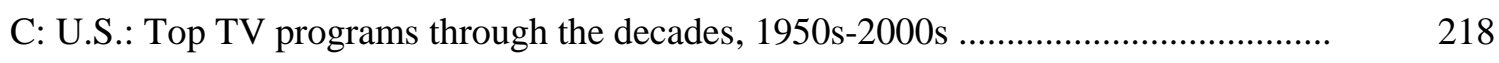

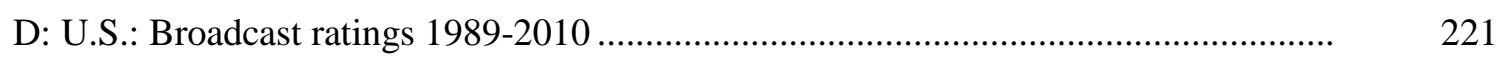

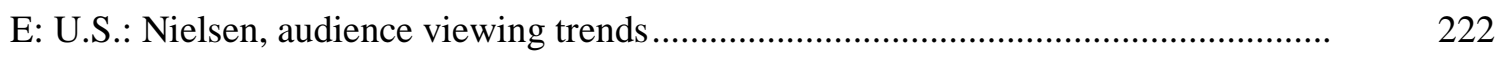

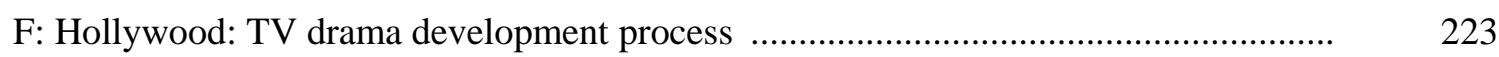

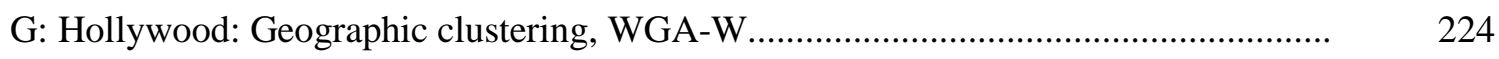

H: Hollywood: Entities commissioning original TV drama ........................................ 225

I: Canada: Prime time audience viewing patterns 1979-2014 _....................................... 226

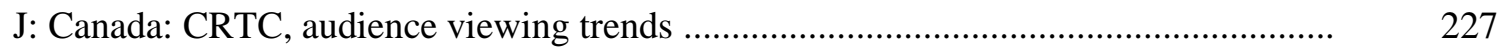

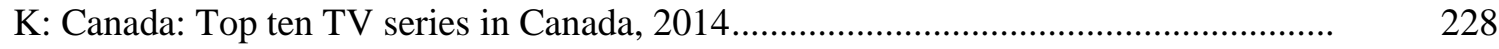

L: Canada: Top ten Canadian TV series, English and French, 2014 …........................... 229

M: Canada: Top ten Canadian English-language TV dramas, 2014 broadcast year......... 230

N: Canada: Top ten CMF-funded English-language programs, 2010-2014 [N-1 to N-4] . 231

O: Canada: English-language premium TV dramas, U.S. presence ……….................... 236

P: Canada: Financial structure, English-language premium TV dramas ........................ 237

Q: Canada: Canadian Media Fund, percent of funding spent on English-language
drama 2005-2015

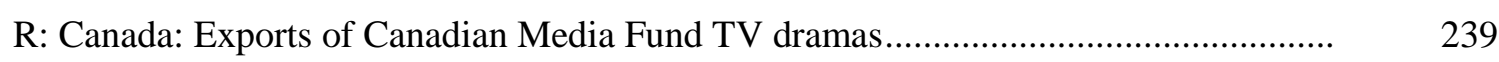

S: Canada: International distributor, Canadian English-language premium TV dramas,

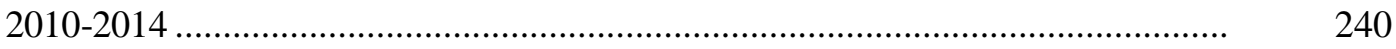

T: Canada: CRTC co-ventures, TV dramas, 2010-2014 ................................................... 241

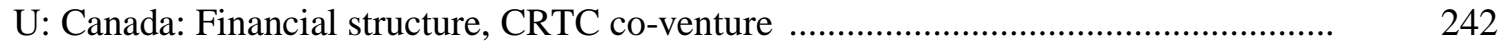

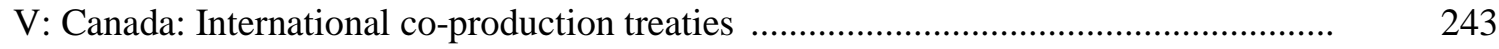

W: Canada: Policy history, Royal Commission on radio broadcasting (Aird Commission) .... 244

$\mathrm{X}$ : Canada: Policy history, CRTC, origin of simultaneous substitution ......................... 245

Y: Canada: Policy history, FCC article on signal substitution........................................ 246

Z: Ryerson University: Research Ethics Board approval through 2015 ....................... 247

AA: Ryerson University: Informant release for field study ......................................... 248

BB: Ryerson University: Semi-structured interview questions and original policies..... 249

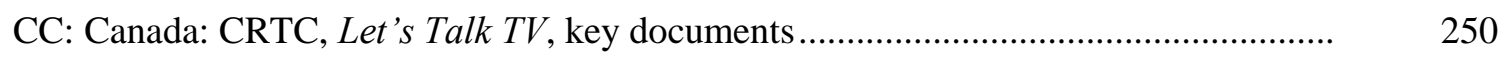

DD: Canada: Media presence: Public impact of this research [chronological] ............... 251 


\section{CHAPTER 1}

\section{THE DRAMA OF CANADIAN ENGLISH-LANGUAGE PRIME TIME TV}

Entertainment is the modern term we apply to story-telling. That human need - to tell, hear and repeat stories - goes back to our beginning. We need entertainment as we need food and shelter. (as cited in Grant \& Wood, 2004, p. 68)

\subsection{Introduction}

At this writing, media is undergoing its most significant shift in nearly 600 years, since the invention of the printing press in the 1450s (Carr, 2010). The global TV industry has long anticipated being caught up in this technology tsunami, which has already profoundly transformed media sectors including music, books, and newspapers. Moreover, many previously non-media sectors, such as banking, researching, socializing, shopping, and many other cultural practices, have joined TV as a screen practice. Much of work, and play, has crowded together in a "global playlist" - experienced anywhere, anytime, on any screen, and nearly always online (Davis, Berkowitz, \& Mills, 2012, p. 1). As long predicted, TV, the original electronic screen media, has now entered a "profound state of transition" and is becoming "unstuck at multiple levels" (O'Regan \& Goldsmith, 2006, p. 69). Through this upheaval of industry structure, technology, and consumption practices, what used to be called prime time, scripted TV content, which is the subject of this dissertation, has remarkably retained popularity, so much so that it is the bait in the switch to online TV viewing. Audiences love TV, newly defined as fictional entertainment, anytime, anywhere, on any screen. People still spend "more time watching television than [on] the Internet, and more time on the Internet [is] spent watching television" (Wolff, 2015b, para. 4). TV, without regard to delivery mode, continues to attract such high levels of audience attention that the second decade of the 21st century has been widely dubbed the latest golden age of TV (Barraclough, 2013; Plunkett \& Deans, 2013), despite the fact that "the age of appointment television is coming to a close" (Parks Associates, 2015, para. 7).

Despite predictions of its demise in the Internet era, TV has such audience appeal that even linear TV network watching has held steady in North America for nearly a decade, at close to 30 hours per week (CRTC, 2010d, 2014a). By some reports, Americans watch up to 5 hours of TV per day (Hinckley, 2014; Libresco, 2015). Even with the transformation in delivery technology, the role of prime time drama, as the core economic engine of TV is holding, for now: "Prime time programs ... remain the centers of longterm profit potential" (Eastman \& Ferguson, 2013, p. 47). In fact, it is the enduring appeal of prime time TV drama that has tempted conventional TV viewers to become hooked on online TV. Consumers have chosen the simplicity of easy, fast, and cheap access to large quantities of TV drama online. Accelerating the disruption, over the top (OTT) online TV distributors, such as Netflix, not satisfied with audiences for second-hand TV hits, have invested heavily in original TV dramas, such as House of Cards (2013-to 
date). A competitive result, for Netflix, has been 50 million global subscribers, predicted to be 100 million by 2020 (Rody-Mantha, 2015). Emboldened by Netflix's success, companies continue to swarm into the online content space, such as digital native Huffington Post (Charlton, 2015).

From a financial perspective, while conventional broadcasting remains (for now) the largest single category of advertising revenue, Internet revenues, largely driven by watching TV online, are reported to be closing in on the long-reigning, global giant (PwC, 2014). Broadband subscriptions in the U.S. and Canada, have surpassed cable (Canadian Media Fund [CMF], 2015b; Wohlsen, 2014). It is claimed that online ad revenues are more profitable, per viewer, than conventional TV ads (McMillan, 2014). The same report, which notes a 5\% CAGR for conventional TV and asserts that the latter is still "the place to be" for advertisers (PwC 2014, TV advertising section, para. 1), also predicts Internet ad revenues will surpass conventional TV by 2018 (PwC, Internet advertising section, para. 1). Such predictions may even fall by the wayside, as the shift accelerates, which currently appears to be causing a decline in linear viewership of more than $10 \%$ per year (Evans, 2015), in favour of online streaming, leading one expert to remark: "this does not bode well for domestic cable TV ad revenues" (Evans, 2015, para. 5).

At this writing, an irreversible shift in the dominant mode of global TV drama distribution seems imminent, from broadcasting and cable to online delivery. Half the buyers of HBO's new HBO-GO app say they will cancel their cable (Parks Associates, 2015); Apple Inc. hints at announcing an iPad app for U.S. networks, to include ABC and CBS (Apple Inc., 2015); and Amazon is debuting an original TV drama series on Facebook (Ariens, 2015).

Like many $\mathrm{PhD}$ dissertations, this one approaches a large story from a very specific vantage, and proceeds to identify a problem that has not been definitively investigated. Standing on the shoulders of previous knowledge, it deepens and extends analyses, puts forth original argument, and ultimately contributes new insights and even proposes solutions to a previously unsolved mystery.

The global decline of conventional broadcasting as a TV drama delivery mode has long been predicted to present challenges for national governments that must "come to terms with changing market conditions" (O'Regan \& Goldsmith, 2006, p. 70). This global change was acknowledged to imply a special vulnerability for Canada, where profits from legacy broadcast and cable distribution, rather than the monetization of original content, has long been the primary business model of broadcasting (Standing Committee on Canadian Heritage, 2003). There has long been a concern for the moment when protective regulation, enabled by the historically robust profitability of conventional broadcasting, would not be able to cross-subsidize original Canadian content, which is required by Canada's Broadcasting Act (The Act) (Government of Canada, 1991). In 1986, a Canadian TV tribunal worried that "technology would be the ultimate deregulator" (Caplan-Sauvageau, 1986, p. 76). Thirty years later, this moment appears to have arrived, forewarned by the irreversible process of content unbundling, which has already impacted other 
media platforms, such as music and newspapers. As TV is increasingly accessed online, it may be that bundled channels of TV channels into cable subscriptions, and potentially, bundles of programs into channels, might become superfluous to the online consumer. In the online era, the ability of an individual program to attract audience attention becomes increasingly visible. This is likely to cause a reckoning for original Canadian English-language TV drama, regarding its ability to attract audience attention, awards, brand prestige, and revenues, whether by ratings, subscriptions, or clicks.

This dissertation enters the global media fracas, not about Canadian TV in general, but specifically about the situation of Canadian English-language prime time TV drama. The dissertation explores why Canadian English-language TV drama, in contrast to Hollywood TV drama, is not considered to be in a golden age. This thesis investigates why the Canadian English-language TV drama sector has not matured, after decades of public assistance, into a financially robust or globally popular genre. On the production side, the need for public funds to support the sector has not declined, with public funds currently providing up to $40 \%$ of the budget of every Canadian TV drama (CMPA, 2015). Despite public assistance, on the audience side, Canadian drama has remained relatively unpopular with domestic and global audiences. During the hours traditionally defined as prime time (8:00 p.m. to 11:00 p.m.), more than $80 \%$ percent of the English-language Canadian TV audiences continue to watch Hollywood TV drama, not Canadian (CMF, 2014c; CMPA, 2015), and have done so since the beginning of TV (Kiefl, 2013; Standing Committee on Canadian Heritage, 2003). Canadian audiences tend to choose Hollywood hits for new practices of online and binge viewing, an indicator being that nearly $40 \%$ of Canadians subscribe to Netflix, up from 30\% in 2013 (CMPA, 2015; Dingham \& Gray, 2015; "Internet Virtually Ubiquitous," 2014; "Nearly 1 in 10," 2015). Nearly a third of Canadian Netflix subscribers are reported to use their Canadian subscription to access the U.S. version of Netflix with a virtual private network, or VPN (Geist, 2015b; Oliviera, 2015), underscoring the Canadian demand for Hollywood hits.

Much has been written about the small audience and its consequence, small financial return, of Canadian English-language TV drama, even by the government, yet the problem has persisted for decades. In the following pages, informants in this dissertation assert that figuring out how to strengthen the market outcome of Canadian English-language TV drama has now become urgent. External pressure to change is problematized in this dissertation as the collision of rapidly compounding global changes, with the unique structure of the Canadian content production business model. This model argues that profits from legacy broadcasting, for decades the strongest pillar in the four-part Canadian system (private broadcasters, public broadcaster, cable distributors, independent producers), are used to cross-subsidize the manufacturing of Canadian content. Moreover, the financial model depends on legacy broadcasting, which, in the Canadian English-language market primarily profits from Hollywood TV due to Englishlanguage audience preferences. This cross-subsidy model was conceived in the mid-20th century, when 
broadcasting was robustly profitable and geographically monetized throughout the world. The new era of global, online TV delivery was unimagined (Cunningham \& Silver, 2013; Noam, 2014; Strangelove, 2015). Moreover, the Canadian model is a TV model which is globally unique, determined by the geocultural proximity of Canada and the U.S., as will be examined closely in the following pages. Further complicating strategies to respond to the change in TV delivery, online distribution in Canada is exempt from regulation and therefore not easily purposed to cross-subsidize Canadian content. The national regulator, the Canadian Radio-television and Telecommunications Commission (CRTC), is, at this writing, limited in its powers to reorganize the value chain, due to its mandate to enforce the tenets of the Broadcasting Act (Government of Canada, 1991), which governs radio and TV, while the Telecommunications Act (Government of Canada, 1993) governs the Internet.

As will be elaborated, the Broadcasting Act (Government of Canada, 1991) stipulates both a cultural and economic importance of original Canadian content. As well, there are many jobs at stake, which justify securing a strong future for Canadian TV, due to decades of successful public governance of Canada's TV drama sector. The CMPA (2015) reports there are 125,000 jobs in the TV and film sector in Canada, of which 50,000 are in TV. Canada's entire telecommunications sector is valued at approximately $\$ 17$ billion, with $\$ 6.5$ billion in TV revenue (CRTC, 2014b), of which $\$ 1.2$ billion is attributed to Canadian English-language TV drama (CMPA 2015).

While relatively small financially, the Canadian English-language prime time TV drama sector appears to be the eye of a perfect storm, a vortex where art, business, audiences, media attention, and even the raw edge of the Canada-U.S. relationship meet. This dissertation enters this vortex at the site of Canadian English-language prime time TV drama, and attempts to understand how this sector might respond to global TV disruption.

Out of the rapidly transforming media melee, a specific mission for this dissertation emerged, which might have been valid a decade or two ago, but which coincidentally became timely, shortly after the field research had been concluded, in Summer 2014. This mission was to understand the role of the development phase of the Canadian English-language TV drama. The argument began with the general observation of the pivotal role of the genre of TV drama in the economics of the TV industry (Kiefl, 2011). The popularity of a TV drama equates to its storytelling excellence, which is the fundamental work of the development phase (Skilton, 2008). Development of TV drama is the phase of the value chain where the asset is created, the D in R\&D (Research \& Development), and can be considered the innovation phase of TV drama. ${ }^{1}$

\footnotetext{
${ }^{1}$ In this dissertation, the term innovation will refer to a change in processes that create new value (Christensen, 2000; Pisano, 2015; Ruttan, 1959), as distinct from invention, a "subset of innovation on which new patents can be obtained" (Ruttan, 1959, p. 603).
} 
This dissertation's argument gained traction with the further observation that while online delivery continues to wreak havoc on the distribution end of the TV drama value chain (Cunningham \& Silver, 2013; Strangelove, 2015), the development phase of the chain has remained relatively stable. Compared to the rapid changes in content delivery and monetization, development might be considered to be distribution agnostic, because the audience's priority is the content of the program, rather than how it gets to a screen. Contemporary hits—such as Netflix's online hit, House of Cards; AMC's cable hit, Breaking Bad; or CBS's conventional network hit, Big Bang Theory-have been created with similar development practices as the CBS network hit I Love Lucy more than 60 years earlier. Despite the use of algorithms to help define audience preferences and select projects to be developed (Madrigal, 2014; Vanderbilt, 2013), there was no evidence in this field research, which includes interviews with some of Hollywood's top A list showrunners, to suggest that the on-the-ground work of TV drama development has yet been practically impacted by digital analytics. The goal of development work appears to be as always: excellence in creators, script, cast, and above all, the ability of a program to attract audience attention.

This thesis pivots on the argument that the genre of Canadian content that, proportionally, consumes the largest amount of public funds is TV drama, which has been a pattern for a decade or more (Le Goff, Brunet, Davis, Giroux, \& Sauvageau, 2011). English-language dramas have consumed about $60 \%$ of English-language funding to the CMF, since 2005 (CMF, personal communication, April 29, 2015; see Appendix Q), about $\$ 200$ million annually. An ongoing puzzle has been that while prime time TV drama is a priority of the government's funding to TV (CMF, 2012b), the genre has not yet succeeded, over nearly six decades, in garnering either a large domestic or a global audience. While TV drama, since the origins of the industry and even during the historic shift to online delivery, has been the most popular genre of content with Canadian audiences, as it is for global audiences, Canadian TV drama is variously estimated to attract $2 \%$ to $10 \%$ of the Canadian English-language prime time viewing audience (CMF, 2015g; CMPA, 2014; CRTC, 2014b; Kiefl, 2011); this dissertation will consider the CMF calculation of $10 \%$. A main point is that this percentage has not significantly budged in nearly 35 years (Kiefl, 2013), as pictured in Appendix I. As others have suggested, the persistence of the audience viewing pattern, compared to the expenditure of public funding, appears to suggest something may have been amiss for decades, which has inhibited Canadian English-language TV drama from attaining popularity (Le Goff et al., 2011). However, that something is not likely the amount of funding in the system, an analysis which the CRTC recently asserted (CRTC, 2015e). The findings of this thesis suggest that the cause of the problem may potentially be situated in the dynamics of the prime time TV value chain, and in particular, in the development phase.

The case could have been made, through most of the previous decades, that a TV business model based on the supply of Canadian content was the correct choice, given the legislated mandate to build a 
TV production sector. Furthermore, the skilled labour in Canada's production centres attracted Hollywood productions, due to available financial discounts, and the Canadian film and TV industry grew into a world-class production sector, third largest in North America, considering Vancouver, Toronto, and Montreal in the aggregate. A result of these efforts is a virtuous circle of strength in the production phase of the value chain, which will be further elaborated in Section 3.3.2 of this dissertation.

While it could have been argued that the development phase of Canadian English-language prime time drama has always been the weakest part of its value chain, externalities in the global TV industry, namely the disruption of conventional broadcasting and the shift to online delivery, have delivered an urgency to understand the cause of the weak market performance of this genre of Canadian content. Informants in this study affirmed an urgency to strengthen Canadian English-language TV drama now, while there is still minimal growth left in the conventional broadcasting sector, which finances Canadian content. Part of the purpose of this dissertation is to join the stories of unprecedented transformation in the TV distribution phase of the Canadian English-language TV drama value chain, with an imperative to strengthen the development phase. Moreover, the observation that distribution and development are codependent is the subject of much focus in the coming pages. Therefore, this dissertation's argument may also be expressed by proposing that there appears to be some urgency for the Canadian TV system to adjust its business model, which currently prioritizes value in the production phase, to include a business model which might be considered a content business model, which would prioritize the development and monetization phases of the TV drama value chain. Such a value chain structure might resemble Hollywood's TV content business model, which is prioritized to create winning content and monetize it.

The focus on the development phase of Canadian English-language prime time TV drama necessitated a focus on the case of the CMF high-budget dramas. As will be further elaborated in Section 2.3.1.1, these series have included Flashpoint, Rookie Blue, Combat Hospital, Saving Hope, and Working the Engels. Because these shows are often licensed by U.S broadcasters, and about half are internationally distributed by U.S. studios (personal communication with informant, June 26, 2015), these shows connect the Canadian English-language TV drama value chain with Hollywood. They are original Canadian content, which aims to partner with Hollywood entities in development, and to compete with Hollywood dramas, in domestic and international distribution, for the attention of Canadian, U.S., and global audiences. As such, the spectre of Hollywood is no bit player in this story about the development phase of Canadian English-language prime time TV drama.

This dissertation defines Hollywood as the planet's dominant cluster for entertainment media, and specifically, for the development of TV drama. Geographically, Hollywood is a "dense agglomeration of motion picture production companies and ancillary services ... within the wider context of Southern California" (Scott, 2005, p. 35). It is also "the single physical location in the world where all the 
necessary ingredients ... are readily accessible” (Hoskins, McFadyen, \& Finn, 2004, p. 319). Perhaps, even more saliently, Hollywood has a mythical power which "radiates a cultural power eerily beyond human scale or comprehension" (Gitlin, 2000, p. 16), attributable to the immense domestic and global popularity of its movie and TV products. TV's historic shift to online delivery has not weakened the dominance of Hollywood as an economic or iconic powerhouse (Cunningham \& Silver, 2013).

Somewhat counter-intuitively, dominant clusters appear to have increased in strength in the digital, knowledge economy (Delgado, Porter, \& Stern, 2010). Therefore, this dissertation further narrows its focus, against a ubiquitous backdrop to the case of Canadian English-language TV drama development, on the relationship of Canadian English-language TV drama to Hollywood. This includes business and creative relationships, which characterize the development phase of Canada-Hollywood partnerships, and also importantly, the long-acknowledged brain drain of Canadian creators to Hollywood (CRTC, 2015e; Government of Canada, Department of Canadian Heritage, 2003; MacDonald, 2007; Royal Commission on National Development in the Arts, Letters, and Sciences [Royal Commission], 1951).

Brain drain is further contextualized by the fact that Canada's largest economic diaspora is in the U.S. (Asia Pacific Foundation, 2011) and by the Canadian government's active promotion of geo-cultural synergies with the state of California (The Canadian Trade Commissioner Service, 2015). There are an estimated 100,000 Canadians working in the Hollywood entertainment cluster (CRTC, 2015e) and also, up to $25 \%$ of Hollywood's creative community has been estimated as Canadian (MacDonald, 2007). These numbers are difficult to verify, since Canada does not track emigration (Asia-Pacific Foundation, 2011). Nevertheless, many Canadians have become high profile, A-list creators who have attained the most elite status in the TV drama industry as showrunners, the lead job on a TV drama series.

Of many paradoxes to be explored in the coming pages, one is that while Canada does not export a substantial percentage of Canadian content drama to the U.S. (CMPA, 2015), it has exported significant numbers of Canadian content creators since the beginning of the industry. While brain drain of creators from Canada to Hollywood, the world's dominant cluster for TV development, has been long documented, the potential value of Canadian brain migrators, and the skills they might bring to the development phase of Canadian English-language TV drama, have not been studied. Unlike other countries, Canada does not appear to have strategically assessed its expat community as a potential asset and designed strategies to systemically recapture value and convert its brain drain into a brain chain (Gereffi, 2011; Lorenzen \& Mudambi, 2013; Smart \& Hsu, 2004). Therefore, the role of local-global, Canada-Hollywood linkages in the development phase of Canadian English-language TV drama will be examined in the coming pages.

This study explores how immutable geo-cultural factors in Canada's relationship to the U.S.conceptualized in Chapter 3 as the 3Ps of population, proximity, and portability-have long contributed 
to a perceived threat of domination by Hollywood of the Canadian English-language TV industry. However, this dissertation argues that each of the Ps might also be perceived as unique opportunity for competitive advantage. As such, connectivity with Hollywood is a thematic presence, which runs through this story about the development dynamics of Canadian English-language, prime time TV drama.

As preparation for this study took shape, it became clear that the development phase of Canadian TV drama not only had been understudied, but also remained under-theorized. To my knowledge, no previous study had situated development of TV drama, not just as a creative enterprise, but as a business function in the value chain of Canadian TV drama manufacturing, or explored how the interplay between financial and creative elements in the development phase might impact the outcome of the manufacturing and monetization process. The findings, because they concern a phase of the Canadian TV drama value chain, which is relatively stable, compared to the rapid shift towards online distribution, may offer insights to the Canadian TV industry, which can be thoughtfully considered.

What, precisely, is the work of TV drama development? Practically speaking, development is the set of business practices, creative and financial, which happen from the moment of a first pitch of a TV drama concept to a financier, to the moment when a TV project is approved, or greenlit, for production. A problem for Canada has been that the development phase, a business function analogous to R\&D in other industries, is acknowledged to be the costliest part of the TV drama process (Eastman \& Ferguson, 2013), and has been estimated to add one-third to the cost of production (Wolf, 1999). It is unimaginably riskyless than 1/1000 chance of success (DeVany, 2004; Grant \& Wood, 2004) — and it involves very few jobs, relative to a TV drama production crew of hundreds. Given the substantial support for TV drama with public funds (Le Goff et al., 2011), it seems understandable that development has received little policy or regulatory attention, which justifiably favours predictable outcomes, such as a supply of original Canadian content, as stipulated by The Act. Nevertheless, as this dissertation will demonstrate, in the current environment, strategically addressing the development phase of Canadian English-language TV drama may be essential.

Urgency is further underscored by the informants, as a need to seize emergent opportunity in Hollywood, amidst the global shift to online TV delivery. While levels of Canadian content production are declining (CMPA, 2015), informants perceive unprecedented creative and business opportunity in the Hollywood TV drama cluster, precisely in the development phase, which should not be missed.

Informants assert that the Hollywood development community is currently characterized by increased receptivity to development partnership, due to increased competition for creative services. While it might seem that Canadian prime time dramas that partner with the U.S. would seem ideally geo-culturally positioned to capitalize on new opportunities in Hollywood, created by online distribution, respondents observed this not to be the case. They reported that Canada appears to be losing competitive edge to other 
countries in TV drama. Informants attributed this phenomenon to weakness in the Canadian development phase, which poorly aligns Canadian networks with the interests of Hollywood studios, which require "limitless focus on creative" (Respondent, Hollywood TV studio executive).

What, then, is the main "drama" in the story of Canadian and Hollywood TV drama? The longstanding narrative has been that, while Hollywood drama is the most expensive, most watched, most profitable media genre on the planet, Canadian TV drama has been the least watched, least profitable Canadian content (McQueen, 2003). This long-standing analysis ties together its creative and market performance. Informants in this study demonstrate explicit understanding of this dynamic, that Canadian networks lose money on Canadian TV drama, but do so to remain in the business of monetizing Hollywood drama (Government of Canada, Department of Canadian Heritage, 2003). The work of this dissertation is to contribute a theoretical approach and a field study that may enable reframing previous analyses, including small audience and insufficient revenue as symptomatic of, rather than the cause of, Canadian English-language TV drama's chronic market weakness. In the following pages, this dissertation reframes development weakness as an unintended consequence of Canadian TV drama policy. Inadvertently, the extant policy framework may have resulted in a value chain structure that appears to compromise the development phase of Canadian English-language premium TV drama, and consequently, may impact its market traction.

Consistent with the Communication and Culture PhD program, of which this dissertation is a product, the scholarly approach of this thesis is interdisciplinary. Unprecedented disruption of the TV industry, including its technology, revenue models and consumer practices, all of which had been reasonably stable for more than 50 years, further suggested a rationale for an unprecedented theoretical approach to examine the development dynamics of Canadian English-language TV drama. As will be elaborated in Chapter 2, a review of diverse arenas of knowledge, including value chains, cluster upgrading, and economic diasporas, was undertaken in the effort to discover the root cause of, and suggest actionable remedies for, market weakness of Canadian English language premium TV drama. Immersion in the field data led to a decision that a priority approach, as elaborated in Chapter 3, would be a value chain analysis (Porter, 1985, 1990, 1996, 1998a, 1998b, 2008), which could be helpful in assessing the extant development dynamics in Canadian English-language TV drama, and as well, might provide a tool for comparing Canadian English-language TV drama and Hollywood TV drama. Furthermore, a theoretical approach, closely related to value chain analysis, might deliver valuable insight on how to approach the problem of effective change, amidst unprecedented transformations. This was value chain evolution, VCE (Christensen, 2000; Christensen, Anthony, \& Raynor, 2013; Christensen, Cook, \& Hall, 2005; Christensen \& Raynor, 2003; Christensen, Raynor, \& Verlinden, 2001), which has been articulated as an industry response to disruptive innovation. VCE implies a need to adjust a value 
chain in order to shift value to where it is demanded in the marketplace. VCE theory seemed to suggest a valuable theoretical tool, to enable a policy response to market conditions in the online era. These tools seemed important, since the question of market performance of Canadian English-language TV drama had been posed during five decades, but yet lacked a satisfactory answer. Moreover, field data for this study suggested that discovering a key to market traction for Canadian English-language prime time TV may have become urgent. This is so, because the decline of legacy broadcasting directly correlates to the decline of financing to Canadian content, and Canadian TV drama policy has long set the source of such financing to be the cross-subsidization of profits from legacy broadcasting.

It seemed advisable to deploy unconventional approaches to aid in the analysis of development dynamics, amidst the ongoing "mediaquake, where the landscape is being redefined at breakneck speed" (Guarino, 2015, para. 16). Nevertheless, the main theoretical approach of the dissertation, as described above, to problematize challenges in the development phase of Canadian English-language TV drama as value chain issues, situates the dissertation in the wider context of cultural economy, an arena of media scholarship which explores intersections of economy and culture (Gibson \& Kong, 2005).This study, of the development phase of TV drama, might be situated as a management or economic sectoral study (Gibson \& Kong, 2005; Scott, 2005), as distinct from three other categories of cultural economy. These include a labour market approach (Miller, Govil, McMurrin, Maxwell, \& Wang, 2005); a creative index approach (Florida, 2002, 2007, 2008); and a political economy approach (Adorno, 1991; Garnham, 2005), which, together with the economic sectoral approach, are considered to be the four main categories of cultural economy (Gibson \& Kong, 2005).

Further to the approach of this dissertation, and intersecting with many discussions in cultural economy, are rich debates regarding notions of culture, entertainment, popularity, as well as debates regarding the definition of the cultural, creative, and entertainment industries (Adorno, 1991; Jenkins, 2004, 2006; Lampel, Lant, \& Shemise, 2000; McLuhan, 1970). These discussion have aired in the political domain, around trade agreements involving Canada and the U.S., such as the North American Free Trade Agreement (NAFTA) (Government of Canada, 2005; Larrea, 1997; Wharton, 1993), as discussed in Section 2.4.2.9. In this thesis, Canadian English-language premium TV drama will be considered entertainment, which is the definition for TV used by the U.S. (Hoskins, McFadyen, \& Finn, 2004), and because it competes, for audience, with Hollywood TV premium drama. Moreover, the NAFTA exemption for cultural products has never been invoked over this genre (Wharton, 1993). This is almost certainly due to the popularity of Hollywood TV drama in Canada, popularity being a proxy for demand. Moreover, the monetization of Hollywood TV entertainment is a financial underpinning of the Canadian broadcast system (CRTC 2015a; Standing Committee on Canadian Heritage, 2003). 
This dissertation builds to a meta-argument, a need for a policy innovation in the online TV era. Early in the dissertation (Chapter 2), a historical review of Canadian English-language TV drama policy establishes that the extant public policy approach began in the 1960's, as an interpretation of the requirements in The Act (Government of Canada, 1991). Canadian TV drama policy was, and could yet, be considered a response to both the market dominance of Hollywood TV drama and the unique geocultural relationship between Canada and the U.S. In Chapter 9.2, based on the findings of the theoretical analysis (Chapter 3) and the field study (Chapters 5-8), a set of "evidence-informed" policies (Young, 2013, p. 9) are suggested for the digital era. These suggestions are specifically targeted to strengthen Canadian English-language TV drama, and are inspired by Grant and Wood's previous "cultural tool kit" for Canadian TV drama (Grant \& Wood, 2004, p. 137).

Further to this dissertation's positioning, as a case study for the purpose of informed policy innovation, both management theorists above, Michael E. Porter and Clayton Christensen, have been outspoken on the role of public policy, as response to industry change. Porter has emphasized that a role of national government is to ensure vibrant competition, the main source of cluster growth, and to ensure that domestic clusters do not remain insular, particularly in transformative moments. Porter describes a decline of "domestic rivalry" as an initially invisible "dry rot that slowly undermines competitive advantage by slowing the pace of innovation and dynamism" (Porter, 1990, p. 170). Christensen has identified two success factors of public policy, which governments can deploy to effect innovation, either the motivation or the ability of industry players: "Government's power to affect innovation lies in its policymaking and regulatory authority [to] affect either the motivation or ability of industry participants" (Christensen, Anthony, \& Raynor, 2013, p. 290).

Consistent with methodological recommendations for case studies, as will be further elaborated in Chapter 4, field data for this research was analyzed iteratively and inductively, with the theoretical framework becoming clear "via recursive cycling among the case data" (Eisenhardt, 2007, p. 25). Deep immersion in the data resulted in a theoretical approach considered "emergent in the sense that it is situated and developed by recognizing patterns of relationships among constructs" (Eisenhardt, p. 25).

As the theoretical analysis in Chapter 3 will elaborate, close reading of the value chain of Canadian TV drama delivered a baseline observation, a categorization of TV drama into three distinct processes: development, production, and distribution. In so doing, the dissertation reframes the chronic challenge of Canadian English-language prime time TV drama as a development phase challenge. An unexpected plot point in the story of Canadian TV drama is that the value chain is found to be missing a strong linkage to a monetization phase, such that there appears to be a muted need to optimize the asset being created in the development phase. The importance of this finding is that the impact of a weak imperative for financial results is shown to flow backwards to the first pitch of development, causing informants to label the 
Canadian development phase as "warped," "broken," and "a bridge to nowhere" (Respondent, Canadian, A-list Hollywood showrunner). Nuances of these findings, such as poor alignment of financial interests in the development phase, may suggest a new explanation for the market outcome of Canadian TV drama.

Surprisingly, value chain analysis led to the possibility that financial alignments in the development phase appear to have more torque than creative ones. The analysis suggests a key priority in upgrading Canadian TV drama development may be to address financial alignments in the value chain. The findings suggest that, unless the value chain for Canadian English-language TV drama is adjusted, such that financiers do have a compelling financial stake in the outcome of Canadian English-language TV drama, it may be difficult to upgrade the Canadian content business model so that it results in popular TV drama. As will be theoretically elaborated in Chapter 3, and confirmed by informants in Chapters 7-8, a plot point in the reframed "drama" of Canadian English-language TV drama is role reversal. This dissertation suggests that the Canadian TV networks, the strongest players in the story of Canadian TV drama in the 20 th century, appear to have evolved in the 21 st century, to a weak link in the value chain. The analysis will show that adjusting the value chain, so that formerly supporting players, the producers, become the new stars of the system, may require following the money, and the risk, in the development of Canadian English-language TV drama.

With a structural fault in the TV drama content model proposed as the main plot in this dissertation's story of Canadian English-language TV drama, the role of local-global (Canada-Hollywood) linkages is a subplot. Dynamics of local-global linkages, global value chains, and cluster upgrading are closely intertwined, especially in contemporary cluster studies (Lorenzen \& Mudambi, 2012; Vang \& Chaminade, 2007a). This overlap will be seen clearly, as informants consider the potential role of Canada-Hollywood linkages, in upgrading the domestic TV drama cluster. The field study of this dissertation, which investigates creative and financial dynamics in the development phase, through the eyes of development workers, is novel, also because no foundational study exists of this strata of the Canadian TV drama sector. While Hollywood is one of the world's most examined industrial clusters, there are relatively few research studies of Hollywood TV development dynamics, although there are indications of a growing mainstream awareness of the primacy of script in contemporary TV drama (Bennett, 2014). This dissertation, inspired by Todd Gitlin's benchmark study of Hollywood TV development, Inside Prime Time, originally written in 1983, and reprinted twice more through 2000, is based on the methodology of in-depth interviews. Similarly, this study goes inside Canadian prime time, to shed comparative light on how TV development works in Canada, compared to Hollywood, and to attempt to understand how the Canadian premium TV drama value chain might adjust its development phase, so as to become a globally applauded drama brand.

The field research triangulates three categories of on-the-ground workers in the development phase 
of Canadian TV drama, none of whom work in government or lobby organizations: (a) Canadian TV drama creators, mostly showrunners based in Hollywood, who began their careers in Canada; (b) CEOs of Canadian TV drama firms, many of whom work both in Canada and Hollywood, and navigate between the two systems as they try to produce the category of Canadian TV drama that competes with Hollywood TV drama; and (c) TV drama development executives in Canada and in Hollywood, who manage the creative and financial processes of Canadian TV drama development. None of these groups has previously been isolated for the purpose of a case study in development dynamics. As such, a baseline value of this dissertation is, most simply, to shed light on the crucial yet previously hidden role of development in the TV drama value chain. However, as will be elaborated in Chapters 5-8, the passionate engagement of informants resulted in a compelling story about a structural fault in the Canadian Englishlanguage TV drama value chain. The findings include nuanced insights on creative and financial dynamics in the development phase, and ultimately, strategic policy incentives for how Canadian TV drama might be future-proofed for the era of online TV distribution.

However, the findings of this study, which culminate in suggestions about Canadian Englishlanguage prime time TV drama might be strengthened, do include a caveat. The caution is that a solution to the conundrum of Canadian English-language prime time TV drama might only be empowered, $a$ priori, by transforming the overall goal of Canadian TV drama, from one purposed to domestic supply of Canadian content, to a system purposed to deliver Canadian TV drama which responds to domestic and global demand. A number of informants, especially Canadian TV drama CEOs, expressed excitement about such opportunities in the current distribution chaos. This is the idea that online TV delivery may deliver a default solution to a problem that has plagued Canada's TV system since origin: a too-small domestic market to finance prime time TV drama. An important contribution by informants is their excitement about creative and financial opportunity to send Canadian stories to the global marketplace.

At this writing, there are no predictions exactly when or how the changes in TV distribution will land, but it is clear the original electronic screen industry, TV, is in seismic disruption. While Canada's geo-cultural situation may be unique, all national TV regulatory regimes may need to shift strategic approaches and forge new alliances, in a cloud-driven, global TV distribution system, and one of the suggested strategies has been to strengthen content-content alliances between nations (Noam, 2008, 2014). Such strategic shifts will require nimble change management. While simultaneous substitution was a unique, cable-based strategic regulatory innovation for Canada's distribution phase, well-suited to finance Canadian content through the second half of the 20th century, findings of this study suggest a shift from a domestic to a global market orientation may be key to building on the system's hard-won strengths and help prepare the Canadian, English-language TV drama sector for the digital age. In this new era of TV drama, a global, online delivery model, complemented by the control of global distribution 
rights, appears to be approaching: "For Netflix, obtaining worldwide rights to acquired and original programming is a big priority" (Spangler, 2015, para. 6). On the ground informants perceive the change, and expressed a need for Canada to shift its focus towards upgrading development phase capability, which means a shift from making shows to making hits, in order to capture audience attention:

We're in the middle of the so-called "Golden Age" of television. If you're moronic enough to call up ABC or NBC to say, "Hey I have a deal for you" - shame on you. You don't understand which way the wind is blowing. It's blowing towards great television. They'll say: "Why don't you just give us a good show instead of your crap?" (Respondent, CEO, Canadian TV drama firm)

\subsection{Motivation for and purpose of this study}

This dissertation's main purpose is to provide primary research, which might enable an evidence informed policy response, for Canadian English-language TV drama, to the global disruptions in the TV drama industry. It is guided by an "open," rather than a "nationalist" policy view, which was put forth nearly two decades ago, by asserting that the "best way to promote Canadian creativity and culture is to build firms that are internationally competitive" (Acheson \& Maule, 1997, p. 4). The open view included the nuance that TV drama products are more likely to attract domestic audiences if they are "able to compete in international markets" (Acheson \& Maule, p. 6). Given the methodology of combining two approaches, business theorization and field research, this research appears to fit into a historical group of public policy approaches, which have had as their goal "insights" and "creative re-arrangement of vision" (Lasswell, 1970, p. 13). Rather than a goal of "speaking truth to power" (Wildavsky, 2007, p. 401), this study is undertaken in the spirit of working towards consensus with industry and policy-makers, in a framework of "give and take with others" (Wildavsky, p. 405), towards the goal of "building policy capacity and coherence" (Parsons, 2004, p. 43).

This thesis might be considered to have been a work in progress for two decades, including my professional experience as a TV development professional in Canada and the U.S., followed by $\mathrm{PhD}$ studies in the Ryerson and York University Joint Graduate Program in Communication and Culture. The mystery of why the Canadian English-language TV drama sector had not produced a string of popular hits was the story which continued to sustain my attention, from my early participation in the industry, including having been head of development for a Canadian TV network and a creator, represented by a Hollywood agency, International Creative Management (ICM). It would be hubristic to imply any comparison of this research to the depth, breadth, and global reputation of the work of Michael E. Porter. However, perhaps similarly to his purpose, which "emerged from an attempt to solve a puzzle" about all industry (Porter, 1985, p. xvii), the mission of this dissertation has been to solve the specific puzzle of the market performance of Canadian English-language premium TV drama. This challenge had been considered so elusive, that previous policy research had labeled Canadian English-language TV drama "a 
riddle wrapped in a mystery inside an enigma" (McQueen, 2003, p. 1). As such, the work of this thesis owes its inspiration to previous investigations, in its purpose is an attempt to solve the puzzle of Canadian English-language TV drama, against a backdrop of urgency: global TV disruption.

Motivation was additionally sustained by my bias as a TV consumer, as well as my participant practice as a TV professional, that TV drama is both a very important business and a very important cultural treasure. This heuristically acquired view aligns with the ontological perspective of cultural economy, and was reconfirmed during academic study of the TV industry. Many writers agree that sharing stories is an iconic activity of human civilization. Story-telling has only become more valuable, and more competitive, in what has been dubbed the "digitoral era" (Sachs, 2012, p. 14) of "info-addled" consumers (Sachs, 2012, p. 13). A consequence of the crowded screen ecosystem is that audiences gravitate towards powerful stories to "remind each other who they are and how they should act" (Sachs, 2012, p. 4). Even the Canadian government has written that "drama is story-telling, and story-telling is close to the heart of human culture" (Standing Committee on Canadian Heritage, 2003, p. 8). As this thesis was being prepared, the enduring power of such observations was underscored, because the TV drama sector, contrary to predictions, sustained its status as the planet's most popular, profitable media content, even as digital distribution moved towards disrupting legacy broadcasting. The iconic lure of TV drama is so strong, that distribution disrupters, such as Netflix, Hulu, Amazon, and Huffington Post have stormed into Hollywood's highest cost, highest-risk content genre to strengthen online distribution businesses (Hagey \& Ramachandran, 2015; Reilly, 2014). Their original TV offerings have proven to be attention grabbing, award-winning competition for legacy TV series. Netflix has asserted it "plans to be the largest producer of original content in the world" (Reilly, 2014, para. 3). On the development side, as the field research will demonstrate, the shift to online TV delivery appears to have created unprecedented opportunities for content creators, due to the expansion of original program commissioning entities. ${ }^{2}$ Informants in this study confirm urgency to empower the Canadian TV drama sector to seize the new moment:

How can we work to bring people together? We should start getting way more strategic, and I include the Canadian broadcasters, because television is getting better and better and better. How do we maintain our ability to be strong Canadian creators? There have been some wonderful ways of ensuring Canadians get money to produce, but as we move forward, only the best shows are going to survive. Canada can recognize we have this unique place and take advantage of it and figure out a smart way to improve on what we're doing. There must be policy changes. (Respondent, CEO, Canadian TV drama firm)

Preparation for this research included successful professional participation in all three categories of informants (writer, producer, TV network development executive), which aided practical knowledge of

\footnotetext{
${ }^{2}$ A list of Hollywood-based entities, which are commissioning original TV drama, is included as Appendix H.
} 
procedures regarding preliminary contact with elite professionals, who are not easily accessible. Moreover, experience helped confirm appointments, by providing comfort to informants and especially, to their managers and agents, that a conversation would be conducted knowledgeably. A result was a series of interviews characterized by exceptional candor and depth, on the part of informants, nearly all of whom occupy elite positions in the TV drama sector.

Personal circumstances prevented an earlier finish to this project, however the timing appears to have been accompanied by a certain synchronicity. I entered the Ryerson-York $\mathrm{PhD}$ program with the intent of studying Canadian TV drama. During preliminary coursework, I explored the historical, legal, management, policy, and technological parameters of Canadian English-language TV drama (Berkowitz, 2005a, 2005b, 2006c, 2006d, 2006e, 2006f, 2009a, 2009b, 2009c). This work included an award-winning essay, Dance with the Elephant (Berkowitz, 2006a), which garnered an invitation to speak in Ottawa at the International Institute of Communications (Berkowitz, 2006b). Truthfully, all this work elicited almost zero traction.

A number of events intervened. It might have been argued a decade ago, that Canadian TV drama development was weak. However, as will be explored in Section 2.3.1.1., there was no compelling evidentiary case to inform the analysis. The Canadian English-language TV drama, Flashpoint, broke through to a position on a U.S. network schedule in 2008, and precipitated the current run of Canadian, premium TV dramas in partnership with U.S. networks and studios, initiating the case of Englishlanguage premium TV dramas, which are a focus of this dissertation. Secondly, the ascent of digital technology, as evidenced by social media, catalyzed global media disruption during the mid-2000s; however, previous to iPhone, iPad, and Netflix's streaming service, there was a sense that prime time TV might eventually be replaced by social media, such as MySpace, then Facebook, YouTube, and Twitter. In 2006, Canadian storytellers described themselves "on the bleeding edge" (Berkowitz, 2006f, p. 11). Further complicating the scenario, during these years TV, the original electronic screen media, stayed robust, appearing immune from the industrial destruction, which was sweeping through music, newspapers, and books (Strangelove, 2015). Confusion made the way forward uncertain for industry and policy. It was not until 2010-2014 that accelerating improvements in bandwidth, devices, and consumer practices ushered in a new golden age of TV. Watching TV became the lure to OTT viewing and, especially Netflix, the "icon of simplicity" (Berkowitz, 2015d, para. 3). The transformations underway imbued the 2014 interviews for this research with passion and urgency, regarding a need for change. While technological capability for global, online TV delivery is nearly done, a global re-organization of media businesses to reflect these changes has scarcely begun (Berkowitz, 2015e), dynamics which may have rendered this dissertation's value chain analysis of the Canadian English-language TV drama value chain as timely. 
Further to the purpose of this dissertation, to contribute to policy transformation which might effectively respond to industry transformation, I decided to contribute to the CRTC's 2014 call for contributions to its proceeding on the future of Canadian TV, Let's Talk TV. The research had been completed, and I submitted an early précis of this dissertation. Timing is not everything, but it proved to be a lot. Serendipitously, the arguments in this dissertation came to be in demand, during and after Let's Talk TV (Berkowitz, 2014a, 2014b, 2014c, 2014d, 2014e, 2014f, 2014g, 2015a, 2015b, 2015c, 2015d, 2015f). A review of this dissertation's connection with the Let's Talk TV policy process, can be found in the epilogue, Chapter 9.5.

\subsection{Definitions and exclusions}

\subsubsection{Television}

The definition of television (TV) has evolved, in the current media eco-system, to refer to entertainment and information content, regardless of when, where, or on which device it is consumed. References to TV in this thesis reflect this definition, succinctly expressed by Netflix's chief content officer, upon Emmy nominations for its original TV drama House of Cards: "Television is what's on the screen, no matter what size the screen or how the content got to the screen" (as cited in Karpel, 2013, para. 7).

\subsubsection{Development; production; distribution}

The arena of TV development, the most hidden business function of the TV drama sector, is the asset creation phase, analogous to $\mathrm{R} \& \mathrm{D}$ in other industries. In this dissertation, TV drama development is defined as the first phase of the process, from concept through onset of principal photography, when creative intellectual property (IP) and financial elements of a project are assembled, including financial partnerships, key cast, and the quintessential element of TV drama, the script. Production is the second phase, wherein the product is manufactured; it culminates when the drama is delivered to a distributor, and accepted for exhibition. Distribution is the third phase, the process of connecting the asset to the audience, wherein it is exploited via various modes of monetization. These phases are similarly defined as

value chain phases for other industries, such as automobile manufacturing (Van Den Steen, 2014). Since development, production, and distribution are the three phases of the proposed TV drama value chain in Chapter 3, more detail will be provided in the following pages.

\subsubsection{Network; broadcaster; studio}

In conversational usage, three TV terms (network, broadcaster, studio) tend to have blurred boundaries. However, in this dissertation, it will be important to maintain distinctions. Because it is the work of this dissertation to unpack the dynamics of the TV drama value chain, it will adhere to the specific definitions of network, broadcaster, and studio. Network will refer to a larger corporate entity 
involved in the TV business. It can be, what is known in Canada, as a vertically integrated media corporation (VI) which may own four types of TV content distribution businesses - broadcasting, cable, broadband, and wireless - as well as other media businesses, such as newspapers and radio stations. Broadcaster will refer to the legacy function of licensing, or renting, TV drama for domestic exhibition, and monetization of that licensed content via advertising revenue. Studio will refer to the wide-ranging function of financing TV drama development and production, with the additional function of monetizing this substantive investment via ex-domestic territories, through all possible revenue modes. As the governance and interplay between financial and creative aspects of TV drama development is the focus of this dissertation, more detail regarding the roles of each of these three types of players in the development process, in Hollywood and in Canada, will be provided in the following pages.

\subsubsection{Prime time}

Prime time is defined, in this dissertation, in two ways. Firstly, it is defined as 22 hours each week. 8:00 p.m. to 11:00 p.m. plus Sunday 7:00 p.m. to 11:00 p.m. This time period is the classic definition of prime time, and despite all media changes, it still attracts the largest TV audiences and, for now, is considered the "centre ring":

A top rated prime time program draws between 10 and 15 percent of the available audience, although extraordinary programs get nearly double that proportion of viewers ... by any standard, audiences for prime time broadcast television networks are enormous....

Although the audience shares of the Big Four broadcast networks dropped from $90 \%$ of viewers to less than $40 \%$ by 2012 , a program can still draw an audience so large it could fill a Broadway theatre every night for a century ... the 22 prime time hours - 8-11 p.m. six days a week and 7-11 pm Sundays constitute the center ring for the traditional networks, the arena in which their mettle is tested. (Eastman \& Ferguson, 2013, pp. xi, 47)

CRTC has used a similar term, defining "evening broadcast hours" as 6:00 p.m. to midnight, for the purpose of allowing the relatively popular Canadian news slots to aid Canadian broadcasters in meeting $50 \%$ overall Canadian content requirements; however CRTC's strategic adjustment to the definition of prime time is not the second definition in this dissertation.

This dissertation's second definition acknowledges that prime time has acquired metaphoric resonance in the current TV viewing ecosystem. From a consumption perspective, it still may imply the evening hours, when the largest audiences consume entertainment, but it may involve watching a program that is delivered by linear broadcast and consumed in real time, or selected from an on-demand menu, or consumed online, either live or on demand. As the shift to online proceeds, and boundaries between originating platforms blur (CMF, 2015b), prime time has evolved to a shorthand for the high-budget, premium TV drama content, which audiences expect to watch during these prime hours "which make or break a network's reputation and continue to be the most visible part of an entertainment corporation's 
business" (Eastman \& Ferguson, 2013, p. 47). Therefore, prime time TV drama, in this dissertation, will be used interchangeably with premium TV drama, to mean high-budget, professionally scripted TV dramatic entertainment content, which aims to become a hit, regardless of what network or platform originally produced it (OTA, cable, OTT), when or how originally released (9:00 p.m. on a Thursday or entire season at once, online), and regardless of where, when, or on what screen it is consumed by the audience.

\subsubsection{TV drama}

In this dissertation, TV drama is defined according to the CRTC definition, as Category 7 programming (CRTC, 2014b; Grant, 2008). Drama refers to all scripted fiction entertainment, including comedy. The CMF defines drama as "an entertainment production of a fictional nature, including but not limited to: series, mini-series, made-for-television movies, theatrical feature films shown on television, situation comedies, sketch comedy, and stage plays adapted for television (television movie)" (CMF, 2015c, p. 9). The most common formats for TV drama are episodic half-hour series and 1-hour series, which are the main focus of this dissertation. Two-hour dramas are often presented as limited run miniseries or Movies of the Week (MOWs), also known as one-offs.

The rationale for focus on TV drama is straightforward; dramas have always been and remain the most popular form of TV content (Eastman and Ferguson, 2013). The evening hours not only bring the largest, and therefore most profitable audiences for all kinds of TV content, but TV drama also is the most popular genre of TV, in Canada and in the U.S. A list of the 50 most watched TV programs in the U.S. 2013-14 season (Appendix B) demonstrates the enduring popularity of this genre: $71 \%$ are dramas. Demand for TV drama has ruled TV since the beginning of the industry, as shown in Appendix B, which lists top 10 shows by decade. Moreover, the popularity of so-called "reality" TV and even variety shows, genres which have been staples of prime time since the early days of the industry, aligns with the appeal of prime time drama. So-called unscripted formats feature similarly compelling elements of fictional storytelling, such as suspense, conflict, and a heroic journey. In particular, reality genres are a "human spectacle that is every bit as scripted, primarily through postproduction editing" (Eastman \& Ferguson, 2013, p. 12).

\subsubsection{Canadian English-language prime time TV drama}

The focus of this study is Canadian English-language prime time TV drama, and specifically, the high-budget Canadian TV drama series which compete with Hollywood TV dramas, for a place on U.S. network, cable, or online rosters. Recent examples include Flashpoint (CTV-CBS, 2008-2011, CTV-Ion 2011-2012); Rookie Blue (Global-ABC, 2010-to date); and Working the Engels (Global-NBC, 2014). Historic examples include Night Heat (CTV-CBS, 1985-1993) and Diamonds (Global-CBS, 1987-1988, 
Global-USA Network, 1988-1989), series which were broadcast on U.S. networks in the CBS Late Night slot, 11:30 p.m. to 2:30 a.m.

Despite their presence on U.S. TV, currently, most of the Canadian premium dramas are financially structured as $100 \%$ Canadian content productions, and as such, receive funding from the CMF, a not-forprofit corporation that delivers annual funding to the Canadian TV industry. An evolution of previous Canadian funding entities, CMF was set up in 2010, by the Department of Canadian Heritage, with a priority to emphasize "original, first-run television programming in prime time" (CMF, n.d., Original FirstRun Performance section, para. 1), which appears to be consistent with the position of prime time drama as historically and globally the most popular genre of TV. A list of the top-10 performing CMF series, in the 4 years available since it began, is reprinted in Appendix N. Consistent with the finding that $70 \%$ of the top U.S. TV shows are dramas, nearly $90 \%$ percent of the top-10 performing CMF-funded programs are highbudget dramas. As exploration of the development phase of Canadian-made English-language prime time TV drama is the subject of this dissertation, much more detail will be provided in the coming pages.

\subsubsection{Showrunner}

Showrunner is an important definition in this dissertation, because it is the top job in high-budget, premium TV drama series, in Hollywood and in Canada. Showrunner means the boss, who runs the show (Nadler, Davis, \& Kaye, 2010), and is the opposite of runner, the lowest job. The showrunner is always a writer, at least when she or he gets the job. Afterwards, they are the top writer, as well as the boss, also defined as "the big brain" (Bennett, 2014, Chap.1, Showrunner 101, para. 2). While historically called Executive Producer, this title had various definitions, and wasn't specific enough to reference the showrunner's wide-ranging, demanding role: "You're in charge of pre-production, production, and post-production. In other words, everything. The most critical task on your agenda, however, is making sure that quality scripts get delivered on time" (Jean et al., 2012, Chapter 4, Executive Producer section, para. 1). The role of showrunner, the top development position, implicitly and conclusively, defines prime time TV drama as writer-driven.

\subsubsection{A list, B list}

Creators work in a constantly evolving ranking and reputation market for talent, a pecking order that is at once ubiquitous and intrinsic to the process of TV drama development (Caves, 2000). Given the high cost and high risk of prime time TV drama, an A-list writer implies top tier, proven ability to write scripts for a hit series, or in the case of an A-list showrunner, proven ability to manage and deliver the whole hit series. B list implies competency in this demanding arena. And so on. While these rankings are nowhere written, they are well understood social capital within a cluster: "the ranking of talent absorbs so much of the small change of conversation in many circles" (Caves, 2000, p. 7). Moreover, the rankings mean revenue. A-list writers have A-list agents, and bring home A-list earnings (Caves, 2000). 


\subsubsection{Above the line, below the line}

Most practically defined, above- and below-the-line refer to the top page of a historic TV budget form, where there was literally a line between the costing of development phase elements and below, all the elements of the production phase, as shown in Appendix A. The importance for this dissertation is that development costs are above-the-line costs, which include very few jobs, namely the creator/showrunner, producer, key cast, and director. Other development costs, such as the purchase of underlying rights is included above the line. Everything else goes below the line, costs incurred only after the completion of an approved script and financial structure. In addition to every conceivable cost, from makeup to catering, costumes, sets, and travel, the below-the-line crew includes such skilled production jobs as assistant director, art director, line producer, location manager, best boy electric, best boy grip, boom operator, CB operator, costume designer, camera operator, composer, dolly grip, graphics, hair stylist, key grip, makeup, script continuity, sound technicians, and many more. The jobs are the core of the specialized labour pool required for a world-class production phase. As Canada boasts world-class production capability, as part of its TV drama value chain, more detail will be provided in the coming pages, especially in Section 3.3.2.

\subsubsection{Exclusion of reality $T V$}

The popular prime time, entertainment format, reality TV, which is officially unscripted, is not included in this study.

\subsubsection{Exclusion of Canadian French-language TV}

This study does not comment on the development, production or distribution of Canadian Frenchlanguage TV drama. As documented, a Canadian French-language prime time TV drama can capture up to $70 \%$ of its potential audience; the genre does not exhibit the same chronically low level of popularity as English-language Canadian TV drama (Canadian Media Fund, 2014c; CRTC, 2014; Le Goff et al., 2011).

\subsection{Gaps in the literature}

A gap in knowledge pertaining to this dissertation is a scarcity of research which focuses on the development phase of TV drama, in Hollywood or Canada, and in particular, research which compares TV drama development in Canada to TV drama development in Hollywood.

Studies have contributed to an understanding of Hollywood development (Bielby \& Bielby, 1994, 1999, 2002; Christopherson, 2009; DeVany, 2004; Grant, 2008; Grant \& Wood, 2004; Scott, 2005; Vang \& Chaminade, 2007a). Nevertheless, studies that focus exclusively on Hollywood prime time TV drama are few. Todd Gitlin's (2000) study of Hollywood development dynamics, Inside Prime Time, stands out for its insight into an enduring set of TV drama development dynamics; the book's record of reprinting (1983, 1984, 1995, 2000) indicates its importance. 
Studies have explored the arena of TV drama development in Canada (Davis \& Kaye, 2010a; Davis \& Nadler, 2012). To my knowledge, none have focused on development dynamics in the category of Canadian English-language prime time TV drama, which competes with Hollywood hits. Other genres and categories of Canadian film and TV drama have been studied, including movies, international coproductions, documentaries, family and children's TV, as well as service productions, which are Hollywood productions outsourced to Canada (Davis \& Kaye, 2010a, 2010b; Davis \& Nadler, 2009; Elmer \& Gasher, 2005; Elmer, Davis, Marchessault, \& McCullough, 2010; Selznick, 2008; Tinic, 2005; Vang \& Chaminade, 2007a). While Canadian TV dynamics have been studied in the context of U.S. dominance, and have included analyses of challenges to Canadian English-language TV drama (Grant, 2008; Grant \& Wood, 2004; Hoskins \& McFadyen, 1991; Hoskins et al., 2000a, 2000b), understanding the dynamics of prime time development has not been an exclusive focus.

A corollary gap in the literature is the connection between the development of prime time TV drama in Hollywood and in Canada, formalized as a set of local-global linkages. This dissertation's focus, on comparing above-the-line business practices in Hollywood and Canada, distinguishes it from previous research on local-global linkages in media. Such studies have more commonly addressed Canada-U.S. cultural labour issues, by focusing on transnational linkages in the production phase (Miller et al., 2005; Vang \& Chaminade, 2007a) or considering the Canadian TV industry in a holistic way (Tinic, 2005; Vang \& Chaminade, 2007a), rather than distinguishing between unique industrial dynamics in the three phases of the TV drama value chain: development, production, and distribution.

Comparative studies have analyzed Canada's English-language TV industry, relative to other English-language markets around the world (Davis \& Kaye, 2010b; Elmer \& Gasher, 2010; Flew, 2011; Grant, 2008; Grant \& Wood, 2004; Tinic, 2005). This research complements those, by focusing on above-the-line connectivity between Canada and Hollywood, as manifested in the case of TV drama development, a function in which Hollywood is the dominant global cluster. Studies have also explored the demand for Hollywood hits, by Canadian audiences, versus the lack of demand for Canadian English-language TV drama, by U.S. audiences, as a function of an asymmetrical market, and affected by a cultural discount between the two markets (Davis \& Nadler, 2012; Grant, 2008). It is the purpose of this dissertation to extend these perspectives by suggesting that the market performance, by Canadian English-language TV drama offerings, in the U.S. market, particularly in the recent attempts to compete for attention in prime time, may also be a function of a weak development phase, which is a function of a weak content model for Canadian English-language TV drama. The audience performance of these high-budget dramas would seem to underscore such an analysis.

With broad gaps addressed, the following is a discussion of specific gaps in the four arenas of literature which form the preparatory foundations of this study: (a) overview of the Canadian and U.S. 
TV industries; (b) policy review of the Canada-U.S. TV relationship; (c) value chains and global value chains; and (d) cluster upgrading, local-global linkages, and economic diasporas.

\subsubsection{Gap: Overview of Hollywood and Canadian TV drama}

Publicly available information is used to contextualize the Hollywood and Canadian TV drama sectors. Given the size of the TV industry and its public-facing profile, many books, articles, news reports, and trade publications cover the industry in both countries.

Qualitative and quantitative information on the U.S. TV industry has been supplied by many writers (Caves, 2000; DeVany, 2004; Epstein, 2005; Miller et al., 2005; Vogel, 2007; Wolf, 1999); numerous trade publications such as Variety, Hollywood Reporter, and many exclusively online sources as cited in this document, as are financial organizations such as PwC and SNL Kagan; digital archives such as Internet Movie Database (IMDb) and Nielsen.com; and industry organizations such as Writers Guild of America (WGC). WGC has an educational development document online, which describes development processes in Hollywood (Jean et al., 2012). Important insights about development are provided by Scott's (2005) On Hollywood, which includes a remarkable geographic graph of the closely huddled Hollywood creator community (Appendix G); but Scott's landmark book on Hollywood, with its economic geography and labour perspective, does not focus explicitly on the development phase. As mentioned, Inside Prime Time stands as a benchmark analysis of Hollywood TV drama development.

Knowledge about the Canadian TV drama sector is also plentiful, yet in a different way. Given the role of regulation and public funds in the sector, many reports are written by government organizations and lobby groups, which represent recipients of the public incentives. Comprehensive information is regularly provided by the CRTC, CMF, Telefilm, provincial and municipal entities, and by professional organizations, including CMPA. Many writers have explored the Canadian TV industry from a critical perspective (Davis \& Nadler, 2009; Davis, Shtern, Coutanche, \& Godo, 2014; Edwardson, 2008; Elmer, Davis, \& McCullough, 2010; Elmer \& Gasher, 2005; Grant, 2008; Grant \& Wood, 2004; Hoskins, McFayden, \& Finn, 1994, 2004; McQueen, 2003; Nadler \& Davis, 2012; Nadler, Davis, \& Kaye, 2010; Noam, 2008; Tinic, 2005; Vang \& Chaminade, 2007a). However, prime time TV drama development remains largely unexplored. To my knowledge, no previous studies have positioned Canadian TV drama development dynamics as a remote cluster in a global value chain, connected to the Hollywood TV drama cluster. As such, this dissertation, with its methodology of a value chain analysis, followed by field research consisting of in-depth interviews with high-level informants in the development phase of TV drama, in Canada and in Hollywood, addresses a gap in qualitative analysis of the development of Canadian English-language prime time TV drama. 


\subsubsection{Gap: Policy review of Canada-U.S. TV relationship}

The Canadian TV industry has been bounded, from its origin, in an evolving regime of regulation and policy, which, as will be elaborated in Chapter 2, appears to have mirrored the larger relationship between Canada and the U.S. A comparison of the TV industries of the two countries can be articulated with a paradox: while the U.S. TV drama sector can be described as enduring dominance of "good stories, well told," the Canadian English-language TV drama sector has been a response to U.S. dominance with "good policy, well implemented" (Berkowitz, 2009b, p. 1). As such, part of the foundational work of this dissertation is to understand core tenets of the relationship between the national neighbours. Additionally, Chapter 2 will re-trace the history of Canadian TV policy and in so doing, position the Canadian TV drama sector as a response to U.S. dominance, beginning with the first public inquiry into electronic media, the Aird Commission (Royal Commission on Radio Broadcasting, 1929).

Understanding Canadian TV drama policy necessitated a background in the cultural relationship between the two countries. A review of communication theorists (Babe, 2000; Edwardson, 2008; Frye, 1971; Godfrey \& Unger, 2004; Johnson-Yale, 2008; Noam, 2008) enables an articulation of Canada's paradoxical love-hate relationship with the U.S., specified as a Canadian cultural comfort with irresolvable contradiction. This perspective, when applied to a key regulation regarding TV drama, such as simultaneous substitution, can enable insights, regarding the Canadian TV drama value chain.

Because it is a regulation central to the story of Canadian English-language TV drama, simultaneous substitution is addressed with original research regarding its origin, in Section 2.3.2.4. As will be elaborated, this strategic innovation, by Canadian broadcasting entrepreneurs, embodies a paradox between rhetoric and regulation. While the Canadian TV industry is ostensibly purposed to protect Canadians from the effects of Hollywood TV hits, the system's financial foundation has depended on enduring affection of Canadian audiences for Hollywood TV hits. Moreover, the value chain analysis, in Chapter 3, demonstrates that substitution of Hollywood hits, in the monetization phase of Canadian TV drama, is found to ripple back to mute the efficacy of the development phase. The effect of this crosssubsidy instrument was not lost on the informants in this field study, and motivated one informant to label the development phase of Canadian English-language TV drama "a bridge to nowhere":

[Canadian broadcasters] had the money to spend, so they spent it. Instead of stopping and saying "We cannot afford to lose this money," it was 2 years writing something nobody wanted... That's why they say here: you're on a bridge to nowhere. They have to spend the money on development and pretend they're doing stuff. My experience was a bridge to nowhere. (Respondent, Canadian, A-list Hollywood showrunner)

\subsubsection{Gap: Value chains and global value chains}

This dissertation delves into business research applicable to the challenge of analyzing the development phase of Canadian English-language TV drama; in its broadest articulation, this study might 
be described as a value chain analysis of the Canadian English-language TV drama content model. The analysis demonstrates how the structure of the distribution phase appears to impact the development stage, and thus, may impair the overall outcome of the market performance. Neither the value chain framework (Porter, 1985, 1998a, 2008); a conceptual extension, global value chain (GVC) analysis (Gereffi, 2011; Giuliani, Pietrobelli, \& Rabellotti, 2005; Humphrey \& Schmitz, 2000, 2002); or a related theory, value chain evolution theory (VCE) (Christensen, Anthony, \& Roth, 2013), have been deployed to understand the development phase of Canadian English-language premium TV drama.

Vang and Chaminade's (2007a) study of the Toronto film sector does include a value chain depiction of the movie industry, albeit its focus is not TV. Two gaps prevent the Vang and Chaminade analysis from contributing key value to this dissertation. Firstly, the depiction itself does not cleanly separate unique dynamics of each segment of the chain: development, production and distribution. This blurring, of value chain boundaries, perhaps led to a set of informants selected from all three phases of the chain. A result is a perspective that is not sufficiently deep or specific to answer a question posed by that study, similar to that of this dissertation: what has prevented the Canadian film cluster from upgrading its value chain from production to development phase excellence?

\subsubsection{Gap: Cluster upgrading, local-global linkages, economic diasporas}

The study of value chains is closely related to research on clusters, cluster upgrading, local-global linkages, and economic diasporas. These arenas cross disciplinary boundaries between business and economic geography, yet intersect in this interdisciplinary, cultural economy dissertation, to further inform the arena of TV drama development.

The concept of industrial clusters is attributed to Alfred Marshall (1890) in Principles of Economics, who is credited with coining the term for an industrial agglomeration, as a concentration of firms specializing in a specific industry, located in a specific geographic locale. Similarly to his work on value chains, Michael E. Porter is also attributed with popularizing and extending the concept of industrial clusters, beginning with The Competitive Advantage of Nations, in which he contemplated that a key dynamic is not that nations compete with each other, but that industries, particularly concentrated clusters of industries, do (Porter, 1990). In this respect, many writers have established Hollywood as the planet's dominant cluster of entertainment innovation (Acheson \& Maule, 1994; Caves, 2000; Hoskins \& Mirus, 1988; Hoskins \& McFadden, 1991; Hoskins et al., 2004; Scott, 2005). To better understand the Hollywood development community, this dissertation looked at research on cluster upgrading (Karlsson \& Picard, 2011); buzz (Bathelt, Malmberg, \& Maskell, 2004); and "the strength of weak ties" (Granovetter, 1973, p. 1360). These arenas, which will be elaborated in Chapter 2, inform a deeper understanding of the role of the development phase of Canadian English-language TV drama. 
Extending the critique of the Vang and Chaminade (2007a) study, discussed above, to the arena of local-global linkages, an additional critique is that Vang and Chaminade's work does not sufficiently deepen the debate on local-global linkages with respect to the Canadian industry, and leaves a gap in explaining why local-global linkages between Toronto and Hollywood have not resulted in upgrading the local film cluster from production to development phase excellence. Other scholars have also demonstrated that media production capability tends not to spill over to creative development capability (Davis \& Kaye, 2010b; Miller et al., 2005; Scott \& Pope, 2007). This dissertation attempts to explain the cause of creative development weakness, suggesting that its cause might be a structural fault in the Canadian TV drama value chain, which appears to be rooted in a weak imperative for market traction. As will be elaborated, a weak relationship between development and distribution, of Canadian Englishlanguage premium TV drama, may, in turn, inhibit development-phase Canada-Hollywood linkages.

Another study with a focus on cluster upgrading via local-global linkages also leaves a gap in knowledge about the role of local-global linkages in Canadian English-language TV drama. Lorenzen and Mudambi's (2012) “Clusters, Connectivity and Catch-up: Bollywood and Bangalore in the Global Economy," develops a typology of strategic global-local linkages to upgrade two clusters in India, Bangalore's technology cluster and Bollywood's entertainment cluster, via the methodology of qualitative interviews. The Lorenzen and Mudambi study suggests an opportunity to apply local-global linkage and cluster upgrading research to investigate the case of the relationship of the Canadian English-language TV drama sector with the Hollywood development community, which is the work of this dissertation.

Further informing the intersection of value chains, clusters, and local-global linkages is a global debate around systemic methods to capitalize economic diasporas, formalized as brain migration of highly skilled professionals (HSPs) to global hotspots. Notably, Canada has the highest percentage of emigrants of any country, nearly 10\%, and the largest group of these expats is in the U.S. (Asia Pacific Foundation, 2011). A gap in information regarding Canadian expats to the U.S. was made clear by this same study, which makes an urgent call for increased research on Canada's economic diaspora. This research argues Canada is losing global competitiveness by not keeping information on emigrants, and therefore not taking part in the global debate on transnational linkages. As will be demonstrated in Section 2.4.5, many countries have designed systemic strategies to capture value from their brain migrators. The gap in this final arena of literature harkens back to early history of Canada's TV industry. While Canadian brain drain to Hollywood has been acknowledged since the 1951 Massey Commission (Royal Commission, 1951), few studies have addressed the potential of formalizing linkages with this group, for the purpose of strengthening the development phase of Canadian English-language TV drama. 


\subsection{Research questions and hypotheses}

This dissertation investigates the following questions:

1. What is the role of development in the value chain of Canadian English-language prime time TV drama?

2. How are dynamics of the development phase impacted by dynamics of production and distribution, in the value chain of Canadian English-language prime time TV drama?

3. How does development of TV drama in Canada compare with and connect to development of TV drama in Hollywood?

4. What is the impact of local-global linkages between Canada and Hollywood, on the development of Canadian English-language prime time TV drama?

5. What development strategies could enable Canadian English-language prime time TV drama to meet new challenges and opportunities, which result from the global transformations in the distribution of TV drama?

An initial hypothesis was that development plays a pivotal role in the value chain of TV drama, because it is the asset creation phase, analogous to $R \& D$ in other industries. As will be elaborated in the theorization (Chapter 3) and field research (Chapters 5-8), this hypothesis was confirmed.

Also, it was initially hypothesized that the root of development weakness might be insufficient local-global linkages, acknowledged as central to cluster upgrading in industries with global value chains. However, the value chain theorization and field research shifted this hypothesis. As will be elaborated, particularly in Chapter 7, weak local-global linkages between Canada and Hollywood appear to be corollary to, and symptomatic of, an unintended consequence of the Canadian content model, which is exhibited as a systemic fault in the Canadian TV drama value chain.

Moreover, a key finding, not initially hypothesized, was that creative dynamics appear to be determined by financial dynamics in the value chain, even in development. This research, by following the money, from development through to monetization, suggests that strategies to strengthen development, and by default, the market outcome of Canadian English-language TV drama, might, $a$ priori, address the alignment of vested financial interests in the development phase, and even in the entirety of the Canadian English-language TV value chain. Evidence, which supports this finding, will be provided in the following pages.

\subsection{Research design and methodology}

This dissertation can be considered a qualitative case study (Baxter \& Jack, 2003; Gerring, 2007; Johannsson, 2003), for the purposes of policy research. The case being studied is the development dynamics of Canadian English-language prime time TV drama. The preliminary part of the study, 
presented in Chapter 2, is an assemblage of data and background sources, followed by the value chain theorization framework in Chapter 3, followed by the field research, in Chapters 4-8. Typically combining various methods of investigation, case studies have been described as "meta methods" (Johannsson, 2003, p. 4), and are recommended tools for studying "complex phenomena" (Baxter \& Jack, 2008 , p. 544). Case studies have the potential to allow a researcher "to peer into the box of causality to locate the intermediate factors lying between some structural cause and its purported effect" (Gerring, 2007, Chapter 3, Causal Insight, para. 5). This potent observation connects the value chain theorization with the field research, as many informants express awareness, in their own terms, of the theorized dynamics regarding the Canadian English-language TV drama value chain.

The value chain analysis, in Chapter 3, begins by isolating three unique segments of the TV drama value chain and, via iterative models, provides a comparison of the Hollywood premium TV drama value chain with that of Canadian English-language premium TV drama. The analysis discovers a structural fault in the Canadian chain, proposed as an unintended consequence of its purpose to achieve 20th century goals. The analysis further identifies weak linkages in the chain, between phase 1 and phase 3 , which impact the development phase.

The field study can be situated as "midlevel field work" (Havens, Lotz, \& Tinic, 2009, p. 234). The focus is on media industry practices, rather than analysis of media texts. The strength of this type of "helicopter perspective" (Havens et al., 2009, p. 239) is to hover slightly above the industry, sufficiently distanced to offer fresh insight, but not so distant as to be removed from business realities and inherent complexities. This mid-level approach is purported to avoid "jet plane" assumptions (Havens et al., 2009, p. 239), resulting from too distanced a perspective, and enables an organic approach to uncovering industry dynamics.

The field methodology features semi-structured, in-depth interviews, a method similar to previous studies of U.S. and Canadian TV industries (Bielby \& Bielby, 1994; Christopherson, 2009; Davis \& Kaye, 2010a; Davis \& Nadler, 2012; Epstein, 2005; Gitlin, 2000; Lorenzen \& Mudambi, 2012; Scott, 2005; Vang \& Chaminade, 2007a; Wolf, 1999). Informants were selected in three categories of stakeholders in the development phase of TV drama: (a) creators, (b) producers, and (c) development executives. The researcher used a network of professional participation in TV development in Canada and the U.S. to identify a small, initial set of three development experts who were previously known to the researcher. The majority of subjects resulted from snowball sampling, a selection methodology acknowledged to be valuable in probing relatively hidden populations of experts (Noy, 2008; Sadler, Lee, Lim, \& Fullerton, 2010), such as creative development professionals in the TV drama sector. Such sampling methodology is warranted when the information being sought is "primarily dynamic, processual, and emergent" (Noy, 2008, p. 329). A sample of interview questions is presented in Appendix 
BB. In addition to open-ended questions, a closing section of each interview explored informants' responses to original policy suggestions, which might strengthen the development phase of Canadian TV drama, and help prepare the sector for an era of global, digital distribution. Ethics clearance was received from Ryerson University's Research Ethics Board (REB), per attached letters in Appendix Z, which approved the field research for this dissertation through 2015.

Analysis of the field research was initially aided by NVivo qualitative data analysis, a computerized tool for analysis of qualitative interviews and reporting findings, by enabling the sorting of informants' responses into categories. NVivo software, provided by Ryerson University, is promoted as the "leading platform for analyzing unstructured data" (QSR International, 2015, para. 1). Following NVivo sorting, successive manual sortings led to close readings of the data, resulting in the findings reported in Chapters 5-8.

\subsection{Original contributions of this thesis}

\subsubsection{Contribution to theory}

In an industry much written about, yet under-theorized, this study offers a new analysis of Canadian TV drama by reframing the TV drama manufacturing process in three unique segments (development, production, distribution), which leads to isolating a new root of the Canadian drama problem: the development phase. Development is the IP creation phase, analogous to R\&D in other industries. Furthermore, the theorization demonstrates interdependence between phase 3 (asset monetization) and phase 1 (asset creation), compared to the relatively discreet phase 2 (production). Related studies on cluster upgrading and local-global linkages are brought to bear on TV drama development, and in so doing, this dissertation reframes weakness as a fault in the Canadian Englishlanguage TV drama value chain, a perhaps unintended consequence of designing the system with a priority to deliver a supply of Canadian content and a strong production phase, as dictated by the Broadcasting Act. A corollary observation is that more policies and subsidies to the production phase may not remedy long acknowledged financial and audience outcomes. This research suggests that chronic weakness in the development phase of Canadian English-language TV drama might be addressed by adjusting financial dynamics in the chain.

\subsubsection{Contribution to field research}

In-depth interviews with an elite, relatively hidden group of high-level development professionals led to confirming the value-chain theorization, and also, to the suggestion of new insights about Canadian English-language TV drama. These observations have included the following: (a) development dynamics, often thought of as creative matters only may not most effectively be addressed separately from distribution or from financial dynamics; (b) insufficient audiences and insufficient revenues may not be a 
root cause of the Canadian TV drama problem, but rather these market dynamics appear to be symptomatic of development weakness; (c) top creators may not be prohibitively expensive and/or unavailable to Canadian TV drama, in an absolute sense; rather A-list creators may be perceived as too costly from an $R \& D$ perspective, in a value chain which appears to lack a compelling need for a positive market outcome; and (d) protecting Canadian producers' right to own IP on Canadian TV drama may not have strengthened market performance of Canadian English-language TV drama, because it may have inhibited formation of Canadian studios, i.e. entities which control global rights to distribute Canadian English-language prime time drama. Such rights which would imply a need for global commercialization, which would flow backwards to a need for asset optimization in the development phase.

\subsubsection{Contribution to cluster upgrading studies}

The findings appear to be applicable to the current debate on the role of global-local linkages in cluster growth and industrial catch-up. This case study, of Canadian English-language TV drama development dynamics, extends and deepens existing analyses by demonstrating that even a creative, writer-driven capability, such as TV drama development, appears to be governed by financial dynamics. Strengthening an R\&D phase, particularly in high-risk endeavours, may require well-aligned financial interests, and even an overall goal to optimize the monetization potential of the asset being created. Moreover, this research has applicability to any nation upgrading domestic creative industries, which, like TV drama, are characterized by an imperative for excellence in R\&D-intensive global value chains.

\subsubsection{Contribution to economic diaspora studies}

This dissertation positions Canada's unique geo-cultural proximity to the U.S. as a potential competitive advantage. The dissertation reframes brain drain of Canadian creators to Hollywood as a potential brain chain and brain gain. Given Canada's high percentage of expats, this dissertation extends calls for Canadian emigration reform and contributes to the debate on value capture of highly skilled professionals (HSPs) in knowledge economies, who seek career growth in global escalator regions.

\subsection{Outline of the remainder of the document}

Chapter 2 presents a review of four arenas relevant to TV drama development: (a) overview of the TV industries in Canada and in Hollywood, with a focus on development; (b) a policy review of the Canada-U.S. media relationship, narrowing inward to focus on TV policy, and expanding outward to position TV policy as a response to the Canada-U.S. relationship; (c) business research on value chains, including global value chains; and (d) research in related arenas of cluster upgrading, local-global linkages, and economic diasporas.

Chapter 3 proposes a theorization of the Canadian English-language TV drama value chain, beginning with a simple depiction demonstrating three segments, each with unique dynamics and unique 
supply chains: development, production, distribution. Iteratively complex depictions suggest a reframing of the root of weakness in Canadian English-language drama as the development phase. Employing a value chain evolution approach (Christensen et al., 2013), the theorization suggests that, while there has been some increasing focus on audience metrics, the Canadian English-language TV value in the chain tends to be measured at the conclusion of phase 2 , where production metrics are tallied. It also suggests that, even though TV drama is writer-driven, strengthening the development stage may not be initially about the script. The analysis suggests that creative weakness is a result of poor alignment of vested financial interests in the development phase. An outcome of this chapter is the perspective that development weakness might be reframed as an unintended consequence of the structure of the Canadian English-language TV drama value chain.

Chapter 4 describes the methodology of the field research including the qualitative interview approach, choice of informants, interview design, and data analysis.

Chapter 5, the first of four chapters on findings of the field study, introduces and defines the little understood, often hidden arena of development, confirms its pivotal role in the TV drama value chain, compares TV drama development dynamics in Canada and Hollywood (including respondents' remarks on the Canadian TV drama's brand), and sets the stage for deeper analyses to come.

Chapter 6 presents a central finding in this study of the development phase of Canadian TV drama. Compelling remarks by informants suggest that strengthening the development phase appears to require following the money to the weak link to monetization. Strengthening the sector may require re-aligning vested interests of stakeholders in Canadian development, especially Canadian networks, around a need to optimize and monetize the Canadian English-language TV drama asset, accomplished by both domestic and global popularity.

Chapter 7 reports findings regarding the deeply intertwined development communities in Canada and Hollywood. The chapter includes informants' perspectives on current levels of connectivity between the Canada and Hollywood development communities, showrunner and junior writer shortages, and the need for writer training. The chapter concludes by reframing the role of local-global linkages, as suggested by the data. An unexpected finding is that the weakest local-global linkage (Canada-Hollywood) appears to be the Canadian TV networks, particularly in their role as TV drama studios.

Chapter 8 presents informants' responses to original strategies to strengthen the development phase of Canadian TV drama. In this chapter, informants offer their deepest, most candid perceptions on how to prepare the Canadian TV drama system for the era of online TV delivery.

Chapter 9 concludes the dissertation, reviews findings and original contributions, discusses limitations of this study, and suggests further research, which might be undertaken, on Canadian English- 
language prime time TV drama. The epilogue, Section 9.5, connects this dissertation with the 2014-2015 CRTC proceeding on the future of Canadian TV, Let's Talk TV.

\subsection{Chapter summary}

Chapter 1 introduced the central thesis of this dissertation, which focuses on the case of Canadian English-language TV drama, and argues that the development phase is the critical determinant in its performance outcome. The dissertation features a value chain approach, which proposes the Canadian TV drama sector in three segments, each with unique dynamics and unique supply chains, with TV drama manufacturing progressing from asset creation to asset monetization: development, production, distribution. This dissertation theorizes that weak audience and financial outcomes of Canadian Englishlanguage TV drama might be reframed as symptoms of an underlying structural fault in the TV drama value chain. The dissertation also argues that the development phase of the Canadian English-language TV drama sector not only is the locus of weakness, but is inextricably connected to the distribution phase. An important nuance to the argument is that development dynamics include both creative and financial elements, and that development-phase financial dynamics determine creative ones. The study is contextualized by the importance of Hollywood as the global centre of TV development, which complicates the case of Canadian English-language TV drama, due to chronic brain drain of Canadian creators to Hollywood. This chapter also presented the research questions, hypotheses to be explored, and identified arenas of existing knowledge, which are integrated to discover gaps in knowledge. This chapter situated the field-study methodology, set forth original contributions of this thesis, and provided a chapter-by-chapter review of the dissertation. 


\section{CHAPTER 2}

\section{GLOBAL DEMAND VERSUS DOMESTIC SUPPLY}

Hits are the fundamental dynamic, the only defining success factor in every business in the entertainment economy. Hits transform mere commerce into a culture statement. (Wolf, 1999, p. 15)

What constitutes merit is contextual to the particular country and will vary greatly. Americans worry about sex more than the French; Swedes fret about violence. Germans are sensitive about racist incitement. China protects party control. Saudi Arabia upholds religious orthodoxy. ... Each country has its concerns, problems, issues, traditions, priorities. Canada is concerned about a weakening of its national identity. Whether these concerns are justified, or in their own public's interest, is not the main question. What is important is that governments act on them. The main purpose of television regulation is to advance such goals. (Noam, 2008, Reasons for regulation section, para. 6)

\subsection{Introduction}

The story of the development phase of Canadian English-language TV drama begins in this chapter, with a critical review of existing knowledge bearing on the dissertation's core argument, that weakness in Canadian TV drama can be located in the development phase of the value chain. The chapter title "Global Demand Versus Domestic Supply" refers both to abiding market conditions of the Hollywood and the Canadian TV drama sectors, respectively, and as well as to the essential nature of the connection, contrast, and competition between the two clusters. Four arenas of knowledge are explored in this chapter, all of which bear on the analysis of the development phase of Canadian English-language TV drama: an overview of U.S. and Canadian TV industry; a review of Canadian TV policy, positioned as a response to Hollywood dominance; a review of value chains and global value chains; and a review of cluster upgrading, local-global linkages, and economic diasporas, all of which are closely related to research in value chains and global value chains. The work of this chapter sets the stage for the value chain analysis in Chapter 3. The outcome of this theorization, in Chapter 3, is a reframing of Canadian English-language prime time TV drama, which informs the field research in Chapters 5-8.

Preliminary to a review of the four arenas of knowledge, the argument of this dissertation officially starts in Section 2.1, with a discussion of three foundational concepts, seminal to this study of the development phase of Canadian English-language prime time TV drama: hits, popularity, and brand.

Section 2.2, an overview of U.S. TV, explores how the U.S. industry and in particular, Hollywood TV drama, has long been the most popular and most profitable media content on the planet (McQueen, 2003). Hollywood TV drama benefits from the world's largest English-language domestic market, the U.S., representing a potential audience of more than 300 million; moreover, global dominance of Hollywood TV hits is well acknowledged (Acheson \& Maule, 1994; Grant, 2008; Grant \& Wood, 2004; Hoskins \& McFadyen, 1991; Hoskins, McFayden, \& Finn, 2004, 2008). 
Section 2.3, an overview of Canadian English-language TV, reports that, in contrast to Hollywood TV drama, the Canadian TV drama sector has been created against daunting odds, including a small English-language domestic market of less than 25 million and this same audience's overwhelming preference for Hollywood prime time TV drama (CMPA, 2015; Grant \& Wood, 2004, Kiefl, 2011).

Section 2.4 examines Canadian English-language TV policy as a response to Hollywood dominance, via two approaches. A discussion of how Canadian English-language TV drama policy and regulation appear to mirror the larger Canada-U.S., love-hate relationship, characterized by a predilection for irresolvable paradox (Babe, 2002; Frye, 1971; Noam, 2008), provides a conceptual foundation for the timeline of Canadian TV policy and regulation, positioned as a response to Hollywood dominance.

Section 2.5 explores the concepts of value chains and global value chains (Gereffi, 2011; Humphrey \& Schmitz, 2000; Porter, 1985, 1990, 1998a, 2008), in preparation for the close reading of the value chain of Canadian English-language TV drama in Chapter 3, and its comparison to the value chain of Hollywood English-language TV drama, for the purpose of understanding its development dynamics.

Section 2.6 explores arenas of research which are closely intertwined with value chains, so as to add further depth and nuance to the analysis of the development phase of Canadian English-language TV drama: cluster upgrading, local-global linkages, and economic diasporas (Asia Pacific Foundation, 2011; Bathelt et al., 2004; Chou, Ching, Fan, \& Chang 2011; Granovetter, 1972; Lorenzen \& Mudambi, 2012; Vang \& Chaminade, 2007a).

Throughout this chapter's review of existing knowledge, which bears on the analysis of the development phase of Canadian English-language TV drama, four general analyses are observed:

1. Canada and the U.S. This chapter will demonstrate that a perception of Canada's place in the world dates may date further back than Pierre Trudeau's famous metaphor, positioning Canada precariously and subordinately, as an ant that must sleep next to an elephant (Berkowitz, 2006a, 2006b; Trudeau, 1969). Canada has been positioned, since the earliest days of the TV industry, as dominated by, and requiring protection from, U.S. culture and its powerful TV industry. Background research for this dissertation discovered that oppositional viewpoints, towards the U.S. TV industry, have surfaced in public discourse at key policy junctures. As elaborated in this chapter, the perspective of this dissertation tends toward a less popular one, which is, to paraphrase a CTV executive who testified in 1949 during the Massey Commission hearings, that Canada's geo-cultural position may be considered a unique competitive advantage and that open competition with the U.S., rather than protection from it, might build strength (Litt, 1992). In this dissertation, there is a departure from a sense that entertainment can be effectively defined in nationalistic terms, a debate also evidenced in academic and journalistic discourse 
(Acheson \& Maule, 1990; Adams, 2009; Doyle, 2009, 2013, 2015; Edwardson, 2008; Freeman, 2013; Fulford, 1986, 2001).

2. Comparative studies. This dissertation complements comparative studies that analyze the relation of Canadian English-language TV, in relation to other small English-language markets (Davis \& Kaye, 2010b; Elmer \& Gasher, 2010; Flew, 2011; Grant, 2008; Grant \& Wood, 2004), by exploring Canada's industry as a unique response to the U.S. industry, the world's largest English-language market, and to Hollywood, the leading global drama creation cluster.

3. Conceptual lens. The lack of a paradigmatic lens can result in a too-general view, or what has been called a "jet plane" approach to analysis of a business sector (Havens et al., 2009, p. 239), which may unintentionally mix cultural, political, and economic observations. Another problem can be a grouping of a wide range of jobs or entertainment platforms together (Florida, Mellander, \& Stolarick, 2009; Miller et al., 2005). This dissertation suggests that such discussions may inadequately capture organic complexities of the TV industry. Based on research reviewed in this chapter, a value chain approach is proposed, which distinguishes unique dynamics of each segment, and informs the field research with well-defined categories of informants. Development enables a specificity of focus, that appears to lead towards novel strategies to strengthen Canadian English-language TV drama.

4. Modes of reportage. The value chain analysis appears to support an earlier observation (Hoskins et al., 2004), that modes of reportage on the Canadian TV industry may unintentionally reinforce existing value chain dynamics. Metrics that emphasize production, employment, and investment volume, rather than returns on investment, appear to be long-standing assessments by Canada's federal government, provincial governments and professional organizations (CMPA, 2014; CRTC, 2014b; Ontario Media Development Corporation [OMDC], 2013). This chapter will suggest that a focus on supply metrics may partially explain why the analysis in the forthcoming pages, which proposes that a source of weakness in Canadian English-language TV drama might be the unexamined development phase, has not been previously put forth.

\subsection{Foundational concepts: Hits, popularity, and brand}

\subsubsection{Hit content is king}

As created in Hollywood, and embraced by global audiences, TV drama is a hit-driven business with a pareto shaped demand curve. Success is, if anything, elusive. Less than $10 \%$ of TV shows are considered responsible for more than $90 \%$ of revenues (DeVany, 2004; Epstein, 2005). The equation is even more unforgiving, if one considers the chances of a concept in development becoming a hit, which are closer to one in a thousand (Grant \& Wood, 2004; Vogel, 2007). Yet, the need for hits is so fundamental to an entertainment business that the absence of hits can take down a company (Eastman $\&$ Ferguson, 2013). On the upside, there would be no Hollywood TV industry without the hit shows that 
attract massive audiences and, in turn, lure advertisers, subscription, and/or broadband services to capture the enduring demand of global audiences and as a consequence, the profits which fuel the industry. As cited to open this chapter: "Hits are the fundamental dynamic, the only defining success factor in every business in the entertainment economy. Hits transform mere commerce into a culture statement" (Wolf, 1999, p. 15). Such analyses demonstrate that content is not king. More accurately, hit content is king. Furthermore, all media platforms, not just TV drama, are hit-driven businesses. Legacy media, such as the New York Times or Washington Post, the Beatles, Beyoncé, or the new web empires, including Google, Amazon, Facebook, and more, are testament to the fundamental point that media survival is foremost an attention challenge, and secondarily, a challenge to convert that attention to revenue. Defining media as an attention good is a powerful, meta definition, which can subsume many other definitions of media, including information good, experience good, shared good, dual good, or symbolic good (Reca, 2006). Hits can be defined as media products or services, which win the battle for consumer attention in the fragmented media marketplace of the 21 st century, where many formerly non-screen media (such as newspapers and books) and many formerly non-media products and services (such as socializing, shopping, banking, and more) have created unprecedented competition for consumer attention. The enduring popularity, and financial viability, of the most legacy of electronic screen media, TV drama, seems even more remarkable against this backdrop, and a testament to the vital role which sharing stories plays in all cultures, and which appears to be continuing, in the era of online TV delivery.

Given the hit-driven nature of TV drama, an important question for this investigation is what level of attention defines a TV hit? Might that attention be expressed as ratings, subscriptions, or clicks? The answer appears to be found in a combination of quantitative and qualitative assessments. Particularly, in the new viewing environment, there appears to be a somewhat solipsistic logic that would claim a hit TV drama is a series that manages to enter the cultural zeitgeist, command attention, and become known as a hit. Hit is a moniker, which can attach to a media product in a viral manner, and be perceived to drive monetization via advertising, cable, or online attention, regardless of absolute audience numbers.

In consideration of the new viewing environment, there are two points to be made concerning the absolute quantity of viewers of a TV drama hit; firstly, that they have not changed and secondly, that they have changed. Despite the disconnection of TV viewing from both the schedule and the set, absolute audience size for a broadcast TV drama hit has not vacillated much since the early days of the industry. An informal review of ratings for hit TV dramas in every decade since the beginning of TV, as assembled in Appendices B and C, shows a general stability of absolute audience numbers for hits, in the 15-20 million range, even as TV households have increased four-fold, from 30 million in 1954 to 116 million in 2014, not even counting the proliferation of connected screens. At the beginning of the industry, the legendary CBS series, I Love Lucy (CBS, 1951-1957) grabbed the attention of 15-20 million viewers, 
which was 50\%-75\% of the available viewing audience. In 1964, Bonanza (NBC, 1959-1973) got 19 million viewers, of 50 million TV households. In 1974, All in the Family (CBS, 1971-1979) got 20 million viewers of 70 million households. In 1984, Dynasty (ABC, 1981-1989) got 21 million viewers of 85 million TV households. In 1994, Seinfeld (NBC 1989-1998) got 20 million viewers of 95 million households. In 2004, CSI (CBS, 2000-to date) got 26 million viewers of 108 million households. In 2014, more than 60 years after I Love Lucy, another legendary CBS series, Big Bang Theory (2007-to date) got 23 million viewers of 116 million TV households, notwithstanding the multiplicity of TV viewing options on phones, tablets, and computers.

However, in the contemporary viewing environment, there appears to be another side to a remarkably absolute numeric definition of a TV hit. Looking beyond TV dramas distributed by conventional broadcast services, there are hits distributed on cable networks and online, which are primarily monetized by subscription revenues, rather than advertising-based ratings. Some of these programs display the attention, accolades, and awards of a conventionally broadcast hit, but with much smaller audiences. Hits from cable services since the 1990s, such as HBO's Sex and the City (1998-2004) or The Sopranos (1999-2007) ${ }^{3}$ have been acknowledged as paradigm-shifting TV drama series, which helped establish HBO's brand and drive subscriptions to the service. Such strategies have continued, with ongoing hits such as Entourage (2004-2011), Girls (2012-to date), and Silicon Valley (2014-to date). While ratings for subscription series are not made public, available estimates report audiences ranging from two to 10 million. In the field study for this dissertation, a number of cable and online TV dramas were repeatedly referred to as hits by informants, including Netflix's House of Cards (2013-to date) and AMC cable network's Breaking Bad (2008-2013), a series widely debated as to whether it usurped The Sopranos as the best TV show ever made (Hibberd, 2014; Hickey, 2013; Lawson, 2012). The audience for Showtime cable network's drama series, The Affair (2014-to date), which won the 2015 Golden Globe winner for Best Television Series, reportedly grew from about 500,000 to one million viewers, as the season progressed (The Affair, Season One Ratings). However, a key question may be how attention around The Affair's awards impacts subscriptions to Showtime and its perceived competitive stance, in comparison to other original program services. The perceived strength of an individual service may become increasingly essential, as services begin to offer solo apps, such as HBO-GO.

As online distribution continues to disrupt cable delivery and unbundle TV channels, boundaries continue to blur, not just between platforms or technologies but also in the line between the popularity of a prime time legacy hit and a cable hit:

\footnotetext{
${ }^{3}$ Movie and TV series' descriptive information, such as originating network, years of distribution, and ratings, is accessed from Internet Movie Database (imdb.com) or Wikipedia (wikipedia.com), unless otherwise noted.
} 
In the last half decade the broadcast networks ... lost over half the audience they had and now have prime time ratings that are the equivalent of those of the better cable networks. ... By mid-decade, cable's collective ratings in prime time had passed those of the combined broadcast networks. (Eastman \& Ferguson, 2013, pp. 46, 50)

While legacy hits, such as Big Bang Theory, still command ratings in the 15-20 million range, the average rating of a U.S. prime time show has plummeted from a high of 18.3 million households in 1980 to 2.9 million in 2010, close to the range of hit cable show, which hovers in the range of 2-3 million households, as shown in Appendix D. These numbers are, of course, huge by Canadian audience standards. With the average U.S. household estimated as 2.6 people, these numbers imply that today's popular cable hits, even if they are not in the elite stratosphere of a Big Bang Theory, receive U.S. audiences of 5-6 million:

In actual numbers, although the ratings look small, each point represents a percentage of the 116 million television households in America. ... Thus, a 2.4 rating stands for about 2 million households, each with an average of 2.6 people viewing. Even a rating as small as 2.4 means the program is attracting 6-7 people at one time. (Eastman \& Ferguson, 2013, p. 52)

As such, the definition of hit appears to be evolving to include shows with audiences that are a fraction of the size of historic legacy hits. What appears to count increasingly so, is the size of an aggregated audience, over time: "cumulative audiences for all showings of a top-notch movie on HBO equal the size of a network's audience" (Eastman \& Ferguson, 2013, p. 191). Netflix, the leading disrupter in the current frenzy for audience attention, appears to understand how much is at stake in the new math for hits. Netflix strives to keep its audience ratings a mystery, relegating estimates of about 13 million to be deduced from broadband usage (O'Connell, 2014), but the company's chief content officers likes it that way: "It's irrelevant to us. We don't sell advertising" (O'Connell, 2014, para. 5). The point is, of course, Netflix sells subscriptions. House of Cards, with a production budget estimated at a legacy network level of nearly $\$ 4$ million per hour (Greenfield, 2013), is a hit that has exerted a cultural attention seemingly in excess of absolute audience numbers, and is considered a factor in the company's projected 100 million subscribers by 2020, which represents a "five fold growth in five years" (Rody-Mantha, 2015, para. 1). More than one-third of Canadians subscribe to the service, with a similar growth curve (Oliviera, 2014). Conflation of the definition of a hit is discernible in the simple exercise of googling Big Bang Theory and House of Cards. The side bar to the right of each search indicates both hits are easily obtained on iTunes, via e-commerce, demonstrating the increasing trend to flattened boundaries and commodification of TV drama. However, respective Wikipedia articles for each series reveal that Big Bang Theory's success is counted in a ratings chart, while House of Cards boasts its awards and accolades. Such analyses appear to suggest that a hit must derive attention from either large and/or important audiences. For example, live broadcasts of major, international awards tend to be watched by large audiences, and subsequently, drive a high volume of print and online media attention. 
As TV hits become disconnected from their platform origins as network, cable, and or even online, the transforming eco-system is increasingly characterized by a "mixed broadcasting/cable/online model" (Eastman \& Ferguson, 2013, p. 90), whereby the definition of a TV hit has also been flattened: the ability to capture attention. Pertinent to the core argument of this dissertation, an implication for Canadian English-language TV drama is that the development phase appears to be more important, as this is where the asset is created. As the field research in Chapters 5-8 will show, it appears to be, precisely the opportunity to capture buzz and accolades, which translates to revenue, which flows backwards to increased opportunity for, creative development, about which informants were most excited, and most disheartened, with respect to the preparedness of the Canadian English-language TV drama system.

More trajectories to hit status appear to be emerging, which may be relevant to the case of Canadian English-language TV drama. For example, Netflix has acquired rights to episodic series which have not performed as ratings hits on legacy broadcast, such as Arrested Development (Fox, 2003-2006; Netflix, 2013-to date), presumably with the aid of audience preference algorithms. More seasons have been financed, and released in new models, such as all episodes of a season at one time, to accommodate new, on-demand viewing habits, such as binge viewing, defined as watching multiple episodes together. A similar case, for which the outcome is not yet known, also distributed by Entertainment One, is the Canadian TV drama, Trailer Park Boys (Showcase in Canada, 2001-2008; Netflix, 2014-to date).

As the definition of a TV hit evolves, strategies to optimize monetization are also evolving. On the one hand, it has been argued that global, digital distribution enables monetization, such that the long tail of the curve would equal revenue in the fat head (Anderson, 2006). On the other hand, an oppositional analysis has also been proposed, which argues the efficacy of a traditional blockbuster strategy, used by the theatrical movie industry, as the best way to attract attention in a crowded screen ecosystem (Elberse, 2013). Blockbuster strategy would argue that high-profile product launches of fewer, more expensive offerings, appear to be the most reliable route to financial success in the digital age. Blockbuster strategy may have important implications for strengthening the capability of the Canadian system to deliver hits, which has been purposed to supply of content and the production of employment, by suggesting that less volume with higher budgets may be an effective strategy for the unprecedented competition of the new screen ecosystem.

Global, online distribution, similar to TV drama ecommerce models, such as Amazon.com and iTunes.com for all media, are able to combine a fat head, or blockbuster (Elberse, 2013), with a long tail (Anderson, 2006) monetization strategy. This applies to vertically integrated global online creators and distributors, such as Netflix, with capability to monetize in numerous territories around the world, in an unlimited time-frame. They have the competitive advantage to consider whether a TV drama will have sufficient global demand to drive subscriptions, and be monetizable over time and space. This analysis 
further implies that not only are TV hits king, but that global rights to TV hits may be prove to be an imperative for financial success in an era of global, online TV delivery, which appears to be fast approaching (Noam, 2014).

The evolving definition of a hit may have implications for Canadian TV drama. Episodes of Canadian dramas, such as Saving Hope (CTV and NBC, 2012; CTV, 2013; CTV and Ion, 2014-to date), have attracted the attention of up to 1.5 million Canadian viewers on CTV. Using a multiplier of 10, these numbers could scale to 15 million U.S. viewers, a solid hit rating; but this did not happen in the U.S. market. NBC cancelled the drama before the end of its first season. With the exception of Orphan Black (2013-to date; Space TV in Canada, BBC America in the U.S.), which was mentioned by nearly every informant in this study as a possible break-through Canadian hit, no Canadian TV drama, that has been broadcast on prime time U.S. TV, has yet become globally acknowledged as a hit. However, with respect to Saving Hope, the case may not be closed on its hit potential. At this writing, Saving Hope has been renewed with CTV and licensed in the U.S. to cable network, Ion, by its Canadian distributor, Entertainment One. This drama's trajectory on U.S. cable could potentially progress towards recognition as a hit, and potentially, a new business model for Canadian drama, which would see potential profits from international distribution retained by a Canadian corporation.

\subsubsection{Popularity versus quality}

A discussion of hits cannot avoid the question of what determines a hit: popularity or quality? In this thesis, this debate will land on the side of popularity. Popularity of a TV drama (or any media content) is what counts, simply because it may be the only finite arbiter of quality that can be counted, and as such, converted into revenue. A number of observations guide this clarity. First, there is the matter of all media as two-sided businesses (Anderson \& Gabszewicz, 2005) that do not sell content; what is sold is audience attention: "contrary to popular belief, broadcasters are not in the business of creating programs; they are in the business of creating audiences" (Eastman \& Ferguson, 2013, p. 9). There is the financial practicality that "good shows cost a lot of money ... bad shows are also expensive" (Eastman \& Ferguson, 2013, p. 8), compounded by the practicality that "a program failure is easier to analyse ... conversely, success is hard to analyse or copy, even though that has been the driving goal" (Eastman \& Ferguson, 2013, p. 88). A final decision on the popularity versus quality debate is rooted in the vagueness of any definition of quality, which means different things to different people, including CEOs of networks, national regulators, development executives, and of course, the audience. Quality can be pegged to writing, actors, genre, production values, and even patriotism: "Programmers are well advised to be careful with the word quality as long as so little consensus exists about what it is. It might be better to strive towards shows that are popular (or critically acclaimed) by external standards" (Eastman \& Ferguson, 2013, p. 11). 
Even critical acclaim seems subject to the exigencies of popularity. More than 15 million viewers watched the August 2014 Emmy awards (Kissell, 2014), and nearly 20 million viewers watched the January 2015 Golden Globes (Kissell, 2015). By contrast, a little more than 500,000 Canadians tuned in to the March 1, 2015 Canadian Screen Awards, compared to 6 million Canadians who had watched the Oscars a week earlier, on February 22 (Tucker, 2015). Without the gravitas of popularity, it may not be likely that critical acclaim would drive social buzz or attention to a TV drama, and therefore revenue, whether collected by ratings subscriptions, clicks, or e-commerce.

The argument might go so far as to say that even culture is a determinant of popularity. If it were not, then hockey or Tim Hortons would not be Canadian cultural icons. Hollywood would not be an American cultural icon. Fashion would not be a French icon. And so on. The primacy of popularity, as a determinant of culture, will be shown to relate to the argument that strengthening the development phase of Canadian English-language prime time TV drama, so as to increase the popularity of its products, would not only be good business, because it would strengthen the bottom line, but would also be great culture, because it would, strengthen the Canadian TV brand, domestically and globally, and therefore, popularize stories told by Canadians.

Respect for popularity, as the ultimate arbiter of value for TV drama, has long been an entrenched value in Hollywood, as articulated by a development executive: 'I'm not interested in culture. I'm not interested in pro-social values. I have only one interest. That's whether people watch the program. That's my definition of good, that's my definition of bad" (Gitlin, 2000, p. 31). Decades after this development executive asserted his TV network's mission to deliver popular programming, Netflix deployed digital big data to attempt to reduce the "mysterious alchemy" of delivering a hit (Carr, 2013, para. 11). Proprietary audience algorithms have helped guide decisions to develop high profile, costly, risky original TV dramas, such as House of Cards (Carr, 2013), which further underscores the primacy of measurable popularity over the ambiguity of quality.

This dissertation argues that the quality of TV drama quality can best be approximated by its popularity, as a proxy for demand. Popularity definitively connects script with audience, which implies a direct connection between development and monetization. Popularity, defined as the most important determinant of TV drama value, will impact the formula for media value in Section 3.2. As demonstrative of the direct connection between phase 1 and 3 of the Canadian English-language TV drama value chain, popularity will be seen to be intrinsic to the value chain analysis in Section 3.3.

\subsubsection{Increasing role of brand}

The debate between quality and popularity extends into a third indicator of TV drama success, which is the increasing role of brand in the digital age, characterized by unprecedented levels of competition for screen attention. An individual can be bombarded with more than 3,500 commercial 
messages every day (Sachs, 2012, p. 12); information overload is a signature of the digital era (Carr, 2010). In today's environment, subservience of brand to popularity may be easier to discern in a nonmedia context. Neither the game of hockey nor the Tim Hortons coffee chain would have become iconic Canadian brands, were they not wildly popular.

In today's crowded screen arena, TV hits like Breaking Bad, The Affair, and Silicon Valley, plus thousands of current and past TV dramas, compete in a personalized attention economy, side by side with breaking news, baby pictures, bill payments, retail price wars, flight changes, and branded content, which are advertisements disguised as TV stories by companies as diverse as Burberry, Red Bull, and Marriott Hotels. Given a relentless information assault, the importance of brand has risen exponentially:

Tough competition for viewers drives most subscription networks to strive for signature programs...that distinguish a network from its competitors. Signature programs create a welldefined image ... and breed a set of expectations. ... With few exceptions, original series are what successfully brand a network by defining it from competing services. (Eastman \& Ferguson, 2013, pp. 314-316)

Jeff Bezos, Amazon CEO and founder, is said to have defined brand as "what they say about you when you leave the room" (Fransko, 2014, para. 1), and in so doing, appeared to reflect a fundamental of creative industries, the importance of reputation (Caves, 2000). An abiding principal of an industry of highly uncertain outcomes, and incomes, is that brand is crucial: "when nobody knows anything, reputation is everything" (Bielby \& Bielby, 2002, p. 22). ${ }^{4}$ The power of brand might be seen in the rapid uptake of the HBO app, forecasted for a 17\% increase in 2015. Even CMF has indicated the importance of a strong brand and the challenge of the TV drama environment of the Internet, with its unlimited shelf space, wherein "the time for trial and error is coming to an end" (CMF, 2015b, Introduction, para. 2).

The field research for this dissertation confirms the importance of brand in the market performance of Canadian English-language TV drama. As reported in Chapters 5-7, the spectre of brand perception appears to impact TV drama at both ends of the value chain, affecting not only audience perception of a finished product, but also has consequences for the careers of TV drama creators, who work in the development phase. Given overwhelming odds for failure, a major consideration in a financier's decision to commission a TV idea is based on the reputation of the creator. Reputation, or brand, has been operationalized as an A-list, B-list mentality, with A-list defined by past ability to create a popular show (Caves, 2000; Eastman \& Ferguson, 2013).

Re-positioning any troubled brand is difficult, media or not. The Ford Motor Company had an uphill battle, following the 2008 economic crisis (Schein, 2012). The retailer Target experienced a brand debacle in Canada, which resulted in abrupt closing of 133 stores (Harris, 2015). Netflix had a tough slog,

\footnotetext{
${ }^{4}$ Bielby and Bielby further note that this iconic quote about the entertainment business is originally attributed to Oscar-winning screenwriter William Goldman.
} 
following its blunder with Quixter, as it forged into online distribution and attempted to separate its legacy DVD mail-only service (Gilbert, 2011). Remedying any brand, whether that of an individual TV creator, TV show, or TV network, is known to be a difficult challenge, requiring a rigorous audit of current status, bold action to change the brand's purpose, story, and ability to regain the embrace and trust, of potential consumers (Christensen, Cook, \& Hall, 2005; Kahn, 2013; Thomas \& Kohli, 2009). From this perspective, re-positioning the Canadian English-language TV drama brand may face an uphill scenario in the online era.

A number of informants remarked on Canadian English-language TV drama's troubled reputation as "cheap ... it flows back to the writing" (Respondent, Canadian, Hollywood showrunner), a finding to be elaborated in Chapter 5. Canadian TV journalism appears to contribute to, or perhaps reflect, a brand perception that Canadian TV drama has not kept up with global trends:

Whatever pride the Canadian industry might take in Flashpoint, Rookie Blue, The Listener and Motive, the truth was put bluntly by Les Moonves, the CBS boss ... he referenced the habit of using "cheap Canadian exports" to fill holes in a schedule. (Doyle, 2013, para. 8)

When ABC needed a summer filler for Grey's Anatomy, the network took a shopping trip north of the border and found Rookie Blue, a perfectly formulaic - and perfectly cheap — cop drama. ... U.S. networks settle for Canadian shows ... because they produce mediocre ratings at a low cost, thanks to content that is heavily subsidized. (Freeman, 2013, para. 1)

We are now back to asking the rhetorical questions: Where is Canada in the Golden Age of TV? And the answer is, of course, that it's nowhere. ... We are happy with competence. We are wellpleased with mediocrity. ... But the crucial element in the situation is the failure to deliver quality TV to the audience. The audience is entitled to better than competence. Other countries do better. (Doyle, 2015, paras. 4-5, 8)

Informants seemed aware of the Canadian TV brand drama problem. Although nearly every informant in the field research for this dissertation mentioned the TV drama Orphan Black as a possible break-through hit for Canadian TV drama (2013-to date; Space in Canada; BBC America in U.S.), I observed a brand peculiarity. This fully Canadian series, which was created, developed, and produced in Canada, including the use of public funds, was not once identified as Canadian in two headline articles about the series in Variety in June 2014 (Birnbaum, 2014; Prudom, 2014), even in keywords. Orphan Black was attributed to BBC America, which presumably benefits from BBC's prestigious global brand. This omission seemed such a contradiction to informants' excitement about Orphan Black, as evidenced in my just-completed field study, that I published an article in the Canadian TV trade publication, Playback, which questioned whether it might be time to re-brand Canadian TV drama from "Can Con" to a globally applauded "Can Brand" (Berkowitz, 2014a). As if to further underscore the existence of a Canadian, English-language TV drama brand crisis, a subsequent review in Variety.com of the series 
Schitt's Creek (2015-to date; CBC in Canada; Pop TV in U.S.) skewered the Canadian TV drama brand: "Schitt's Creek ... makes a case for putting a cap on Canadian imports" (Lowry, 2015, para. 1).

Given evidence that a Canadian English-language TV drama brand crisis may further complicate its crises of hits and popularity, a nuance to the argument of this dissertation may be an imperative, not only to strengthen domestic and global audience reception to Canadian English-language TV drama, but a corollary that doing so may require re-positioning its brand, as a necessary strategy to increase audience attention. Such re-positioning may only be achievable by examining the unexamined arena of TV development, the $R \& D$ phase, where the content is created. In order to drive revenue, in whatever commerce model is standing when the distribution chaos subsides, Can Con may need to be rebranded as Can Brand. The only way to do that may be the hard way, a series of TV drama hits.

In closing this discussion of hits, popularity, and brand, it might be observed these concepts might be described, as market success indicators of TV drama. How might they be achieved? The work of this dissertation is to explore, via value chain analysis and field research, a possibility that market traction may be closely related to a strong development phase, or more precisely, strong story-telling. Ultimately, this dissertation will suggest that strengthening the market performance. of Canadian English-language TV drama, may imply an urgency to tighten the relationship between script and audience.

\subsection{Overview of U.S. TV}

Tests of TV broadcast technology in the U.S. date back to the 1920s. The National Broadcasting Company (NBC) was founded in 1926, followed by the Federal Communications Commission (FCC) in 1934. The U.S. TV industry's breakthrough year was 1939, the same year that Gone with the Wind and The Wizard of $O z$ were released. TV sets were demonstrated at the New York World's Fair and the San Francisco Golden Gate Exhibition, and soon went on sale. Roosevelt became the first U.S. President to give a speech on TV. The first baseball game was broadcast by NBC. By 1950, there were more than 10 million TVs in the U.S. (Berkowitz, 2005b; Standing Committee on Canadian Heritage, 2003).

Broadcasting was immediately a consumer-driven, demand marketplace. Hit shows, like I Love Lucy, regularly attracted more than half the potential audience, spectacularly monetizing ad revenue, which had begun with a 10 -second Bulova watch commercial, which delivered a mere $\$ 7.00$ profit (Palmer, 2006). The U.S. domestic market, largest in the world, was big enough and the ratings/revenue model sufficiently elastic to thrive during the decades of channel proliferation and audience

\footnotetext{
${ }^{5}$ Schitt's Creek is produced by CBC, which, as the public broadcaster, has different dynamics, which are not a focus of this dissertation. Nevertheless, CBC is participating in the same genre of English-language prime time TV drama, targeted to U.S. network simulcasts, as the Canadian, private, conventional networks. As this dissertation has argued, the platform or channel origin of a TV drama is increasingly blurred to the audience. More than ever before, it is the show that must demonstrate audience appeal.
} 
fragmentation. Today, annual advertising revenue of U.S. TV is estimated at more than $\$ 150$ billion (PwC, 2014; Television Bureau of Canada, n.d.).

In the U.S., the TV business rapidly extended first mover advantage to global dominance. Exports of U.S. TV drama hits have controlled more than $75 \%$ of the global marketplace since the industry began (Hoskins \& McFadyen, 1991; Hoskins et al., 2004). For the moment, TV is surviving as "the biggest advertising medium," (PwC, 2014, Segment Insights section, para. 1), but the tipping point is very close, or has arrived. Reports conflict, further underscoring the shift. Linear viewing has dropped to a slim majority of viewing, $51 \%$, as on-demand TV viewing becomes the norm.

With a population of approximately 300 million in the 2+ demographic (meaning all ages greater than 2-years old), of which 90\% have access to TV services, the U.S. has 1,381 TV stations, which include conventional, specialty, and pay broadcasters (Television Bureau of Canada, n.d.). The average weekly viewing time that Americans (18+) spend watching TV in the U.S. is reported as more than 36 hours (Television Bureau of Canada, n.d.), which is corroborated by Nielsen's claim that Americans spend more than one-fifth of their 168 hours each week watching traditional TV, not including online TV viewing (Nielsen Company, 2014). U.S. TV distributors include about 10 conventional, advertisersupported networks, which reach about 116 million TV households. Additionally, the U.S. has nearly 200 subscription services including cable and online, nearly half of which reach 50 million homes (Eastman \& Ferguson, 2013). OTT disruption is ongoing. Netflix has more than 30 million subscribers in the U.S. Competitors include distributors on a number of competing platforms, including Hulu, an OTT service; HBO-GO, a stand-alone app; and e-commerce entities, such as Amazon.com and Apple's iTunes.

TV advertising revenues are a function of audience demand. Ratings have been long established as one of several currencies, which measure audience demand, so it can be converted into revenue. Ratings are enabled by a division of global audiences into TV markets, determined by population, and globally divided into geographic territories. With the exception of the U.S., which is sold by metropolitan area, most of the world, including Canada, is sold as a single national market. The U.S. is divided into approximately 210 TV markets. The size of media markets ranges from first largest (New York area at 19 million) and second largest (Los Angeles area at 14 million), to small cities, such as Lafayette, Indiana, with populations less than 200,000 persons (Television Bureau of Canada, n.d.). Of course, the advent of borderless, online TV delivery is a threat to this legacy monetization model.

The U.S. is the largest English-language TV market in the world. Outside the U.S., the five largest English-language markets are the United Kingdom, with an approximate population of 59 million; English-language Canada, with an approximate population of 25 million; Australia, with an approximate population of 20 million; Ireland, with an approximate population of four million; and New Zealand, with an approximate population of four million (Grant, 2008). 
The Nielsen rating was a media measurement innovation, which grew from entrepreneur Arthur C. Nielsen borrowing $\$ 45,000$ in 1929 to test conveyor belts, expanding to drug and retail testing, subsequently acquiring rights to an audio meter for radio markets, and beginning to measure TV markets in 1950 (Nielsen, n.d.). While discrepancies are acknowledged between measured and actual audience, there has been, for the most part, an acceptance that although ratings "lack precision" (Eastman \& Ferguson, 2013, p. 6), their enduring value is a relative ranking of a program's popularity:

To the degree [ratings] are somewhat imprecise in terms of the actual precise number of millions, they are not imprecise in terms of ranking what is most popular to least popular. That's all that matters. Whatever Nielsen measures, it measures consistently. The ratings are like the Gross National Product - they measure something connected with audience size, but exactly what is irrelevant, for they measure the same thing in the same way week after week, year to year, and therefore the relative differences and shifts over time should be taken seriously. The numbers are a currency for transactions. (Gitlin, 2000, pp. 53-54)

Nielsen has kept pace with media transformation, by evolving towards what is described as a $360^{\circ}$ assessment of audience attention, analytics which integrate audience viewing on four screens, including TV sets, computers, smartphones, and tablets (Nielsen Company, 2014). As a further indication of the primacy of TV content, a recent trend is to convert digital viewing data, for the top digital offerings, such as YouTube Preferred channels, YouTube's top five percent, into legacy terminology, such as demographics and overnites. Familiar sales metrics help advertisers to consider digital media buys (Nikitopoulos, 2015). At this writing, uncertainty continues to challenge the understanding of audience demand for TV drama: "Even in the most advanced TV markets, broadcasters and advertisers are still unclear how audiences consume their content ... existing players need to adopt new metrics if they are to compete with advertising revenue in the long term" ( $\mathrm{PwC}, 2014$, TV Advertising section, para. 4).

\subsubsection{Hollywood TV drama development}

Hollywood is defined as the areas around metropolitan Los Angeles, devoted to the business of entertainment. It is the unchallenged, global centre of TV drama development: the "world's leading centre of conception, design and content development of popular culture" (Scott, 2005, pp. 35). Further underscoring Hollywood's lead role as the global centre for TV drama development is an assessment of competitiveness, which proposes that competitiveness is determined by concept initiation activities:

It is not where the company has its corporate headquarters or where a majority of its shareholders are domiciled. For television programming, film, and video, what matters is where concept initiation, script writing, and crucial decisions with respect to budget, marketing and distribution occur (Hoskins, McFadyen, \& Finn, 2008, p. 37)

Development is the name for the preliminary set of TV content creation activities. As the first phase of the value chain, development is the $\mathrm{D}$ in $\mathrm{R} \& \mathrm{D}$, and is the segment of the chain where the 
intellectual property (IP) asset is created. As defined in Chapter 1, development is defined as the phase from the first pitch of a project to a financier to the first day of principal photography. Due to the project nature of the TV business (Caves, 2000), development includes assembly of both creative and financial elements of a project; as a result, each TV drama series has not only a unique creative but also a relatively unique financial structure. When development is complete, the project receives a greenlight because key financial elements, broadcast licenses and production financing, have been secured. Also, key creative elements, chiefly script and usually lead actors, have been approved. The production phase can begin. The process of Hollywood network creative development, from initial review of a pitch, outline, or script, through a greenlight for a series order, is reflected in Appendix F.

An important characteristic of development is its high risk, even in the context of an industry characterized by high risk on every node of the value chain. The chance of any single concept in development becoming a hit is described variously, as less than 1 in 1,500, to as little as 1 in 10,000 (Grant \& Wood, 2004; Vogel, 2007). An industry rule of thumb is that development, always an expense, is the most costly phase of the manufacturing process (Eastman \& Ferguson, 2013), estimated to add an additional third on top of production costs (Wolf, 1999, p. 103). For example, a recent report estimated that the big four legacy networks, ABC, CBS, NBC, and CBS each spend " 80 million-100 million on programming R\&D each year" (Littleton, 2014, para. 8). The Hollywood TV drama business model has been that the high-cost, high-risk development phase of has been financed by profits resulting from distribution, and especially from the rare hit. So relentless is the pressure for hits, "forget about growth, winners are increasingly essential simply to keep companies alive” (Wolf, 1999, p. 157). It has been said that the business of Hollywood TV drama can be defined as "accumulating those huge and growing audiences ... the only game they [are] really interested in playing" (Gitlin, 2000, p. 325).

Development workers are the men and women who create TV drama, and their talent gives TV drama its moniker as writer-driven. The creatives "work at the critical juncture where content connects with audience, where talent is the indispensable mediator" (Wolf, 1999, p. 102). The work of creators is that which is most commonly referenced when development is described: "the process by which a script is gradually written, revised, polished, and often entirely reconceived to the satisfaction of all concerned parties" (Epstein, 2005, p. 133). Their work is essential to the development process: "without a script, you can't make a drama" (Wolf, 1999, p. 102). The Writers Guild of America West (WGA-W) has about 12,000 members, with an additional 4,000 members who belong to Writers Guild of America East (WGA-E). According to the 2015 WGA schedule, minimum compensation for a 1-hour prime time TV script is about $\$ 40,000$; but compensation is many times higher for A-list writers (WGA, 2015).

As indicated in the definitions at the outset of this dissertation, the top job in development is the top writer, who may have the formal title of executive producer, but more precisely, is known as the 
showrunner. Since not all executive producers are writers, showrunners is a more exact nomenclature, because all showrunners are top writers. The journey to this elite position is well described by the WGA (Jean et al., 2012). It implies having climbed a brutally competitive ladder of achievement from freelancer to staff writer, story editor, writer-producer, and perhaps along the way also having acquired the title, and increasing responsibilities of co-producer, consulting producer, supervising producer, and/or co-executive producer. The writers' room, or "the room," where the creative team gathers to invent the story to be produced, is the subject of much lore. It's described as a "bit like being on an extended tour on a submarine ... any place large enough to accommodate a dry-erase board and a sizable group of sleepdeprived writers for hours at a time. This is where the merciless job of creating weekly episodes is done" (Jean et al., 2012, p. 21). As one ascends to running a TV drama, the pressure of the job expands to include more than writing, which is still its core function: "you have a literal army of people working for you.... effective showrunners constantly perform production triage: who or what needs attention most, what can be put off, what can be saved, what must be sacrificed" (Jean et al., 2012, p. 46). Tales from "the room" are told in the field research of this dissertation, which involves a number of Canadians who have climbed the ranks to become Hollywood A-list showrunners.

Considering the profound transformations in delivery technology and consumer practices, Hollywood development practices do not appear to have significantly altered: "As much as things are changing, much remains the same" (Littleton, 2014, para. 5). While the number of pilots are reported to have been slightly reduced, substituted with a greater number of series orders straight from an approved script (a trend confirmed in the field research), the traditional Spring pilot season remains busy (Littleton, 2014). Amidst TV industry upheavals, the goal of drama development, a compelling, greenlit script, has remained remarkably stable, even considering ground-breaking use of proprietary data analytics by services, such as Netflix, to inform development decisions:

The workings of the system are so opaque, even to insiders, decisions apparently so arbitrary, errors so abundant and visible - how does a prime time show actually get on the air? As I repeated this naïve question, I sometimes heard a cut-and-dried answer. Each network contains an entertainment division, within which there are development departments. They plant ideas for shows with producers, or major suppliers who hire the right producers and writers for the project. They take ideas, "pitches," directly from writers and producers. If they think the characters, relationships, and premises will resonate with a mass audience, they underwrite a script. (Gitlin, 2000, p. 20)

The high level of risk involved, in a career as a creator, is further corroborated by a high level of geographic concentration, even within the Hollywood creative cluster. A remarkable map of Writers' Guild of America West/WGA-W membership, shown in Appendix G, demonstrates that $90 \%$ of the union's membership reside within 15 miles of one Los Angeles intersection, Beverly and La Cienega 
Boulevards, a central intersection of the Hollywood district. The proposed reason for such concentration is competitive advantage in the profession: "capable and aspiring neophytes recognize that personal and professional fulfillment in their chosen line of work can best be attained by migrating to a centre where that sort of work is well developed and highly valued" (Scott, 2005, p. 7).

Other writers have corroborated Scott's characterization of Hollywood as a tightly clustered, intensely competitive agglomeration, even a "magic circle" of insiders (Epstein, 2005, Chapter 3, para. 2) where physical presence confers necessary strategic advantage: "Hollywood is a magnet for migrants from all over the world with burning ambition to work in the industry" (DeVany, 2004, p. 128). As will be elaborated in Section 2.6, the perceived imperative of being present in Hollywood appears to support economic geography cluster research, and in particular, the phenomenon that in an increasingly virtual, weightless, knowledge economy, the importance of geographic clusters has, perhaps counter-intuitively, increased.

Even if physical presence is one hedge against risk, a career as a Hollywood creative is still a career with remarkably little security; "success at one moment in time is no guarantee of continued upward mobility ... one screen credit is more often followed by anonymity than by yet more credits" (Scott, 2005, p. 129). It has been established that nearly $50 \%$ of WGA members are out of work at any one time; in a given year, a third of the membership was found to earn nothing, which further underscores that even working in the Hollywood cluster is highly lucrative for a tiny minority, but even a sustainable income as a creative proves unattainable for most (Bielby \& Bielby, 2002, p. 22). Another study characterizes Hollywood as an "industry of wannabes" where "at any time, most of the people are not working" (DeVany, 2004, p. 4), further describing the cluster as a "meritocratic pyramid with a bloated mass at the bottom made up of individuals whose goal is upward mobility" (DeVany, 2004, p. 127).

The risks are not only nearly insurmountable for TV drama creators. For financiers, they are statistically described as random. A quantitative analysis of entertainment industry economics characterizes the Hollywood revenue curve as a "kurtocracy," where unpredictable events mean everything (Vogel, 2007, p. 129). From the first pitch, financial risk is found to impact the creative aspects of the Hollywood development process:

Of some three thousand ideas floated each year, about a hundred will go to script, of which perhaps twenty-five will go to pilot. These are cast, shot, and tested, and then, each spring, the entertainment division executives, with other top network executives, meet in marathon sessions to look at the pilots and put together the new schedule. At each network, five or ten new shows will get on the air ... one or two shows will stay on long enough to be renewed for a second season. Each filtration step ... screens by a factor of five, or ten, or thirty. (Gitlin, 2000, p. 21) 
While "the odds working against any new work of popular culture are difficult to overstate" (Grant \& Wood, 2004, p. 63), so are the rewards for a financier, should the outcome be a hit. Huge financial resources are required:

At every stage of this process, money flows like water. The price of a single pilot - which may or may not air - then may or may not win a series spot — can reach \$6 million USD. If the odds against winning make pop culture resemble Las Vegas on a grand scale, so does the jackpot that awaits the lucky few. It can be enormous. And the potential pot seems close to bottomless. (Grant \& Wood, 2004, p. 63)

Adding further risk to financing development is scarcity of creative talent, a reality which may run counter to a popular perception that development talent is plentiful:

A popular fallacy holds that innumerable workable new program ideas and countless usable new scripts by embryonic writers await discovery and that only the perversity or shortsightedness of program executives keeps this treasure trove of material off the air. ... A national talent pool, even in the country the size of the United States (and even for superficial, imitative programming) is not infinitely large. It takes a certain, unusual gift to create programs capable of holding the attention of millions of people ... week after week. (Eastman \& Ferguson, 2013, p. 13) ${ }^{6}$

Social media popularity, and ideally, virality, has been a route to Hollywood development deals for nearly a decade (Ault, 2014; Brookers, n.d.; McGrath, 2006). More recently, traditional R\&D practices have been augmented by the availability of digital data, which can provide a detailed profile of audience preferences. Netflix is known to augment its development processes with predictive algorithms for such audience preferences (Carr, 2013; Madrigal, 2014; Vanderbilt, 2013; Wu, 2015), a development strategy in which "big bets are now being informed by big data" (Carr, 2013, para. 3). Netflix has operationalized data-driven development to include teams, which assign more than 76,000 tags to content, and analyze more than 30 million searches per day. Nevertheless, for now, a meaningful reverse engineering of the development process seems a long way off; human interpretation of audience data, so as to make final development commitments, is still said to reign supreme, because data can decipher what audiences have liked in the past, but cannot predict what audiences might like, or do not even know they might like. Therefore, admits Netflix, "creative decisions remain in the hands of creators" (as cited in Carr, 2013, para. 16). Further evidence, that development by data is just beginning, is offered by the field research in this dissertation. As will be elaborated in Chapters 5-8, the informants suggest that the need for top writing talent has intensified, not diminished, as financiers attempt to develop distinguishing programs, in an era of unprecedented competition. Consistent with the adage that it is not what happens in a story, it's how, not one of the informants mentioned digital analytics as a threat to their development work.

\footnotetext{
${ }^{6}$ Eastman and Ferguson further note this comment is from a statement by the late Sydney W. Head, frequent contributor to earlier editions of their book, Media Programming: Strategies and Practices.
} 
Further evidence that data driven algorithms have, as yet, only begun to inform development practices, may be Netflix's own record of hits. While House of Cards (2013-to date) and Orange is the New Black (2013-to date) are unquestionable hits, other Netflix originals, such as Hemlock Grove (2013), Marco Polo (2014), Bloodline (2015), Marvel's Daredevil (2015), Unbreakable Kenny Schmidt (2015), and Grace and Frankie (2015), have not, as yet,, made it into the popular zeitgeist. There is also the question of what percentage of legacy TV dramas, that have been acquired by Netflix for re-development, will deliver sufficient popularity to drive subscriptions. With acquisition presumably informed by the powerful combination of audience analysis, unlimited shelf space, and a global geographic monetization model, Netflix remakes include Arrested Development (Fox, 2003-2006; Netflix 2013-to date); The Killing (AMC, 2011-2013; Netflix, 2014), and Longmire (A\&E, 2012-2014; Netflix, 2015).

In addition to new media adding new development practices, online TV distribution has additional relevance to this investigation of development dynamics. By exponentially expanding shelf space for finished product, online distribution has appeared to have also stimulated an expansion in the number of Hollywood entities that commission original programming, which, in 2015, is no longer limited to a list of less than 20 conventional and cable network buyers of creative services, an approximate number of sales options for original programming, merely a decade ago (Hollywood Creative Directory Staff, 2005). Informants report that the list of entities commissioning original TV drama in Hollywood has expanded to approximately 50 financiers, including OTTs and newer entrants from digital media; a list of current buyers of creative services is shown in Appendix H. Expansion of buyers of creative services in Hollywood is reported to have caused increased demand for creative workers and also to have increased pressure on the TV studios that finance content development and production (Littleton, 2014); both trends were confirmed in the field study. The combination of increased competition for creative and financial resources in the development phase, combined with the trend towards online TV drama delivery, characterized by unlimited shelf space, will be shown, in Chapters 5-8, to be perceived by informants as unprecedented opportunity to upgrade Canadian TV drama development.

To summarize this section on Hollywood development, the literature suggests that despite changes wrought by the advance of digital technologies, the processes of TV drama development remain relatively distribution agnostic, and not dissimilar to those practiced at the origin of the industry. The modus operandi of development has always been a chase for audience attention. When Gitlin's TV development study was reprinted in 2000, nearly two decades after it was first written, TV drama development was summed up in his (then) new introduction: "although many of the names have changed, the following analysis of the network industry remains — in its main features, its principles, its logic_valid" (Gitlin, 2000, pp. vii-xii). As will be seen in Chapters 5-7, informants who are high-level development professionals with experience in Hollywood and Canada, re-confirmed, in 2014, the enduring value of 
such analysis, including the lure, risk, costs, creative skills and business processes of Hollywood TV drama development.

\subsection{Overview of Canadian English-language TV}

Compared to the explosive start of the U.S. TV industry, that of the Canadian industry was modest. TV technology was demonstrated at the 1939 Canadian National Exhibition, the same year it debuted in the U.S. However, the first Canadian broadcast did not come till nearly a decade later, with a broadcast received, rather than sent, in Windsor, from a Detroit station (Berkowitz, 2005b; Standing Committee on Canadian Heritage, 2003). The history of the Canadian TV industry officially began that year, with a report by the CBC on a 15-year plan for the TV in Canada, initiating the "honourable cottage industry" of Canadian policy reportage (McQueen, 2003, p. 20). In 1949, the Royal Commission on National Development of the Arts, Letters, and Sciences was initiated, chaired by Vincent Massey. Canadian TV got airborne in 1952, with the launch of CBC in Montreal and Toronto. CTV was launched in 1961, when Gunsmoke, Candid Camera, The Price is Right, 77 Sunset Strip, The Ed Sullivan Show, Perry Mason, Bonanza, and The Flintstones were in the top 20 U.S. shows, and U.S. TV ad revenue was already $\$ 1.7$ billion dollars (Berkowitz, 2005b).

Today, with a population of more than 35 million, in the 2+ demographic, including English and French-language, $96 \%$ of Canadian households have access to TV services. The English-language market is about 25 million. Canada has 745 TV stations, including conventional, specialty, and pay. Considering that Canada's population is approximately one-tenth of the U.S., this number of stations appears to be nearly five times what might be expected, compared to the 1,381 stations in the U.S., as reported above (Television Bureau of Canada, n.d.). The average weekly time that Canadians, in the 18+ demographic, spend watching linear TV is reported as slightly less than in the U.S., about 29 hours per week or more than 4 hours per day. The growth of online TV viewing has also been similar; both metrics are shown in Appendix J (CRTC, 2014b).

This level of Canadian audience attention to linear TV translates to total broadcasting TV sector revenues of $\$ 17$ billion, which includes $\mathrm{TV}$, radio, and the cable companies, known as broadcast distribution undertakings (BDUs). Nearly $\$ 9$ billion is attributed to TV, which includes advertising and subscriber revenues to conventional private TV, CBC, and all the pay and specialty services. Within this, the TV drama sector has $\$ 2$ billion of revenue, of which approximately $\$ 1.2$ billion is attributed to Canadian English-language TV drama, category 7, which includes TV drama in prime time, family, and children's genres (CRTC, 2014b).

Compared to the 210 U.S. TV markets, there are 38 geographic TV markets in Canada. Their size ranges from the three largest markets, which are the Toronto metropolitan area (population 7.6 million), 
the Montreal area (4.8 million), and the Vancouver area (3.5 million), to small markets with populations less than 100,000, such as Dawson Creek $(63,000)$ and Kenora $(36,000)$ (CRTC, 2014b).

The distribution phase of conventional TV in Canada is structurally similar to that of the U.S., monetization of programs by geographic territories, cable subscriptions, and pay TV. As such, Canada is subject to, and is undergoing, a similar process of technological disruption. Canada's telecommunications sector is said to be characterized by a high-level of vertical integration, with English Canada dominated by three media corporations, known as the VIs (vertically integrated). BCE Media, Shaw Media, and Rogers Media account for more than $80 \%$ of revenues in the telecommunications sector (CRTC, 2014b), which includes conventional TV, radio, cable distribution, broadband Internet, wireline, and wireless mobile services. As will be elaborated in Chapter 3, with specific respect to Canadian English-language TV drama and the VIs' ownership of multiple TV drama distribution capabilities, including legacy broadcast, online, and wireless, these media conglomerates appear to be horizontally integrated, rather than vertically integrated (Berkowitz, 2015d, 2015e).

As will become significant in the coming pages, the shift to online TV delivery has had the impact of shifting historic patterns of telecommunications profitability (Ferrall, 1989; Museum of Broadcast Communications, n.d.); linear broadcasting stations are no longer the "cash cows" (Ferrall, 1989, p. 10) they were in the 1960s. Two distribution technologies, conventional broadcasting and cable distribution, are today in decline, with less than 5\% growth, while broadband Internet and wireless mobile services demonstrate significant growth patterns and double-digit returns (CRTC, 2014b; Hearle, McHenry, Reitzes, Verlinda, \& Bazelon, 2014); one report calls Canada "the country most gouged by telecom companies" (Nowak, 2013, para. 1). While a report suggests Canadian wireless returns of close to $50 \%$ (Hearle et al., 2014), corroboration is suggested by a report regarding cable returns in the U.S., which, for Time Warner Cable, have been exposed as close to 100\% (Kushnick, 2015). Another comparison of the various businesses, which will become relevant to the analysis of the financial aspects of TV drama development, is investment in R\&D. For example, the telecom sector, which is dominated at more than $80 \%$ by the VIs, reports $\$ 6.9$ billion invested annually in plant and equipment, which is nearly five times the total value of the TV drama sector (CRTC, 2014b).

Canadian media corporations, by legal stipulation in The Act, must be Canadian companies and as such, are not part of any U.S. network. Yet, due to the similarity of audience preferences between English-language Canadian and U.S. audiences, Canadian English-language TV prime time drama schedules are mostly comprised of Hollywood TV dramas, licensed from various U.S. sources. A unique characteristic of TV in Canada, determined by both the small population and its geographic proximity along the U.S. border, is that a Canadian broadcast distribution regulation provides for optimization of the financial value of a Hollywood prime time program, via simultaneous substitution. This regulatory 
instrument, a financial foundation of the Canadian broadcasting system (CRTC, 2015a), has the result of increasing the revenues of Canadian geographic markets by up to 30\% (Armstrong Consulting, 2014). Simultaneous substitution requires substitution of local Canadian commercials, even if the Canadian consumer is tuned to a border station, such as Buffalo or Seattle, TV signals which are readily available in Canada. Original research on the origin of this broadcasting innovation, in place since 1971, and purposed to protect monetization rights, guaranteed by program licences, will be reported in Section 2.4.2.4.

Simultaneous substitution is a cross-subsidy regulatory instrument, which might be called “AmCon for CanCon,” with “Am” meaning American (Berkowitz, 2005a). Its importance was recently reasserted by the CRTC: "Revenues generated by simultaneous substitution are important to the broadcasting system. They keep advertising dollars in Canada, which in turn helps create programs that Canadians value" (CRTC, 2015a, Simultaneous Substitution section, para. 5). While Canadian broadcasters make money on distributing Hollywood hits, it has long been acknowledged that original Canadian drama loses money and that Canadian broadcasters invest in Canadian TV drama mainly to satisfy license obligations (Standing Committee on Canadian Heritage, 2003). Informants in this study expressed an acute awareness of the relationship between Hollywood and Canadian TV drama, and moreover, expressed their views on how obligatory investment negatively impacts the Canadian TV drama value chain: "Canadian broadcasters make their money by buying U.S. shows and simulcasting them. They make Canadian shows because it's a requirement and it goes to the whole culture of how they approach Canadian content" (Respondent, CEO Canadian TV drama firm). An aspect of the argument of this dissertation is that the impact of obligatory investment ripples all the way back to the beginning of the value chain, even to the first pitch of development, and as such, contributes to inhibiting effective competition, by Canadian English-language prime time TV dram, with Hollywood hits.

The demand, by Canadian TV audiences, for Hollywood hits, is an important component of the argument of this dissertation. Canadian English-language audience demand is underscored by Canadian broadcasters' expenditures of more than $\$ 483$ million annually on Hollywood drama, compared to $\$ 66$ million on original Canadian drama (CRTC, 2014c). Some audience statistics, reported in Chapter 1, bear review. TV drama, as a genre, represents $40 \%$ of all TV viewing, the largest single category in a comprehensive list of genres, which includes news and information, sports, music, dance and variety, game shows, and reality TV. Canadian attention to CMF dramas is approximately $10 \%$ of the audience, as shown in Appendix I. When calculated to include Canadian, but non-CMF audiences, the estimated audience market share to Canadian English-language TV drama is 17\% (CMF, 2015g).

Also relevant to this dissertation is the attention of the remaining $80 \%-90 \%$ of the English-language Canadian audience for prime time TV drama. During prime time, they are tuned to Hollywood TV dramas, a statistic which has not significantly altered since TV's earliest days, when Canadians' rooftop antennas, 
called yaggis, were turned south to capture Hollywood hits. Appendix I demonstrates the endurance of this viewing pattern for the last 35 years, from 1979 through 2014. The popularity of Netflix subscriptions in Canada, at $40 \%$ penetration, also reported earlier, further underscores the appeal of Hollywood hits to Canadian English-language audiences. It appears that an observation made a decade ago holds true today; Canadian TV drama has retained its chronically unpopular status in Canada while Hollywood drama remains the most watched, most popular genre of TV in Canada and the world (McQueen, 2003).

Consistent with the appeal of Hollywood hits, the top-10 TV series in Canada for 2013-2014 (Appendix K) do not include any English-language Canadian TV dramas, although the list does include two French-language TV programs: one drama, Unité 9, and La Voix, the French Canadian version of the Hollywood hit reality series, The Voice. The English-language top shows range from Big Bang Theory (CBS and CTV, 2007-to date), with an average audience of 3.3 million Canadians to C.S.I (CBS and CTV, 2000-to date) and Marvel's Agents of Shield (ABC and CTV, 2013-to date) at just over 2 million. A list of the top-10 performing Canadian English-language TV dramas (Appendix M) is led off by two Canadian productions, Rookie Blue (Global and originally ABC, 2010-to date) and Saving Hope (CTV and originally NBC, 2012-to date), each with about 1.5 million viewers. Perhaps more important than numbers is a qualitative observation, which acknowledges the global force of change, increased competition for attention, and perhaps even the wisdom of blockbuster strategy, which, as discussed in Chapter 1, suggests the theoretical advantage, in the highly competitive attention economy, of fewer highbudget TV dramas:

Over the last five years, the quality of television programming from Canada and the United States is perceived to have increased considerably ... driven further by online, video streaming services creating original programming. With competition increasing externally (between other regulated groups and non-regulated platforms) and internally (between channels of the same group), broadcasters report focusing more on creating a few brand-defining landmark Canadian hits, rather than commissioning many low-budget television programs that are generally viewed as being less successful at attracting audiences. In addition to a crowded marketplace, viewing patterns are evolving from appointment television to time-shifted and binge viewing. In the hopes of drawing (and keeping) audiences, brands, and advertising revenues, commissioning trends are moving towards more expensive, one-hour, character-led series in the drama and reality categories, as these have better chances of drawing attention, no matter when, where, and how the shows are consumed. (CMPA, 2015, p. 43)

Without saying so directly, the above analysis, by the Canadian producer's lobby organization, implies a rationale to strengthen the development phase of Canadian English-language TV drama, so as to better compete in a crowded attention economy. As will be seen in Chapters 5-8, Canadian producers undertake the most risk in the Canadian TV drama value chain. Given that the work of high-budget prime time Canadian English-language TV drama straddles the Canadian and Hollywood TV clusters, Canadian producers are also the group who most urgently observe emergent opportunities to improve the market 
performance Canadian English-language TV drama.

Exports are also important to this dissertation, as a metric of audience demand for Canadian English-language TV outside of Canada. The CMF reports that Canadian TV drama comprises $45 \%$ of Canadian TV exports and that TV drama is sold to 19 countries, as reprinted in Appendix R. The CMPA reports $\$ 2.5$ billion in film and TV exports, and that Canadian TV and film producers earned $\$ 244$ million in revenue in 2013-2014, with 80\% coming from outside Canada, but does not specifically isolate TV drama exports. However, the assessment of export values appears to be muted by the definition of export in a tourism-inspired manner, as a supply of Canadian jobs by foreign entities, which appears to be combined with the export of programs:

Export value tracks the value of international financial participation in the film and television production industry in Canada. It includes foreign presales and distribution advances for all projects certified by CAVCO; estimates of presales and distribution advances for non-CAVCOcertified productions; and the total value of foreign location and service production in Canada.... The export value of films and television programs produced in Canada reached a ten-year high of $\$ 2.5$ billion in 2013/14. An increase in FLS production combined with higher levels of foreign financing of Canadian television and theatrical feature films contributed to the overall increase in export value. (CMPA, 2015, p. 10)

In the value chain analysis discussed in Chapter 3, international distribution will be shown to be a weak structural link in the Canadian English-language TV drama content model. In addition to the tourism definition of exports, which includes income from foreign location production, the prohibition on Canadian broadcasters to acquire international rights to distribute Canadian English-language TV drama, per the Terms of Trade agreement with producers (CMPA, 2011b), will be shown to be an additional factor which may reduce pressure for creative excellence, in the development phase. Additionally, it will be argued that while there are a limited number of Canadian distribution companies that are substantial enough to acquire international distribution rights, about $60 \%$ of the CMF English-language TV dramas are distributed by foreign entities, usually Hollywood studios, such as 20th Century Fox International, NBCUniversal Television Distribution, or Sony Pictures Television. A list of this distribution is provided as Appendix S; an implication is that even if the program were to become a global hit, the profits would tend to flow out of Canada, enabled by substantial public investment of up to $40 \%$ of the budget. As will be analyzed in Chapter 3, the role played by the international distributors of Canadian English-language TV drama may be a potential node of value chain adjustment. The international distribution portion of the financial structure comprises about $30 \%$ of the budget, per a typical financial structure for a Canadian English-language TV premium drama, provided by a respondent, is shown in Appendix P.

While Canadian TV drama distribution is characterized by a similar structure and is undergoing similar transformations as in the U.S. and elsewhere in the world, the original TV content business in Canada occurs against a very different strategic backdrop than in the U.S. The production of Canadian 
English-language TV drama accounts for about 51\% of English-language TV production volume (CMPA, 2015 ) and has consumed close to $60 \%$ of the funding provided by the Canadian Media Fund. A history of funding to English-language TV drama, 2005-2015, provided by CMF, is shown in Appendix Q.

However, in contrast to an organic U.S. business sector geared toward profitability, the original content sector in Canada largely evolved as a response to a legal obligation, as set out in Canada's extant Broadcasting Act, including the following tenets:

(d) the Canadian broadcasting system should

(i) serve to safeguard, enrich and strengthen the cultural, political, social and economic fabric of Canada;

(ii) encourage the development of Canadian expression by providing a wide range of programming that reflects Canadian attitudes, opinions, ideas, values and artistic creativity, by displaying Canadian talent in entertainment programming and by offering information and analysis concerning Canada and other countries from a Canadian point of view...

(iv) be readily adaptable to scientific and technological change; (Government of Canada, 1991, Broadcasting Policy, Section 3, para. d, [my italics])....

(i) the programming provided by the Canadian broadcasting system should

(i) be varied and comprehensive, providing a balance of information, enlightenment and entertainment for men, women and children of all ages, interests and tastes,

(ii) be drawn from local, regional, national and international sources,

(iii) include educational and community programs,

(iv) provide a reasonable opportunity for the public to be exposed to the expression of differing views on matters of public concern, and

(v) include a significant contribution from the Canadian independent production sector. (Government of Canada, 1991, Broadcasting Policy Section 3, para. i)

The Act directs the Canadian broadcasting system to achieve a series of cultural, economic, and technological goals. Whether or not these goals have been achieved, in part or as a whole, has been the subject of debate (Doyle, 2013; Freeman, 2013; Fulford, 1986; Lester, 2013; Watson, 2013). The debates tend to question whether cultural or industrial goals have been achieved by the regime of subsidies and tax incentives. A corollary has often been to ask what the aggregate financial cost of TV subsidies have been, which have been estimated as high as $\$ 800$ million per year (Le Goff et al., 2011). This may be notable, in the context of the chronic lack of popularity of Canadian English-language TV drama, compared to the relative popularity of other genres, including Canadian sports, news and information, reality shows, and family and children's genres (CMPA, 2015; CRTC, 2014b), which can capture the attention of, in the case of children's TV, 30\% of the audience (CMF, 2015g), or in the case of sports, even more. Hockey Night in Canada was known as the most profitable program in Canada, attracting two 
million viewers when it was broadcast on CBC (Bradshaw, 2014). ${ }^{7}$

As technological transformations have accelerated in the 21st century, there has been debate regarding whether the Broadcasting Act should be updated and/or merged with the Telecommunications Act (Geist, 2015a; Palmer, 2015), as was done in the U.S., with the Telecommunications Act of 1996 (Lamolinara, 1996). This research does not take sides in this debate. The strategy of this dissertation, via value chain analysis and field research, is to reframe the vulnerabilities of Canadian English-language prime time TV drama, and ultimately, to suggest strategies how its market traction might be improved, which would imply improvements in audience popularity and a consequence, economic strength. Improved market performance by Canadian TV drama would seem to address cultural, economic, and technological goals of The Act, and might serve to quiet some of the debate, regarding The Act's efficacy for the era of online TV delivery.

Implementation and governance of The Act are assigned by the CRTC, which was established in 1968. A requirement to contribute to the manufacturing of Canadian content is stipulated in the CRTC's licenses to four large media groups, which commission most of the prime time, high-cost Canadian English-language TV drama: Bell Media, Shaw Med, Rogers Media, and Corus Entertainment, and additionally the national public broadcaster, Canadian Broadcast Corporation (CBC). ${ }^{8}$ The system has long positioned Canadian broadcasters as the primary gatekeepers and underwriters in the financing and exhibition of Canadian English-language TV drama. The efficacy of this structure, particularly for the era of online distribution, will be elaborated in the discussion of Canadian content in Section 2.3.2, and is a focus of the value chain analysis in Chapter 3 and of the findings of the field research, in Chapters 5-8.

Canadian TV drama is financed by a framework of public financing instruments, bounded by regulations and policies that have been in place, and many times iterated, since the 1970s. The main entity that currently supports the financing of Canadian TV drama is the Canadian Media Fund (CMF), a nonprofit, public-private partnership between the government of Canada and cable and satellite distributors (CMF, 2015a) which, in 2013-2014 provided financial contributions of \$375 million including English and French TV productions in all genres, and \$240 million to English language production in all genres (CMF, 2015a, 2015-2016 Programs Commitment Allocation section). CMF funds are the result of Canadian cable and satellite distributors contributing 5\% of their profits towards the production of Canadian content and additional funds from the Department of Canadian Heritage (DCH), which in 2013-

\footnotetext{
${ }^{7}$ Ratings are more difficult to obtain in Canada, than in the U.S. Unlike Nielsen, a private company, Canadian ratings are controlled by Numeris (formerly BBM), a non-profit company controlled by TV, radio, and advertising: "It has no discretion to release numbers beyond the list of top-30 shows it publishes nine days after the end of the viewing week. Individual broadcasters will quickly release numbers that make them look good - CTV wants you to know that 9.23 million Canadians watched the Super Bowl - but clam up pretty quickly when journalists ask about shows that aren't performing" (Taylor, 2015, para. 8).

${ }^{8}$ The broadcast licences for each of these entities can be found at www.crtc.gc.ca.
} 
2014 was approximately 134 million dollars (CMPA, 2014c). According to CMPA, the CMF contributed 25\% of TV project funding in 2013-14 (CMPA, 2015), and per CMF's annual report, the return on this investment in Canadian content has been approximately 2\% (CMF, 2014c). Public incentives, chiefly targeted to production, also include a number of other types of public financing, including federal tax credits and provincial tax credits. More than a decade ago, the government analyzed that nearly $40 \%$ of every Canadian TV drama was underwritten by public funds (Government of Canada, Department of Canadian Heritage, 2003). A 2011 report confirmed this assessment (Le Goff et al., 2011), which is further reconfirmed by the CMPA's annual Profile report (CMPA, 2015).

As mentioned, reporting on the Canadian TV industry, especially by lobby organizations, includes a number of supply metrics, such as volume of productions, employment and the aggregated size of production budgets (CMPA, 2015). It has been noted that the availability of numbers can complicate a research purpose, such as charting a direct relationship between public funding and audience reception (Le Goff et al., 2011). Thus said, of the total volume of film and TV production in Canada (approximately $\$ 6$ billion), about half is Canadian content and the other half is service production for foreign productions (CMPA, 2015). The arena of service productions, mostly from Hollywood, comprise a category of TV and film productions that utilize Canada as a cost-effective location, which has been well documented (Elmer \& Gasher, 2005; Elmer et al., 2010; Gornostaeva \& Brunet, 2009; Tinic, 2005), and will be further elaborated in Section 3.3.2. However, these productions usually do not count as Canadian content, except if they are structured as an official Canadian co-venture, as described in Section 2.3.1.2. The volume of TV production, French and English, is about \$2.3 billion. Drilling down further, English-language TV production volume (all genres) is about $\$ 2$ billion of the latter (CMPA, 2015). Narrowing the focus even further, English-language Canadian TV drama represents about $82 \%$ of total fiction programming which is to underscore that the annual volume of Canadian English-language TV drama is reportedly, about $\$ 1.2$ billion (CMPA, 2015).

TV drama production in Canada takes place in three main locations: Toronto, Vancouver, and Montreal. These centres together account for about $90 \%$ of the total volume of production, which will be discussed more fully in Section 3.3.2.

Employment in screen media sector delivers 125,400 full-time equivalent jobs (FTEs), which are said to generate $\$ 7$ billion for the Canadian economy. Jobs specifically in TV number about 49,000, with about 20,000 attributed to Canadian content programs (CMPA, 2015). Nearly half the production and jobs are in Ontario (CMPA, 2015), confirming the Toronto metropolitan area as Canada's main creative cluster.

This preliminary overview of the Canadian English-language TV industry will conclude with return to a consideration of Canadian English-language prime time TV drama, against the backdrop of the 
global disruption, which is impacting TV everywhere on the planet. In the ongoing evolution to online TV delivery, TV drama content is so much the focus that TV drama has nearly become the definition of TV. Genres other than entertainment appear to have retained their specific monikers, such as news, documentary, and reality; but watching TV tends to mean watching scripted, narrative content. Many aspects of Canadian English-language TV drama will be further explored in the coming pages, its value chain dissected, and its development experts consulted. However, in more than six decades, with drama now clearly enduring as the world's most popular content, an observation is that it does not appear that Canada has constructed a content business model which has resulted in strong domestic or international market performance for Canadian English-language premium TV drama. This dissertation will argue that the weak link in the value chain has been the development phase.

\subsubsection{Canadian content}

Canadian TV drama is closely associated with the term "Canadian content," an official category incorporated into policy and regulation since the 1960s, and driven by legal stipulations in The Act.

As part of its mandate to enforce The Act, the CRTC is charged with implementation of Canadian content, rules which were conceived and first implemented in the 1968 version of The Act. A Canadian content program is defined by its Canadian elements. Conventional TV broadcasters, who were considered the strongest pillar in the Canadian system when rules were conceived, have been obligated to certify that $60 \%$ of their overall schedule is Canadian and 50\% Canadian from 6 p.m. to midnight. ${ }^{9}$ The expanded evening hours help fulfill Canadian content requirements, since both the supper hour and 11 p.m. news shows count towards the $50 \%$ of programs, which attract about $15 \%$ of the Canadian viewing audience (CRTC, 2014b). This nationally customized definition of prime time has the effect of releasing the traditional prime time, 8:00 p.m.-11:00 p.m., for profitable Hollywood dramas, which are often simulcast. Furthermore, as a condition of licence granted by the CRTC, Canadian broadcasters are obligated to spend approximately $30 \%$ of gross revenues to commission original programming, known as CPEs (Canadian Program Expenditures) (CRTC, 2011b). Historically, this investment has not been profitable (McQueen, 2003, Standing Committee on Canadian Heritage, 2003).

Canadian broadcasters, as a function of their Terms of Trade agreement with Canadian independent producers, do not acquire U.S. or global distribution rights to original Canadian TV dramas (CMPA, 2011). ${ }^{10}$ A number of informants in this study conceptualized this limitation as a contributor to Canadian broadcasters' relative disinterest in the financial outcome of Canadian English-language TV drama.

\footnotetext{
${ }^{9}$ On March 12, 2015, in CRTC decision CRTC 2015-86, The Way Forward, it was announced that Canadian daytime quotas will be removed in 2016.

10 On March 12, 2015, in CRTC decision CRTC 2015-86, The Way Forward, it was announced that, as of 2016, the CRTC would no longer enforce the Terms of Trade agreement between CMPA and Canadian broadcasters.
} 
There are three main types of Canadian content TV drama (10 point dramas, co-ventures, treaty coproductions), each of which is described below in sections 2.3.1.1-2.3.1.3. A fourth type of drama produced in Canada is as mentioned, referred to as service production. Service productions are not certified as Canadian content, but are productions, nearly all from the U.S., that locate in Canada to take advantage of tax incentives and other production discounts, for the same reasons that productions locate elsewhere in the world, including competitive destinations in North America, such as Arizona, Florida, or Michigan. They are relevant to TV drama, from a below-the-line labour perspective, because about half the TV production in Canada is in this category (CMPA, 2015).

Canadian content dramas fall under the CRTC's category 7, which includes subcategories 7A/ongoing dramatic series; 7B/ongoing comedy series; 7C/specials, mini-series, \& made for TV feature films; and 7D/drama-feature films (CRTC, 2014g). There are three types of Canadian content. Canadian TV dramas certified as meeting all 10 points receive a C number (CRTC, 2015); only these 10-out-of-10 point dramas are eligible for CMF funding (CMF, 2015a). Secondly, there are Canadian co-ventures, partnerships with non-treaty countries, by default, the U.S., which are allowed to count, if structured according to certain rules, as Canadian content; these receive an SR number. These programs are listed in Appendix T. Thirdly, Canadian co-productions are treaty partnerships with approximately 53 countries, as set out in Appendix V. Each type is described in more detail, in Sections 2.3.1.1 to 2.3.1.3.

The Canadian content system has evolved, such that each of the three types of Canadian TV dramas is approved by a different government authority. Canadian productions report to the Canadian Audio Visual Certification Office (CAVCO). Co-ventures depend directly on CRTC for approval, as to whether they meet the requirements for Canadian content. International treaty co-productions are approved by CAVCO, pending a recommendation by Telefilm Canada (CRTC, 2000, 2015; Zitzerman, 2012).

To count as one of the three types of Canadian content, all TV dramas must meet CRTC's definition of a Canadian Program, which includes points requirements, based on the rubric below:

(a) producer must be Canadian citizen or permanent resident;

(b) a live action production must have minimum of 6 out of 10 points performed by Canadians, based on the following key functions, with the condition that either the director or screenwriter of each episode and 1 of the 2 lead performers is Canadian:

- Director -2 points

- Screenwriter -2 points

- Lead Performer - 1 point

- Second Lead Performer - 1 point

- Production Designer - 1 point

- Director of Photography -1 point

- Music Composer - 1 point

- Picture Editor - 1 point

(c) at least $75 \%$ of all below the line costs, with certain exceptions must be paid to Canadians; 
(d) at least $75 \%$ of all post production/laboratory costs must be paid for services provided in Canada by Canadians or Canadian controlled companies. (Zitzerman, 2012, p. 6)

It is important to note that the point system, above, is implicitly a decades-old interpretation, by the CRTC, of The Act's requirement for Canadian content. Informants in this dissertation were outspoken on a perspective that The Act's requirement for a significant story-telling sector might require new interpretation, so as to meet the exigencies of unprecedented competition for attention in the new era (Berkowitz, 2015f).

Programs of National Interest (PNI) is the name of the extant set of Canadian content rules applicable to Canadian TV drama, set to be in force through 2017 (CRTC, 2010a). Their purpose has been to "address the single most difficult problem in broadcasting - how to support high-cost local drama production" (Grant, 2012, p. 2). CRTC defines PNI as three genres - drama, long-form documentaries, and national award shows - and asserts the PNI regime represents a response to the new viewing environment: "a shift in regulatory focus from program exhibition to program creation ... to ensure the continued presence of Canadian programming options for Canadians, however the broadcasting system may evolve" (CRTC, 2010a, p. 2). In establishing PNI, CRTC has continued to require that Canada's large, vertically integrated private broadcasters (VIs) spend a minimum of $30 \%$ of gross revenues on Canadian programming and that cable distributors would continue to contribute to the CMF at about 5\% of CPEs, with the condition that $75 \%$ be spent on independent productions (CRTC, 2010a). As will be seen in the informants' assessments, the Canadian stipulation to support an independent production sector, or at least, as currently interpreted, is perceived as having originated in an era when strong independent production also characterized the Hollywood system, protected by the U.S. Financial Syndication rules, a.k.a. Fin Syn. ${ }^{11}$ Significant to this dissertation's argument, about development dynamics, is that the PNI regime, while it requires expenditures on TV drama, has abolished time credits for prime time drama exhibition; theoretically, PNI could be spent on TV drama development. Also perhaps significant is the goal of PNI, as expressed above, to support the production of high-budget drama, rather than an expressed alternately, such as a goal to strengthen market performance of this genre.

Canadian content has been, at times, controversial, even from the perspective of the government. Over the decades, as the rules tended to expand, reports have bemoaned their complexity and suggested simplification (Macerola, 2003; Standing Committee on Canadian Heritage, 2003):

The system has become an exceptionally complicated and bewildering experience (p. 151)... Canadian content ... has a set of contradictory definitions that do not necessarily allow creators to

\footnotetext{
${ }^{11}$ The U.S. Fin Syn rules, which were enacted in 1970, were loosened in the 1980s, when conventional broadcasting first began to weaken, due to competition from cable channels, and fully repealed by 1993, which allowed U.S. broadcasters to vertically integrate. This evolution, in the U.S. of the TV drama value chain, emerged as a focus in the field research for this dissertation, and will be addressed in more detail.
} 
create. They are dealing with a mountain of paperwork. ... But even this does not scratch the surface of the system's complexity (pp. 153-54). ... In short, the rules governing what is or is not Canadian have become so complex that they defy easy description or explanation (p. 164).... Michael Ondaatje's, The English Patient, an internationally successful movie and film, does not qualify as Canadian even though it is a Canadian story, has many visible Canadian elements, and as a film, won nine Academy Awards. (Standing Committee on Canadian Heritage, 2003, p. 164)

The concept of Canadian content been challenged, with respect to its justification as a market intervention. Its public interest purpose, as being well suited to further the goals of The Act, has been questioned. From the theoretical perspective of competitive advantage theory, it has been argued that nations should avoid protecting industries in which they may be at comparative disadvantage, in order to strengthen the weak sectors (Hoskins et al., 2004, p. 329). Moreover, costs of government intervention in weak sectors may outweigh benefits, while doing little to prevent the so-called market failure (Hoskins et al., 2004, p. 304). It has been suggested that protecting an industry can lead to strategies which inhibit or unintentionally weaken clusters:

Government policies often unwittingly work against cluster formation. ... Restrictions on industrial location and subsidies to invest in distressed areas, for example, can disperse companies artificially. Protecting local companies from competition leads to excessive integration and blunted pressure for innovation ... companies have to spread activities globally to source inputs and gain access to markets. Failure to do so will lead to a competitive disadvantage. (Porter, 1998b, pp. 86-87)

Critiques of Canadian content have extended to its impact on labour, suggesting that a case for protecting weak or infant industry sectors should not be based on motivation to increase employment, and arguing that, while jobs may increase in the protected sector, they do not appear to increase in the aggregate (Hoskins et al., 2004, p. 320).

The debate on Canadian content appears to have been limited during broadcasting's decades of stability and profitability in the latter half of the 20th century. As Canadian productions, often produced in partnership with Hollywood entities, increasingly found their way onto U.S. prime time schedules in the 21st century, and Canadian English-language TV drama competed head-to-head with Hollywood TV drama, the debate over the future of CanCon became more public: "It is the paradox of Canadian television: producers struggle to de-Canadianize content to play to international audiences while trying to maintain enough distinction to appear 'Canadian enough' to appease CRTC requirements. ... So are CanCon rules worth saving?" (Freeman, 2013, paras. 23, 25). This debate was passionately reflected by informants, in this dissertation's field research:

We have to step back and look at the Canadian system from first principles and say, these rules came into place in the 60s and 70s and evolved over time and may have made sense then, but do they make sense now? The whole system needs an overhaul. It's now a business where development is more important than it's ever been. (Respondent, CEO, Canadian TV drama firm) 
In September 2014, precipitated, in part, by voluntary testimony of a representative from Netflix at the Let's Talk TV hearing, the debate over CanCon heated up further. Global transformation in TV delivery highlighted the contrast between broadcasting and online TV drama, which is exempt from CanCon regulation. During Let's Talk TV, the Canadian TV industry appeared to be overwhelmingly in favour of extending CanCon regulation to OTT services:

The government of Ontario is pushing Canada's federal telecom regulator to regulate new media services like Netflix, much the way it regulates traditional TV, requiring the U.S. based service to pay for the development of Canadian content. ... The CBC supports regulating Netflix and similar services. ... The Canada Media Production Association is also pushing to regulate Netflix. (Freeman, 2014, paras. 1, 8, 12)

It seems important to qualify that I actively participated in this 2014 public conversation In my presentation to the CRTC (Berkowitz, 2014c, 2014d) and subsequent remarks in the media (Berkowitz, 2014f), I recommended that OTT services should not be regulated. I suggested a strategy to loosen CanCon rules so that Canadian premium TV drama producers might better align with Hollywood partners, and compete more effectively in the global attention economy. In March 2015, the CRTC set forth a pilot project, which did loosen the points system for development of high-budget Canadian English-language TV drama, an indication this research may have been considered (CRTC, 2015f). A full review of the intersection of this dissertation and Let's Talk TV can be found in Section 9.5.

\subsubsection{Canadian English-language TV drama}

Canadian English-language TV dramas, which meet the requirements to receive all 10 points, as set out above, receive a "C" designation from the CRTC. These series are the high-budget premium TV dramas, which compete with Hollywood TV drama, for a prime time slot in both Canada and the U.S., and as such, are the focus of this dissertation. They are the programs that comprise the Canadian Media Fund's top performing English-language programs each year. For clarity, these programs appear in four lists shown in Appendix N.

With respect to this dissertation, these TV dramas have another important distinguishing feature, in addition to having met the $100 \%$ Canadian requirements for CMF funding. Many of them have achieved licenses with U.S. networks and may be simulcast with a U.S. network, including the following: Flashpoint (2008-2012, CBS/CTV), Rookie Blue (2010-to date; Global/ABC); Saving Hope (2012-to date; CTV in Canada; cancelled by NBC), and Working the Engels (2014-2014; cancelled by Global after 12 episodes; cancelled by NBC after five episodes) (Goldberg \& Vlessing, 2014). By definition, these TV dramas have placed themselves in competition with Hollywood TV dramas, for the attention of the North American audience, not just the Canadian English-language audience. A list of the U.S. network partners of these programs has been compiled in Appendix O. 
In this respect, the audience results of these premium TV dramas appear to bear further discussion. As discussed above, it is a foundational concept to this dissertation, that popularity is the only measurable element of quality, and as such, of the efficacy of the development phase. The following comments integrate observations on the lists of popular shows in Appendices K, L, M, and N; since there are some discrepancies between these lists, the discussion will adhere to broad observations. While top hits in Canada, such as Big Bang Theory, attract in excess of three million viewers, to make the top-10 list, as a hit, two million viewers seems necessary. The most popular English-language TV dramas, such as Flashpoint, Rookie Blue, Combat Hospital, and Saving Hope have come close to this number, but typically get about 1.5 million viewers. Several observations are suggested. Firstly, even though this dissertation does not study French Canadian TV, it seems imperative to observe that $70 \%$ of the top Canadian TV shows in Canada are French shows, in absolutely numbers, made for a market approximately one-third the size of English Canada's population of 25 million. Notwithstanding factors of language, cultural distinction, and development dynamics of French-language Canadian TV, which are outside the scope of this dissertation, the comparison nevertheless underscores that Canadian Englishlanguage TV dramas are competing, not most actively with French Canadian shows, but their main competitive set is Hollywood TV dramas. As such, their intended audience is the entire North American audience. While an audience of 1.5 million in Canada would seem to scale up to 15 million in the U.S., this math has not occurred; the shows have tended to be cancelled by their U.S. networks. Nor have they achieved the critical acclaim of cable shows, such as Showtime's The Affair, which, as discussed earlier, had ratings of less than one million viewers, but won the Golden Globe for the best TV series, thus acquiring the buzz of a hit, and the power to drive subscriptions to Showtime.

It seems to follow that, to be considered a hit in Canada, Canadian English-language TV dramas will need to become hits in the U.S. The numbers suggest that a domestic rating of excess of two million in Canada might be a minimum essential for this category. What is holding back Canadian Englishlanguage TV dramas from capturing this level of attention? The value chain in Chapter 3 and the field research reported in Chapters 5-8 both explore this question, and suggest weak development dynamics might be the answer. Furthermore, weak market traction in the U.S. may lead to a weak brand for Canadian English-language TV dramas, which further decreases positive buzz, even in Canada. As will be suggested in Section 9. 4, a future quantitative study might attempt to ascertain how to predict a minimum Canadian numeric rating which could indicate development might be strong enough to secure a distribution deal for the U.S. and possibly project how large the Canadian audience should be to predict a strong position in the U.S. market. A concluding observation may be that Canadian English-language premium TV dramas are already good enough to be welcome to play the Hollywood TV drama game, but as yet, they are not winning it. The mission of this dissertation is to strengthen that effort. 
Of relevance to this dissertation's focus on the development phase of Canadian English-language premium TV dramas is how these episodic series first broke into U.S. network schedules. Partly attributed to a need for programming, resulting from a 6-month writers' strike in 1988, Canadian TV dramas got picked up by U.S. networks in the 1980s, with programs including Night Heat (1985-1991, CTV; CBS Late Night, 1987-1993), Adderly (1986-88, Global, CBS Late Night), and Diamonds (1987-1989; Global, CBS Late Night and USA Network). The first wave of presence of Canadian dramas in the U.S. ended with Due South (CTV, 1994-1999, CBS, 1994-1996) in 1996 (Stelter, 2008). It had been officially created by Paul Haggis, a Canadian in Hollywood, who had been a supervising producer on Thirty Something (1987-1991, ABC). Haggis was not the showrunner; but a Canadian who went on to become one of the top showrunners in Hollywood today, David Shore was (Battle Creek, House, NYPD Blue). Except for Due South, ${ }^{12}$ all the shows in the first wave were relegated to late night slots in the U.S., rather than prime time.

Flashpoint ignited a21st century wave of Canadian English-language TV drama on U.S. network schedules, also attributed to a development opportunity, afforded by another WGA writers' strike, 20072008:

As the networks search for work-arounds to find fresh material during the writers' strike, CBS has hit on a novel strategy: go to countries where the writers are not on strike. On Tuesday CBS announced it will pick up a new police drama from the Canadian broadcast network, CTV, which uses Canadian writers, producers, and actors. The program will be shown in both the United States and Canada concurrently. ... Flashpoint will become the first Canadian series since CTV's Due South in 1994 to air in network prime time in both Canada and the U.S. (Stelter, 2008, paras. 1-2, 5)

Rookie Blue, with a working title, Copper, followed Flashpoint's trajectory, a partnership between Global and ABC. And so followed, the current U.S. line-up of Canadian English-language premium TV dramas.

The field research for this dissertation confirms that global disruption of linear broadcasting, by online TV delivery, appears to have created a third, new type of opening in Hollywood, for Canadian English-language premium TV drama. As mentioned, the number of Hollywood entities who are commissioning original drama, has increased. Informants reported this increasingly competitive landscape for TV drama in Hollywood has put pressure on the demand for creative talent and for financing partners, to meet increased audience demand. This has caused U.S. studios and networks to find it more attractive to partner on TV drama, as observed in a discussion of current trends:

Canadian producers are increasingly going after global investors and major Canadian television series and mini-series are receiving pre-sales from US networks... the pooling of resources has become even more vital and US broadcasters are reportedly more willing to do cross-border collaborations. ... Canadian broadcasters have also started to get involved in the development phase sooner with their co-financing US partners. For instance, Orphan Black, which was among Time Magazine's top ten television shows of 2013, premiered both on Space and BBC America.

\footnotetext{
${ }^{12}$ A theme of Due South, which starred a Mountie and a U.S. police detective, was the relationship between Canada and the U.S.
} 
The show broke ratings records for the Canadian specialty channel, leading to an encore run on CTV and an acquisition by BBC3 in the UK. (CMPA, 2015, p. 43, [my italics])

Increased willingness to partner in Hollywood would appear to be a good fit with the unique geo-cultural positioning of the Canadian English-language TV drama sector, and well-suited to the interests of Canadian TV drama firms seeking to move up the value chain, from production to development phase excellence. However, this field study suggests that reliance on production discounts, i.e. a value chain distinguished by a low cost model, rather than differentiated by creative excellence (Porter, 2985), may be inhibiting the contemporary, competitive capability of Canadian TV drama producers in Hollywood.

Per the financial structure of a Canadian TV drama, as shown in Appendix Q, the U.S. financing portion of a Canadian English-language TV drama can comprise about 30\% of the budget, roughly equal to CMF participation. Notwithstanding the status of these dramas as 100\% Canadian, a U.S. pre-sale brings with it, development governance from a U.S. broadcaster, who is licensing, and/or a Hollywood studio, who acquires international distribution rights in exchange for financing. The complex coordination of financier governance, particularly in development, is also a theme of the field research, as reported in Chapters 5-8. Not only in the final analysis, by the audience, but also from the first moment of a pitch to a Hollywood broadcasters or studio, Canadian English-language premium TV dramas are competing with Hollywood dramas. The high-stakes competition, which these dramas have entered, starts in development.

\subsubsection{Canadian co-ventures}

Canadian co-venture dramas, which receive an "SR" designation by the CRTC, are a much smaller category than "C" productions. Compared to the CRTC's listing of 15 pages of "C" dramas since 2010, which include children's and family dramas, in French and English, there are four pages of "SR" coventures (CRTC, 2014g). In an abbreviated version of the CRTC list, they are shown in Appendix T. These programs, which are default partnerships with the U.S., are often broadcast in both countries on cable channels, and as such, are not usually simulcast. They include such programs as Beauty and the Beast (2012-to date, Showcase, The CW, Netflix), Skins (2011-to date, Movie Central, The Movie Network), Hard Rock Medical (2013-to date, TVO, APTN), and Life with Boys (2011-2013, YTV, Teen Nick). Co-ventures were a category created by the CRTC in 2000, and reconfirmed in 2010 and 2015 (CRTC, 2000, 2010c, 2015). During the time frame when co-ventures were created, about 2000, Canadian TV dramas had no presence on U.S. TV schedules; as such, the timing may suggest a purpose might have been to loosen restrictions and, by default, encourage Canadian TV drama producers to move up the value chain, and partner in Hollywood.

Canadian co-ventures are default partnerships with the U.S., with whom there is no co-production treaty. The reason there is no co-production treaty with the U.S. is a function of the success of the U.S. TV industry, from an asset popularity and market size perspective, there has never been a need for the 
U.S. to enter into such agreements. The flexibility of this content category reflects its purpose to be workable with U.S. partners, who may not be equally motivated to work with Canadians:

International co-productions between Canadian controlled companies and foreign controlled companies... are not included under the international co-production treaties administered by Telefilm Canada ... there is no treaty with the United States. However, a co-venture between a Canadian co-producer and a United States co-producer is permitted by the CRTC and, in fact, is the most common form of co-venture. (Zitzerman, 2012, p. 7)

The structure of Canadian co-ventures can be complex, as shown in Appendix U.

Co-ventures in all Category 7 subcategories, including episodic series, MOWs, and features which are licensed for TV, include children's and family programming, which is not delineated as a separate category. Only a small minority of co-ventures, which do have presence on prime time U.S. cable channels, directly connect Canadian English-language TV drama development to Hollywood TV development, and as such, are implicitly included as a focus of this dissertation.

\subsubsection{Canadian international treaty co-productions}

Canada, like many countries around the world, but not the U.S., has audio-visual co-production treaties, which set out the terms of international cooperation on TV and film projects, in order to satisfy regulatory regimes and facilitate the financing of costly media genres, such as TV drama. Canada has treaties with 53 countries (Telefilm Canada, n.d.), a list of which is provided in Appendix V. Of significance to this dissertation is the decreased number of international treaty co-productions, versus the increased profile of high-budget, prime time CMF TV drama productions. The CMPA reports the number of English-language co-productions has decreased from a high, in 2008, of 88 productions, to 49, virtually the same amount as a decade ago (CMPA, 2015). For certification purposes, the Canadian portion is treated separately (Zitzerman, 2012), and may qualify as a 100\% Canadian production. International coproductions do not directly connect Canadian English-language TV drama to Hollywood; as such, as a genre they are not a focus of this dissertation, except that analysis of weakness in the development weakness is systemic to all Canadian English-language TV drama. Moreover, the significant challenges of the development phase in such productions, including issues of cultural discount, have been addressed by other studies (Davis \& Nadler, 2009; Grant, 2008).

\subsubsection{Canadian English-language TV drama development}

On the surface, the creative processes of TV drama development in Canada, as reported by Canadian development executives in this study, appear to be similar to a Hollywood TV drama process, and follow the same progression from pitch to greenlit project. Showrunners based in Canada and Canadian development executives report a likeminded sense, if somewhat more muted than their Hollywood counterparts, that managing creative development is always a balancing act, characterized by 
a Canadian researcher as a need to "master innovation" with "consistent execution" in order to achieve a successful outcome to a process for which the right elements "defy codification" (Brunet, 2004, p. 7).

Beneath the surface, as the field study will show, the development phase does not appear to have a similar priority or intensity in Canada, as it does in Hollywood. The contrast was summed up by an informant in this study: "People here in L.A. are terrified of failure. In Canada I feel people are tenured. They don't feel like they're going to lose their jobs. Here in L.A., you're the big exec who makes the wrong decision on a show: you're gone" (Respondent, Canadian, A-list Hollywood showrunner).

Canadian English-language TV drama development numbers, from the perspective of financiers, have been looked at via two organizations, CMF and CRTC. A review of CMF performance and development envelopes to the three major broadcasters, Bell Media, Rogers Media and Shaw Media, shows their development envelope, of about $\$ 3$ million, appears to be an additional $12 \%$ to the performance envelope of approximately $\$ 25$ million (CMF, 2015e, 2015h). Even multiplying this number by 10 would not bring it close to the reported 80-100 million dollars spent, per year, on development by Hollywood studios, as previously noted (Littleton, 2015). CRTC's financial summaries for conventional television report lower percentages spent on development, than indicated by CMF envelopes (CRTC, 20151), with the qualification of difficulty in knowing exactly what is measured. Of nearly $\$ 60$ million in Canadian Program Expenditures (CPEs), approximately 478,000 is spent on category 7 drama, "script and concept—not telecast," or less than 1\% (CRTC, 20151, 1. Programming - Canadian: other Canadian programming expenses). While these numbers are not meant to conclusively indicate total spending on the development phase of Canadian drama by financiers, they seem a general indication of the priority of the R \& D phase of Canadian English-language TV drama. A nuance to interpreting the cost of Canadian TV drama development is that these same Financial Summaries show that conventional TV broadcasters report expenditures of more than $\$ 550$ million on non-Canadian programming expenses in Drama, Category 7 , for which they have no development expenses. Moreover, as will be elaborated in Chapter 3, U.S. drama acquisitions correspond to the network's business model as a territorial a broadcaster; development expenses reflect their mixed role in original content, as both broadcaster (domestic licensor) and studio (typically, invests to monetize via international rights). Also, since the CRTC's current TV drama policy, Programs of National Interest (PNI), as discussed in Section 2.3.1, does permit development expenditures to be counted against requirements for Canadian networks' total drama expenditures, there would seem to be little motivation for a Canadian network to substantially under-report development expenditures.

A useful comparison between the development phase of the Canadian English TV drama with that of Hollywood, may be the importance of development to the company's overall success or failure, and the priority of potential ROI value of Canadian TV drama to Canadian networks, as will be elaborated in the value chain theorization in Chapter 3 . As will be seen in the field research findings, Chapters 5-8, a 
striking difference in development dynamics between Hollywood and Canada appears to be driven by the difference in the goals of each system. Canadian TV drama development in appears to lack the singularity of one goal, deeply embedded in the Hollywood drama R\&D process. This goal can be stated simply as profitability: the need for a hit.

In Hollywood, the financial goal is so connected to the creative process that it is woven into the WGA's directives to showrunners on how to manage dynamics in the writing room: "So as long as shows are profitable, despite management issues, the studios and networks will see little reason to change.... The business needs professional writer-producers too badly to let a good one slip through the cracks" (Jean et al., 2012, p. 36). As the field research will show, a weaker financial imperative, in the Canadian system, impacts the Canadian TV drama development process. A Hollywood studio executive, who manages Canadian TV dramas, observed: "It's the DNA of the [Canadian] system that needs to change."

From a creative labour perspective, there appears to be proportionally more creatives in Canada than in the U.S. Compared to the WGA's total membership of about 16,000 members, the WGC has 2,200 members. Much like the scarcity of information on the Hollywood development community, the Canadian TV development community has been little studied: "While Canada occupies—geographically, economically, linguistically and culturally — a position unique in the world ... the role of screenwriting is little understood" (Davis \& Kaye, 2010a, p. 2). Corroborating the characterization of a career as a TV creator as very risky, similarly to Hollywood, the same study reports that more than half of the membership of the WGC earns less than $\$ 40,000$ per year (Davis \& Kaye, 2010a). A profile of Canadian creatives appears to conform to descriptions of their counterparts in Hollywood: "Screenwriting is steeply stratified, with relatively few, highly visible and well remunerated individuals at the centre, and many part-time and economically inactive screenwriters at the margins" (Davis et al., 2012, p. 77).

Nearly half of Canada's English-language screenwriters are based in Toronto, supporting the production metric, mentioned earlier, that Toronto is the main Canadian cluster for English-language TV drama. The importance of being in Toronto is described to include connections with gatekeepers, decision makers, mentorship opportunities, as well as networking with and other writers (Davis et al., 2012), an imperative for connection, which is also consistent with the advantages of clusters, as will be discussed in Section 2.6.

Government presence in the Canadian TV sector has created a need for effective paperwork to secure public funds, and a need to become skilled at doing so; research has shown that managing patronage relationships has become a skill set of Canadian producers (Davis, Vladica, \& Berkowitz, 2008). Funding processes appear to have become embedded as important aspects of the business models of Canadian TV drama firms (Le Goff et al., 2011). The role of paperwork has even been shown to impact the design of jobs in the development phase. One study, which explores the role of the showrunner on a 
family drama, a Canada-France international co-production, contrasts the role of a showrunner, the lead creative position in Hollywood, with that of a non-writing, economic, or e-showrunner, a job invented to deal with the complexity of managing Canadian financing (Davis \& Nadler, 2012). The Davis and Nadler study concludes that diffusion of priority, from managing creative to managing the deal, damages the resultant product, a point underscored by this study's field research, reported in Chapters 5-8.

While Toronto may be the centre of the Canadian industry, is it perceived, by creators who live there, as the "centre of the periphery," a reference to Hollywood as the centre. Many Canadian screenwriters believe that the brightest talent moves to Hollywood. When asked for a general word of advice to young, aspiring Canadian screenwriters, many of our respondents replied simply, "Move to L.A" (Davis et al., 2012, p. 87). Acknowledgement of Hollywood's dominance in development is further underscored by $11 \%$ of WGC reporting they are based in Los Angeles (Davis \& Kaye, 2010a). Canadian screenwriters report that an advantage of working in Hollywood is the quality of the competition, "meeting the most demanding standards," while "occupational dynamics of screenwriting in Canada can lead to creative stagnation" (Davis \& Kaye, 2010, p. 11). Such advantages are reflected in the field research for this dissertation, by Canadian TV drama creators who did move to L.A.

The brain migration of talented Canadian creators, to Hollywood, has long been acknowledged. The brain drain of Canadian TV drama creators has been documented since it was first mentioned in the Massey Commission (Royal Commission on National Development in the Arts, Letters, and Sciences, 1951). However, previous to this study, the impact of brain drain on the development of Canadian English-language prime time TV drama has not been strategically examined. As brain migration is an important focus of this research, more detail will be provided in the next section.

\subsubsection{Canadian brain drain to Hollywood}

Canadians have had a vibrant presence in Hollywood, since its origin. Mary Pickford (1892-1979) was born in Toronto. Known as "America's Sweetheart," she was an actress and a business woman, one of the founders of the United Artists Hollywood studio in 1919, and of the Academy of Arts and Sciences, the Oscars.

The term brain drain was coined by the British Royal Society, to name the pattern of skilled emigration of workers, particularly scientists and technology experts, from the U.K. to Canada and the U.S. in the 1950s and 1960s (Cervantes \& Guellac, 2002). Brain drain of Canadians to the U.S. has been an observable phenomenon since the earliest days of broadcasting, reflected in the 1951 Massey report: "Of American institutions we make the freest use, and we are encouraged t5o do so by the similarities in our ways of life. ... Canada 'sells down south' as many as 2500 professional men and women in a year" (Royal Commission, 1951, Chapter II, paras. 10, 14). There may be a certain irony to the story of the Massey Commission's Chair, Vincent Massey. He had a younger brother, Raymond, who had moved to 
Hollywood, where he became a star. By 1951, Raymond had already received an Oscar nomination for a bio-pic about an American icon, Abe Lincoln in Illinois.

The famous Canadian comedy duo from Toronto, Johnny Wayne (1918-1990) and Frank Shuster (1916-2002), got their break in the U.S.:

Their biggest television success came in 1958 when Ed Sullivan, whose ratings had slipped, invited them to appear on his Sunday night variety show ... they were the biggest hit in ten years. ... His ratings shot up whenever they performed and their contract was renewed again and again. So too was their CBC contract, which had been on the verge of being canceled before their American success. (Miller, 1987, p. 193)

During the 1980s, the L.A. Telefilm Canada office, together with the Canadian Consulate in L.A, coordinated a list of Canadians in L.A., called the Canadian Talent Directory, which helped Canadian broadcasters to identify Canadian creators working in Hollywood, to aid in development of TV drama, especially productions being co-financed with Hollywood broadcasters and studios, which tended to require Canadian writers with U.S. network approval. However, since then, the L.A. Telefilm office has been closed and the list is defunct, having never been digitized. ${ }^{13}$

More than 50 years after the Massey Commission, in 2003, another comprehensive government report on the Canadian TV industry (Standing Committee on Canadian Heritage, 2003) listed dozens of well-known Canadians in Hollywood, many of them globally recognized, and still famous. ${ }^{14}$ Canadian brain drain to Hollywood includes the planet's most revered creators: James Cameron (Titanic, Avatar, two biggest box office films of all time); Paul Haggis (Crash, Million Dollar Baby, Thirty-Something, only director since 1950 to win back-to-back Oscars); Lorne Michaels (Saturday Night Live, TV's longest running entertainment series, now in its 41st season), Ivan Reitman (Animal House, Ghostbusters, billion dollar director), David Shore (House, most watched program in world in 2008, now working with Breaking Bad creator on Battle Creek), and very many more.

It has been estimated that up to 100,000 Canadians currently work in the Hollywood entertainment cluster (CRTC, 2015e) and that Canadians comprise $25 \%$ of the Hollywood creative community (MacDonald, 2007). As noted, brain drain figures are challenging to verify, because Canada does not keep track of emigration statistics. An irony seems that, while Canada has not been exporting much TV drama, it has, for nearly 100 years, exported TV drama creators, who are the key to its popularity and

\footnotetext{
${ }^{13}$ I am personally familiar with the Canadian Talent Directory, having used it in my work as head of development for Global Television Network (now Shaw Media). In 2011, I was involved in an initiative to update and digitize a Canadian creators directory, with the endorsement of the Canadian Consulate in L.A.

${ }^{14}$ The names listed in Our Cultural Sovereignty include the following: "Dan Aykroyd, Pamela Anderson, Raymond Burr, Neve Campbell, James Cameron, John Candy, Jim Carrey, John Colicos, James Doohan, David James Elliott, Dave Foley, Michael J. Fox, Tom Green, Graham Greene, Lorne Greene, Paul Gross Phil Hartman, Jillian Henessey, Michael Ironside, Norman Jewison, Rich Little, Norm MacDonald, Raymond Massey, Lorne Michaels, Colin Mochrie, Rick Moranis, Dave Thomas, Scott Thompson" (Standing Committee on Canadian Heritage, 2003, p. 149).
} 
consequent financial performance.

In contrast to what appears to be Canada's decreasing institutional linkages with Hollywood, the British Academy of Film and Television Arts (BAFTA) runs a program to support British nationals in Hollywood:

We see our newcomers as the next wave of British film, television, and games professionals to make their mark in Hollywood. ... Each participant is assigned a mentor from the BAFTA Los Angeles membership, to help support and guide them in their transition to the U.S. industry. (BAFTA, n.d., para. 1)

Few initiatives have examined the strategic potential, for the Canadian English-language TV drama sector, of converting the Canadian pattern of brain migration to a brain chain or brain gain. This study is the first to explore the perspectives of Canadian creators, who began their career in Canada, often being trained on Canadian English-language TV dramas, before emigrating to Hollywood. As such, the discussion of Canadian brain drain of development workers to Hollywood will be further contextualized by the review in Section 2.6.3 of existing knowledge on Canadian brain migration, as it pertains to economic diasporas.

\subsection{Canadian TV policy: Response to Hollywood dominance}

Many issues in Canadian life, not just TV, are bound up in Canada's connectivity with the U.S., so much so that it has been suggested there is a downside to defining Canadian as what is not American:

Canadians define themselves by what they are not-American — which is not only disingenuous but also destructive. Canadians have more in common with Americans than with any other country in the world. They share many of the same values: freedom, democracy, rule of law, a Judeo-Christian ethic and an (at times grudging) belief in a market-driven economy. With all that great inheritance, why focus on the negative? Doing so creates the impossible task of trying forge an identity in a vacuum that inevitably leads to feelings of inferiority. (Mandel-Campbell, 2007, p. 308)

In TV, the Canada-U.S. relationship has never been simple, at least from the Canadian perspective. Given the two countries' respective populations, both have developed robust industries, albeit by different strategies. The U.S. industry dominates by monetizing globally popular content, which I have called "good stories, well told" (Berkowitz, 2009b, p. 1). The Canadian industry has been well built to feature strength in production and conventional broadcast distribution with a brilliant regulatory regime, which I have called "good policies, well implemented" (Berkowitz, 2009b, p. 1). As the work of this section is to position Canadian TV policy as a subset of Canada's relationship with the U.S., the discussion proceeds with a review of the connection between the neighbouring nations.

\subsubsection{Canada-U.S. media relationship}

The Canadian identity dilemma has been well documented. Observations assert that English Canada comes by this challenge organically, lacking two key factors which define national identity, a native tongue and unique civic values, since most are shared with the U.S. (Godfrey \& Unger, 2004). A 
comparative analysis of national identities of eight countries asserts that, in Canada, "nation and nationalism have been the main course at political and academic banquets for ... a century or more" (Godfrey \& Unger, 2004, p. 17). A reason for the uncertain Canadian weltanschauung has been postulated as a north-south, love-hate discomfort: "If the Canadian faces south, he becomes either hypnotized or repelled by the United States; either he thinks up reasons for being different and somehow superior to Americans or he accepts being swallowed up by the United States as inevitable" (Frye, 1971, pp. iii-iv).

Canada's relationship with the U.S. has also been described from an economic perspective, linking Canadian identity issues to an inability to brand globally or unlock export potential:

That seeming lack of identity, in turn, has serious ramifications for Canada's inability to project itself into world markets. Think of Jamaican rum or Italian leather ... we don't stand for anything. ...

Canadians are in danger of boring the entire world to death. (Mandel-Campbell, 2007, p. 309)

Extending the conceptualization that a love-hate paradox defines the Canada-U.S. relationship, communication theorists have linked this general observation to Canada's TV industry. A communication theorist observed that the Canadian worldview might be defined as a comfort with irresolvable contradiction (Babe, 2000). Comfort with paradox may be manifested in Canada's core TV regulation, simultaneous substitution, which depends on monetizing Canadian affection for U.S. drama, in order to finance Canadian drama, ostensibly purposed to protect Canadians from U.S. drama. Building on the idea of dichotomy, three subplots in the relationship have been identified: cultural imperialism, proglobalization, and emancipation (Johnson-Yale, 2008). The emancipation subplot contains an irresolvable paradox, a desire for Canadian English-language TV drama to become distinct, by becoming exactly like Hollywood TV drama (Johnson-Yale, 2008).

Canada's cultural identity issue has been directly linked to its media regulation, as cited in the beginning of this chapter:

What constitutes merit is contextual to the particular country and will vary greatly. Americans worry about sex more than the French. Swedes fret about violence. Germans are sensitive about racist incitement. ... Each country has its concerns, problems, issues, traditions, priorities. Canada is concerned about a weakening of its national identity. Whether these concerns are justified, or in their own public's interest, is not the main question. What is important is that governments act on them. The main purpose of television regulation is to advance such goals. (Noam, 2008, Reasons for Regelation section, para. 6)

However, the validity of a cultural rationale for media policy has been questioned: "Ostensibly the major concern with U.S. dominance has been cultural rather than economic, although we note artistic communities ... invariably stand to gain economically from policies advocated on cultural grounds" (Hoskins \& Mirus, 1988, p. 499). Skepticism regarding a cultural protection rationale is further supported by a study which suggests that exposure to foreign media does not appear to undermine indigenous 
culture (Olson, 1999). Nevertheless, a study of Canadian content asserts that the cumulative cultural effect of the Canadian government's media discourse has been successful, so much so that the idea of nationhood has been coupled with culture. Canadians have developed a predisposition to connect art with patriotism (Edwardson, 2008). Separating art from patriotism may be essential if the Canadian cultural industries are to successfully compete in a global media ecosystem:

Federal bureaucrats need to come to terms with the fact that economic strength and industry growth do not equate with opportunities for national discourse. ... [Until these concepts are decoupled] citizens will continue to be bound to a paradigm of Canadianization, at odds with their best interests. (Edwardson, 2008, p. 283)

\subsubsection{Timeline of Canadian response to Hollywood dominance}

The following timeline of the history of Canadian TV policy shows that it has reflected Canada's paradoxical relationship with the U.S., and is a sequence of choices made in response to U.S. dominance.

\subsubsection{1-1929: Aird Commission}

By the time of the first Royal Commission on radio broadcasting in 1929, the Aird Commission, Canadian audiences had a love for U.S. media. CBC radio was broadcasting popular U.S. radio shows, such as Bob Hope and Jack Benny to maintain audience share (Litt, 1992). The Aird Commission, acting on behalf of the government, apparently did not regard the U.S. as a desirable model for broadcasting. The report, only 14 pages, tiny by today's standards, already belies a dichotomous response to dominance. Its appendix, part of which is reprinted as Appendix W in this document, lists 26 countries studied, describing in detail broadcasting in countries such as Estonia, Finland, and Turkey. The U.S. blurb is shortest of all, two lines about an industry that had already captured the attention of Canadian audiences: "United States of America: Broadcasting in the United States is carried on by private enterprise under licence of the Federal Radio Commission. There are 604 stations licensed. There is no licence fee for listeners" (Royal Commission on Radio Broadcasting, 1929, p. 17).

\subsubsection{2 -1949-1951: Royal Commission on National Development in the Arts, Letters, and Sciences (Massey Commission)}

Twenty years later, the Royal Commission on National Development in the Arts, Letters, and Sciences, known as the Massey Commission, more explicitly formulated anti-U.S. policy rhetoric. At the time, similar genres to today, such as The Lone Ranger (drama), You Bet Your Life (reality game), and Arthur Godfrey's Talent Scouts (reality talent search) were top 10 shows. I Love Lucy (sitcom) would hit the airwaves in 1951 (Classictvhits.com, n.d.).

The Muses, the Masses, and the Massey Commission probes the inside story of the Massey Commission and its role in crafting the public perception that Canada is victimized by the U.S (Litt, 1992). As noted above, there is a possibility that sibling rivalry between the Chair and his younger 
brother, a Hollywood star, informed the Chair's views. The Massey Commission's comparative studies of other countries had a similar dismissive tone, as the Aird report, regarding the U.S: "While in New York, Neatby [the Commissioner who examined the U.S. industry] talked informally with television viewers and an actor from Canada who worked in television, who (sic) watched fifteen hours of television herself, an experience she described as personally 'an unrewarding occupation"” (Litt, 1992, p. 48). ${ }^{15}$ Of direct relevance to a central argument of this dissertation, that Canada might strengthen its English-language TV drama sector by increasing Canada-U.S. linkages, this issue was debated at the Commission's Western Canada hearing, in November 1949. CTV broadcaster, Kent Cooke, was reportedly admonished by Massey for his impassioned pitch to work with, rather than against the U.S. (Litt, 1992):

An American is basically the same as a Canadian - motivated by the same impulses, exposed to the same influences of literature, music, the theatre, movies and radio. ... By "non-Canadian material," the $\mathrm{CBC}$ is obviously referring to American material. In the first place, what is wrong with American material? If we are ever to have a Canadian culture, it will come as a result of exposure to what is undoubtedly the fastest rising culture in the world today — that of the U.S.A. (Litt, 1992, p. 71) ${ }^{16}$

Litt's assessment is that the Massey Commission's profound impact was to hasten an era in which Canadians came to expect government support for culture. Perhaps its most important result was the impact of its rhetoric on the Canada-U.S. TV relationship. In Chapter II, "The Forces of Geography," the report makes a dagger-like turn on the hand already feeding it, and intones the once-uttered, neverforgotten metaphor of the American invasion:

We are thus deeply indebted to American generosity. Money has flowed across the border.... Many institutions in Canada ... could not have been established or maintained without money provided from the United States ... every intelligent Canadian acknowledges his debt to the United States for excellent films, radio programmes and periodicals, but ... the price may be excessive ... the American invasion by film, radio, and periodical is formidable. (Royal Commission, 1951, Chapter II, paras. 9-10, [my italics])

The Report nearly demonizes U.S. TV, speaking of it as emanating from "an alien source" (Royal Commission, 1951, section 18, para. 26) and criticizing the U.S. industry, which had already produced talents like Carl Reiner, Mel Brooks and Lucille Ball, and, as mentioned above, would soon welcome Canadians Wayne and Shuster to the Ed Sullivan Show (CBS-CTV, 1948-1971). ${ }^{17}$ The report asserted: "Television in the United States is essentially a commercial enterprise, an advertising industry. Thus sponsors, endeavouring to give the majority of people what they want, frequently choose programmes of inferior cultural standards" (Royal Commission, 1951, Chapter III, section 47, para. 18).

\footnotetext{
${ }^{15}$ Litt further notes the source of the Neatby remarks to be the Neatby Papers, Saskatchewan (Litt, p. 282).

${ }^{16}$ Litt further notes the source of these remarks by Ken Cooke to the Commission, to be CKEY briefs (vol. 7 no. 86 , pp. 28-29).

${ }^{17}$ Wayne and Shuster become the most frequent performers on The Ed Sullivan Show, at 58 appearances, beating out Topo Gigio, a mouse puppet, who was on the show 50 times (SOFA Entertainment, 2010).
} 
Litt notes that Massey's prose was so effective, that even those who vilified the report, praised its writing. Its framing of the Canadian broadcasting industry, as a guardian of protection from U.S. TV, took hold; 40 years later, the still-prevalent impact of Massey's rhetoric was assessed as a "downer":

At first glance, Vincent Massey (1887-1967) was precisely the wrong man to ignite popular interest in the arts ... the crisply written report they delivered in 1951 became the most important official document in the history of Canadian culture ... at the same time (it) got us going in the wrong direction. ... It framed support of the arts in essentially political terms, and we have been burdened by those terms ever since. ... Its central argument was that the nation should support the arts so that the arts could support the nation.... All nonsense of course. Still, the argument needed something more, an outside enemy and a threat. Massey, whose sympathies lay entirely with English culture, knew where to direct negative attention. ... The U.S. emerged as both bad example and menace. The commercialized Americans lacked sensitivity and intelligence. Worse, they were monstrously popular. ... We were to support culture not for its own sake but to save us from Americanization. Ever since 1951, that idea has haunted the discussion of the arts in Canada. ... Certain key words dominate our language when we discuss this subject: save and protect and rescue and preserve. Those words alone, "guard" and "protect" seem to prophesy defeat, or at best stasis ... with Massey's encouragement we have over-emphasized this struggle. ... Making survival the focus of our attention hardly encourages a vibrant cultural atmosphere. It's a downer. (Fulford, 2001, paras. 7-8)

\subsubsection{3 - 1968: Broadcasting Act and creation of CRTC}

In 1968, a new Canadian Broadcasting Act created the Canadian Radio and Television Commission, now the CRTC. It was created as arm's-length body purposed to create regulation and policy to implement the stipulations of Canadian broadcasting, as set out in the Broadcasting Act:

Issue broadcast licences and a mandate to ensure ownership and control of broadcasting remain in Canadian hands, programming to be of high quality with substantial Canadian content, Canadian broadcasting safeguard, enrich, and strengthen Canada from sea to sea. (Standing Committee on Canadian Heritage, 2003, p. 37)

With a number of revisions since, the extant version of the Broadcasting Act is 1991 (The Act). Relevant to the argument of this thesis, while it requires Canadian content which enriches Canada, The Act does not prohibit Canadian content from being globally distributed or popular, an attribute which would not likely have been envisioned when The Act was conceived. The road taken, with regards to interpretation of The Act's mandate to build a TV industry, was to prioritize domestic supply of content. Pivoting the interpretation of The Act, with a strategic implementation to prioritize programs which exhibit popularity, with large and/or important audiences, would not appear to be contrary to The Act. ${ }^{18}$

\footnotetext{
${ }^{18}$ Following Let's Talk TV, CRTC's definition of Canadian content, on its website, appears to have been altered to reflect a priority of Canadian content in the global marketplace. Previous to the hearing, the CRTC information page on Canadian content CRTC had prioritized the dual value of Canadian content, cultural protection and job creation: "Simply put, it's about Canadian artists and Canadian stories having access to the Canadian airwaves. Culturally, Canadian programs and music give voice to Canadians, to their talent, and their shared experiences. Economically, it means jobs for thousands of Canadians" (http://www.crtc.gc.ca/eng/cancon/t_support.htm, retrieved in 2013).
} 


\subsubsection{4-1959: Canadian content}

As previously introduced, Canadian content was a policy interpretation of The Act's requirement for indigenous programming, which would presumably distinguish and protect Canadian cultural identity from that of the U.S. The first content quotas were established in 1959 (Standing Committee on Canadian Heritage, 2003). Despite numerous revisions, the overall broadcast requirements remained relatively stable for more than 50 years, at 60\% Canadian during the daytime and 50\% from 6:00 p.m. to midnight. As discussed, over the decades, Canadian content rules would prove to be both workable and controversial over the succeeding decades. While the quotas resulted in a strong production sector, there were many calls to simplify Canadian content rules and reduce bureaucratic complexity, both of which have tended toward expansion through the decades. Moreover, CRTC's Let's Talk TV removed overall exhibition quotas, set to take effect at the next license renewal of each service, and will be retaining only the evening 50\% stipulation (CRTC, 2015f).

A purpose of this thesis is to argue for a rethink of Canadian English-language TV policy, and its content funding model, for the era of online distribution. As explored in Section 2.3.2, reports have critiqued complex, confounding definitions of Canadian content (Macerola, 2003; Standing Committee on Canadian Heritage, 2003), as well as its "bewildering and exasperating bureaucracy" (Standing Committee on Canadian Heritage, 2003, p. 121):

The rules... are contradictory, produce absurd results, and do not make creative sense ... the system would be easier for all if the definitions of "Canadian content" assumed that a production made by Canadians is Canadian. (Standing Committee on Canadian Heritage, 2003, p. 132)

A recent policy shift, relating to TV drama development, has included a proposal, which appears to be synchronous with the government's 2003 observation above, as it simplifies Canadian content to emphasize the creator, from "made in Canada" to "made by a Canadian" (CRTC, 2015e, Today's Decision section, para. 13).

\subsubsection{5-1970-1971: Simultaneous substitution}

While Canadian content was the policy response to The Act's cultural requirement to distinguish Canada from the U.S., simultaneous substitution was the regulatory response to a need for a business model for Canadian TV broadcasters. This section includes original research on the origin of simultaneous substitution, undertaken due to its importance in the comparison of Canada-U.S. TV drama,

Currently, the wording reflects a more global orientation: "Simply put, the CRTC supports the creation of content made by Canadians for both Canadian and global audiences. CRTC broadcasting policies and regulations support all Canadian talent that contributes to the Canadian broadcasting system. Policies and regulations support the artists themselves as well as the industries behind them" (http://www.crtc.gc.ca/eng/cancon/t_support.htm, retrieved in 2015). 
specifically the paradoxical way it links Canadian English-language, prime time TV drama with Hollywood TV drama.

The story of simultaneous substitution begins in 1969, when it was already a habit of Canadian audiences to turn their rooftop antennas south to capture U.S. TV signals. A dilemma emerged; due to the popularity of U.S. TV, Canadian networks were experiencing difficulty attracting audiences and, consequently, advertisers. Nevertheless, advertisers in the U.S. had purchased rights to the hit shows, and CRTC, then the Canadian Radio-television Commission, respected that contract. A fascinating process began when CRTC issued Decision 70-03 on April 10, 1970, which prohibited simultaneous substitution, ensuring protection of geographic rights to U.S. broadcasters: "The non-Canadian programs broadcast by Canadian broadcasting stations shall not be duplicated on a cable system simultaneously or during the week prior to and the week subsequent to the date of airing" (CRTC, 1970, p.3).

However, by February 26, 1971, a CRTC Public Announcement acknowledged objections to the May Decision and by July 1971, the policy prohibiting simultaneous substitution was reversed. Simultaneous substation had transformed from a regulatory prohibition to a mandatory obligation. Canadian cable distributors (BDUs) would be obliged to remove U.S. commercials from border stations watched by Canadians, and substitute Canadian advertisements, when programs were broadcast simultaneously, as indicated in Appendix X:

In its first public announcement on cable television policy of May 13, 1969, the Commission accepted, for the time being, the long-standing Department of Transport policy that cable television systems should not alter the signals received from broadcasting stations. Since then, the Commission has carried out extensive studies, which demonstrate that the unaltered carriage of some of these signals disrupts the ability of Canadian television stations to fulfill their mandate. The Commission is concerned to restore the licensing logic of the Canadian broadcasting system, and to strengthen Canadian television service. (CRTC, 1971, Canadian Broadcasting, A Single System: Policy Statement on Cable Television, section 4)

This CRTC policy reversal appears to have been driven by TV industry entrepreneurs who reconceived the Canadian broadcast industry challenge, a small population huddled close to a broadcasting powerhouse, as opportunity. While broadcasters were the direct beneficiaries, it seems likely that CRTC enshrined this regulation because of its potential benefit to the entire Canadian broadcast system, to deliver profits, which might be cross-subsidized to support the manufacturing of Canadian content, and thus fulfill legal requirements of The Act. This motivation is further suggested by an article in The Globe and Mail from May 1970, which indicates that the FCC had recently figured out the technical aspects and the potential cross-subsidy benefits of simultaneous substitution for the U.S. market 
(New York Times Service, $1970^{19}$ ), a copy of which is included in Appendix Y.

An exclusive interview with Pip Wedge, CTV Programming VP 1973-1993, recalls the conception of the Canadian version of simultaneous substitution:

No one is specifically named as the "father of simultaneous substitution"; it was the environment of the day. We were down in Hollywood arranging the American buy. Pre-release had been the first step which broadcasters negotiated with the Americans. With changes in network schedules between May and September, we would find we had two programs from competing networks, scheduled at the same time. At first the Americans were terribly nervous about pre-release, until we were able to guarantee this would not interfere with any of their program rights in the U.S. Simultaneous substitution was the next step. The cable guys were initially against it, because it meant costs for them. (P. Wedge, personal communication, December 8, 2005)

A unique marketplace quirk had been found - a function of the unique geo-cultural proximity of Canada and the U.S., and in particular, the affection of the audiences in both countries for the same TV content. This innovation created a new advertising market, Canada. U.S. border stations would have few complaints about simultaneous substitution, because it was based on purchased rights. The regulation came to be known as sim sub. It enabled a business model of Canadian broadcasters, as re-broadcasters, similar to local stations in U.S. markets, such as Los Angeles, New York, Miami, or Minneapolis.

Simultaneous substitution would seem to challenge Massey's argument of a U.S. media invasion, since the fiscal health of the Canadian broadcast system would hinge, from 1971 through today, on voluntary, enduring affection of Canadians for U.S. TV. Reflecting on insights regarding the Canadian predilection towards paradox, sim sub appears to embody a sustained dissonance between rhetoric and regulation. Contrary to saving Canada from American TV, the viability of Canada's broadcast system depends on the enduring affection of Canadian audiences for American TV (Berkowitz, 2006a, 2006b). Because of Canada's unique geo-cultural position, relative to the U.S., this innovative, financially valuable, obligatory regulation would not be possible in any other country.

The importance of simultaneous substitution as a cross-subsidy instrument was reconfirmed in Canada's 1976, 1986, and 1997 broadcast distribution regulations (Grant \& Buchanan, 2010b). Its role has been recently underscored by CRTC: "Revenues generated by simultaneous substitution are important to the broadcasting system. They keep advertising dollars in Canada, which in turn helps create programs that Canadians value (including news and information), maintain jobs and supports local economies" (CRTC, 2015a, Simultaneous Substitution section, para. 5).

A quantitative assessment of value added to the bottom line of Canadian broadcasters, by simultaneous substitution, had long been estimated at $30 \%$ :

\footnotetext{
${ }^{19}$ During the preparation of this dissertation, I was contacted by Ken Goldstein, Canadian media historian and economist, and provided with a photocopy of this article, which originally appeared in the New York Times service.
} 
The $\mathrm{CAB}$ conservatively estimates the increased audiences at ... an average of $26 \%$ of national advertising sales ... estimates of the size the audience that is repatriated or returned to local services as a result of simultaneous substitution range from $2-22 \%$ in minor markets and an impressive $44-75 \%$ in major markets (adults 18-49). ... These audiences directly affect a stations ability to generate revenues. (Canadian Association of Broadcasters, 2002, p.2-3) ${ }^{20}$

Due to the transformations in viewing options and habits, calculations became more challenging over the last decade. In the lead-up to the 2014 Let's Talk TV hearing, the value of simultaneous substitution was temporarily unavailable to the public, as it was under a non-disclosure agreement (Numeris, personal communication, July 2014). However, testimony at the 2014 hearing, confirmed by public submissions by companies such as Bell Canada, Shaw Media, and Rogers, and in particular, a report by Armstrong Consulting, confirmed that simultaneous substitution continues appears to deliver approximately a $30 \%$ boost to the broadcasting bottom line of Canadian broadcasters. This calculates to approximately $\$ 420$ million (Armstrong Consulting, 2014) of TV revenues of approximately \$1.2 billion.

\subsubsection{6-1971: MAPL}

MAPL, the acronym for the Canadian content rules for the Canadian music industry, is attributed to music industry businessman and Canadian country music Hall of Fame inductee Stan Klees (1932-to date) (Canadian Country Music Association, 2015). MAPL is an acronym for M (music), A (artist), P (performance) and L (lyrics) (CRTC, 2006, 2009). Its emphasis on the role of the creative process is considered to have contributed to the success of Canadian music stars with star status, including Celine Dion, Shania Twain, Avril LaVigne, and Drake. Its relevance to the argument of this dissertation is its focus on content created by Canadians. MAPL will be seen, in Chapter 8 , to be a predecessor to my original TV policy suggestion to strengthen development, LEAF.

To be eligible for MAPL, and thereby help fulfill Canadian content requirements for Canadian radio broadcasters, only two of the following four requirements must be met:

$\mathrm{M}$ (music) - the music is composed entirely by a Canadian

A (artist) - the music is, or the lyrics are, performed principally by a Canadian

$\mathrm{P}$ (performance) - the musical selection consists of a performance that is either (a) recorded wholly in Canada or (b) performed and broadcast live in Canada

L (lyrics) - the lyrics are written entirely by a Canadian. (CRTC, 2009, How Does the MAPL System Work section para. 1)

The MAPL policy, which defines Canadian content music, is a policy instrument which works in conjunction with broadcasting quotas for Canadian content music, as set out in conditions of licence for Canadian radio stations. For commercial music, quotas for Canadian content music have historically been

\footnotetext{
${ }^{20}$ This quote comes from a Canadian Association of Broadcasters (CAB) letter to CRTC, November 29, 2002, Simultaneous substitution and described video programming, originally accessed on CAB website, www.cab.ca. for my research paper (December 2005a). However, the CAB archives no longer go back to 2002.
} 
set at $35 \%$, while specific genres range from a requirement of $25 \%$ (for example, jazz and blues) upwards (CRTC, 2006).

How MAPL defines a Canadian is also relevant to this dissertation, with respect to its exploration of local-global, Canada-Hollywood, linkages in the case of Canadian English-language TV drama. MAPL requires that only one of the following four criteria be met to be designated as Canadian: Canadian citizen, official permanent resident of Canada, in residence in Canada for the 6 months previous to participation in the project, or status as a radio licensee.

\subsubsection{7-1983: Canadian content funding models}

While Canadian content quotas for TV had been introduced nearly two decades earlier, and the Canadian Film Development Corporation (CFDC) had been formed in 1967 to support the Canadian feature film industry (Telefilm Canada, 2015), it wasn't until 1983 that the Canadian Broadcast Program Development Fund was formed, with its purpose "aimed at revitalizing Canadian television. At the time, $85 \%$ of all programs aired in prime time by Canadian broadcasters are imported from other countries" (Telefilm Canada, 2015, 1983 section, para. 2), which meant Hollywood. More than a decade later, in 1996, the Department of Canadian Heritage (DCH) formed the Canada Television and Cable Production Fund, a public-private partnership, which was rebranded, in 1998, as the Canadian Television Fund (CTF), and again rebranded in 2009, by DCH, as the Canada Media Fund (CMF, n.d.a). Today's CMF is a public-private partnership with the cable companies, with a focus on TV drama. Canadian cable companies, Broadcast Distribution Undertakings (BDUs) contribute 5\% of their profits; broadcasters must spend 30\% of revenues on Canadian Program Expenditures (CPEs); and taxpayers are involved via the CMF's support from DCH. In setting up the CMF, drama was asserted as a priority: "Because Canadians support the Fund through their cable, satellite and tax dollars, it will focus on the kinds of programs that viewers watch. The Fund will put particular emphasis on drama, including comedy and children's programming" (Government of Canada, Department of Canadian Heritage, 2009, para. 27). In 2011, DCH announced it would provide ongoing support to the CMF, of more than $\$ 130$ million annually (Canada Media Fund, n.d.a; Government of Canada, Department of Canadian Heritage, 2009).

\subsubsection{8 - 1986: Will technology be the ultimate de-regulator?}

Technological advances of the 1980s enabled proliferation of cable channels, VCRs, fax, satellite distribution, and pay-TV. A report by the Canadian government predicted that fragmented audiences would characterize the approaching broadcast era (Government of Canada, Federal Cultural Review Committee, 1982). Included in the response to the new environment was a criticism of the supply-driven Canadian content regime, saying it clearly did not work, suggesting that broadcasting profits might more effectively be used to finance Canadian content which could compete in the new global marketplace 
(Government of Canada, Federal Cultural Review Committee, 1982). While the prediction of conventional broadcast disruption took nearly 30 years to meaningfully arrive, this report is also memorable for its vision of a commercial-free CBC, a suggestion made by a number of informants in this study.

A report on new opportunities in the U.S., which envisioned emerging opportunities in the new technological environment, obscure and never digitized, may have laid conceptual groundwork for the category of official Canadian co-ventures. This Pierre Trudeau era report observed that, going forward, opportunity and mutual need would define the U.S. market for Canadian TV programs. Emphasizing a need to upgrade creative, the report asserted: "In the final analysis, it is the strength of the program idea that matters most. Canadians do not lack talent or ideas" (Grieve, Horner, \& Associates, 1983, p. 1).

In 1986, another report wondered: “will technology be the ultimate de-regulator?” (Caplan \& Sauvageau, 1986, p. 76). Yet, it took nearly 30 years for technology to seriously impact the national, geographically bounded, legacy broadcast TV business model. However, the roots of concepts, salient to this thesis, are as present in analyses from the 1980s, as they were in the 1949 hearings, which preceded the Massey Commission. This is the idea that technology would create global audiences for Canadian content and new business opportunities, in Hollywood, for Canadian producers. As well, there is the theme that Canadians are sufficiently talented to compete in an open, global market for creative goods. These contentions were re-iterated by informants during this study's field research, discussed in Chapters 5-8, and also garnered public attention in CRTC's 2014 Let's Talk TV hearing, elaborated in Section 9.5.

\subsubsection{9-1988: Free-trade}

The Free Trade Agreement (FTA) between Canada and the U.S. was debated in Canada, and signed in 1988, with the purpose of liberalizing trade and eliminating barriers between the neighbours. However, it included a sovereign right to protect cultural industries, education, health care, and water (Lemieux \& Jackson, 1999). On January 1, 1994, FTA was superseded by the North American Free Trade Agreement (NAFTA), maintaining the exemptions for cultural industries (Government of Canada, 2015; Lemieux \& Jackson, 1999). Cultural exemptions were again debated in the 1998 Multilateral Agreement on Investment (MAI), and again in 2007, by the United Nations Educational, Scientific, and Cultural Organization (UNESCO). To date, Canada's TV industry continues to operate under an exemption from free trade (Government of Canada, 2013, 2015).

The cultural exemptions have not been without contention, in the U.S. and Canada. In contrast to Canada's defense of the importance of cultural industries, the U.S. does not recognize this category, and calls these sectors entertainment industries: "The United States views cultural arguments as rhetoric used as a smokescreen to promote protection, a protection demanded by industry lobby groups" (Hoskins et al., 2004, p. 323). Cultural exemptions have been similarly criticized in Canadian media. As free trade was 
being debated, writer Robert Fulford commented on the rhetorical twists being taken, analyzing that stakeholders were huddling under an empty cause célèbre:

At times lately it has appeared that Canada has substituted cultural politics for culture. (We may not have great art but we have great task forces.) ... People who have seldom read a Canadian book or seen a Canadian film have declared themselves passionately devoted to our 'cultural sovereignty,' a term previously unknown in their vocabularies. (Fulford, 1986, p. 7)

\subsubsection{0-1999: Online exemption}

In May and June of 1999, with digital convergence on the horizon, two CRTC decisions impacted audiences and producers of Canadian English-language TV drama. May 1999's New Media Exemption Order made CRTC one of the world's first regulators to exempt the Internet from media regulation: "[CRTC will] not regulate new media activities on the Internet under the Broadcasting Act" (CRTC, 1999c, The Commission's approach to new media, para. 6). This position presumably flowed from a directive in The Act, that the Canadian system must be technologically current (Government of Canada, 1991). CRTC stated that it had found no evidence the Internet had yet had any negative financial impact on the audience or advertising revenues of traditional TV.

History has shown that almost immediately thereafter, Internet advertising revenues began to leap, wreaking negative financial impact on traditional broadcasters, and have continued to increase during the last 15 years, along with rapidly transforming technological transformations in TV data delivery. A result is that linear TV audiences have been eroded. At this writing, online revenues challenge global TV advertising revenues for first position. Despite periodic challenges to this decision, CRTC has held firm in its decision not to regulate digital media (CRTC, 2011c). This decision has been considered so impactful to the TV drama sector, that together with simultaneous substitution, these two issues appeared to spark the most heated debate at the Commission's 2014 hearing on the future of Canadian TV. Many organizations, including legacy broadcasters and lobby groups, called for extending regulation to exempted online drama distributors, such as the U.S. headquartered Netflix (CRTC, 2014f).

\subsubsection{1-2003: Our cultural sovereignty}

In 2003, a 1,000-page report acknowledged six dynamics impacting Canadian English-language TV drama: uncertain future of simultaneous substitution; insufficient audiences for Canadian drama; insufficient revenue for Canadian TV drama; failure of Canadian content rules to remedy either audience or financial issues, despite high levels of public subsidy; comparative success of simpler MAPL rules; and brain drain to Hollywood (Standing Committee on Canadian Heritage, 2003). These concerns are also themes in this dissertation. 
Since technology had already begun to disrupt TV delivery models dependent on geographic boundaries, the CRTC worried about the system's reliance on a geographic rights-based distribution model, and as such, the continued ability of simultaneous substitution to boost revenue:

The Canadian broadcasting system can be likened to a complex machine where the breakdown of a single working part can threaten the functioning of the machine of a whole.... In particular (Committee) it is very worried that the existing programming model—which has become overly reliant on the cross-subsidization of Canadian revenues through revenues generated by American programming — will eventually collapse. (Standing Committee on Canadian Heritage, 2003, pp. 5, 301)

With respect to issues concerning Canadian English-language TV drama, especially its low audience ratings, the report quotes a former CBC president: "We cannot make Canadians watch more Canadian programs. No one can, and no one wants to" (Standing Committee on Canadian Heritage, 2003, p. 69). Observing that Canadian English-language TV drama had not evolved into a self-sustainable sector, the report assessed its financial performance, with an analysis still considered reasonably accurate:

Since the beginning of private broadcasting in Canada, regulatory framework has required Canadian private broadcasters to contribute to the development of Canadian programming. To do this, private broadcasters have used revenues generated from profitable foreign shows to produce or purchase less profitable Canadian programs...even after subsidies and advertising revenues are taken into consideration, an English-language Canadian broadcaster averages a net loss of about $\$ 125,000$ for each hour of Canadian drama, and a net profit of about $\$ 275,000$ for each hour of American-made drama. (Standing Committee on Canadian Heritage, 2003, p. 136)

Notably, the report assessed the failure of the Canadian English-language TV drama in ROI terminology, although the value chain had been purposed to satisfy supply metrics:

Given the cost of developing an hour of high-quality Canadian television, it can be seen why very little would be produced without support from the Canadian taxpayer ... the Canadian market is simply too small to support reasonable amounts of high-quality programming ... at least $50 \%$ of all costs - in the form of payments from the Canadian Television Fund (CTF) an tax credits, both federal and provincial - are covered directly or indirectly by Canadian taxpayers. (Standing Committee on Canadian Heritage, 2003, p. 19)

Two more themes of the report, frustration with Canadian content bureaucracy and continuing brain emigration of highly skilled professionals (HSPs) are also important aspects of this dissertation.

\subsubsection{2 -2003: Drama crisis}

In 2003 reports also focused on a problem, which became known as the drama crisis (Coalition of Canadian Audio-Visual Unions, 2003). A succinct CRTC report restated the Canadian formula: "no broadcaster has ever made money on drama. It exists entirely and only because of political and regulatory will" (McQueen, 2003, p. 4). The report compared Canadian TV drama, "the least watched genre on Canadian screens" to Hollywood TV drama, the "most expensive, most risky, and most watched drama" 
(McQueen, 2003, p. 5); this report suggested an audience focus, which has been increasing since. Another report on Canadian content, similarly to the Aird and Massey Commissions' exploration of other countries' national content, omitted a comparison of Canadian English-language TV drama to that of the U.S. (Government of Canada, Department of Canadian Heritage, 2003).

A 2004 CRTC decision acknowledged the size of audiences as key to a TV business model, and defined a Canadian hit, as a show with an audience of one million, which seemed reasonable, considering that Canada is one-tenth the population of the U.S. (CRTC, 2004). However, as discussed above, there may be two problems with this number. Firstly, this absolute number can never be enough to generate sufficient advertising revenue to deliver profitability on costly TV drama content. Secondly, as analyzed above, it appears that an audience of two million might be better suited to represent a hit in Canada, similar to numbers, which are achieved by top U.S. shows in Canada. Such analysis may suggest that an audience of two million in Canada might correlate to popularity in the U.S., which might be an important bar, for financial sustainability. This type of analysis will factor into the policy tool in Chapter 9.2.

The 2004 CRTC decision did not address the potential of a North American or global audience; online video was in its infancy, and Netflix was a DVD mail-order business, operating in the U.S. only.

\subsubsection{3-2011: Programs of National Interest (PNI)}

The PNI policy, which sets out TV drama expenditure requirements for broadcasters, will be in force until 2017. As discussed in Section 2.3.2, its significance, as a response to Hollywood dominance, appears to be that development expenses are allowed to be counted towards PNI by default, because they are not disallowed. While the development phase has not been a visible priority of Canadian TV policy, PNI policy might potentially be deployed to strengthen the development phase of Canadian Englishlanguage prime time TV drama, so as to better compete with Hollywood TV drama.

\subsubsection{4-2014: CRTC's Let's Talk TV}

The CRTC's inquiry on the future of Canadian TV, Let's Talk TV, was undertaken against the backdrop of weakening linear TV, and inversely, the growth of online TV. The Working Document for the hearing (CRTC, 2014e) called for debate on three elements that might affect English-language prime time TV drama. Each of these elements specifically reflected the Canada-U.S. TV relationship: Internet exemption, simultaneous substitution, and Canadian content. Section 9.5 contains a review of this Let's Talk TV, a public hearing, which occurred after completion of research for this dissertation.

\subsection{Value chains and global value chains}

With the stage set with an overview of the U.S. and Canadian TV drama industries (Sections 2.2-2.3) and the Canadian industry further contextualized by a policy and regulation timeline, which positions Canadian English-language TV drama policy as a response to Hollywood dominance (Section 
2.4), the view now widens to consider business research in value chains and global value chains. These studies will be seen, in Chapter 3, to be essential to the argument of this dissertation. This is the idea that strengthening the development phase of the value chain might have positive outcome on audience and financial performance of Canadian English-language prime time TV drama.

\subsubsection{Value chains}

The concept of a value chain, attributed to Michael E. Porter, and originally proposed at the firm level, has become a widely accepted strategic analysis (Porter, 1985, 1998a, 2008). A value chain was proposed as a way of operationalizing business strategy, rendering it "no longer just a broad vision but the particular configuration of activities a firm adopts compared to its rivals" (Porter, 1985, Introduction, para. 10). As a tool to understand the "interrelated activities from which value stems," (Porter, 1985, Preface, para. 6), it was defined as interdependent business activities needed to produce a product: R\&D, design, production, marketing and sales, distribution, and customer service.

The business of TV drama adapts well to these value chain categories. Development includes the first two (R\&D, design); production stands alone in the middle; and distribution includes the final three activities (marketing and sales, distribution, and customer service). The linkages between segments of the chain are critical, both to the concept of a value chain (Porter, 2008) and to the argument of this dissertation. As will be elaborated in Chapter 3, central to the value chain analysis of TV drama is the idea of a close relationship between the first and third phases of the chain (development and distribution), while phase 2 (production) is relatively independent. Production, as the most separate phase of the overall process, is the phase of the chain, which is most easily outsourced to the lowest cost jurisdiction.

Also important to both the framework and the argument of this dissertation, is the definition of value, which is the outcome of the chain of activities. Implicit in a value chain is the important role of customers, or in the case of media - audience. In a Porter framework, value is ultimately defined as financial profit, or "creating value for buyers that exceeds the cost of doing so" (Porter, 1985, Chapter 2, para. 7), and wealth creation is the fundamental logic of why a business organization exists. A value chain, such that the cost of inputs is less than the cost of outputs, forms the basic building block of competitive advantage. As has been a theme in this dissertation, consumer demand, also expressed as popularity, is similarly positioned as the ultimate determinant of the value of a TV drama.

This is not to dismiss or discount the notion that the efficacy of a value chain may depend on how value is defined within a wider socio-economic context. The term value might reference different types of contribution to society in addition to economic, such as social, cultural or political. As will be seen in Chapter 3, the term value in the Canadian TV drama value chain appears to have had a mixed definition, with performance assessments at various stages of the chain, in response to cultural and political goals, as well as economic. In a largely supply-driven market, which has characterized the case of Canadian 
English-language TV drama, the cost of inputs has been greater than the resultant revenue, with a portion of the costs covered by public funds. Even though the product is not profitable, the product has continued to be produced, over decades, and has exhibited important value to the system, including legal value, as stipulated by The Act.

Further leveraging the importance of a value chain approach, is its importance as a strategy to respond to profound market disruption. A market upheaval of great concern to the Canadian English TV drama content model is that the national context for TV monetization, seems likely to be replaced by a global, cloud-driven TV delivery system (Noam, 2014). Eventually, the overall impact of the current TV disruption may be to diminish the role of nationally defined TV industries, while strengthening a local-global consumer orientation (Sandvoss, 2003). Amidst such chaos, there is a strategy, called value chain evolution theory (VCE), which affords a way which is "breathtakingly simple" (Christensen et al., 2013, p. xix) to respond to market disruption:

The [VCE] theory suggests companies ought to control any activity or combination of activity within the value chain that drive performance along dimensions that matter most to customers. Directly controlling, or integrating, an activity gives companies the ability to run experiments and push the frontier of what is possible. (Christensen et al., 2013, p. xix)

The deployment of VCE, as a strategic approach to chart a way forward, and in particular, to how the value chain for Canadian English-language premium TV drama might be adjusted to meet the unprecedented challenges of the current TV environment, is underscored by a further assertion:

Solving hard problems allows firms to capture value. ... Solving tomorrow's hard problems creates tomorrow's profits. [Forward-thinking firms] unwittingly follow the advice of hockey legend Wayne Gretzky who, when asked what made him so great, replied that he always tried to skate to where the puck was going to be, not to where it was. (Christensen et al., 2013, p. xx)

As Chapter 3 will demonstrate, a comparison of the Canadian English-language TV drama value chain, with that of its competitive set, Hollywood premium TV drama, yields numerous observations which might be useful in adjusting TV policy to meet the demands of the online TV era.

Given the value chain approach of this dissertation, some further specificity seems warranted, to distinguish the term value chain, from a closely related term, business model. A business model can be considered the set of activities by which an organization delivers value to the marketplace (Porter, 1985; Christensen et al., 2013), and therefore might be considered a meta-description of the outcome of a value chain. As such, the overall business model of Canadian English-language premium TV drama might be considered as both a production (phase 2) and a distribution (phase 3) business model, identifying values in the chain that have been optimized, largely by a framework of policy and regulation, while IP or development (phase 1) appears to have been a lesser priority. A value chain optimized towards the 
creation of hits, which would imply a focus on excellence in the development phase, might be called a content business model, or as popularly termed, a content model.

Moreover, business models can be further distinguished by their mode of specialization, with two primary strategic options for delivering market value, either a low cost model or a differentiation model (Porter, 1985). Regarding original Canadian English-language TV drama, it seems that the focus might have been on designing a value chain, which optimizes a low cost advantage, a term even used by an informant in this field study. Discount production appears to have been an important calling card for Canada's world-class production sector. Moreover, it is usual for infant industries to begin a cycle of maturity with a low cost business model, and as they mature, graduate to a differentiation model, which implies an appeal to the marketplace based on product distinction, rather than low cost (Porter, 1985). Notably, public policy and regulatory choices also enter into the design of value chain dynamics and can result in a business model, which prioritizes either low cost or differentiation: "A lowest-cost strategy involves one set of activity choices, differentiation another" (Porter, 1985, p. xviii).

\subsubsection{Global value chains}

During the 1990s, as globalization of the world's economy accelerated, the concept of a value chain was extended to the global value chain (GVC). Gereffi is credited with extending the Porter framework, observing that similarly to value chains, which pivot on relationships between actors in the chain, a GVC "draws attention to the question of what actors add value where" (Gereffi, 2011, p. 9). Moreover, a global value chain perspective can help determine "which activities and technologies a firm keeps in house and which should be outsourced, and where the various activities should be located" (Gereffi, Humphrey, \& Sturgen, 2005, p. 79).

The Canadian TV drama value chain, in particular that of series produced in partnership with Hollywood entities, can be considered a GVC, based on multiple factors, including Hollywood's status as the centre of creative development, and as such, the workplace of many Canadian TV drama creators and producers, even if not a full-time destination. Additional attributes which suggest a consideration of Canadian English-language TV drama as a GVC, include brain drain of Canadian creators to Hollywood; outsourcing of Hollywood productions to Canada, which has led to Canadian domestic production expertise; and Canada's geographic, rights-based distribution model, which substitutes Hollywood TV drama for original Canadian TV drama in the distribution phase of the value chain.

Substantial research has well categorized types of value chains and as well, the types of improvements, or upgrading, which might be sought (Humphrey\& Schmitz, 2000a, 200b). GVCs have been categorized has having four possible modes of governance. Arm's-length chains require no need for co-ordination between buyer and supplier. Network chains are characterized by an equality between buyer and supplier. Quasi-hierarchical chains are characterized by a high degree of control by the buyer, who 
would incur losses from product performance failure. Finally, hierarchical chains feature complete control by the buyer, over manufacturing operations. Because many of financial and design functions of prime time Canadian TV dramas have close connections to the Hollywood cluster, Canadian English-language TV drama seems most well suited to being labeled a quasi-hierarchical GVC.

Upgrading a GVC can take place at several nodes on the chain (Humphrey \& Schmitz, 2000a, 2000b, 2002). Process upgrading increases efficiency. Product upgrading increases sophistication of the product. Intersectoral upgrading describes the transfer of extant capability in the chain to another sector. Finally, functional upgrading implies the extending upwards to new arenas of expertise, such as design. These categories can be well applied to the Canadian TV drama sector. Successful efforts to build worldclass production-phase capability might be characterized as process and product upgrading. Intersectoral upgrading, which refers to transferrable skills between related value chains, might reference application of production capability to sectors such as advertising, digital media, or video games, a capability which has been given much policy attention. An outcome would appear to be Canada's strong position as a video game developer, said to be third largest in the world, after the U.S. and Japan (Entertainment Software Association of Canada [ESAC], 2013; Nordicity, 2013). Functional upgrading would seem to imply extension into new arenas of expertise, such as R\&D. In this respect, efforts to strengthen the development phase of the Canadian English-language premium TV drama value chain might be categorized as a functional upgrading challenge. This concept of upgrading strongly intersects with concepts of cluster upgrading, local-global linkages, and economic diasporas, as elaborated below.

\subsection{Cluster upgrading, local-global linkages, and economic diasporas}

\subsubsection{Cluster upgrading}

The idea of regional clusters, collections of business activities that are focused on a single industrial sector is acknowledged to have originated with Albert Marshall, who labeled geographic industrial concentrations as industrial districts or agglomerations (Marshall, 1890). A century later, Michael E. Porter popularized the concept of clusters (Porter, 1990). Troubled by the task of writing on the competitive advantage of nations, Porter observed that nations do not compete, but industries do (Porter, 1990). Similarly to Porter's value chain work, cluster studies have inspired research on closely related concepts which are central to this study; in particular these concern strategies for cluster upgrading in the context of global value chains, and the important role of local-global linkages. Value chain analysis and cluster upgrading are implicitly linked, when cluster upgrading is defined as innovating "to increase the value added of [its] products and processes" (Guiliani, Petrobelli, \& Rabellotti, 2005, p. 550).

Numerous competitive advantages of clusters have been identified, which appear to be relevant to the case of upgrading the development phase of Canadian English language premium TV drama, 
particularly advantages regarding the important role of social capital and information dissemination within a cluster. Knowledge spillovers (Feinberg \& Gupta, 2004; Gertler, 2003) explain how ideas are shared between individuals in a cluster. The related concept of social capital refers to the potential of competitive advantage being gained by creating and sharing knowledge within a cluster (Inkpen \& Tsang, 2005; Nahapiet \& Ghoshal, 1998).

Buzz, which is information resulting from presence in a hot-spot cluster, enhances competitive advantage, since "it is almost unavoidable to receive rumours and news about other cluster firms and their actors" (Bathelt et al., 2004, p. 38). Buzz is considered to be a particularly important aspect of strength in clusters with "a rich history of social interaction, which offers opportunities for multiplex relationships, face-to-face contacts and meetings (Bathelt et al., 2004, p. 37). Such advantage is both automatic and non-substitutable: "location within an industrial cluster brings further advantages that are not available to firms elsewhere” (Bathelt et al., 2004, p. 37). In today's competitive media ecosystem, "it is critical for firms in media industries to actively monitor the products of their competitors, and transform their own products accordingly" (Karlsson \& Picard, 2011, p. 11). Relative to the argument of this dissertation, the advantage of co-location in the Hollywood hot spot, seems understandable from the perspective of creators, who seek career acceleration. As will be suggested in Chapter 8, perhaps of more significance, is a lack of presence in Hollywood by Canadian networks, who seem to be substantially charged with a proxy governance of public funds for Canadian English-language prime time TV dramas.

While clusters deliver co-location advantages of strong ties between actors in the cluster, which is positively linked to innovation (Tortoriello, Reagans, \& McEvily, 2012), also of significance to this investigation of TV drama development is an enduring concept, the "strength of weak ties," defined as "key resources of social cohesion, especially within professional specialties which set up elaborate opportunity networks" (Granovetter, 1973, p. 1373). Thick connections, both strong ties and weak ties, promote the flow of information and social capital in a cluster. As will be underscored in the field research, particularly in Chapter 7, given the project-oriented nature of TV development, and the critical importance of relationships to professional growth, concepts of social capital explain a key mechanism of cluster upgrading, which is a continuous upgrading of social networks. A rich social fabric within a cluster serves to promote another important internal cluster characteristic, competition, which strengthens individual and corporate actors. Increased rivalry creates an upward cycle of excellence and further intensifies competitive advantage of the cluster, the firms and the individuals (Porter, 1998b).

In an increasingly digital economy, where knowledge has become increasingly weightless and portable, paradoxically, the importance of geographic clusters has strengthened (Karlsson \& Picard, 2011; Porter, 1998b). Important features of knowledge-intensive clusters, such as social capital, knowledge spillover, buzz, and the power of social ties do not translate well over geographic distance. Ironically, in a 
digital era, the nuances of complex communication and the value of non-printed information appear to make physical presence in a cluster more essential than ever, to high-skilled workers.

Survival in a global economy is said to require capability to compete in international markets and be a global exporter; clusters must function as "local systems capable of producing global products" (Karlsson \& Picard, 2011, p. 22). For many sectors, not limited to Canadian TV, "demand for local industries is inherently limited by the size of the local market, but exporting clusters can grow far beyond that limit" (Porter, 1998b, p. 82). For example, the Minneapolis medical supply cluster, or the Phoenix golf equipment cluster, could not flourish absent global distribution; local markets are too limited.

An implication of the types of cluster upgrading, discussed above is that functional upgrading of Canada's TV drama sector is the focus of this dissertation; that is, an exploration of which processes might be required to upgrade the Canadian English-language prime time TV drama value chain from world-class production capability to world-class R\&D capability. As such, the Canadian TV drama challenge might be effectively reframed as a cluster upgrading challenge. The sector has developed excellent production capability to make TV programs, but needs to upgrade design-phase capability to deliver hits, which successfully compete for global attention.

However, there is a caution in upgrading a cluster from production to design capability, said to be slower and more difficult than process and product upgrading (Giuliani et al., 2005). While investments in new capabilities are said to be essential to achieve such functional upgrading, the literature warns that a preoccupation with local capabilities can also lead to neglecting global business realities and local-global linkages (Giuliani et al., 2005). There seem many connections in such analyses, to the case of Canadian English-language TV drama. As confirmed in the field research, in the focus on building capacity in the Canadian production sector, upgrading the development phase may have been unintentionally overlooked. Should strengthening development migrate to a priority, it will be important to consider that "upgrading strategies fail when failing to recognize the interaction between local and global governance of value chains" (Humphrey \& Schmitz, 2005, p. 7).

Other key challenges to cluster upgrading in a GVC, have been identified. These include a need to consider institutional contexts, such as "trade policy, regulation and standards" (Gereffi, 2011, p. 39). An important role of public policy may be to understand how to help institutions adapt to ongoing creative destruction and to incentivize innovation (Potts, 2008).

Other studies examine specific challenges at the opposite end of the value chain from $R \& D$, which concern upgrading the distribution phase of a GVC. These are chiefly issues in transforming from domestic to global export capability, noting that "breaking into export markets represents a discontinuous step" (Gereffi, 2011, p. 19). One study analyzes the cases of Mexico and China, which have deployed “different mixes of government policies, institutions, corporate strategies and work skills" (Gereffi, 2011, 
p. 45) to achieve cluster upgrading in their export oriented industries.

The conceptual challenge of cluster upgrading has been explored from a governance perspective (Florida, 2002, 2007, 2008; Scott, 2006; Storper \& Scott, 2009). While there are differing perspectives on which governance dynamics build a strong creative cluster, there are two arguments, one applicable to development, and the other to distribution, which suggest the complexity of upgrading secondary clusters, particularly those which are remote to world centres, and as such, part of GVC's. A persuasive thesis seems that "people follow jobs," (Storper \& Scott, 2009, p. 147), rather than vice-versa. Also convincing is a caveat that once strengthened by the presence of creative workers, clusters must be "capable of mounting effective systems of commercialization and distribution of their outputs (Scott, 2006, p. 13). As the theoretical analysis in Chapter 3 will demonstrate, a critical connection between the production of creative products (development) and their commercialization (distribution) seems precisely the relationship which appears to require strengthening in the Canadian English-language TV drama cluster.

Certain actors in a value chain may inhibit a cluster upgrading process. These may include government and industry trade organizations (Porter, 1998b). Trade associations may pose challenges to a strong response to a globalizing sector, because their scope is domestic and their purpose is to lobby government. It is suggested that lobby organizations "would be better served by working to promote a higher plane of competition" (Porter, 1998b, p. 88). In the field study for this dissertation, informants' frustration with lobby organizations was explicit:

There's a challenge because there's an old guard and a new guard, both at the producers' level and the Writers' Guild level. (Respondent, CEO, Canadian TV drama firm)

You've got so many interest groups. You've got the writers' guild and all the guilds saying "This sounds like a recipe for jobs being lost to Americans." Maybe in the short run they're right. But think about the long term play you can create. (Respondent, CEO, Canadian TV drama firm)

Can we let the protection barrier down for the moment and just talk about the development of talent? [Lobby groups] feel very threatened in these conversations. It's easy for them to feel the threat first. So you have to help them let the threat go and think about their betterment. Could it be done in installments, so nobody gets too scared? There are all kinds of transitions that could be put in place. (Respondent N, Executive, Canadian TV drama firm)

Debate between stakeholders in Canadian English-language TV drama intensified at the Let's Talk $T V$ hearing in September 2014. Lobby organizations representing development phase workers, including CMPA, WGC, DGC, and ACTRA, lobbied for the status quo, and even for extending regulatory instruments, such as imposing Canadian content quotas on global TV drama disrupters, such as Netflix (CRTC, 2014f). As will be reviewed in Chapter 9.5, the outcome of Let's Talk TV appeared to demonstrate that CRTC has set a policy course to prepare the Canadian English-language TV drama sector for the possibility of a global, media eco-system. It began the process of delayering regulation, with 
the intent of fostering innovation and the production of English-language TV dramas which perform well in the domestic and the global marketplace (CRTC, 2015e, 2015f).

\subsubsection{Local-global linkages}

Closely intertwined with cluster upgrading is the arena of local-global linkages, which examines the importance, particularly in GVC's, of connecting with primary clusters, for the purpose of strengthening the capabilities of a secondary, remote cluster.

A comparative study explores the importance of local-global linkages, and in particular, the strategic exploitation of global hot spots in North America to upgrade remote clusters: "many countries from China to South Korea to India and others have demonstrated that development of the homeland can be accelerated by making strategic use of their diasporas in North America" (Patterson, 2006, p. 1892). Even more specific to the Canadian TV drama sector, a study of India's media diaspora reports how India industrially and semantically positioned the "global invasion of media companies" as an opportunity for domestic cluster upgrading. "Rather than equating foreign ownership with domination," the sector made use of "a conveyor belt of one-way transmission inwards of global industrial practices and structures" to figure out how "local industries could follow the same model of commercial development" (PanthaniaJain, 2001, pp. 168-170). Delving into the subtleties of quasi-hierarchical global value chains, the study delivers a positive spin on the presence of a global parent company, positioned to represent the stature and security of a "well-heeled trophy parent who signals the local company is in the big league" and concludes with an endorsement of strong local-global linkages: "in a world of imperfect strategy options, alliances are often the fastest, least risk and most profitable way to go global” (Panthania-Jain, 2001, p. 172).

Studies on China further document strategic use of local-global linkage strategies to upgrade a knowledge-based cluster, encouraging relationships in the Taiwan technology cluster with U.S. hot spots, such as Silicon Valley (Smart \& Hsu, 2004). Another study notes: "Strategic coupling of regional assets and transnational Chinese talent strengthens global linkages and facilitates entrepreneurial knowledge absorption of domestic leading firms" (Chou et al., 2011, p. 3020).

\subsubsection{Economic diasporas}

While the previous section focused on research on local-global linkages, as a subset of cluster upgrading, this section shifts focus towards insights on the expat populations themselves, and their potential role in value-capture of knowledge produced in primary cluster. Knowledge workers, formerly termed as highly skilled professionals (HSPs), who emigrate to global hot-spots for career acceleration, can be categorized as economic migrators, in contrast to refugees, who are political migrators. To my knowledge, these insights have rarely been applied to strategically examine the case of Canadian brain drain to Hollywood, which can be formally termed brain migration. 
Canada has the highest percentage diaspora of any country, nearly 2.8 million Canadians, and nearly 9\%, live outside the country (Asia Pacific Foundation, 2011, p. 1). The largest percentage of Canadian emigrants live in the U.S. (nearly one million). ${ }^{21}$ Of particular significance to this study is that the city of Los Angeles is the most popular U.S. destination, said to be home to 100,000 Canadians (CRTC, 2015e). However, compared to other countries, Canada lacks formal linkage or value recapture strategies; a suggested reason is that Canada "does not keep any exit data on emigres, one of the basic challenges of researching Canadians abroad" (Asia Pacific Foundation, 2011, p. 3). Consistent with Canada's national predilection for enduring dichotomies, as discussed in Section 2.4.1, there appears to be a Canadian ambivalence towards emigration:

Canadians have always had mixed feelings about their fellow citizens who choose to live outside the country. For more than three decades, concerns about "brain drain" and the liabilities associated with Canadians abroad have shaped public debate. ... Increasingly the government and the media are recognizing that Canadians abroad are potentially a large asset. Nevertheless there is very little evidence-based research that government agencies can use to inform their policies abroad. (Asia Pacific Foundation, 2011, p. 3)

In opposition to incentives for local-global linkages, it has been suggested that "Canadians face significant economic disincentives to return to Canada" (Asia Pacific Foundation, 2011, p. 6). It has been observed that Canada's unexamined diaspora seems in contrast to that of other countries, citing aggressive strategies by nations, who moreover, do not face Canada's industrial challenge of a small domestic market. The study recommends a list of strategies necessary to "unlock the potential of the Canadian diaspora suggesting that Canadians abroad should be seen as more as an asset than a liability" (Asia Pacific Foundation, 2011, p. 3). These recommendations overlap with Mandel-Campbell's call for a concerted effort to strengthen Canada's export orientation and brand globally (Section 2. 4.1). Given that the Canadian presence in Hollywood has been long acknowledged, even by the government (Sections 2.4.2.2 and 2.2.2.10), there appears to be an opportunity to transform Canada's expat community in Hollywood, into unique comparative advantage. The contrary could also be true, that Canada stands to lose global competitive advantage unless it proactively engages its diaspora community and "confronts a long-established ambivalence to citizens living beyond its borders" (Friesen, 2011, para.3).

A comparative study, of national attitudes towards economic diasporas, observes that Mexico has seen positive results from strategies designed to conquer ambivalence towards emigration to the U.S. Until recently, Mexicans "viewed members of the diaspora in the U.S. as 'sellouts"” (Patterson, 2006, p. 1900). However, this study relates how a Mexican president, with a Harvard PhD, was able to pivot this conceptualization towards the political and economic utility of the U.S. diaspora, and succeeded in

\footnotetext{
${ }^{21}$ The Asia-Pacific Foundation study notes that the second most popular international destination for Canadians is Hong Kong, with 300,000 expats; the rest of Canada's expats are globally dispersed.
} 
turning brain drain into brain circulation (Patterson, 2006, p. 1901). The case of India's ambivalence towards economic diaspora has also been documented. India "has taken a pro-active, comprehensive and strategic approach to its collaborative diaspora homeland development effort, hence brain circulation" (Patterson, 2006, p. 1900). These results are underscored by a separate study: "Indians, who did not initially encourage linkages from non-resident Indians, are now surging ahead due to the intellectual capital and prominence of their diaspora Indian professional community" (Huang \& Khanna, 2003, p. 74).

At this writing, the story of local-global linkages in the Canadian English-language TV drama sector may have taken a turn. In March 2015, the CRTC announced a goal to strengthen Canada-Hollywood linkages and convert brain drain to brain chain, as part of a set of new strategies to strengthen Canada's ability to internationally compete in the arena of English-language TV drama.

\subsubsection{Two important studies}

Two previous studies stand out as having integrated research in global value chains, cluster upgrading, local-global linkages, and economic diasporas, in ways which are relevant to this research. Mark Lorenzen and Ram Mudambi's (2012) “Clusters, Connectivity and Catch-up: Bollywood and Bangalore in the Global Economy" and Jan Vang and Christina Chaminade's (2007a) "Cultural Clusters, Global-Local Linkages and Spillovers: Theoretical and Empirical Insights from an Exploratory Study of Toronto's Film Cluster" both integrate these arenas of research to focus on media clusters, and do so via qualitative interview methodology.

Lorenzen and Mudambi's (2012) study originates with the premise that cluster connectivity is a "crucial-and under-researched characteristic of clusters" (p. 502) and asserts the current debate is to ascertain the impact of global-local linkages on cluster growth and catch-up, noting these types of linkages are of the highest value because they possess the capability to "de-lock" the trajectory of a secondary cluster (Lorenzen \& Mudambi, 2012, p. 503). The study investigates two cases of global-local linkages: (a) India's Bollywood entertainment cluster in Mumbai and (b) India's technology cluster in Bangalore. Both clusters strive to catch up with their comparative global hot spots in the U.S., Hollywood and Silicon Valley. The study confirms that linkages to globally dominant "centers of excellence" (Lorenzen \& Mudambi, 2012, p. 504) deliver the most potential for cluster growth and catch-up.

Additionally relevant to the case of the development of Canadian, English-language TV drama, this study asserts that upgrading a cluster towards $\mathrm{R} \& \mathrm{D}$ excellence, is a difficult path:

Clusters that enter global competition late ... are challenged to catch up. ... Many do so by taking on low-level roles as suppliers in global value chains designed and controlled by actors based in early-moving clusters. The aim is to implement catch-up processes along two dimensions: value creation and value capture. ... Catch up is often a long process involving movement through a series of phases. (Lorenzen \& Mudambi, 2012, pp. 502-503) 
The Lorenzen and Mudambi (2012) study attempts to solve the strategic puzzle of cluster catch-up and connectivity by theorizing two types of linkages and differentiating the impact of each type: pipelines, which are organizational linkages, versus personal relationships, afforded by the presence of social networks in a cluster. Of relevance to this dissertation, the study finds that personal relationships, rather than pipelines, are the type of linkages which best accelerate cluster upgrading in sectors like entertainment, because they prioritize social capital and buzz. It concludes that social linkages might function as the precursors to more formal linkages, strengthening the remote cluster via an organic process of upgrading: "For producers seeking to create value through linkages to a remote market, a network of personal relationships ... is a more efficient source of information and inspiration than a focused, rigid, and expensive pipeline" (Lorenzen \& Mudambi, 2012, p. 524). With further applicability to the case of Canada-Hollywood, the study notes that when local agglomerations attempt to catch-up with globally dominant clusters which value "local embeddedness," an "influx of a plethora of diaspora members can lead to high-levels of entrepreneurship and be instrumental" in upgrading the distant cluster (Lorenzen \& Mudambi, 2012, p. 511).

Similarly to the Lorenzen and Mudambi research, Vang and Chaminade (2007a) use qualitative interview methodology to investigate cluster connectivity, cluster upgrading, and value chain analysis, in order to deliver insight regarding the case of Toronto's film industry. While the Vang and Chaminade study concerns the theatrical film sector, rather than TV, its relevance to this dissertation is its research question about why, despite substantive public investment, Toronto has not upgraded to a mature agglomeration, and persists in exhibiting limited spillover to development functions. Like the Lorenzen and Mudambi study, the Vang and Chaminade research starts from the premise that local-global linkages are currently a fashionable strategy for cluster upgrading, and frames its investigation by underscoring Hollywood's enduring control over development elements (Vang \& Chaminade, 2007a). The study problematizes the challenge of the Toronto film cluster as a local-global linkage issue, observing that providing discount production opportunities cannot be sufficient to accomplish the task of upgrading a domestic cluster from production to design capability:

Hollywood films do not approach Toronto firms because of any specialized competencies that are hard to find in L.A., but because of their lower production costs: hence, investments in "subsidiary" competence building are zero (14).... Global-local linkages are most likely to generate positive spillovers when cost reduction is not the main motive behind outsourcing. ... However in the case of Toronto, the main reason to offshore and outsource Hollywood productions to Toronto is costcutting. (Vang \& Chaminade, 2007a, pp. 413-414)

Two critiques limit the value of the Vang and Chaminade study to this dissertation, in addition to an obvious difference that its focus is on film, rather than the TV sector. However, even its focus on the film sector may be inherently flawed. Its comparison of Toronto to Hollywood, the global centre of 
blockbusters, with movie budgets increasingly in the hundreds of millions may be inappropriate since the Toronto film sector, and Canada generally may be more strategically comparable to other "indy" film jurisdictions around North America and the world, where movie budgets under $\$ 5$ million are common. A focus on finding fault with limited spill overs from run-away film productions may be a red-herring, since fulfilling the needs of large-scale, U.S. productions has been an important element of building Canada's world-class production capability. The design phase of Hollywood blockbusters was never intended to be considered Canadian content. A flawed analysis may cause the study to miss a research question: why Canada has not produced the type of award-winning small films, which come from other regions in North America, including the French-language movie sector in Quebec, and the world.

However, a second critique may be most relevant to this dissertation. While the study does include a value chain discussion, the analysis does not identify as pivotal, three functionally distinct phases of the chain, as proposed in the following chapter. A muddled conceptualization of the value chain appears to lead to problematizing Toronto's cluster upgrading issue, without the benefit of a well-defined theoretical lens:

Toronto, despite a long history of media production, world-class infrastructure, a well-functioning network of suppliers, high human and social capital, the ability to attract foreign productions and a certain "institutional thickness" in terms of public financing... has not managed to developmeasured in market share - an indigenous film cluster. (Vang \& Chaminade, 2007a, p. 3)

The lack of a sufficiently crisp theoretical lens, on the part of the Vang and Chaminade study, may conflate or even obfuscate the role of various actors in the value chain. A field-study consequence, for the Vang and Chaminade study, appears to be that interview subjects were chosen from different functional phases of the value chain, resulting in a mix of below-the-line production workers, above-the-line producers, and representatives from government funding organizations. This prevents a deep dive into any one aspect of the chain. Absent both a well-defined theoretical lens and as a probable consequence, a well-defined category of informants, the study does not discover a persuasive answer to why the Toronto film cluster has not upgraded from production to design function.

In contrast to the Vang and Chaminade study, the value chain theorization in the following chapter, and the field research, which follows, take a deep dive into one node on the Canadian Englishlanguage TV drama value chain, the development phase. This dissertation's focused investigation sheds light on why the sector has not upgraded to design excellence, and ultimately, suggests actionable strategies to strengthen development, and in so doing, improve the domestic and global market traction of Canadian English-language TV prime time TV drama.

\subsection{Review of gaps in literature}

Calls for further research on Canadian TV drama development, qualitative and quantitative, emanate from many of the arenas reviewed in this chapter. There is a need for more quantitative and 
qualitative information on creators in Canada and U.S., and a better understanding of the dynamics of the business and creative aspects of TV drama development, in Hollywood and in Canada.

Scott (2005) underscores a paucity of statistics on the U.S. industry and barriers to obtaining firmbased data, calling for more research in creativity and innovation. Bielby and Bielby (2002) and Christopherson (2009) echo complaints of a scarcity of information on Hollywood TV development.

There have been calls for more research on the Canadian TV drama sector, both in its comparative relationship to the U.S. and for qualitative research, both needs which this dissertation addresses. The Vang and Chaminade study calls for further study of the "complementary competencies" between Canada and Hollywood (Vang and Chaminade, 2007a, p. 14). The value of reliance on official reports on the Canadian industry has been questioned (Le Goff et al., 2011; Hoskins, McFadyen, \& Finn, 1994). It has been noted that the difficult job of rationalizing available numbers may obfuscate a key understanding: "the relationship between funding received and the audience reached" (Le Goff et al., 2011, p. 27).

The main gap in knowledge, addressed by this thesis, is the unsolved puzzle of how to improve the market performance of Canadian English-language TV drama. As reported in this chapter, the question has been posed many times, including by the government, yet has remained unsolved (Doyle, 2013; Freeman, 2013; Kiefl, 2013; McQueen, 2003; Macerola, 2003; Standing Committee on Canadian Heritage, 2003). A policy response to this abiding mystery has been numerous iterations of the Canadian content rules for TV drama (CRTC 1999a, 2000, 2004, 2010a, 2010b, 2010c). Yet, these strategies have resulted in an unchanged outcome, a fractional share of both the domestic and international market, and the consequence of such unpopularity, insufficient monetization.

This dissertation attempts to address this challenge, by shifting the focus of exploration to an overlooked arena, the development phase. In the next chapter, examination of the Canadian Englishlanguage TV drama value chain demonstrates why R\&D might be key to strengthening the sector, how the elements of the value chain interact, and how weak development is determined by distribution dynamics. The field research, reported in chapters 5-8, dives deeply into the development phase of Canadian English-language TV drama. Elite informants confirm the analysis that development is the weak link in the chain. The field study deepens and extends the value chain analysis, with passionate descriptions of how the value chain actually affects on-the-ground processes of the development phase of Canadian English-language prime time TV drama, rendering it "warped" and "broken" (Respondent, Canadian, A-list Hollywood showrunner). Informants underscore that strengthening development of Canadian English-language TV drama appears to have become urgent, because the impact of online TV delivery may be to render the creation and exploitation of winning content one of the few reliable TV business models left. In other words, this dissertation argues that, in order to bring on a golden age of Canadian TV, Canada will need to evolve its value chain to include a strong content model. 


\subsection{Chapter summary}

This chapter began with a discussion of the key background context (Section 2.1), defending the study's focus on prime time TV drama by exploring the enduring importance of hit TV content, even in the historically transforming viewing eco-system, and reviewing a corollary result of digital transformations, including the foundational concepts of hit, popularity, and brand in the attention economy. The chapter then integrated four arenas which surround the question of the role of development in the manufacturing of Canadian English-language TV drama: industry overviews of the Canada and U.S. TV industries (Sections 2.2-2.3); a TV policy review, which positions Canadian TV policy as a response to Hollywood dominance (Section 2.4); a discussion of value chains and global value chains, which comprise the theoretical lens through which the sector will be analyzed in the upcoming chapter (Section 2.5); and a review of cluster upgrading, local-global linkages, and economic diasporas (Section 2.6). Section 2.7 reviewed gaps in the literature, which were identified by the work of this chapter.

A result is that this dissertation is empowered to propose, in the next chapter, a value chain analysis of Canadian English-language TV drama which explains how the linear sequence of activities interact, and in particular, how development and distribution are inextricably linked. Canada has long had a wellfunctioning, legacy broadcasting model, similarly to other geographic TV markets in North America, based on the monetization of Hollywood hits. The extant value chain priority might be expressed as favouring national profits on global content. In the next chapter it will be seen that Canada's system has lacked a strong original content model. As the world changed, the TV drama value chain has not been adjusted to also deliver global profits on national content, which may be an imperative business model in the online era. A comparison to the Hollywood TV drama value chain will show that a viable content model appears to require a studio structure, which features a vertically integrated value chain. As will be elaborated, the lack of an imperative for financial results, and weak linkage between the R\&D and ROI phases of the Canadian English-language TV value chain, may be the underlying issues, which have inhibited maturity into a domestically popular, and even globally competitive TV sector. 


\section{CHAPTER 3}

\section{A BRIDGE TO NOWHERE: \\ THEORETICALLY REFRAMING CANADIAN ENGLISH-LANGUAGE TV DRAMA}

"Skate to where the money will be" (Christensen, Raynor, \& Verlinden, 2001, p. 72).

\subsection{Introduction}

As set out in Chapter 1, this dissertation argues that the inability of Canadian, English-language prime time TV drama to achieve substantive market traction may be attributable to weak development, the preliminary phase of the value chain, wherein the IP is created. Subsequently the product is manufactured in the production phase, and monetized in the distribution phase. In Chapter 2, a synthesis of diverse literatures, which bear on the case of Canadian English-language TV drama development, included a review of value chains and global value chains, which set the stage for this chapter to extend previous analyses of Canadian English-language premium TV drama, and offer a novel analysis.

The choice of a paradigmatic framework, in this chapter, which is a comparative business analysis of the value chains of Canadian English-language TV drama and Hollywood TV drama, is a theoretical approach which was emergent, i.e. which evolved organically from the research process. As is normative in case study methodology, this process involved "cycles of expanding complexity and simplification, to gain appreciation of the subject matter being investigated" (Pettigrew, 1990, p. 282). Building theory from case data is further validated: "The data provide the discipline that mathematics does in formal analytic modeling" (Eisenhardt, 2007, p. 25).

Against the backdrop of global upheaval in the TV industry, this chapter will analyze the development dynamics of Canadian English-language TV drama genre from a value chain perspective. Ultimately, in Chapter 9.2, following the presentation of the findings of the field study, the dissertation will further integrate the findings of this theorization with the field data, to suggest a new policy approach for the online TV era. A theoretical approach, is recommended as a strong opening strategy, in any industry undergoing profound disruption and rapid transformation (Christensen et al., 2013):

Theory is even more helpful when there is an abundance of data. This is the critical challenge of the Information Age. With more information available, it is harder to discern what information really matters. Theory helps to block out the noise and amplify the signal. (Christensen et al., 2013, p. xxi)

As will be further elaborated in this chapter, value chain evolution theory, VCE is positioned as one of three possible types of strategic orientations (Christensen et al, 2013). The two others are disruptive innovation and the resources, processes, and values theory (RPV). While a detailed investigation of the other two strategic innovations lies outside the scope of this dissertation, a few notes seem important, in 
order to contextualize the upcoming analysis. Firstly, disruptive innovation, the substitution of linear broadcasting by global, online TV delivery, is the market event, which is remaking the TV value proposition and precipitating urgency for a strategic response by Canadian English-language TV drama. RPV, the third logical option in Christensen's menu of innovation strategies, might be described as a more nuanced, downstream approach to innovation, whereby existing capabilities and available funds might be re-allocated, in response to market disruption. RPV might well be a useful approach to strengthening the development phase, once the source of weakness of Canadian English-language TV drama has been definitively identified and value chain evolution would be accomplished. From this perspective, it may be that previous incremental policy initiatives, such as adjustments in the funding and rules mechanisms, often targeted to production, may not have addressed the correct phase of the value chain, which appears to be development. RPV may prove to be of value in follow-up studies to this dissertation, as suggested in Section 9.3, regarding the question of how to adjust the point system, so as to tighten the relationship between script and audience, the relationship which will be shown to be the weakest link, in the upcoming pages.

Seven conceptual observations result from the value chain analysis of Canadian English-language TV drama, to be elaborated in this chapter:

- Phase 1 and 3 are connected. Phase 1 (development, i.e., asset creation) and phase 3 (distribution, i.e., asset monetization) of the TV drama value chain are inextricably related, while phase 2 (production, i.e., asset manufacturing) appears to be the most discrete phase of the chain.

- Phase 2 and 3 have been built by strategic use of the Canada-U.S. geo-cultural relationship. Current strengths of phase 2 (production) and phase 3 (distribution) of the Canadian TV drama value chain have been built via strategic deployment of the unique Canada-U.S. relationship, which is characterized by the 3Ps of proximity, population, and portability.

\section{- The role of Canadian networks appears to be mixed, including that of domestic broadcaster} and some functional aspects of a studio. Canadian networks, chiefly the large, integrated media companies known as VI's, appear to have a mixed function in the Canadian TV drama value chain, dynamics which have been described as "fuzzy links" (Christensen et al., 2001, p. 10) to the outcome of original English-language TV drama. The VI's function, in the development phase, as a blended broadcaster, who licenses programming, and also as a quasi-proxy studio, who finances programming and governs production financing, but they do not obtain the right to monetize investment outside of Canada, as currently stipulated by the Terms of Trade (CMPA, 2011b, 2014). In the distribution phase, the networks do function as broadcasters, but they do not rely on original Canadian content for monetization, which appears to result in limited corporate interest in optimizing the asset in development. Vested interest may be further muted, by a financial balance 
between the benefits of simultaneous substitution, which delivers approximately thirty percent additional revenue, and the obligation of CPE's which are also about thirty percent, which appears to neutralize the risk of Canadian content (Armstrong Consulting, 2014; CRTC, 2011b).

- Alignment of financial interests in the development phase of Canadian TV drama is shown to differ from that of the development phase of Hollywood TV drama. This difference is theorized to impact both the financial and creative outcome of a Canadian TV drama project.

- Canadian TV drama value chain tends to be assessed at conclusion of phase 2. As a result of the value chain structure, the extant Canadian TV drama value chain tends to be assessed at the end of phase 2, manufacturing, where a number of outcomes are measured.

- The structural fault in the Canadian English-language TV drama value chain appears to ripple backwards to impact creative development. The extant value chain structure of Canadian TV drama has resulted in a world-class production sector and as well, via the substitution of Hollywood hits in the monetization phase, a robust linear broadcast distribution sector. However, an unintended consequence of this structure, which features a weak linkage to monetization of Canadian English-language TV drama, ripples backwards to negatively impact both the creative and financial processes in development and as a consequence, appears to impact the market performance of Canadian English-language TV drama.

- Local-global linkages, or a lack thereof, in the development phase, may be a function of the alignment of financial elements in the development phase of the value chain. The value chain analysis suggests that financial alignments determine creative development linkages, not vice versa. Comparing to the case of Hollywood TV drama, it appears a financial imperative may be a key ingredient in optimizing creative elements. Upgrading local-global linkages in Canada's domestic TV drama cluster will be shown to include, not just a need to strengthen linkages with Canadian creators in Hollywood, as hypothesized, but also appears to require a strengthening of financial linkages with Hollywood. For example, such linkages might be enabled by network presence there, to support Canada's TV drama producers, in the complex exigencies of development.

These seven development dynamics, in addition to being suggested by theorization, were confirmed in the field research. They could be summarized as an imperative to follow the money. Rather than operating with great risk and imperative for a hit, the modus operandi of key actors, namely, the Canadian broadcasters, might be characterized by a weak need to succeed. Field research confirmed that a muted financial imperative in Canadian TV drama can be felt from the first pitch in development. The title of this chapter comes from the words of a Canadian, A-list Hollywood showrunner, who returned home to create a Canadian TV drama, and characterized Canadian English-language TV drama development as a 
"bridge to nowhere," indicating a strongly felt sense of a missing link to commercialization, in the value chain.

Similarly to Chapter 2, this chapter begins with a discussion of foundational concepts, which underpin the approach, and in particular, the value chain comparison between Hollywood TV drama and Canadian English-language prime time TV drama. The first is a reframing the Canada-U.S. relationship as "3Ps" (Section 3.1). The second is a discussion of, and proposed formula for, media value (Section 3.2). The main analysis (Section 3.3) reframes the challenge of Canadian English-language TV drama as a value chain issue, and moreover, as an opportunity for value chain evolution. The chapter's theorizations conclude by reframing the role of creative local-global linkages, suggesting that creative dynamics appear to be determined by financial dynamics, even in the development phase of the Canadian Englishlanguage TV drama value chain.

\subsection{Reframing the Canada-U.S. TV relationship as 3Ps}

As elaborated in Chapter 2, many issues in Canadian English-language TV drama appear to be bound up the connectivity between the TV industries of Canada and the U.S. The neighbours share the planet's largest trade relationship, more than $\$ 700$ billion annually in 2012 , the latest figure available (Office of the United States Trade Representative, n.d.). With respect to the TV industry, and specifically, Canadian English-language TV drama, Canada's qualitative side of this relationship can be summarized by three unique, immutable characteristics of its domestic marketplace, postulated as 3Ps: population, proximity, portability (Berkowitz, 2009b). The combined impact of these three characteristics delivers, to the Canadian English-language TV drama sector, a relationship to Hollywood, which might be considered unique on the planet. This dissertation implicitly considers the question of whether the combination of the 3Ps might be cause for competitive disadvantage, or advantage in Canadian English-language TV drama.

Population: English Canada's relatively small population, at about 25 million, is approximately the size of the largest U.S. market, the New York metropolitan area. Canada's English-language population is positioned, in this dissertation, not as explanation for Canadian English-language TV drama's market performance. Rather, population is positioned as immutable, just one of the many challenges of manufacturing TV drama, wherever it originates. Moreover, this particular challenge is contextualized by the goal of all TV drama manufacturing: "the primary goal ... is to maximize the size of an audience" (Eastman \& Ferguson, 2013, p. 8). The meaning of this first "P" seems further moderated in today's transforming TV eco-system, since the potential market of viewers in a digital distribution system can be considered a global audience.

Also transformative, the explosion of viewing choices and patterns in an online viewing ecosystem has narrowed the gap in audience size, which used to differentiate legacy broadcast and cable hits, whereby the average U.S. legacy broadcast rating has become close to that of a cable hit: "the cumulative 
audiences for all showings of a top-notch movie on HBO equal the size of a television network's audience" (Eastman \& Ferguson, 2013, p. 191). The combination of flattened boundaries between TV dramas, such as country or platform origin, and the theoretical ability to monetize a global audience, may, together, weaken the rationale for regulatory protection of Canadian English-language TV drama. Moreover, shelf space has become unlimited in an online environment. Programs are monetized, not when initially broadcast, but on-demand and cumulatively, over time, by e-commerce services like iTunes, or subscription streaming services, like Netflix. A time frame for commercialization may be limited, only by the program's ability to attract and sustain attention. In the era of online delivery, any aggregation of audiences, over geography, time, and a multiplicity of screens, seems key to successful monetization of TV drama. Small domestic population may be an audience characteristic, which may no longer be a justification for unpopular content. A "fundamental shift" on the issue of a small domestic population appears to have been implicitly addressed by the CRTC in March 2015: "Truly great content doesn't always have to come from south of our border. ... If it's possible for Britons, Australians and Danes to create world-class television programs and films, why not us?" (CRTC, 2015e, Creating Content for the World Stage section, para. 3).

Proximity: As described in Section 2.4.1, English Canada's geographic and cultural proximity to the United States is unique in the world. A shared language, peaceful border, and of no small matter, a climate which has caused the Canadian population to huddle near the country's southern border, have been key to the broadcasting alchemy between the neighbours. U.S. TV signals have always been receivable, and demanded by Canadian audiences. Guaranteed reception has been incorporated into regulation as a key revenue strategy, simultaneous substitution, elaborated in Section 2.4.2.4. In 2015, economic, political, and cultural connections between Canada and the U.S., specifically to the state of California, are stronger than ever, as articulated by Canada's Senior Trade Commissioner with the Canadian Consulate in San Francisco: "the cultural similarities that we share have placed our two economies on parallel track in their competitive strategies" (Canadian Trade Commissioner Service, 2015, para. 30).

Portability: An open trade relationship between the U.S. and Canada encourages migration of its TV industry labour. Below-the-line portability of technical expertise, from Hollywood to Canada, has played a role in the upgrading of Canadian production crews. Above-the-line migration, especially of Canadian creatives, whose skills are highly transferable to the Hollywood cluster, features unparalleled opportunity for career acceleration.

For decades, brain migration has been documented, but previous to this research, largely unexamined as a strategic advantage. A précis of this dissertation, submitted to the CRTC, suggested that, to strengthen the development of Canadian English-language TV drama, long-acknowledged brain drain 
of Canadian creators to Hollywood might be re-positioned as a unique competitive advantage (Berkowitz, 2014a, 2014c, 2014d):

While Canada is not (yet) branded as an exporter or global hits, it has (for nearly 100 years) exported drama creators, the talented individuals who are key to hits. ... Brain migration of our knowledge workers is driven by 2 unique "Ps" (geographic/cultural Proximity and skill Portability). For Canadian creators, the lure of Hollywood is easy to understand. An untapped opportunity may be a lack of systemic linkages with Canadian hit-makers who work there. ... A "brain chain" strategy of strengthening linkages with Canadian creators working in the US system could enhance the compellability of Canadian TV drama. (Berkowitz, 2014a, pp. 10-11)

In March 2015, CRTC's Let's Talk TV decision regarding Canadian TV drama content, acknowledged this policy recommendation, as will be elaborated in Section 9.5.

The issue of Canada-Hollywood portability, with regards to TV drama, might be further contextualized by consideration of the Canadian government's current positioning of the overall CanadaCalifornia relationship, in regards to both the portability of HSPs and to trade. A recent podcast from Canadian Trade Commissioner Service, California, golden state of opportunity (Canadian Trade Commissioner Service, 2015), noted that a Canadian is currently president of the University of California and that Canada's annual exports to the state of California exceed $\$ 26$ billion, more than the next three export destinations combined: U.K., China, Japan. The podcast includes the following remarks by the Canadian Consul General of Los Angeles: "First and foremost, put California on your radar screen. ... California is directly related to your competitiveness.... What has made the strength of California is its risk culture" (Canadian Trade Commissioner Service, paras. 10-12).

To conclude presentation of the 3Ps, their purpose is to summarize three immutable characteristics of the unique Canada-U.S. media relationship: population, proximity, portability. As described in Chapter 2, in the case of Canadian English-language TV drama, each of these factors has been often positioned as a competitive disadvantage, requiring regulatory or policy intervention. As the Canadian English-language TV drama sector moves forward to embrace a global perspective, afforded by the era of online program delivery, each of the 3Ps may have potential to be reframed as unique competitive advantage. Furthermore, the 3Ps inform the value chain analysis, to be presented in Section 3.3. As will be demonstrated, both the production (phase 2) and distribution (phase 3) of the Canadian TV drama value chain have successfully deployed aspects of the 3Ps to build global competitiveness in the Canadian English-language TV drama value chain. Previous to this research, deployment of the 3Ps to strengthen the development phase had not yet been examined.

\subsection{Reframing TV drama value}

Any value chain implicitly turns on a definition of value. Therefore, an important task, preliminary to presentation of the value chain theorization of Canadian TV drama (Section 3.3), is to clarify what is 
meant by value. The word value can reference different types of contribution to society, mainly cultural, political, or economic. Value is closely related to the foundational concepts of hit, popularity, and the role of brand, as discussed in Section 2.1. This section briefly reviews a definition for media value (Reca, 2006) and extends it, by proposing a formula for media value. The formula for media value is a foundational premise of the value chain analysis in Section 3.3.

As reviewed in Chapter 2, the Canadian government, in asserting the importance of a national TV industry, protected and promoted it, based on cultural value. The cultural value rationale was central in the design of a framework of regulations, policies, subsidies, and incentives to support and protect the TV industry during the latter half of the 20th century. As reviewed in Chapter 2, in the case of Canadian English-language TV drama, results include a world-class production and a robust linear distribution sector. Ironically, it has been argued that, in the case of Canadian English-language TV drama, these instruments have delivered more economic, than cultural results (Hoskins et al., 2004; Le Goff et al., 2011; Lester, 2013; Watson, 2013).

One practical outcome of the Canadian TV industry's historic interpretation of value, appears to be that Canadian TV has not been framed as a profit-seeking enterprise, but as a sector, which has had, as its chief value, a supply of series of cultural, employment, infrastructure, and technological outcomes. According to The Act, in addition to a requirement for a presence of story-telling sector, values have included social goals such diversity, accessibility, and a requirement for technological currency (Government of Canada, 1991). Nevertheless, at every technological juncture, since the 1980s, the Canadian government has expressed concern that funding for Canadian content, in particular Canadian English-language TV drama, which has been enabled by the cross-subsidy benefits of simultaneous substitution, and which has, arguably, delivered more jobs and shows, than economic wealth, would be threatened by borderless, global, online delivery of TV, and especially, whether "technology would be the ultimate deregulator" (Caplan \& Sauvageau, 1986, p. 76).

It took more than three decades for digital technology to become a measurable threat to the global, linear broadcast TV industry, and so, to the Canadian industry. The Internet has disrupted industry silos of broadcasting along numerous planes, and destructed boundaries between devices and platforms, and significantly for Canada, between the "once rigid barriers between domestic and foreign programming" (Eastman \& Ferguson, 2013, p. ix). In the era of global online drama distribution, discussions of value in the Canadian TV drama ecosystem take on renewed importance.

A useful conceptualization of value stems from the concept of "value migration" (Slywotzky, 1996, p. 3), which refers to the shifting of value within a value chain, during times of profound innovation, such as currently in the global TV industry. During such transformations, value may only be continuously captured, if management maintains a finely tuned understanding of customers' priorities (Slywotsky, 
1996). The value migration paradigm proposes a rubric for categorizing the shifting of value in three phases of an industry: infant, maturity, and decline, which can be alternately characterized as "value inflow, stability, or value outflow" (Slywotsky, 1996, p. 6). This dissertation has previously established that the TV industry, after stability during the second half of the twentieth century, might be seen as currently in an intense period of value migration, whereby economic value appears to be flowing away from a linear broadcast business model, and towards online distribution. Moreover, numerous business and consumer characteristics of online TV drama delivery, which include on-demand viewing, channel unbundling, unlimited shelf space, decline of national media suppliers, ascendency of global media suppliers, and a blurred boundary between TV drama and all other online content, appear to be value migrations which are placing intense pressure on the need for a given program to capture audience attention. A consequence of this new market demand profile appears to be that strong IP and the ability to commercialize that IP, may become more important to the ultimate value of a TV drama. In other words, value has migrated towards the development phase of the chain: "In outflow ... value starts to move away from an organization's traditional activities towards business designs that more effectively meet customer's priorities. Although the outflow may start slowly, it accelerates as business design becomes increasingly obsolete" (Slywotsky, 1996, p. 7).

As Canadian policy makers predicted in 1986, technology may prove to be the final deregulator. It may also force an imperative for the Canadian TV drama sector, and other national TV regimes around the world, to align their definition of TV drama value with Hollywood's classic formula: the economic value of IP. This seems a result of the unbundling work of the Internet, which appears to render the value of an individual TV program, or brand, to its ability to attract audience attention.

For the reasons discussed above, in the value chain analysis proposed in the following pages, value is defined as economic value, as determined by demand. From Gone with the Wind, which reigns as the most popular movie of all time, when figures are inflation adjusted (Guiness Book of World Records, 2015), to the iconic new web empires, Google, Amazon, Facebook, and Apple (a.k.a. GAFA), with their market capitalization of more than a trillion dollars (Deighton \& Kornfield, 2013), the formula for media value has remained the same. As Google's 3.5 billion searches per day attest (Internet Live Statistics, n.d.), the media formula for value appears to be derived from demand, or popularity. This observation further supports the popularity versus quality discussion in Section 2.1.2.

Media is variously defined as many types of goods, including information good, experience good, public good, credence good, and shared good; however, it is best described as an attention good (Reca, 2006). All media operates in an economy of attention, and relies on massive consumption for success (i.e., demand). As such the following media wealth formula is proposed:

$$
T(\text { talent })=A(\text { attention })=M C^{2}(\text { massive consumption })=\$ \$ \$(\text { media wealth })
$$


- $T$ equals the talent to deliver popularity, or attention;

- $A$ equals attention, expressed as consumption and/or popular critical acclaim;

- $M C^{2}$ equals conversion of consumption into tickets, ratings, subscriptions, clicks, ecommerce or a combination thereof;

- $\$ \$ \$ \$$ equals the wealth created, when attention is converted, via various formulas, into money.

Like all equations, the formula above might be considered a tautology. Each of the concepts implies the other. Media delivers financial value only when it attracts attention. The formula is meant to imply that the most reliable media talent is an ability to attract attention (Eastman \& Ferguson, 2013). For prime time TV drama, this formula seems critical, as the cost of TV drama is millions of dollars per program

To conclude the discussion of value, the global transition to online TV delivery appears to offer the Canadian English-language TV drama sector a challenge and an opportunity to enter the global battle for attention, and win it. This could mean transforming its TV value proposition to a simpler one, in line with Hollywood's time-tested media value proposition: market traction equals financial value.

\subsection{Reframing the Canadian TV drama value chain: Bridge to nowhere}

This section proposes a theorization of a value chain for Canadian English-language Canadian TV drama, which situates the overall contribution of this dissertation as a value chain analysis of the sector. To recap, a value chain is defined as a linear sequence of business activities, which deliver a product to market (Porter, 2008a). Moreover, value chain adjustment has been configured as VCE, an effective response to market disruption and a strategy to "untangle the messy process of innovation" (Christensen et al., 2013, p. xv), which well describes the current global chaos in the TV industry. VCE "assesses whether a company has made the right organizational design decisions to compete successfully" (Christensen et al., 2013, p. xix), with the qualification that this dissertation is targeted, not towards any specific firm, but towards the genre of Canadian English-language prime time TV drama. An attribute of VCE, which will become useful in the coming pages, seems its "golden rule," which is to decide what to vertically integrate and what to outsource, as a sector undergoes disruption (Christensen et al., 2013, p. xx).

The first depiction of the TV drama value chain is straightforward, per Figure 3.0 below. Subsequent iterations will be more specific to Canadian English-language TV drama and more complex, as the development, production, and distribution phases are elaborated, in Sections 3.31-3.33. Each representation will identify unique industrial dynamics of each segment of the chain. 


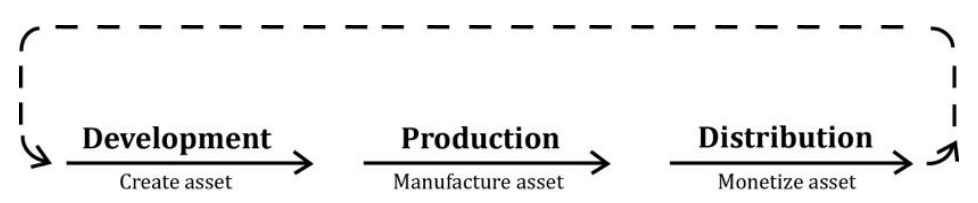

Figure 3.0. TV drama value chain.

The three phases of the linear TV drama chain are development, production, and distribution; these functional distinctions can also be expressed as the creation, manufacturing, and monetization of the asset, a TV drama. The overall progress of the chain is from $R \& D$, which is research and development, through ROI, which is return on investment. Consistent with three different goals, each phase of the chain exhibits distinct business dynamics. Development is a business to business (B2B) function, which can be characterized as an oligopsony, where there are many sellers of creative services, but relatively speaking, few buyers of these services, the TV drama financiers. Production, the middle of the chain, can be characterized as a supply-demand B2B market, with a globally geographic competitive set and as well, inter-sectoral complementaries to other screen sectors. The distribution phase of the chain refers to monetization processes and strategies, which have as their ultimate goal, to connect product to consumer. As such, distribution, while involving many B2B processes, is quintessentially the business to consumer (B2C) function. In contrast to development's oligopsony, the monetization phase can be characterized as an oligopoly, which features a few sellers and many buyers, a potentially global audience. The only detail on this initial depiction demonstrates the critical linkage between distribution and development. The timetested business model has been that the investment in development, an R\&D function, are normally underwritten by distribution profits, or ROI, returns on investment.

The sustained competitive dominance of Hollywood TV hits around the world, accounting for more than seventy percent of TV drama exports, is attributed to reasons which can be summarized as strength in two phases of its TV value chain: development and distribution (Hoskins et al., 2008). Development dominance can be explained by the unparalleled concentration of $R \& D$ talent in the Hollywood cluster. Distribution strength can be explained by the U.S. being the largest domestic market in the world, for English-language TV.

Such an analysis of the reasons for dominance notably omits the middle of the chain, the production phase of TV drama manufacturing. As this chapter will demonstrate, the development phase and the distribution phase of TV drama are inextricably linked, while the production phase is the most independent. Moreover, a close reading of the Canadian English-language TV drama value chain reveals weak linkage between the development and distribution phase. Identification of a structural fault in the Canadian TV drama value chain, which may have prevented it from maturing to a popular or economically robust sector, is a core finding of this dissertation. 
In the following sections, each phase of the Canadian TV drama value chain will be closely examined and compared to Hollywood TV drama. The discussion will progress backwards from distribution, to production, and land on development, because the processes of development, which contribute to the creation of a Canadian English-language TV drama, are the focus of the remainder of this dissertation.

\subsubsection{Monetization phase of Canadian TV drama: Weakest link}

As noted above, distribution is defined, in this value chain analysis, as the monetization phase of the TV drama asset. It is the final phase of the TV drama value chain, whereby the program is connected with an audience and financially exploited. Since 2000, distribution processes, as distinct from those of production or development, have been subject to historic, global disruption (Cunningham \& Silver, 2013; Noam, 2014; Strangelove, 2015). An effect of online distribution may be to force an imperative for the Canadian media system, which has been largely structured to ensure a cultural sovereignty, within a market captured by controllable TV offerings, to transform to a market of "consumer sovereignty" in which consumer preferences rule (Hoskins et al., 2004, p. 78).

In this discussion, distribution implies the sum of business activities, which enable audience contact and capture audience attention for a TV drama product. Measurement of audience attention is the holy grail of the TV distribution value chain, because it converts audience attention into economic value, whether calculated by ratings, subscriptions, or clicks. With distribution conceptualized as the last mile in the value chain, whereby audience contact is enabled, the main dynamic of TV program distribution is a one-to-many activity with numerous sub-processes, including acquisition of content by middle-entities, complex rights acquisitions; the division of the global market into monetization markets by advertising, subscription, and/or online distribution; windows for monetization, which are time-based rights; and not the least, the historically transforming data delivery mechanisms. Nevertheless, it is useful to consider the main dynamic of phase 3 to monetize the asset, via contact with end-users. As indicated above, the main dynamic of distribution can be expressed as a B2C oligopoly, with few sellers, and many buyers, the audience.

Optimizing TV drama revenue can be considered to necessitate two requirements: possession of rights to distribute content, and maximizing audience connection with that content. The level of risk in rights acquisition and the imperative for popular content can be understood in the consideration that it is not uncommon for a broadcast network to have "an entire season without a single new hit" (Eastman \& Ferguson, 2013, p. 88) but that over time, failure to have a hit can precipitate failure in an entertainment business. A main take-away of the distribution phase of the value chain is its inexorable connection to the development phase, the costly process where the asset is created, and imperatively, hits. 
In order to understand the value chain of Canadian English-language TV drama, and especially the high-budget dramas which are co-financed with Hollywood entities, it is useful to examine the Hollywood TV drama value chain, as pictured below in Figure 3.1.

A Hollywood financial structure for a TV drama might be generalized to include a U.S. distributor (broadcast, cable, or online), which licenses rights to distribute in the U.S. and a studio, which purchases the remainder of global rights (ex-U.S.), for exploitation. When financing from two major sources, domestic and global rights does not cover the budget required to develop and produce the program, another entity may be sought to cover a short-fall in financing. This brings in an additional entity, or entities, into the development structure, noting that all parties have non-overlapping interests, which are aligned to one goal: optimization of the value of the asset, however distributed to the eventual audience. Also, as depicted, the creator/producers of the program, while usually compensated for work as performed, during development and production, sometimes have a share in net profits, but always have a reputational imperative in the outcome of the monetization phase. In a business where the reputation of the producer and writer are key components of the selection process (Eastman \& Ferguson, 2013), where A list/B list rankings mean everything (Caves, 2000), and in which any program which becomes a hit could be a career maker, this is no minor vested interest in the outcome of the development process. In Hollywood TV drama, as shown below in Figure 3.1, the interest of all the players, in the development phase, are aligned towards one goal: a hit.

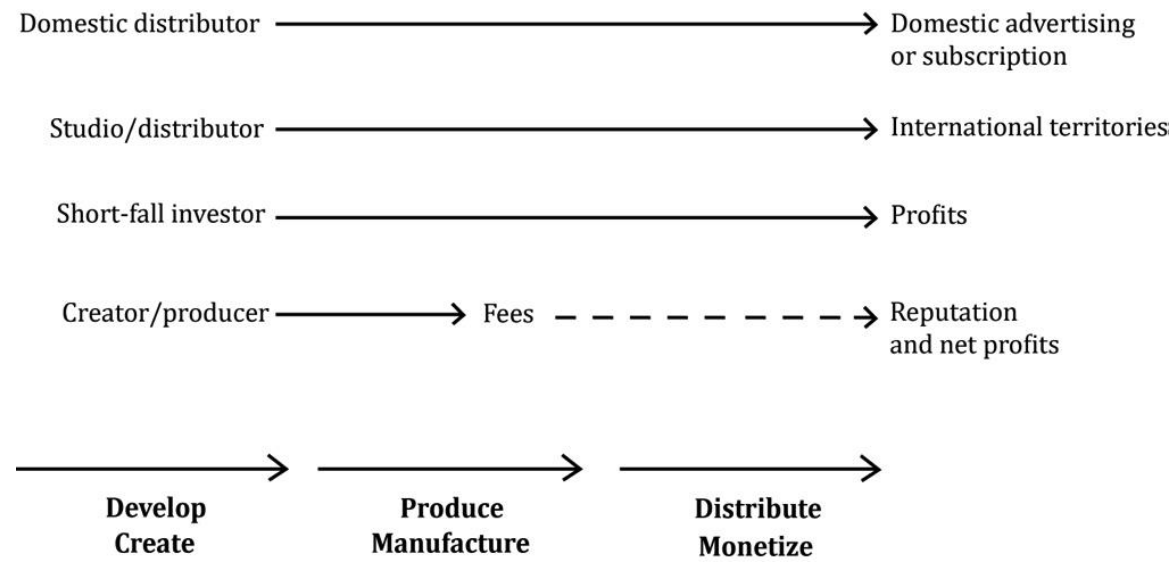

Figure 3.1. Hollywood: TV drama value chain.

The Canadian English-language TV drama value chain appears to operate with different dynamics, as shown below in Figure 3.2. In contrast to the monetization phase of Hollywood TV drama, the Canadian English-language TV drama distribution phase appears to be impacted by various systemic features. The Canadian networks' dual role in the value chain as both a broadcaster (licensing rights for 
the domestic territory) and a quasi-proxy-studio (overseeing government investment, but not purchasing global rights) impacts the chain in several ways. Firstly, in contrast to a profit motive from the outset of the value chain, Canadian broadcasters contribute to the cost of developing and producing Canadian TV drama, in order to fulfill their broadcast license obligations, which require $50 \%$ of their evening hours to be Canadian content. An outcome, as reported in the field research, is that licence fees, which are normatively population based, can be set in excess of market value, because the broadcasters' obligation is to spend approximately $30 \%$ of revenues on Canadian content via the Canadian Program Expenditures (CPEs). According to informants, inflated licence fees make profitability from the domestic market even less achievable. Similarly, public funds do not have onerous profit or popularity imperatives, yet they comprise a substantial component of the financing for a TV drama, nearly $40 \%$ of the budgets of all Canadian, English-language TV dramas (CMPA, 2015). Another key difference in the monetization phase of the Canadian value chain, compared to the Hollywood TV drama value chain, may be an unintended consequence of simultaneous substitution, the substitution of profitable Hollywood TV drama in the monetization phase of Canadian TV drama. While financing of Canadian TV drama is pegged to profits from distribution of Hollywood TV drama, ironically its monetization potential appears to blunt the chain, which prioritizes the supply of hit content to the domestic marketplace.

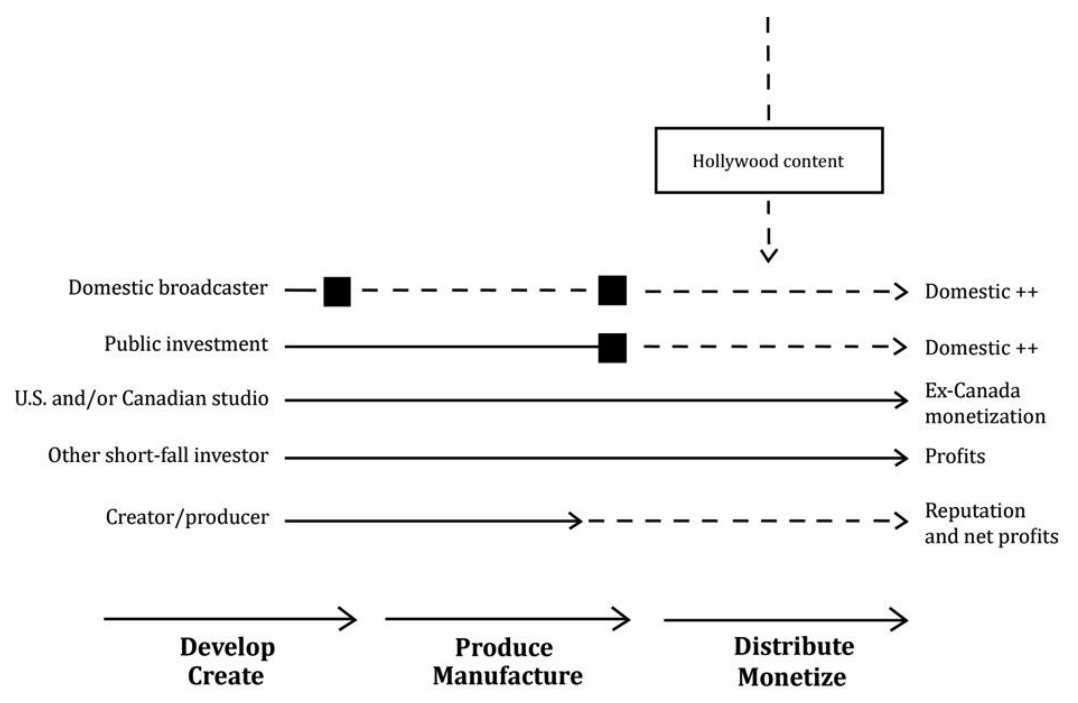

Figure 3.2. Canada: English-language TV drama value chain.

Another observation regarding the distribution end of the chain, which may impact a profit imperative for Canadian English-language TV drama, is the so-called vertical integration of the three large media companies, responsible for most of the product: Bell Media, Rogers Media, and Shaw Media. While these companies are commonly referred to, even by lobby and government entities, as the VIs, 
meaning vertically integrated, they do not appear to be vertically integrated, specifically with respect to Canadian English-language TV drama. With classic vertical integration defined as the progression from R\&D to ROI on a value chain, the Canadian VIs appear to be more accurately characterized as horizontally integrated, along one node of the chain, phase 3, distribution. No matter how Hollywood TV drama is ultimately monetized, via broadband, wireless and including the two sunset technologies, cable and broadcasting, the VIs appear to be strongly positioned to profit, via complementary distribution capabilities.

In comparison, in the Hollywood chain, and partly as a result of the repeal of the U.S. financial syndication rules in 1993 (as discussed in Section 2.4), currently, more than 70\% of TV dramas, made for conventional broadcasters, are owned by the broadcasters, which doesn't even include cable companies, like HBO or Showtime, or vertically integrated online companies, like Netflix. Even so-called independents tend to be big conglomerates, such as Sony or Warner Brothers, not small independent producers (Adreeva, 2015). This is not only a function of the high-risk, high-cost nature of program development, it may also be an imperative business model in the new TV era: "Owning content becomes crucial in the new digital universe where there are so many means of distribution. ... Program ownership has become the next primetime frontier" (Andreeva, 2015, paras. 11, 13). Informants in this study noted the positive impact of vertical integration, which appears to engender a need to succeed, from the first moments of the development phase.

By contrast, the Canadian rules were conceived in the 1970's, likely modeled after the Hollywood system then, and possibly even the 1970 Fin Syn rules. However, Canada's rules have not been revised:

You've got to open up the rules and look at what's really important- which is ownership and control of the shows. ... Even if the project doesn't shoot in Canada, it would help if the Canadian broadcaster owns the project so ... if it's a hit, the Canadian company gets the profits. ... We have to step back and look at the Canadian system from first principles and say 'OK these rules came into place in the 60s and 70s - they may have made sense then, but do they still make sense now? (Respondent, CEO Canadian TV drama firm)

The possibility that lack of actual vertical integration, in the value chain for Canadian, English-language TV drama, might contribute to its weak financial outcome, led to a number of recommendations from informants, in Chapter 8, and as well, factored into in this dissertation's concluding recommendations to strengthen Canadian English-language TV drama, in Chapter 9.

In comparison to the Hollywood TV drama chain, there appear to be numerous other differences in the Canadian chain, which demonstrate that the imperative for financial results in the Canadian chain is not a clear path. The reason for the "plus plus" signs in Figure 3.2 is to highlight the mixed function of both the broadcaster and of the public funding, the interests of which may extend to various types of equity investments, under various conditions. Such interests include a Super Licence in the Terms of 
Trade agreement, which may involve such rights additional to conventional TV, such as online, games, and merchandise. However, a Super Licence may not extend to any rights outside of Canada (CMPA, 2011).

There is another type of "fuzzy linkage" (Christensen et al., 2001, p. 10) in the distribution phase of the Canadian English language TV drama value chain. This weak link is the potential of international distribution to ripple backwards, so as to increase pressure for creative excellence, in the development phase. As previously noted, and as shown in Appendix U, an international distributor can deliver up to $30 \%$ of the budget for a Canadian English-language prime time TV drama. Currently, only about forty percent of these dramas appear to be distributed to Canadian distribution companies, mostly by one company, Entertainment One, information publically available on the Internet. A recent venture, Elevation Pictures, was founded in 2013 by an ex-employee of Entertainment One, saying "there is tremendous opportunity in the Canadian landscape" (Punter, 2013, para. 6). However, because distribution investments do not appear to be well integrated into the current design of the development phase of the value chain, the relationship of such investment, in Canada, to a pressure for development excellence seems unclear. Moreover, other prominent Canadian distribution companies, such as Nelvana and DHX Media Ltd., while they are leading global producers and distributors of children's and family content, do not appear to distribute prime time drama.

In addition to seemingly limited national industrial capability for international distribution of Canadian English-language prime time TV drama, some history of broadcasting's acquisition of production and distribution firms may be another inhibiting factor to the appeal of vertical integration, with respect to Canadian English-language TV drama. Fireworks Entertainment was purchased by Global TV in 2003 (Tillson, 2003), and later resold to a British distribution company. A few years later, Canwest acquired Alliance Atlantis (Friend, 2007), but mostly for its specialty cable channels; the distribution wing was later sold to a non-broadcasting distributor (personal communication, June 26, 2015). However, both these acquisitions pre-date the current, global TV disruption of linear broadcasting. Given a goal to adjust the Canadian English-language TV drama value chain, so as to deliver a robust content model for the online era, perhaps such vertically integrated capabilities are worth re-examination. This appears to underscore an important observation in VCE that value chain evolution theory helps identify which capabilities should be vertically integrated, and which should be outsourced, when a sector is facing market disruption (Christensen et al., 2013).

However, adjustments to the Canadian English-language TV drama value chain need not be solely purposed to convert existing legacy broadcasters into vertically integrated TV content studios, or to require incumbents to add studio capability. What appears to be most important is that whatever entity invests in TV drama development must undertake real financial risk in the development phase, 
which implies a need to commercialize the asset in the distribution phase, with a daunting probability of failure. This observation underscores a co-dependence between development and distribution, which this research suggests may be critical to strengthening the development phase of TV drama.

Also factoring into the distribution phase of the value chain is that, in the allocation of public funds to Canadian English-language TV drama, there has been an increasing focus on market share. Domestic popularity implicitly comprises aspects of three of five metrics, deployed by CMF to formulate annual allocations of public funding, which are accessed by broadcasters on behalf of producers, in the form of annual envelopes (CMF, n.d., Performance Envelopes). The three metrics related to popularity include historic performance, audience success in Total Hours Tuned (THT), audience success in Original First Run (OFR). Two other factors, used to determine broadcaster funding envelopes, are regional production licences and digital media investment, which appears to be a non-repayable public investment (CMF, n.d., Performance Envelopes). The envelopes provide indirect pressure on audience performance, as they are a formula used to relatively rank allocations, but do not determine a broadcaster's right to access public funds. Moreover, it could be argued that U.S. audience metrics might be factored into the audience results calculated by the CMF, since these programs are explicitly competing in with Hollywood TV drama, and are often pre-sold to U.S. networks. A more aggressive, and possibly algorithmic, assessment of audience results, by CMF, might lead to deeper insight about what long-term factors might have been inhibiting market performance of Canadian English-language prime time TV drama, and how to improve it.

A corollary observation to the analysis of CMF reportage is that it might be argued that the lack of a strong financial imperative has inhibited the formation of an ongoing feedback loop, into an upward virtuous circle, which implies incremental innovation: "learning is the result of a trial, feedback, and evaluation process" (Karlsson \& Picard, 2012, p. 11). If the need to succeed were more unforgiving in the Canadian TV drama value chain, this might organically result in value chain adjustments necessary to improve market performance. In this respect, the records of early cancellations by U.S. networks, to which broadcast licences were pre-sold, might be examined. For example, Working the Engels was cancelled by NBC after five episodes (Gelman, 2014). Combat Hospital was cancelled by ABC after one season (TV Series Finale, 2012). Saving Hope was cancelled by NBC after one season (TV Series Finale, 2014). Of course, very many Hollywood TV series are cancelled, and the risk of success in this elite genre, premium TV drama, is extreme. However, the point is that, by missing an inexorable need for hits, such as exists in the Hollywood system, the Canadian English-language, prime time TV drama sector may have been shielded from a need to "apportion risk and uncertainty to different institutions" (Potts, Cunningham, Hartley, \& Ormerod, 2008, p. 180) because successful management of today's creative sectors mean an "ongoing challenge 
to adapt institutions" (Potts et al., p. 180). As will be elaborated in the field research, Chapters 5-8, informants in this study commented passionately on the negative impact on development, in a value chain wherein the first phase of the chain is weakly linked to a need for market performance. The value migration framework, introduced above, in Section 3.2, may suggest further gravitas to an observation that insulating Canadian broadcasters from market realities, while successfully protecting a long-term business model may have inadvertently created a resistance to change:

As an organization grows and becomes more successful in the value-inflow stage ... customers move from center stage to the periphery as management turns its attention to fine-tuning its successful business design. ... In other words, institutional memory is built. ... Although customers begin defecting, opting for new business designs, warning signals from the marketplace rarely penetrate an organization's protective layers. And if they do, they are met with denial. ... The organization's ability to move is lowest at precisely the moment when the need to move is greatest. (Slywotzky, 1996, p. 17)

A closing observation on the distribution phase of the Canadian English-language TV drama value chain, is that distribution strength in this sector has been built by strategically deploying two of the 3Ps, population and proximity. In this respect, the business model of private Canadian broadcasters, as distributors of Hollywood hits, is nearly indistinguishable from that of U.S. broadcasters in all of the 210 U.S. markets, with the exception that all of Canada is aggregated into one market, a function of a need to aggregate Canada's small population centres. The difference is, of course, regional U.S. broadcasters are not obligated to contribute a portion of their revenues towards original content, and to play a substantial role in the governance of such content.

In concluding this section comparing the distribution phase of the Hollywood and the Canadian TV drama value chains, many differences have been identified. As well, many underlying factors, discussed in Chapter 2, affect the distribution phase of Canadian English-language prime time TV drama, and as will be seen, ripple backwards to impact the development phase. These include, but may not be limited to, such factors as the current interpretation of the Broadcasting Act's requirement for a supply of Canadian content; the benefit of simultaneous substitution, balanced by the cost of Canadian content; the horizontal integration of Canadian media companies, which mutes a need for linear broadcasting profits; interpretation of audience results; a Terms of Trade agreement which appears to have discouraged acquisition of international rights; and limited firm capability for international distribution, even if such rights were to be acquired. All these factors appear to complicate the task of adjusting the value chain for Canadian English-language prime time TV drama, such that a robust content business model, designed to capture migrating value, might result.

\subsubsection{Manufacturing phase of Canadian TV drama value chain: World-class}

The central phase of a linear progression from creation to monetization is the production phase of 
the TV drama value chain. As in many industries, it begins when R\&D has been completed. In this dissertation, the production phase will include both pre-production and post-production. The production phase will be said to end upon delivery of the product, and its acceptance for distribution. Screen production is a world-class, Canadian industry capability, but relative to the development and distribution phases, it is a stand-alone segment of the Canadian English-language TV drama value chain. It is shown below, in Figure 3.3.

The competitive set of the Canadian English-language TV drama production phase might be characterized as part of a globally dispersed, B2B supply-demand competition for screen production manufacturing. This robust business arena has been well studied, and is said to be comprised of more than 200 hundred jurisdictions in North America, and globally, which vie for valuable below-the-line screen production business, which was estimated, in 2005, at nearly 3 billion dollars (Elmer \& Gasher, 2005; Elmer et al., 2010; Goodmans, 2012; Gornostaeva \& Brunet, 2009; Tinic, 2005). Competing successfully for screen production business requires cluster capability that includes both infrastructure and a specialized labour pool. This highly-skilled and semi-skilled work has been described as an “international division of cultural labour" (Miller et al., 2005, p. 111). This is in reference to the idea that Hollywood has remained the design, $R \& D$ center of this global value chain, where most of the above-the-line decisions are made, and where the financial and creative components of a production are assembled, i.e. the development phase of the value chain.

The Canadian TV industry, including English and French languages, has achieved elite status in screen production. The total of TV and film production volume in Canada is estimated at about \$6 billion dollars. About half is attributed to Canadian content productions, and about $\$ 2$ billion to service productions, which do not count as Canadian content. The remainder of the productions are in-house broadcaster productions, and as such, do not comprise part of the independent production sector (CMPA, 2015).

Canada has three strong production clusters. The two main English-language production centres, Toronto and Vancouver, rank third and fourth, after Los Angeles and New York City (ACTRA, 2013). Three provinces, Ontario, Quebec, and British Columbia account for more than $90 \%$ of the production volume (CMPA, 2015; OMDC, 2014). Ontario, with about half of the 125,000 jobs in the sector, specializes in Canadian content production. Quebec specializes in French content, with about a third of the national business, and British Columbia attracts many Hollywood productions, which accounts for an additional $13 \%$. The remaining $10 \%$ is spread out among the provinces, including production centers in Nova Scotia, about 3\%; Alberta, about 2\%, and 1\% or less in Newfoundland/Labrador, Manitoba, Saskatchewan, New Brunswick and Prince Edward Island (CMPA, 2015). 
The competitive set for the TV drama production phase is represented in Figure 3.3 below. Two intersecting circles with Canadian English-language TV drama describe industrial intersections which synergize and embolden the Canadian TV production community, forming a virtuous circle of excellence, which was sustained, in Canada, even through a period of par CAD-USD, 2009-2014 (Canadian Forex, 2015). One circle represents the way that labour in the production phase, including both Canadian productions and service productions, connects to and intersects with competitive expertise and incentives in numerous jurisdictions competing for TV production business. In Vancouver especially, the presence of highly skilled below-the-line labour from Hollywood, on highbudget blockbusters, is acknowledged to have helped upgrade the Canadian production labour pool (Elmer \& Gasher, 2005; Tinic, 2005). A second circle strengthens the sector by connecting to and intersecting with skilled, below-the-line jobs in other screen media, including film, digital content, games, children's, news, documentary, sports, and advertising.

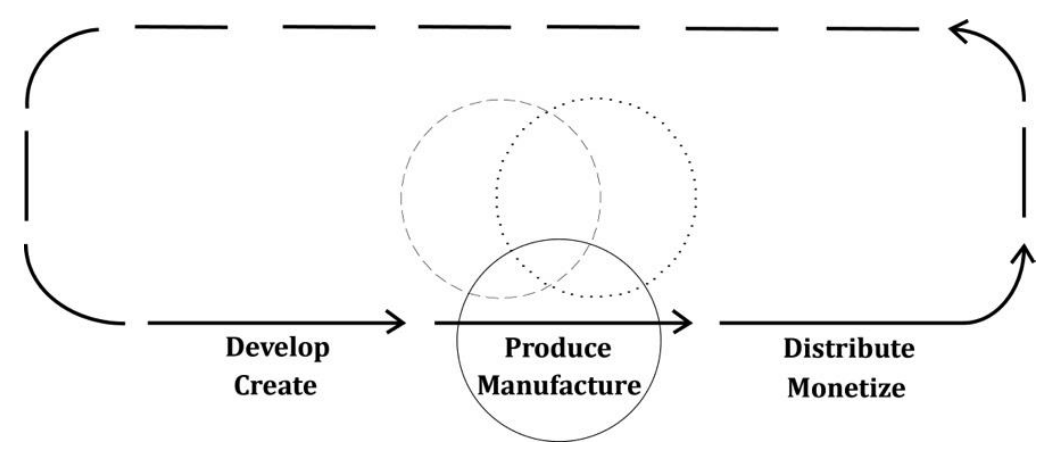

Figure 3.3. Canada: TV drama value chain, production phase.

There are two important observations regarding the production phase of the value chain. Similarly to the distribution phase, a reason for Canadian strength in TV drama production is Canada's relationship to the U.S., including two of the 3Ps: proximity and skill portability. For example, shared language, timezones, and common business practices helped make Vancouver an attractive alternative for high-budget feature films, which delivered money, skill spillover, and infrastructure into the area, helping to further strengthen Canadian screen administrative processes and crew capabilities, which evolved into an upward circle of excellence in TV and film production. Due to its proximity to the major financiers, Toronto became the site of most of the Canadian content drama production, which allowed for ready coordination with Hollywood partners to closer deals. With portability easy between the three centres of production, they function as a triumvirate of production capability, more than $90 \%$ of all film and television production in Canada (CMPA, 2015). The first take-away, for the production phase of Canadian Englishlanguage TV drama, is that domestic strength in production, similarly to distribution, has been built by 
exploiting Canada's unique geographic and cultural linkages with the U.S., and have made Canada into a world-class destination for screen-based production. In the case of production, these two connections to the U.S. have been the two Ps of geographic proximity and skill portability.

A second observation has compelling implications for this dissertation, which is primarily focused on the development phase. As revealed by this value chain analysis, supported by the review of reportage on the industry, in Section 2.3, and overwhelmingly confirmed by informants' frustration, elaborated in Chapters 5-8, the Canadian TV drama value chain tends to fade out at the conclusion of the production phase. Assessments are reported at the conclusion of phase 2, which tend to prioritize dollars invested and jobs created (CMPA, 2015; CRTC, 2014). These supply metrics tend to mute an imperative for popularity of the product, which, over decades, has remained at $10 \%$ domestically, and has also not achieved compelling record of global popularity.

While the production sector remains a strong centre of excellence, as a result of decades of policy and industry focus, concentration on building expertise in the middle of the chain appears to have caused an unintended consequence: weak development. The development phase, of the Canadian Englishlanguage TV drama value chain will be the focus of the next section, and the remainder of this dissertation.

\subsubsection{Development phase of Canadian TV drama: Warped}

The development phase of TV drama, as previously defined, is the phase from the moment of the first conceptual pitch to a financier, whether idea, treatment, or completed script, until the first moment of pre-production. This initial phase of the value chain is the IP creation phase; the D in R\&D. The competitive pressure of working in a oligopsony, wherein there are many more sellers than buyers of creative services, even in Hollywood, has been explored, in Chapter 2, as a key feature of a risky career TV drama development (Bielby \& Bielby, 2003; Davis \& Kaye, 2010; De Vany, 2004; Gitlin, 2000; Grant \& Wood, 2004; Scott, 2005).

The broad strokes of development of TV drama are similar in Hollywood and Canada. Chiefly, this work is characterized by extreme risk, both financial and creative, and a tight clustering of its workers. Successful development requires the following essential elements: (a) secured financing; (b) approved lead writer or showrunner; (c) an approved script (or scripts) for production, as stipulated by the financier; and (d) confirmation of lead actors. The conclusion of the development phase of the TV drama project is signaled by approval for pre-production. As explored in Chapter 2, the quintessential, global centre of TV drama development is Hollywood, while Canadian creatives appear to position Canada as a peripheral cluster for development. In the case of Canadian dramas with U.S. studio financing partners, the Canadian English-language TV drama value chain exhibits characteristics of a quasi-hierarchical global value chain, with many capabilities in this phase, financial and creative, connected to Hollywood. 
As noted, development might be characterized as distribution agnostic, because, in the online era, value increasingly resides in the direct lure of the program, rather than how the content gets to a screen. As such, the enduring processes of development — taking pitches from creators, selecting projects, developing and re-writing scripts - may render development, while a difficult cluster upgrading, achievable, because it is not so rapidly evolving. Popular TV drama is above all, writer-driven: "It wasn't a fluke our show was great. It had a great script" (Respondent, CEO, Canadian TV drama firm).

An observation is that strategies for developing Canadian English-language prime time TV drama development, unlike those in either the distribution or production phase, have not yet exploited potential strength in Canada's unique relationship with the U.S., and specifically in the case of development, with Hollywood. Two of the 3Ps, geo-cultural proximity and skill portability appear to suggest that Canada might deploy these factors to upgrade to unique competitive advantage in English-language TV drama, while continued focus on production and distribution may potentially leave the system vulnerable to digital shift "and it may be too late the extant structure to build a national reputation for global hits" (Berkowitz, 2014a, p. 17).

There is another value chain observation to be made, regarding the development phase of Canadian English-language TV drama. This observation turns on a comparison of the case of Hollywood versus Canadian TV drama, and the way that value is defined in each cluster. For clarity, the two value chains are reproduced below, as Figures 3.4 and 3.5. It was clear, in the field research, that in Hollywood, the development phase is characterized by financial pressure from the first pitch in the development phase. This observation is that ever-present financial risk appears to imbue creative development with urgency and importance. During Hollywood development, failure, and its consequences, loom as very likely. In Hollywood, the financial partners, which include, at minimum, a broadcaster (domestic monetization), a studio (global monetization), and the creators, are well aligned in the development process, in a mutual need to succeed: "Development is where a show is made or lost. It's always the creative process that makes or breaks the value" (Respondent, CEO, Canadian TV drama firm).

In comparison, the Canadian development process has been described as "pretend" and "a bridge to nowhere" (Respondent, Canadian, A-list Hollywood showrunner). While creative elements are assembled via established practices, the exercise was reported to lack the organizing principle of well-aligned financial partners who undertake great risk to create a TV drama which must become popular, and as such, drive monetization. In Hollywood, careers and companies may be jeopardized if development fails.

As seen in Figures 3.4 and 3.5 below, compared to the clean alignment of vested interests in the Hollywood chain, in a relentless push towards monetization, Canadian financial interests in the development phase are poorly aligned, with players in the chain having various priorities. The broadcaster, as the primary gatekeeper in the current system, substantially completes its obligation in 
development, by committing a licence fee in fulfillment of CPE, perhaps the higher the better, given that the broadcaster's licence obligation is to achieve the 30\% CPE. Public funds are dispensed in production, and substantive metrics, including volume of shows, jobs, and investments, are assessed at the conclusion of phase 2. Financial risk is undertaken by the creator/executive production company, and is moderated by repayment of expenses if the project is greenlit. Authentic risk, with little safety net for failure to achieve popularity, is mostly undertaken by the studio/distributor. Conflicting goals in the development phase, also observed by the informants, are a finding of this value chain analysis. The impact of poorly aligned financial interests, especially regarding the gatekeeper to most of the financing (i.e., the Canadian broadcaster) who appears to have a muted corporate stake in the outcome of the endeavor, other than to maintain a broadcast licence, is proposed as a reason for weakness in the development phase of the Canadian TV drama value chain.

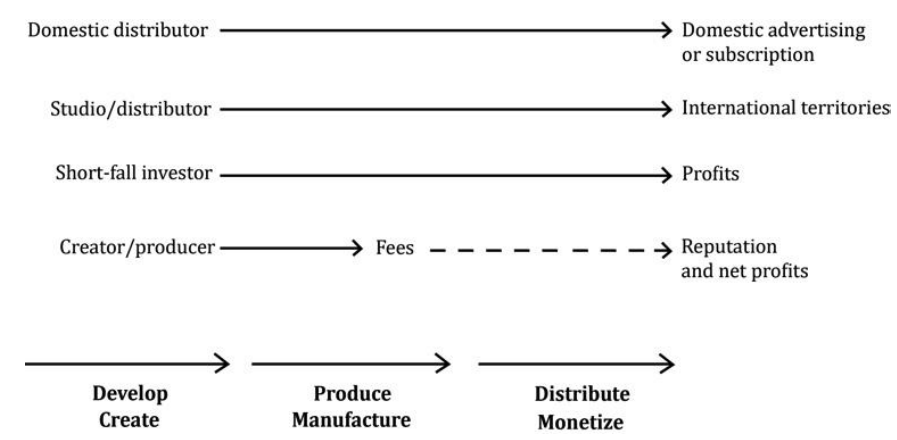

Figure 3.4. Hollywood: TV drama value chain, alignment of financial interests, development phase.

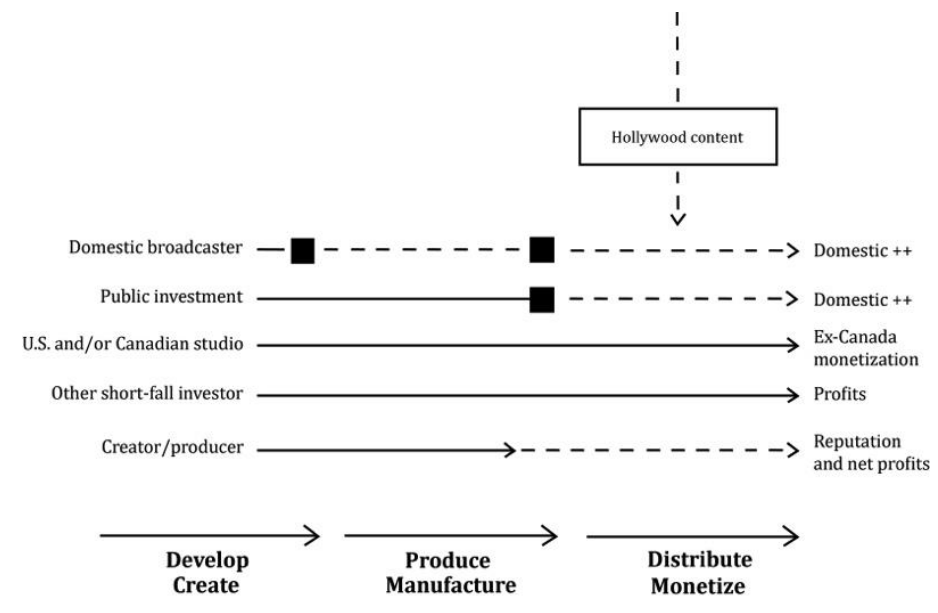

Figure 3.5. Canada: English-language TV drama value chain, alignment of financial interests, development phase.

Following the money led to the above analysis of the development phase of Canadian Englishlanguage TV drama. The analysis suggests that, absent an imperative for financial success in the distribution phase, it appears that an unintended consequence has been to compromise optimization of 
creative elements in the development phase. As will be made clear in the field research, it appears that financial elements, even in development, may be determinants of creative elements.

\subsection{Reframing local-global linkages in Canadian TV drama: Follow the money}

As discussed above, a close reading of the Canadian TV drama chain reveals that weakness in creative development appears to be driven by poor alignment of financially vested interests in the development phase. This section will extend these observations to reframe the importance of local-global (Canada-Hollywood) linkages in the market outcome of Canadian English-language TV drama.

The presence of Canadian creators in Hollywood has been established (Section 2.3.4). Moreover, the case of Canadian English-language TV drama has proved to be readily applicable to the vibrant debate regarding the role of local-global linkages in cluster upgrading (Section 2.6). While there seems little doubt that a regime of systematic local-global linkages may be required to capture the value of Canada's talented creators, who have sought career acceleration in Hollywood, applying a value chain evolution perspective suggests a reframing of how these creative linkages might be achieved. The value chain analysis suggests that strategies to link Canada's TV development cluster with Hollywood creators might be reframed as a determinant of an overall financial need, or not, to monetize the asset being created. Therefore, a dual approach to local-global linkages is theorized, a need for linkages with creators and another need, for financial linkages, which is a more nuanced observation of the value chain.

Creative linkages may be the easier challenge. If Canadian gatekeepers and financiers of Canadian TV dramas had an inexorable need to succeed in monetizing Canadian English-language TV drama, it seems possible that strategic R\&D investments might be made, similar to those in the other businesses of the large media companies, for example, in upgrading wireless and broadband services. Compared to the cost of cell towers and fiber optics, the cost of an A-list Hollywood writer, on the order of a few hundred thousand dollars, might be relatively affordable $R \& D$, presuming a necessity to commercialize.

Moreover, there is another type of local-global linkage, a financial linkage, which might be a competitive advantage that could potentially benefit the Canadian TV drama sector. As will be underscored in the field study, it seems common for Canadian co-venture producers to seek financing from a Hollywood-based studio, in exchange for the right to exploit the project in the U.S. and other territories. By following this money, it might be inferred that substantial sums of Canadian public monies may be inadvertently deployed to strengthen Hollywood studios, because these financiers would benefit from any international monetization of the asset, outside of Canada. A logical alternative might be for the system's gatekeepers, the Canadian networks, to take a pro-active presence Hollywood, at minimum to actively participate in overseeing the Canadian portion of the investment. As yet, the potential for Canadian networks to align their interests with Canadian TV drama producers, with active presence in 
Hollywood's complex deal-making and creative development cluster does not appear to have been explored. Moreover, this relatively inexpensive strategy would appear to align with the current climate of Canada-California trade, promoted by the Canadian government, as discussed in Section 3.1.

As will be seen in the field research, Canadian TV networks appear to consider themselves outsiders to the Hollywood-centered, Canadian TV drama process, to which they are principal gatekeepers and proxy governors of public funding for Canadian English-language premium TV drama. The findings suggest that global disruptions in the TV business have collided with a systemic fault in the Canadian TV drama chain, resulting in a role reversal of Canadian broadcasters, from strongest to weakest link in the value chain. Close reading of the Canadian TV dram chain leads to an insight that a key weakness in local-global linkages may not be the absence of Hollywood-based, Canadian creators in Canadian TV drama; but rather, it may be Canadian TV networks' absence in Hollywood.

A policy adjustment, suggested by this reframing of local-global linkages, may be to consider detaching Canadian broadcasters from their role as gatekeepers to Canadian TV drama. An additional pathway towards strengthening development might be to adjust the value chain, such that Canadian networks have an overall motivation to succeed in the business of original content, by incentivizing them to vertically integrate TV drama capabilities, and to own the process, R\&D to ROI, as has been done in Hollywood, These suggestions will be integrated, in Chapter 9.2, as a policy tool kit for the online era.

In closing this section on local-global linkages, it seems important to note an implication of the analysis. Canadian broadcasters' annual pilgrimage to Hollywood, for the market known as the upfronts, to purchase Hollywood hits, is well known (Vlessing, 2014, 2015); upwards of \$500 million is expended annually for the rights to broadcast Hollywood TV drama (CRTC, 2014c, 20151). However, this annual journey to Hollywood is purposed to service the part of the distribution value chain, which re-broadcasts Hollywood hits, almost exactly per the business model of regional broadcasters in 210 U.S. TV markets. As discussed, this geographic, linear TV monetization business model is in decline, disrupted by online content delivery. Moreover, temporary presence at the upfronts does not appear to benefit the year-round original content business of Canadian English-language TV prime time drama, wherein these same companies' function as gate-keepers to the system, and provide proxy governance of substantive public funds which contribute to development. In a business sector, where making and taking meetings has always been paramount, and given rapid transformations, which suggest the importance of physical presence in the cluster may be more important than ever before, the Canadian networks appear to forego an easily achieved link with Hollywood, a simply staffed development office in Hollywood. Canadian networks appear to be forfeiting the non-substitutable affordances, of buzz and pipeline knowledge spillovers, which might be gained by presence in Hollywood, the global hot spot for English-language prime time TV drama development. 
While currently, Canadian prime time drama broadcasters, including Bell Media, Rogers Media, and Shaw Media do not appear to maintain year-round offices in Hollywood, some English-language international broadcasters do. A very informal Internet search yielded Los Angeles offices for U.K. broadcasters BBC and ITV, both of which are vertically integrated TV drama producers. Australian broadcasters Seven, Nine, and Ten also have Los Angeles offices. ${ }^{22}$ This is neither an exhaustive or formal search, merely a superficial indication of a possibly different assessment of the Hollywood TV drama game, assuming there's a will to win it.

\subsection{Chapter summary}

The value chain analysis of Canadian English-language TV drama in this chapter might be summarized to observe that it has been well built to prioritize national profits on global (i.e., Hollywood) content, and this structure has worked well enough, through the 20th century, and has resulted in a worldclass production cluster and a robust distribution sector, modeled on rebroadcasting Hollywood hits, similarly to the U.S regional TV markets. However, the value chain has not been effective to deliver global profits on Canadian content. For the online era, a robust content model may be important.

This chapter has proposed four new reframings of the Canadian English-language TV drama sector. Section 3.1 reframed the Canada-U.S. Relationship as 3Ps, identifying that the characteristics of population, proximity, and portability impact the Canadian English-language TV drama chain in all three phases: development, production, and distribution. Section 3.2 proposed a formula for media value, as $\mathrm{T}$ $=\mathrm{A}=\mathrm{MC}^{2}=\$ \$ \$$, extending the earlier discussion that measurable popularity is the determinant of $\mathrm{TV}$ drama quality. Section 3.3 theorized the TV drama value chain as development-production-distribution, characterized by a weak link to monetization and poor alignment of vested interests in the development phase. Section 3.4 re-framed local-global creative linkages as a determinant of financial elements in development. Overall, while phases 2 and 3, production and distribution, of the value chain have been successfully strengthened via Canadian regulatory and policy frameworks which have deployed strategic use of the 3Ps, phase 1, development, remains largely unaddressed by policy. Yet, development is increasingly, the site of value creation.

The value chain theorization in this chapter leads to new insights regarding the role of the Hollywood cluster in the GVC of Canadian English-language TV drama and appears to suggest the advisability of policy innovation for the online TV drama era. It seems a given, that no public policy can force any company, including Canada's large media conglomerates, into any new business arena, and certainly not a high risk enterprise, such as the TV studio business, which entails the creation of scripted content for the purpose of global commercialization. A valuable approach may be to adjust the Canadian

${ }^{22}$ BBC: 10351 Santa Monica Blvd. ITV: 15303 Ventura Blvd. Australia Channel Seven: 10100 Santa Monica Blvd. Channel Nine: 6255 Sunset Blvd. Channel Ten: 3440 Motor Ave. 
TV drama value chain by introducing incentives and rewards as policy levers. This approach may imply the efficacy of an overall policy shift from sticks to carrots. Stronger market outcomes for Canadian English-language TV drama might be incentivized with new types of controls over levels of access to public funds. Chapter 9.2 will integrate the theoretical findings in this chapter with those of the field study, as reported in the next chapters, and elaborate a set of policy recommendations for Canadian English-language premium TV drama in the online era.

In closing this theoretical analysis, the stage is set for the field research in Chapters 5-8, a close examination of development dynamics in Canada and Hollywood, from the perspective of elite Canadian development workers with experience in Canada and the U.S. The insights to be revealed in the coming chapters, deliver deeper, and more intimate, insight on the largely hidden, little studied arena of Canadian English-language, prime time TV drama development. 


\section{CHAPTER 4}

\section{METHODOLOGY OF THE FIELD RESEARCH}

If you want to understand where the entertainment business is going, get to the people who control it. Numbers and trends are a less important story in a business dominated by personalities. I knew I had to get face-to-face or least phone-to-phone with the top broadcasters, advertisers and studio executives and understand their points of view. (Wolf, 1999, p. 102)

\subsection{Introduction}

As set forth in Chapter 1, this field study takes a mid-level perspective, with the goal to produce nuanced insight from an organic, qualitative approach. The goal of the field study was to uncover dynamics in the case of the previously unexplored arena of the development phase of prime time, Canadian English-language TV drama. It stayed authentic by focusing on the perspectives of on-theground TV drama development practitioners, informants who had been rarely studied. Perhaps this partly explains why informants were remarkably generous with their time and thoughts, but another reason may be the rapidly transforming realities of their already risky business arena.

From a personal perspective, as will be seen in upcoming chapters, the informants' generousity, with time and spirit, is reflected in the breadth and depth of their passionate contemplation of development issues, and as well, their sense of urgency regarding the way forward for Canadian Englishlanguage TV drama. Unexpectedly, the subject of discussion was clearly a priority to participants.

The choice of a case study, for the purposes of policy research, conforms to the parameters of a "rich, empirical description of particular instances of a phenomenon" (Eisenhardt, 2007, p. 25). In Chapter 3, it was seen that the data's compelling "patterns of relationships... and their underlying logical arguments" (Eisenhardt, 2007, p. 25) led to the choice of value chain analysis as the theoretical construct. It is acknowledged that a "staggering volume of rich data" in case studies may involve a risk that the researcher will not be able to "assess which are the most important relationships" (Eisenhardt, 1989, p. 547), a phenomenon also labeled "data asphyxiation" (Pettigrew, 1990, p. 281). A goal, in this study, was that deep immersion in the field data, might empower a clarity, which would be "capturing the complexities of the real world, then making sense of it (Pettigrew, p. 281). It is said that strong interview data "goes beyond chronology to develop analytic themes" (Pettigrew, p. 3); this too, reflects the approach taken in reporting findings, Chapters 5-8, which are presented according to thematic topics.

The field research was conducted February-July, 2014. Several dynamics link development practices in Canadian TV drama with those in the Hollywood cluster: the visible presence of Canadian creators in Hollywood; the fact that Canadian TV dramas compete for prime time slots on U.S. network schedules; and the trend towards online TV delivery, which has increased the number of competitors for creative and financial services in Hollywood, which appears to translate to new potential opportunity for 
upgrading the Canadian English-language TV drama development phase. In consideration of these factors, the approach was to compare development dynamics in Canada with development dynamics in Hollywood, seen through the eyes of Canadian creators.

Informants were chosen for elite status in three categories of development stakeholders:

1. Creators, most of whom trained in Canada, mostly A list showrunners;

2. High-ranking executives of award-winning Canadian English-language TV drama firms, mostly CEO's, whose firms maintain offices in Toronto and Hollywood, and all of whom have developed and produced TV drama series, broadcast on Canadian and U.S. networks;

3. Development executives in Canada and Hollywood, all of whom have experience managing Canadian English-language TV drama productions;

From a methodological perspective, the three categories above appeared to meet four criteria, which have been proposed as helpful in avoiding interviewer bias (Pettigrew, 1990, p. 275):

1. Informants are "polar types" which can be triangulated as seller/creator; buyer \& seller/TV drama CEO's, and buyers/development executives;

2. Informants are elite professionals with "high experience";

3. The background context is an "extreme situation," i.e., unprecedented disruption of the global TV industry;

4. The interviews were conducted in "key locales" for Canadian English-language prime time TV drama development, i.e., Toronto and Los Angeles.

The resultant field process was a "constant juxtaposition of conflicting realities" a case study process, which has been assessed as having a potential to "unfreeze' thinking" and thus, contribute to an ability to "generate theory with less researcher bias" (Eisenhardt, 1989, p. 546).

The field study adhered to established administrative processes for qualitative research. Sampling followed a snowball methodology, where a few key contacts led to deeper penetration of a relatively hidden, well-guarded group of informants. Data analysis methodology followed an iterative categorization model, helped by the use of NVivo software, a common software analytics used for policy research, which promotes its use value as follows:

Government agencies use NVivo to deliver evidence-based findings and shape policy. Businesses use NVivo in pilot studies, program evaluation and to inform decision-making. Academics use NVivo to produce rigorous research. (Products, n.d., para. 1)

The result of the field research was a large cache of data, more than 600 pages of transcribed interviews. The following sections of this chapter describe the sampling methodology (Section 4.2); the interview process (Section 4.3); and the data analysis (Section 4.4). The goal of the analysis, as recommended for 
this type of study, was a deep "understanding of a phenomenon" (Hsieh \& Shannon, 2005, p. 1278), in this case, the role of development dynamics in the Canadian English-language premium TV drama.

\subsection{Sampling methodology}

The researcher's TV experience provided two necessary foundations for effective sampling: (a) knowledge of the most effective ways to initiate the research and (b) experience in TV development, which provided credibility with informants, aiding in the probability of interview acceptance.

As noted above, sampling was accomplished with a snowball process (Noy, 2008; Sadler, 2010). The launch had two parts. The preliminary step was attendance at the annual Canadian TV industry conference in February 2014, known as Prime Time Ottawa, ${ }^{23}$ where a number of contacts were initiated. Not only did attendance at this conference ensure an up-to-the-moment understanding of industry trends and issues, the conference attendance was explicitly used to expand contacts and launch the field research, by telling conference participants about the study and asking permission follow up to arrange an interview. The second part of the launch was a preliminary trip to Hollywood for one initial, face to face meeting, which got the snowball rolling. The author's knowledge and credibility became valuable, both as a former head of creative development for original Canadian production for a Canadian network (which included contact with many Canadian creators based in Hollywood) and as an independent producer, having been a client of one the major Hollywood talent agencies, International Creative Management (ICM). Per the snowball process, one face to face meeting led to a series of contacts, as each informant, whether in Toronto or Hollywood, most generously provided further recommendations. Knowledge of Hollywood processes, and unwritten courtesies, were equally essential, as only three informants were personally known by the researcher before the study. It became clear that the high percentage of interview acceptances, $80 \%$, was a result of snowball generated initial contacts, followed by appreciation for the author's insider respect for process, and for accessing informants through Agents, Managers, and Assistants. The launch processes worked well to produce a total of 19 semi-structured, open-ended interviews. Consistent with recommendations on qualitative research (Elo \& Kyngas, 2005), the sample was categorically representative of the universe from which it was drawn, rather than numerically exhaustive. Also as recommended, the field research process concluded when informants' remarks tended to be repetitive, regarding the dynamic being explored.

Each category of informant was comprised, at minimum, of four interviews. Nineteen interviews took place in Toronto and Los Angeles, February-July 2014. Two-thirds were face-to-face; the remainder were conducted via telephone. These semi-structured interviews lasted 45 to 90 minutes.

\footnotetext{
${ }^{23}$ Details of this annual conference, run by the CMPA, can be found at www.primetimeottawa.ca
} 
Informants' level of trust was clearly aided by the researcher's understanding of the substance of their daily work. Moreover, my experience might also add to the credibility of data analysis, said to be connected to a researcher's lengthy immersion in the issues being explored (Hsieh \& Shannon, 2005).

\subsection{Interview methodology}

Before the research began, the author received official clearance from the Ryerson Research Ethics Board (REB), included as Appendix Z. An informant release, in Appendix AA, included approval and signature on a release waiver by every informant, which explained the purpose of the interview to the informant and requested two kinds of permissions: (a) for the interview and (b) for recording the interview, to aid in transcription. All but one informant readily agreed to recording. The signed waivers are in the files of the Researcher and PDFs are saved on Ryerson's dedicated Google Drive. Respondents were randomly assigned alphabetical name-placeholders, which were retained through most drafts. To further protect anonymity, in the final draft, alphabetical placeholders were dropped, leaving informants identified only by their categorical role in the value chain: creator, producer, or development executive.

Out of 23 requests for interviews, only three refused. One refusal bears telling. A Hollywood studio network executive, who manages Canadian TV drama, who confirmed availability, previous to the research trip to L.A., re-scheduled the meeting several times while I was in L.A. which, in my experience, is unusual when traveling to L.A. Subsequent to my L.A. travel, this informant subsequently declined a phone interview several times, giving schedule reasons. The final explanation was the studio's legal department did not grant permission for the interview, which the informant knew would explicitly focus on development of Canadian TV drama. While there is no proof of the real reason for the refusal, deducing from the substance of the existing field research, which is almost universally critical of the state of Canadian TV drama development, this may imply the interviewee did not want to go on record in any way, even anonymously, expressing a critical view of Canadian TV drama development. Given the studio in question, there may have been active and/or nascent partnerships between the studio and Canadian producers.

As recommended for this type of study, when the main data is the interviews, mostly open-ended questions were used (Hsieh \& Shannon, 2005). A general set of questions was prepared to be use as a baseline; questions for each interview were customized, taking into account the role of the informant and expected length of the interview. A sample set of these semi-structured interview questions is included as Appendix BB. The thrust of the interview, after some warm-up discussion, was to uncover development dynamics. For further clarity, and this was made clear to the informants in the initial inquiry for the interview, the purpose was not to profile the careers of any of the informants, nor to probe for any personal or confidential project information about shows in development. This seemed much appreciated, and 
perhaps added to the informants' comfort, because TV drama development is a strictly confidential process. In this respect, the informants' obvious trust in this research process is even more greatly appreciated.

Ten minutes before the end of each interview, each informant was asked to respond to a series of closed-ended questions designed to move the focus of the interview from the present to the future of Canadian English-language TV drama development. These conversation starter policy suggestions were designed by the researcher to potentially strengthen the development phase going forward, but avoid negative impact on the Canadian system's capability in the two other phases of the value chain, production and legacy distribution. Meta-analysis of the data reveals this aspect of the research had dual value. In addition to providing the basis for strategic recommendations, including some which appear to be reflected in the Let's Talk TV decision of March 12, 2015, ${ }^{24}$ the request for informants to provide specific suggestions seemed to help them dig most deeply, and most candidly, into their own views on how to future-proof the Canadian TV drama sector for the 21st century. The results of this part of the research are reviewed in Chapter 8.

\subsection{Data analysis methodology}

The methodology of analysis was inductive, qualitative content analysis, an acknowledged method of analyzing written or verbal communication (Elo \& Kyngas, 2005), in keeping with the goal of all content analysis to "provide knowledge and understanding of the phenomenon under study" (Hsieh \& Shannon, 2005, p. 1278). This methodology is said to offer researchers a flexible, pragmatic method to develop and extend knowledge (Hsieh \& Shannon, 2005). Qualitative content analysis was selected as the best type of content analysis because it is "a research method for making replicable and valid references from data, with the purpose of providing knowledge, new insights, and practical guide to action" (Elo \& Kyngas, 2008, p. 107). Qualitative content analysis was assessed to have the most applicability to designing actionable industry and policy strategies for the Canadian English-language TV drama sector. Content analysis can be deductive or inductive; this study used inductive analysis, recommended in cases when there are none, or few previous studies dealing with the phenomenon being explored (Elo \& Kyngas, 2008).

Another advantage of qualitative content analysis is that it allows a researcher to explore the feasibility of new theories and/or theoretical approaches to an issue (Elo \& Kyngas, 2008). This is exactly what was done at the end of each interview, when informants were asked to respond to specific policy and industrial strategies to strengthen development, which had stemmed from a preliminary value chain analysis of the TV drama sector.

The data analysis process in this type of study involves categorical coding, defined as "a research method for the subjective interpretation of text data through systemic classification process of coding and

\footnotetext{
${ }^{24}$ For example, para. 128 of CRTC $2015-86$ sets out a new pilot project, with a relaxed point system for Canadian English-language TV drama, which appears to reflect the principals in my LEAF strategy, as detailed in Chapter 8.
} 
identifying themes or patterns" (Hsieh \& Shannon, 2005, pp. 1277-1278). There are three potential approaches for coding:

1. Conventional: coding is derived from the text data;

2. Directed: tests informants' responses against existing research or an established theory;

3. Summative: characterized by the more commonly referenced word-counting process.

This study fits well within the conventional approach, which allows categories to flow from the data, and is considered effective when there is little existing theory or research on a phenomenon. The process is that the researcher immerses herself in the data and allows new insights to emerge (Hsieh \& Shannon, 2005). The findings of this type of qualitative content analysis go beyond "merely counting words;" rather, the purpose is to closely examine language to reveal concepts, meanings, and insights into arenas which are poorly understood (Hseih \& Shannon, 2005).

Furthermore, in this type of research, it is acknowledged that the most suitable unit of analysis is the whole interview. As such, the following recommended steps were used as a preliminary approach to the cache of data (Elo \& Kyngas, 2008; Hsieh \& Shannon, 2005):

1. Read each transcript twice, first similarly to reading a novel, taking few notes.

2. On second reading, highlight important concepts and identify preliminary codes.

3. After reading three or four transcripts (randomized by alphabetical order), decide on a set of preliminary codes.

4. Re-code remaining transcripts, adding new codes whenever new categories or concepts are encountered

5. Examine final codes and organize into hierarchical structure.

The use of NVivo software aided the above steps 2-5. However, in practice, NVivo coding proved to be merely a kick-start for data analysis. The imperative to derive meaningful insights from such a large cache of complex material demanded that the interviews be read many more than the recommended several. Following the NVivo sorting, a succession of category documents was compiled, with topics subsequently divided into large piles, according to possible chapters and sections, printed, re-read and highlighted, reorganized, and so on. The researcher's deep dive into the material yielded deeper and deeper insights, as analysis proceeded. The data analysis could be characterized as a process of increasing intimacy with a huge cache of raw material, which proved to be rich, thick body of text about a complex business dynamic, which was found to be of urgency to the stakeholders. Informants wanted to talk. Some wanted to bare their souls, including highly placed Canadian writers in Hollywood, who got their professional start in Canada, and clearly maintained close emotional ties to home.

Inductive, qualitative content analysis is well purposed to build a conceptual system by which to understand a case, such as the development of Canadian English-language prime time TV drama (Elo \& 
Kyngas, 2008). The data overwhelmingly confirmed the choice to examine the Canadian English-language TV drama sector through a value-chain lens, as presented in Chapter 3. The findings were consistent with descriptions of qualitative case studies, as "highly iterative and tightly linked to data" (Eisenhardt, 1989, p. 532), further described as an approach considered "especially appropriate in new topic areas" (Eisenhardt, 1989, p. 532). Intersecting theory with data enabled this study to extend previous analyses of the Canadian English-language TV drama problem, which had proposed the root of the market performance problem as audience and money. This study was able to reframe these two metrics of market performance as symptomatic of deeper structural issues in a value chain, a business dynamic which has been generally observed (Porter, 1985, 1990). The value chain analysis also led to reframing local-global, CanadaHollywood, linkages as corollary to structural issues in the value chain.

The outcome of the methodology in this dissertation seems consistent with the goal of case study methods and inductive content analysis, which is a rich understanding of a phenomenon, in this case the development dynamics of Canadian English-language premium TV drama (Eisenhardt, 1989, 2007; Hsieh \& Shannon, 2005, Pettigrew, 1990).

\subsection{Chapter summary}

This chapter has described the methodology of the field research. Section 4.0 introduced the field research and provided an overview of the approach. Section 4.1 detailed the methodology for informant sampling and selection. Section 4.2 detailed the interview design. Section 4.3 detailed the methodology employed to approach and analyze data.

Results of this research, reported in Chapters 5-8, are in not intended as quantitative truths. In the tradition of qualitative, interview-based studies, the goal is to shed light on a little-understood arena, and to offer nuanced insight, identify pressing issues, and explore strategies for strengthening the development phase of Canadian English-language premium TV drama. The story is told from the perspective of expert informants who work on its frontlines, such as one informant who said this study was "trail-blazing" (Respondent, Canadian A-list Hollywood showrunner). A goal of this study will be met, if its results are regarded by researchers and policy-makers, as insightful and useful in formulating a policy response for Canadian English-language TV drama, to disruption: "Strong studies are those which present interesting or framebreaking theories ... and are grounded in convincing evidence" (Eisenhardt, 1989, p. 549).

The findings of the field study far exceeded my expectations. Elite informants, who work on the front lines of development, told the truth, as they perceive it. Each expressed well-articulated views on how and why the Canadian English-language TV drama sector must change to meet historic opportunities in the 21st century media ecosystem. These findings are reported in Chapters 5-8, which follow. 


\section{CHAPTER 5}

\section{FINDINGS, PART 1}

\section{HIT CONTENT IS KING:}

\section{ROLE OF DEVELOPMENT IN CANADIAN TV DRAMA VALUE CHAIN}

The development process is so warped and broken. It just doesn't work properly. Here it does. They're so focused; they're on you because they're not going to lose their money. My bridge to nowhere was that there was no way my Canadian show was ever going to go. At the point they were confused, they should have just stopped. Instead they had the money to spend, so they spent it, instead of stopping and saying we can't afford to lose this money. (Respondent, Canadian, A-list Hollywood showrunner)

\subsection{Introduction}

As elaborated in Chapter 4, the field study for this dissertation targeted a largely unexplored, rather hidden business arena, the development phase of English-language Canadian TV drama. Access was granted to top tier professionals; their eagerness to discuss issues facing the Canadian TV drama sector yielded a rich, thick description of current development dynamics. The informants included development experts in three categories; (a) TV drama creators, (b) CEOs of prime time TV drama firms and (c) TV drama development executives. Adding to confidence in the findings is that, within each group, perspectives were remarkably similar, and different from group to group.

This chapter will relate the first part of the story, providing informants' perspective on introductory concepts, which set parameters for a conversation, which always moved to deeper levels. Preliminary insights of the participants organically sorted into five categories, each of which will be explored in the coming sections, comprising the first, of four chapters reporting the informants' story of the development phase of Canadian English-language drama:

5.1 Role of development in the TV drama value chain

5.2 Significance of the Hollywood cluster

5.3 Development dynamics in Canada vs. Hollywood

5.4 The Canadian TV drama brand

5.5 Current challenges in Canadian TV drama development

\subsection{The role of development in the TV drama value chain}

All we care about is making great content. We've risked our company on that over and over again. We're not in the business of making paper clips. It's a content business - it has to be great. If your content is great, you will prevail - but it is still a tough business. (Respondent, CEO Canadian TV drama firm)

Early in each interview, with development defined as the phase in the TV drama value chain from first pitch to first day of principal photography, informants were asked to weigh in on the role of development. These introductory comments function in two important ways: (a) opening questions in the 
interviews served to focus and clarify the topic of discussion, by putting informant and interviewer on the same page; and (b) these comments provide for the reader of this dissertation, an introduction to the TV drama development process from the perspective of insiders, as preparation for the deeper analysis of the development phase, to come.

When asked to weigh in on the role of development in the value chain, there was general consensus among all three groups of informants (writers, producers, development executives). All three groups unquestionably reconfirmed, as studies have suggested (Davis et al., 2012; Nadler et al., 2010; Simonton, 2002), that the development phase of the TV drama chain is where key value is created:

The development process is crucial. (Respondent, CEO, Canadian TV drama firm)

It comes down to the creative. That's when you're creating whatever it is the people are going to watch or buy or sell. (Respondent, Canadian TV network development executive)

Most of the value comes at the front end ... this is also where the most damage can be done. (Respondent, Canadian, A-list Hollywood showrunner)

It is not possible to make a critical or popular hit without quality development. (Respondent, Canadian, A-list Hollywood showrunner)

Moreover, there was consensus that the key element of the development is script development. While numerous other R\&D activities were mentioned as components of the TV drama development phase - including pitching and casting — there was an almost unified perspective this one critical element trumps all others; TV drama is writer-driven:

Development is where a show is made or lost. It's always the creative process that makes or breaks the value. First and foremost it starts on the page. It starts with the written word, so it's the development phase for sure. (Respondent, Hollywood studio development executive)

Even at this preliminary phase of the interviews, a slight fissure in the perception of development became evident between Canadian network executives and the other two groups of stakeholders, writers and producers. Canadian executives mentioned that from the first moment of development, a major concern is production financing:

When we develop, we are always thinking, how are we going finance these projects, what is the structure going to look like, how are we going to make up a budget that's going to give this project justice, right, do it justice? We're ultimately just looking at a project for its suitability to our schedules, to our shows, to our - to our channels. (Respondent, Canadian TV network development executive)

However, at this point in the analysis, this concern seemed reasonable, given the role of the network, which includes governance of creative and financial structures, the enormous cost of TV drama, the difficulty of financing such a costly product, and the high risk of monetization failure, even under ideal circumstances. It was only in retroactive consideration of the data that such comments seemed to 
hint at a fundamental flaw in the Canadian system. It gradually became clear that these opening remarks were crumbs on the trail to why, in more than six decades (as noted by an informant, award-winning Canadian TV drama producer), that "Canadian drama has not broken into U.S. prime time," meaning, as yet, there's been no unqualified prime time hit.

When asked about the goal of the development phase, creators and producers framed creative excellence, a great script, as a means to reach the real goal of a wide audience. However, the goal of the script was expressed, not as a great script, but as a huge audience, for which a great script is the key means of achieving this goal. As expressed by creators working at the top tier of the industry in Hollywood, the distribution phase of the chain was perceived as an intrinsic and explicit consideration in the development phase, from the first moment of creation:

Ultimately the only thing that matters in terms of getting a global market is pleasing that market, getting 20 million viewers. And you need to be scared you might fail. (Respondent, Canadian A-list Hollywood showrunner)

Number one is audience. I think about viewing the show, the experience of watching. (Respondent, Canadian, Hollywood showrunner)

Success is defined by renewed. Renewed is defined by getting an audience. (Respondent, CEO, Canadian TV drama firm)

Canadian network executives also noted the role of audience in the development process, but comparatively, the comments lacked urgency: "We try and shape it a little bit based on what we think the audience will find most appealing for whenever the show's intended" (Respondent, Canadian TV network development executive). Aside from the focus on linear broadcast schedule, which seems a dated consideration in the current environment, the sense of "shaping it a little" seems to contrast with the urgency, expressed above, to connect with a wide audience.

It became clear why audience was a top consideration to development stakeholders: money. Two of the three groups (creators and producers) connected creativity with audience and revenue. Audience attention is the bar by which their work would be critically evaluated and financially compensated. Therefore, from the earliest moments of development, these TV drama developers would be judging their own work by its ability to perform as the core element of a hugely risky, hugely costly, yet potentially hugely profitable media product. This responsibility imbues gravitas to the role of development. The perspective of Hollywood-based informants, whether seller or buyer, is that it's not just better to develop a great script; development excellence is perceived as the sole mode of survival in the business. This is even more so in the increasingly competitive "golden age of television," where content competes, at unprecedented levels, for global attention. Creative excellence and financial success are perceived as seamlessly interwoven, by development professionals with Hollywood experience. The inescapable corollary is that the goal of development may not, ultimately, be a creative goal: it is a business goal. 
Success is defined by a hit, which is defined by audience and money. These outcomes cannot strategically be disconnected from the development phase.

The following are some informants' quotes which demonstrate the media wealth formula in action: $\mathrm{T}=\mathrm{A}=\mathrm{MC}^{2}=\$ \$ \$$, from the earliest moments of creative conception:

You need to develop a great product - that's where the asset is created. (Respondent, CEO, Canadian TV drama firm)

The reason people keep making them [hits] is audiences want to see them and when there's a huge hit, it goes into syndication and becomes an even bigger hit monetarily. (Respondent, Canadian, Alist Hollywood showrunner)

I'm leery of magic formulas, but I do believe in the market. ... Let the creatives do what the creative do. It's the only chance you have of creating something truly great, creatively and commercially, by letting a vision go through. (Respondent, Canadian, A-list Hollywood showrunner)

A Hollywood studio development executive who, manages Canadian TV drama, summed up the goal of development by characterizing development as a business dynamic, with talent as the key ingredient: "At the end of the day, this is a talent-driven business" (Respondent, Hollywood studio development executive, [my italics]).

Again, the group, where the link between R\&D and monetization seemed subdued, was the Canadian TV network executives. While their job is to work with Canadian TV drama series, which are Hollywood partnerships, these are the only group of informants who don't regularly work in Hollywood. Perhaps removed from the buzz and pressure for success, which is the Hollywood DNA, their remarks, regarding the goal of development, did not include the intrinsic notion of content as a profitable business. As one informant expressed: "Canadian content is not an ROI business" (Respondent, Canadian TV network development executive). This statement, even considering it is simply a statement of fact, with respect to Canadian TV networks, took on greater significance as the analysis progressed.

\subsection{Role of the Hollywood cluster}

Confirming the review, in Chapter 2, of the long-established dominance of Hollywood as the world's mecca for entertainment development, all categories of informants acknowledged Hollywood's allure, and its central place in the universe of TV drama development:, both creatively and financially:

This is the apex. This is the centre of the universe of creativity. (Respondent, Canadian, A-list Hollywood showrunner)

The myriad of needs. The opportunities. The money. (Respondent, CEO, Canadian TV drama firm)

This is where TV is. It's Hollywood. (Respondent, Canadian, Hollywood showrunner)

Informants used words like epicenter, heartbeat, and cradle. The lure of Hollywood is such that Canadian creators from across Canada told of quitting dependable, professional careers to live 
precariously in the city of Los Angeles, before gaining a foothold in the business, even knowing the new career would never offer security. While they used different words to describe the affordances of buzz, social capital, knowledge spillovers, strong and weak ties, there was a sense the advantage of being there could not be substituted by being anywhere else. Informants who are producers of Canadian Englishlanguage prime time TV drama, also maintain offices in Hollywood, as part of great risk undertaken by this category of stakeholders. Hollywood presence, for these informants, is perceived as a business essential, in order to keep up with rapid creative and financial transformations in the business, and as well, its famous imperative for relationships and on-the-ground, current information, known as taking meetings.

On the creative side, informants agreed; there is no other place where a creative can be subjected to the necessary pressures of the development learning curve:

I'm the only idiot who listens to the commencement day speaker. He said, whatever you're doing, be near the heartbeat. If your company's headquarters are in New York, find a way to get to New York because that's where the action's at. That's where you'll learn the most. For what I wanted to do, it meant being in Los Angeles. Hollywood is where the movies were born. It's the cradle. (Respondent, Canadian, A-list Hollywood showrunner)

To learn what is involved in the development process, it's essential to be in L.A. (Respondent, CEO, Canadian TV drama firm)

A Canadian network executive also acknowledged the role of Hollywood, but voiced an exception to a need for presence there:

It's the epicenter, ground zero for mass market entertainment of all kind in the world. If you can make it there you can make it anywhere. It's intensely competitive but there is incredible opportunity. And it's incredibly lucrative. Our industry is a very different structure. We - our networks - operate very differently. (Respondent, Canadian TV network development executive)

The informants' views on the significance of Hollywood, when coded and sorted, revealed richer significance than was apparent in single interviews; the methodology of qualitative content analysis worked well to provide stepping stones toward deep insight regarding the Canadian English-language TV drama process. A nuanced appreciation of respondents' statements, such as the one above, seemed to suggest Canadian networks perceive their role as outsiders, corporations working on the periphery of the TV drama business. Here, the contrast, between the Canadian networks' annual presence at the upfronts, contrasts to their year-round role as broadcasters who license original programming, but do not maintain ongoing corporate presence in Hollywood, where they might govern their investment, support creators and producers, and innovatively address financial issues in development. As explored in Chapter 2, the affordances of physical presence in knowledge-based clusters have, counter-intuitively, increased in the weightless digital economy. 
The Canadian networks' self-perception as Hollywood outsiders, at this preliminary phase of the interviews, was a clue to unraveling the mystery around sustained weakness in the Canadian, Englishlanguage TV drama value chain. It gradually became clear that a main factor preventing Canadian TV networks from establishing presence in the world's mecca for TV development, is these firms have no need to succeed in the business of original content.

\subsection{Comparing TV drama development in Canada and Hollywood}

Informants who had worked in both systems were asked to compare the development dynamics of Canadian English-language TV drama, as practiced in Hollywood and Canada. Some informants immediately went to financial comparisons, and some focused on creative; most acknowledged the process is not perfect in either cluster. However, a significant difference, which emerged, was that, in Hollywood, development has one goal: to attract a huge audience and deliver profitability. The survival of careers and companies depend on achieving a hit, further confirming the theorization that phase 1 of the value chain, asset creation, is functionally dependent on phase 3, asset monetization.

Development dynamics in Canada appeared to differ in two ways. Firstly, descriptions of development by Canadian TV network representatives tended to be relatively procedural. Secondly, these descriptions did not inherently acknowledge a goal of profitability. The goal to get to phase 2, production, seemed more of a concern. A resultant insight is that development in Canada typically lacks the clarity and urgency of a singular goal of profitability. By contrast, in Hollywood, the risk of not satisfying audience demand looms as an ever-present danger, from the very creative first pitch in the development phase of the value chain.

A Hollywood studio executive, a Canadian, expressed a perspective common to other informants, when comparing development dynamics:

Here the writer is supreme. There the writer is seen as the help. Here it always begins with the writer - what's your idea? It seems to be more common in Canada to be a hired gun for someone else's project that has deal elements. Here you sell an original idea. (Respondent, Hollywood studio executive)

The respondent spoke from the vantage as a buyer of creative services:

Maybe it's because I've been a buyer for a long time, when I hear I a pitch I always see a trailer. Literally, if I don't see the trailer, I won't buy it or I won't do it. What am I seeing? Certainly I did that as a buyer, but even as a seller I think that way. What makes it stand out?

Thirdly, the same respondent also related experience as a content seller in Canada:

On the TV side they were so obsessed with the deal coming before the creative side of it. I don't know how you do that. I met with [Canadian network] people, they just sit there like, you know, like a group of accountants. There was like no creative anything. It's so bizarre for me to see it. 
A close reading of these comments confirms an implicit co-dependence of development and distribution in Hollywood. The respondent's perspective is a key difference in development is that in Hollywood, a need for financial success drives the need for creative excellence:

I thought working in Hollywood would be way more difficult. But, I found it easier to work here, than in Canada, because of the clarity. If you can demonstrate that your idea, your script, your series will get them more than something else, they'll buy it. In Canada, there were bureaucracies to deal with.

Another Canadian producer, also experienced in both clusters, expressed a similar perception of the difference in development dynamics:

Pitching in the U.S. and Canada was like two different universes. To me, it wasn't the same game. It's rigged a different way and the criteria's different. First of all, in Canada it's a much smaller pool, and it's quite incestuous. The rationale for why certain things got made wasn't based on merit and wasn't about taking risk and developing new things. (Respondent, Executive, Canadian TV drama firm)

In the following comment from a U.S. studio executive who works with Canadian productions, the pressure of inexorable connection between creative development and financial results is clearly discernible, as the goal which unifies the value chain from creation to monetization.

I've developed three different [Canadian TV drama series] and noticed a pattern. Passion is so critical when you're talking a creative medium. We talk about this all the time here. ... In the content which has come through the Canadian gateway, the execution was just below par. It starts with the writing and the written word, the development phase. The writing process in particular was, to me, really second rate. We want to ramp up our slate, but without eating away at the integrity of the vision. (Respondent, Hollywood studio development executive)

When asked about how development practices impact market performance of a TV drama, a Canadian TV drama development executive replied with candor. Notice the reason given for why Canadian drama is not a profitable business - the expense and the market size.

It's often very difficult to tell why something doesn't do well. When it does do well, we don't think about it a lot. It's like, "Yay, it's done well." But I would say that Canadian drama original production is not an ROI business because it's incredibly expensive. Of course it's better when they do well than when they don't do well, but it's a very difficult business proposition in a country this size. (Respondent, Canadian TV network development executive)

A follow-up to this informant noted Hollywood TV drama is also expensive to produce, yet ROI from Hollywood TV drama is the very business model which sustains Canadian broadcasting. In responding what might be holding the Canadian system back from delivering a string of global hits to the market place, the informant replied:

We do have lots of global hits. ... I think Canada is the second biggest exporter of television entertainment in the world. For a country our size we're remarkably successful. I think it would be 
incredibly difficult to sustain without subsidies and without the participation of the Canadian Media Fund, you know, which is this remarkable private-public endeavour. It's also very difficult the way our system is structured wherein, you know, if you look at the way an American network-owned studio retains all rights to a show and is able to exploit it around the world and reap the benefits of that revenue, a Canadian broadcaster is not able to do that. (Respondent, Canadian TV network development executive)

This defeatist response seems significant in that it may reflect a three-part, abiding belief system on the part of the Canadian networks. The first belief, which can be summarized as the losing battle, is located in their role as a domestic broadcaster, that is, that Canada's small domestic market renders it impossible to profit from original TV drama, a situation, which, informants noted, is complicated by their payment of a licence fee, which is inflated beyond a geographic/population-based norm, due to their regulatory obligation to spend, and the Terms of Trade, which prevent even a theoretical consideration of international rights. A related dynamic, also rooted in the systemic weakness of the value chain, is the Canadian network's role as a proxy studio, since as gate-keeper and governor public funds, but an entity which does not acquire international rights for monetization. A third belief, seems structurally embedded in positioning the need to finance Canadian English-language TV drama, as a burdensome cost of doing business, one to be minimized. The sum of these beliefs appears to be the Canadian TV networks' assumption of financial failure in phase 3 of the value chain, monetization. As will be elaborated in the foregoing pages, this assumption profoundly impacts the development phase. By contrast, a U.S. studio executive, who works with Canadian TV drama, expressed the development dynamic differently, merging financial and creative goals: "It's a very challenging, tough business and it's only going to get harder and harder. The bottom line is, the goal is, to have financial and creative successes" (Respondent, Hollywood studio executive).

In Canada, the goal of drama development appears to peak at the conclusions of phase two of the value chain, production. While there has been increasing emphasis on audience reception, the system pivots on the dollars invested, the employment created, and the supply of product; these are the essentials, which do not include market success. A Canadian development executive worried about development in a supply-driven value chain:

Sometimes I think, as much as I love the CMF and we need it and we're lucky, are we rewarding mediocrity? It's a mystery to me. Are we too rewarding? If you can do an okay series and get renewed, why would you have to do something brilliant? (Respondent, Canadian TV network development executive)

It will be seen clearly in Chapter 6 that the TV drama problem is not, in any way, attributable to the development executives; their skills and demeanor were often praised by other informants. It will be seen that development issues are rooted in a glitch in the Canadian TV drama value chain, which is characterized by weak linkage between development and distribution. 


\subsection{Canadian TV drama brand}

A number of informants remarked on the reputation of Canadian TV drama. Brand equity is an increasingly debated concept, as many media and non-media entities compete on-screen for consumer attention. As acknowledged, a strong purpose brand resonates not only externally with customers, but also internally, impacting every aspect of decision making within an organization or system (Christensen, Cook \& Hall, 2005). Informants' perceptions of the Canadian TV drama brand are important because they suggest both reputational and internal process attributes. Following are comments on the Canadian TV drama brand, by Canadian creators working in Hollywood and Canadian producers of TV dramas which are broadcast in Canada and the U.S.:

Excuse me, but you know, cheap. Sometimes it's budgetary, but it flows back to the writing that makes it feel like that. (Respondent, Canadian, Hollywood showrunner)

Predominantly, the history has been more of a filler than something you're going to get excited about. ... Americans see Canada as a place for providing them with cheap content. That is the truth. Canada's looked at as the low-cost model. (Respondent, CEO, Canadian TV drama firm)

A simple answer is those shows are viewed as cheap Canadian imports that are okay and we can put them on the air and they will get a small audience. But that is fine because they're paying almost nothing for them and they serve a purpose. (Respondent, Canadian, A-list Hollywood showrunner)

Unfortunately, here there is still the mentality that most Canadian television is shit. (Respondent, Canadian, A-list Hollywood showrunner)

Except for the arena of production capability, in which Canada has a world-class reputation, a Canadian, Hollywood-based showrunner expressed a sense of foreboding, upon learning his series a Canadian co-venture:

When we heard we might be a Canadian co-venture, we were devastated because we saw the quality of the other shows. We thought, oh no, how are we going to make this look great. There are a lot of rules. But, it can be done. Our show looks good; it doesn't look Canadian. (Respondent, Canadian, Hollywood showrunner)

Informants weighed on what it might take to change the Canadian TV drama brand, using phrases like "lightning in a bottle" (Respondent, CEO, Canadian TV drama firm). There was consensus that winning global attention, i.e. a string of successes would be the only way to re-brand Canadian TV drama:

All we need is one show to become a major prime time non-summer show on a U.S. network and everything will change. (Respondent, CEO, Canadian TV drama firm)

What you want up there is not jobs, you want some individual Canadian to create a show in Canada that is respected around the world. And to do that takes one person; it doesn't take a committee. It will be destroyed by a committee. (Respondent, Canadian, A-list Hollywood showrunner) 
A predictable pattern emerged; Canadian network executives did not perceive the problem, in this instance, the Canadian TV drama brand, quite the same way as the other stakeholders:

From a scheduling point of view, they view them as a great price point, why not a new show, instead of a repeat? From a creative point of view, the (Hollywood) executives like exciting new projects. (Respondent, Canadian TV network development executive)

The above comment seems to imply acceptability by the Canadian financier, of the reputation of Canadian drama as a "great price point" summer replacement. Moreover the comment seems somewhat backwards facing, as scheduling matters less and less. Today's audience finds a hit, no matter when or where it's on. Development executives everywhere like "exciting new projects;" yet, in Hollywood, they work under excruciating pressure to develop them into hits.

\subsection{Current challenges in Canadian drama development}

The introductory part of the interviews established common ground on the role of development in TV drama, and compared development in Hollywood and Canada. To close out the introductory section, informants weighed on the currently changing role of development. Many, including Canadian TV network executives, expressed concern that the Canadian system might be unprepared for the era of online TV delivery.

There was consensus among informants that if the Canadian system continues to focus its efforts on strengthening the production phase, the quality of content will not improve, because the quality of the asset is determined in the development phase of the value chain:

Look at all the money that's in the system on the production side. It all goes primarily into production and very little goes into development. (Respondent, CEO Canadian TV drama firm)

Without question it can only help to have more emphasis on development. There's a real tendency to rush into production to try to recover the cost of development. You build those development costs into your production budget and you get repaid when you go into production. (Respondent, Executive, Canadian TV drama firm)

It's such a golden age of television now. The reason it's happening is because the writers have power. Canada's maybe a half-step behind. (Respondent, Canadian A-list Hollywood showrunner)

Canadian development executives also expressed concern regarding the current model:

We're in a situation where just having rights to programs made elsewhere is not a very secure goforward business model. Having programming that is unique to you is really critical. But in a small market of 35 million people, that's hard to monetize. So there's a little bit of a struggle as you try to figure that out. (Respondent, Canadian TV network development executive)

However, the relatively dispassionate concern of the network, "a little bit of struggle," contrasted with the level of concern by a Canadian TV drama producer, perhaps because of the relative risk undertaken: 
Development is the most challenging process. Our development budgets are so tiny compared to the U.S. We've got the Cowboy American personality that goes "yes just throw money at it" and we've got the Canadian personality that goes "oh we shouldn't do that because it's too risky and we're risk averse." The truth is studios spend 100 million on development every year. Our development budget has been half a million dollars a year, so that gives you an idea about how little we are. What's happening now is everyone is spending money upfront, 75 to 150,000 just to get a script written before they pitch it. It's become a business where development is even more than important than it has ever been. (Respondent, CEO Canadian TV drama firm).

\subsection{Chapter summary}

This chapter has provided an introduction to the Field Research, conducted in Spring 2014. The sections of this chapter have surrounded the role of development, including Section 5.1, defining development; Section 5.2, assessing the impact of the Hollywood cluster on the development of Canadian TV drama; Section 5.3, comparing development dynamics of TV drama in Canada and Hollywood; Section 5.4, reflecting on the Canadian TV brand; and Section 5.6, assessing current challenges in the development of Canadian TV drama.

In this chapter, a series of cracks in the Canadian TV drama value chain have been identified, which impact the development phase. The beginning of the big story, regarding development, is revealed by these introductory insights. As suggested by the value chain analysis in Chapter 3, it appears that a core problem is that phase 3 , monetization, is functionally disconnected from phase 1 , development.

In the following chapter, this central story of the findings, weak linkage in the Canadian Englishlanguage TV drama value chain, between phases 1 and 3, will be explored in depth. 


\section{CHAPTER 6 \\ FINDINGS, PART 2}

FOLLOW THE MONEY: WEAKEST LINK IN CANADIAN TV DRAMA VALUE CHAIN

When you over-subsidize and over-regulate an industry, you suck out all the competitive will and drive and create a very lazy culture for people who sloth their food from the trough. There's no need to compete. Why do you need to compete? If the numbers don't matter, then why be competitive? (Respondent, CEO, Canadian TV drama firm)

The system is set up to fail, so there's a self-fulfilling prophecy of failure. ...If the big Canadian media companies threw the same amount of effort into developing content as they do building their corporations, they would make money there. I believe they could make great Canadian television that's globally loved. But it's the accepted loss. The money is given to them. They have to follow the rules to do a certain amount of Canadian content, but that's not where they make their money. They make their money on American acquisition. So they have to spend the money on development and they have to pretend that they're doing stuff. (Respondent, Canadian, A-list Hollywood showrunner)

I know how much pressure Canadian broadcasters are under. Their margins are being squeezed right, left, centre. But the Canadian [content] business is a necessary evil. In order to have a license, they have to invest in it. Every broadcaster would love to get rid of Canadian content quotas. There's not one broadcaster, other than the development executives, that would say, we're doing this because we believe in Canadian culture. That's bullshit. They're doing it because they have to. (Respondent, CEO, Canadian TV drama firm)

\subsection{Introduction}

This chapter presents a central finding of the dissertation, and in doing so, proposes a reframing of the chronic challenges of Canadian English-language TV drama sector. The methodology of iterative, inductive categorization of data confirmed weakness in the development phase, and led to a deeper understanding of how segments in the value chain interact, causing an unintended fault in the value chain of Canadian English-language TV drama. Since the extant value chain is set up to achieve production excellence, and as well, to maximize profits on Hollywood content, future-proofing Canadian TV drama for the online era may mean altering the goal of Canadian English-language prime time TV drama.

In the previous chapter, stark comparisons were reported between TV development in Canada versus Hollywood. It was often mentioned that pressure for financial success, via creative excellence, was felt in Hollywood, from the first moments of development, in the dynamics of the first pitch to a network or studio. By contrast, Canadian English TV drama was factually characterized: "not an ROI business." Ironically, TV drama ROI, via substitution of TV dramas which have been developed in Hollywood, is the financial foundation of the Canadian broadcast system, and has been so nearly five decades.

A dynamic, which emerged from the data analysis, is that weakness in TV drama development in Canada appears to be an unintended consequence of a value chain which has been optimized to result in 
world-class production capability, but currently lacks sufficient pressure points, pivots, and triggers to develop popular TV drama. By contrast to the Hollywood system, the Canadian TV drama system is purposed to make shows for the domestic market, rather than to make hits for a domestic and global audience. As theorized in Chapter 3, the default goal of the system is the supply of product, an intent which peaks at the conclusion of the second phase of the value chain; asset monetization of has not been prioritized. Remarks by informants confirmed an on-the-ground understanding of this value chain anomaly. Detached from pressure for monetization, Canadian development was described, by elite TV drama development professionals as "haphazard" and "disorganized." In remarking that "there will never be a monster hit out of Canada," (Respondent B, CEO, Canadian TV drama firm), an informant captured an important meta problem, the current goal of the Canadian system. If responding to global demand, rather than domestic supply were the expressed purpose of the TV drama system, many strategies might suggest themselves, such as pro-active programs to strengthen local-global linkages.

A system built to prioritize production capability may unintentionally sacrifice a triplet of goals: critical acclaim, numeric popularity and financial profitability. It is a finding of this study that these factors are inseparable. Without the intense pressure of all three together, the industry is so risky, there is even less chance of a successful outcome than in a value chain which is tightly rigged towards ROI. An outcome of this analysis is that unless the Canadian English-language TV drama sector re-formulates its goal from domestic supply, which has historically prized program delivery, to programs which powerfully respond to global demand, strengthening the sector's chronically low audience, money, and beleaguered brand seems unlikely. Without a need to succeed, from the earliest moments of development, it appears that a TV drama value chain cannot deliver value. A Hollywood studio executive, who manages Canadian TV drama observed: "It's the DNA of the Canadian system that needs to change" (Respondent, Hollywood studio development executive).

Canadian producers may be in the best position to sense the structural flaw, because this category of informants participates in every phase of a project from creation through monetization, negotiating between the Canadian networks' and the U.S. studios' development practices. Moreover, these informants have the most vested interest, and undertake the most authentic risk:

It's a systemic structural problem. Canadian broadcasters make their money by buying U.S. shows and simulcasting them. They make Canadian shows because it's a license requirement. The Canadian model is an artificial system that doesn't make any sense. I don't care whether my show satisfies Canadian content requirements. I care about how to raise $\$ 2$ million to get it made. I don't know if there is a way to train the Canadian networks to be in the commissioning business. I don't think they want to be. Currently they have very little risk. They're servicing a licensing requirement. They wouldn't do it if they didn't have to do it. (Respondent, CEO, Canadian TV drama firm). 
As such, a core finding of this dissertation is that the impact of the truncated Canadian TV drama value chain ripples backwards, to the first moment of Canadian TV drama development. Development may not be effectively strengthened without considering the creation phase as part of an inexorable process, which begins with development of an asset, and ends with monetizing it, based on its popularity.

\subsection{No need to succeed}

Whether contemplating creative or financial aspects of development, Canadian TV drama producers identified a problematic dynamic in the development phase:

The norm for every broadcaster in Canada is producers will make anything for the fees and to a large part the outcome is a mediocrity in terms of the quality of the content that we've made. The Canadian approach is "let me get some development money so I can keep my lights on and a production order." The broadcasters are in alignment with this: "Let's keep making that show, it doesn't matter what the quality is, doesn't matter what the ratings are, doesn't matter what the reviews are." (Respondent, CEO, Canadian TV drama firm)

An informant relayed an anecdote which demonstrates the push towards production, where fees are paid out, and as well, an entrenched, and perhaps myopic mindset among Canadian producers, regarding opportunities to deliver a show which is profitable, if it means side-stepping Canadian content rules and regulations. This informant seems to be observing the impact of decades of a message that Hollywood TV drama is a threat to Canadian audiences, even though its popularity finances Canadian TV drama:

The whole mindset as a producer or broadcaster is regulatory, terms of trade driven. I remember one time years ago talking to this Canadian producer who pitched me a pretty good idea. It was set in Windsor. I said, "it's a great idea and if you set it in Detroit I think I can sell this in the U.S." He said "but then we'd lose our Canadian financing.' I said, 'Who cares about Canadian financing? I can get you a full licensing in the U.S. You get way more money." He said, "I can't really. How do I do that?" The protectionist regulatory framework that's seemingly protected Canadians from Americans has also created a mindset among Canadians they can't go the other way. (Respondent, CEO, Canadian TV drama firm).

Another CEO observed the systemic development glitch:

The Canadian product was created because it was government mandated. But there's a danger, because if you, as a creator, you are eligible for something because the government has mandated it, there may be a different approach to developing than if you better get out there and make it amazing or no one's going to buy it. (Respondent, CEO, Canadian TV drama firm).

A Canadian, A-list Hollywood showrunner observed the weak linkage between financial risk, creative excellence, and the imperative for a large audience:

I worry about subsidies because they distort the market. I think it reduces your likelihood of something good. What I mean by distort is you have different priorities in terms of who should or shouldn't get the money. You've got things that appear to be achieving some sort of agenda, and they get approved, other stuff doesn't. It's not about the creative. People think it's about the creative but it's not, because the creative people aren't making the decisions. The problem is, if 
you're in the Canadian market and it's all financed before-hand, it doesn't ultimately matter whether it's good or bad, you're going to make money either way. You need to be a little scared. You need to know you need to reach a big audience or you're going to fall flat on your face because you need to have something great. (Respondent, Canadian A-list Hollywood showrunner)

A Canadian creative who trained in Canada and became a Hollywood A-list show-runner, shared a powerful anecdote, which itself might be considered a mini case-study of Canadian English-language TV drama development dynamics:

I'm a proven show-runner on a prime time, $\$ 4$ million per episode series with big actors. Demands on this kind of show are massive; I spend $\$ 90$ million/year on 24 episodes, and it's on my head.

I'm also proudly Canadian. I went back to Canada on my own dime and pitched them a show. They loved the concept and said 'we want to get into development with you.' They agreed to spend more for my name than ever. That was very positive.

But it turned out to be a bridge to nowhere. The money was spent on me because they had to spend a certain amount of money. I've never dealt with the disorganization and lack of organized thought... I'm not putting the development executives down. I don't believe they're the problem. I walked away from a 2-year process 3 weeks ago. I don't know how they stay afloat as a company.

It would take forever to get feedback. I'd give the outline and nobody would get back to me. I'd hand in notes. I'd never hear back. When I came into town [from L.A.] for meetings, they'd cancel. They weren't avoiding me. They were running around like chickens with their heads cut off.

I said, "Someone has to make a decision. I can't keep spinning one way then the other. Who are you answering to?" Whoever the head of the network was, they said "He's a guy who's busier than we are. Just keep going. We'll tell you to stop if we don't like it." I said "What?" I couldn't figure out who was generating comments, but I assumed someone above them.

I finished an entire year's worth of work. I had worked for 1/10th of what I earn because I wanted to do this. I was willing to be up there to shoot, bring my wife up. A U.S. Studio had committed to distribution and we had lined up a production partner.

After the first year, the Canadian executives said, "We only want procedurals. Can you remove the family?" I said "Are you joking? It's about three sisters and their dad." They said, "We don't want to lose you. But we want you to start again." Four months later they phoned to say "We'll pay you to do another script and re-write the pilot" and they gave more notes. I agreed.

Meanwhile, my agents were saying "God, you're going on 2 years now."

After another 4 weeks they called to say, "We want to change it again. We want serialized. No procedural elements." I said "What? You're the ones who insisted I do procedural. I pitched you a serialized show 2 years ago. At the end of last year you wanted only procedural." They said "It's not your fault but we want you to do serialized." I said, "I'm not doing this again." They phoned to ask "Could you? Would you?" I said "Thank you. No I'm done."

I'd written hundreds of pages, nine or 10 drafts. I don't think my show at any chance to go, but I don't think it was sabotaged. The development executives had the best intentions but somewhere above them at a corporate level, no one was steering the ship.

Every time I had direct talks with the development execs they said "We're not quite sure." They were waiting for a corporate head to say "This way or that way." It's not their fault. It was like a captain-less ship that went in circles and circles.

I've never been apologized to by more people, but I will never develop in Canada again. It was such an unpleasant process. It was a waste of my time. I lost so much money.

At the point they were confused as to what they wanted, they should have stopped me and said 'We're not sure if this is right for us.' Instead they had the money to spend, so they spent it. Instead of stopping and saying 'We cannot afford to lose this money.' It was 2 years writing something nobody wanted because they didn't know what they wanted. 
That's why they say: you're on a bridge to nowhere. They have to spend the money on development and pretend they're doing stuff. My experience was a bridge to nowhere.

(Respondent, Canadian A-list Hollywood showrunner)

The informant offered an analysis of the root cause of the "bridge to nowhere," capturing the idea that the

Canadian TV drama regime can be described as "demanding a supply" rather than "supplying a demand":

If all of a sudden a Canadian network said "Wait, we don't want to lose \$22 million; we're going to be accountable because that's our money." They would make content that would sell. But what's the motivation for the Canadian networks to fix this problem? The big money's not theirs, they only lose a small percentage of their own money, and they write it off. It's going to take really ballsy players to break out of the system that seems to be in play at the Canadian networks. I feel like they don't care if they make money from Canadian television because they make their money elsewhere. They're going to get the money from the government anyway and they buy American stuff to make money. (Respondent, Canadian A-list Hollywood showrunner)

\subsection{Never again}

Some informants have chosen not to continue to engage with the Canadian TV drama system, due to development dynamics:

Somehow or other there's got to be a way of hiring executives at the networks who are idea-driven, creative driven people. They're not. That to me is so critical. You want to go to a place to pitch your project that's driven by creative ideas. I've stayed away from Canada. What surprised me is the lack of passion. They don't act like the people who get excited here. I don't want to go there. I don't want to work there. I went there and I looked at someone afterwards and said "I don't need this crap. This is just pathetic." (Respondent, Canadian, Hollywood TV drama executive)

An informant expressed preference for Hollywood pressure, which proves helpful to the work, versus a disorganized Canadian development phase:

I forgot to tell you why I will never do it again. Here they stop you after two drafts. They lose money hand over fist when they make mistakes, so their due diligence is so intense. When you create a show here, they're on you. If they sniff any weakness they send someone to help you, they jump into it with you. They're helping you in every way because they don't want to lose on the backend. (Respondent, Canadian, A-list Hollywood showrunner)

A CEO reported the company has repeatedly refused to go into production prematurely, because the company's goal was a hit which could deliver global attention, intrinsically related to development phase excellence, but this goal did not appear to be shared by the Canadian broadcaster:

We've had two identical conversations with two different Canadian broadcasters. In two separate situations the broadcasters wanted us to make TV shows but weren't prepared to pay enough. They weren't prepared to find the budgets that we felt we needed to make great television. Both times we said to the broadcaster: "We're not making that show." They were literally dumbfounded: "What are you talking about?" We said, "We don't care to potentially lose millions of dollars. Since we can't make the show we think will be successful and will sell internationally, we're not going to do it." But what's dumbfounding about this is their reaction. In L.A. it's about making the best possible show, the best possible asset. (Respondent, CEO, Canadian TV drama firm) 
The above remark above segues to the next section, because it shows a producer asking a network to function both as broadcaster and studio. Dual functionality of Canadian networks is an important observation in unpacking the development phase weakness in the Canadian TV drama value chain.

\subsection{Follow the money}

As informants spoke with increasing candor, a compelling perspective on a systemic flaw in the value chain emerged. In the Canadian system, the network functions in a dual mode, as both broadcaster, who acquires a domestic licence, but not need to profit from that licence; and a proxy studio, who triggers and provides oversight for a large portion of financing, including public funds, but doesn't acquire any international rights to be monetized. These indistinct interests appear to lead to weakness in the chain.

As explored in Chapter 3, in the Hollywood TV drama system, the roles of the broadcaster and the studio tend to be perfectly aligned in the development phase, towards optimizing the asset for profitability. This was understood and clearly expressed by an informant: "The studio foots the bill. They have much more money at risk ... so they want to deliver the best product possible" (Respondent F, Canadian TV drama showrunner).

Comparatively, in the Canadian system, the financial risk of development appears to be muted by the presence of public funds. The Canadian development dynamic puzzled a Hollywood studio development executive:

I'm not saying I have to hear of every great Canadian writer, but the speed at which these trains leave the station and they're not coming back. ... The person we passed the baton to run the show literally cracked under pressure. We weren't happy with the material so we kept giving notes and notes, even the night before a scene would shoot because it still wasn't ready. We were trying to patch the blood that was hemorrhaging from the wound, because they could never get ahead of it. If I remember correctly, they shut down for a while to get the scripts in shape and do the re-writing so when production went up again, we wouldn't have the constant starting and stopping, starting and stopping, because the scripts just weren't written or ready to shoot. (Respondent, Hollywood studio development executive)

Another informant assessed the lack of financial risk, on the part of the Canadian TV networks, as impacting development from the earliest moments of asset creation:

What's happening is in some ways the lack of a studio system in Canada. In both countries, networks, only license material. In Hollywood, television shows are financed by the Studio, and the Studio holds the network to task. They say, "We're not going to put up $\$ 80$ million and let you guys fuck it around." All the shows I've worked on, the turnaround for notes was 2 days. We have thoughtful notes calls. And the script hasn't just been to one executive. It's gone all the way to the top and back down, so whomever I'm speaking to, each of them have read the script and they've all had a discussion. When I spoke to the Canadian network, the CEO had never read anything.

(Respondent, Canadian, A-list Hollywood showrunner) 
An additional finding is the perception by informants that the supposed advantage of Canadian producers, to keep the IP rights, promoted as a wealth strategy, in practice may not accrue significant advantage, either to the producer or to the Canadian system. In contrast, rights which informants identified as pivotal, are rights to distribute content (i.e., to monetize). Canadian TV drama producers assign international distribution rights to U.S. studios, in return for production financing. The outcome is that TV drama producers are compensated with fees, as they would be, without the so-called advantage of owning the IP rights. This purported competitive edge, that keeping IP which would lead to more wealth in the Canadian model, appeared to be part of the belief system of Canadian development executives:

The structural difference allows for us to have a little bit of an advantage, with writers and showrunners who are Canadian who've been living in the U.S., and are paid very well, but do not have ownership of their shows. You have to be Shonda Rimes to own something there. Canadians have the ability to come here and say "Here's my idea." We say great, and they own their own show and keep the backend. They would probably team up with a production company to actually execute it, but they would make whatever arrangements they wanted to contractually. Overall, it could be a development advantage — absolutely. (Respondent, Canadian TV network executive)

However, TV drama producers suggested that, in practice, owning IP is an empty promise, which reflects structural inefficiencies in the Canadian English-language TV drama value chain. In consideration of the premise that the only rights that matter, are the rights to distribute content, the current structure allows the Canadian network, a significant player in the financing, to operate without vested interest in monetization. Money is triggered and governed by an entity, the broadcaster, with little skin in the game, either domestically (because the Canadian content expenditure is obligatory) or internationally (because they do not have the right to monetize). The data suggest that Canadian development executives are not entirely reliable narrators of the story of Canadian English-language TV drama, as indicated by this analysis of the supposedly lucrative advantage of rights ownership, which in practicality, becomes the ability to trade those rights to a Hollywood studio for financing:

It's very difficult the way our system is structured-if you look at the way an American owned studio retains all the rights and is able to exploit it around the world, a Canadian broadcaster is not able to do that. The producers have the upside. In fact, I think it's one of the reasons we're attracting some top level Canadian talent back into Canada because if you're working in the U.S., you have to be attached to a studio, the studio's going to make money, but you can actually come back here to Canada and produce your own show, retain the rights, sell it internationally and actually could be quite lucrative. (Respondent, Canadian TV network development executive)

In critiquing the so-called IP rights advantage, the informant below with Hollywood presence, reported that U.S. studios partners who are assigned the right to distribute Canadian English-language TV drama, understand how to administrate paperwork, so that the drama in question might qualify for CMF eligibility. In more than half the Canadian English-language premium TV dramas, if there would be an upside, a significant portion of the profits would appear to leave the Canadian system. Furthermore, from 
a global brand perspective, success can be attributed to whichever studio distributes the project. The

following analysis functions as a mini case study of the financial dynamics of the IP rights aspect of

Canadian English-language TV drama development:

Small Canadian producers are trained to think they have to hold onto all their rights. They go "maybe we'll do a deal with you, but we really want to hold onto our rights and Telefilm is funding us to go to MIPCOM and we've got a little desk where we sell our show." I say "Really? I can sell your show along with Rookie Blue, Walking Dead, and get you 10 times the price. Plus, buyers are coming to our stand Monday. You're getting the buyers who run out of stuff to buy and they'll get to you Thursday." Jerry Bruckheimer would never think, "I'm not going to work with the studio anymore. I'm just going to market on my own. I'm going to do everything." The biggest producers in the U.S. would never think it's better to not work in a studio environment. But it's just the opposite in Canada. We need to figure out the rules because now all the profits are going inside the companies and the really good shows in Canada that have big deficits are using all the CMF money and now the U.S. studios are coming in and taking those shows so they're hiding behind the [production companies] but they are not the distributor. For example, a [Hollywood TV studio] will acquire the worldwide rights. So [the Canadian production company] will make a fee, but all the upside, all the revenue is going to be owned by the [studio's parent U.S. media company]. What's happening now is the American studios are investing in Canadian companies or executives that have relationships in Canada and can get some shows sold, but they've got their own creative people. The U.S. Studio does own that show, not on paper because they have to comply with the rules, but they own all the distribution rights all around the world. So that's a great model if you're an independent producer and you want to pull fees out and get your shows financed. But it's a horrible model because all the profits are leaving Canada. To fix it I would make the creative rules more flexible, open it up so there's something between the option of just using Canada as a location for production services and something where a Canadian producer or distributor has real ownership of the show. (Respondent, CEO, Canadian TV drama firm)

The two anecdotes below extend the suggestion that creative aspects of development of Canadian

English-language TV drama might be strengthened by adjusting rules concerning rights and ownership:

It would be interesting if a Canadian network had a studio. Because now, what is their motivation? They need to make money but they're doing it with American product so why do they need to care? It would be great to see how that would play out. Now, in Canada, if a network says "I love the show," they'll commit to $\$ 300$ thousand of a $\$ 1$ million budget. As an individual, I have to get that other $\$ 700$ thousand. I'll get part of it from the government, a great grant, $\$ 300-\$ 400$ thousand. You're now up to about $\$ 800$ thousand of your $\$ 1$ million. You may get gap financing from someone else in exchange for 20 points. Now you have financed your show. Here in L.A. it's not like that. Here the $\$ 4$ million for an episode might have a network license fee of about $\$ 800$ thousand, but the Studio puts up \$3.2 million and they're risking that it better succeed. If it doesn't succeed, they're going to lose a lot of money. That's why they rip shows off the air so quickly here, because no one can afford to make television that fails anymore. It's too expensive! Except, in Canada when it's taxpayer money. Who gives a shit because the government is going to give it anyway. The big joke is everyone in Canada says "Who cares? We'll get the money anyway. And we don't have to pay it back" (Respondent, Canadian, A-list Hollywood showrunner)

Another analysis suggests the system may not be equipped for the era of borderless, online TV delivery. As currently structured, profits from public funds would flow towards U.S. studios, since too 
few Canadian distributors have financial weight to underwrite a premium TV drama:

The easy part is Canada as a location. If it works - great. If not-great. Either way, it's not building an infrastructure in Canada. All the valuable content is owned by American studios. The U.S. media business is huge because they own valuable content. I'm very close with the broadcasters in Canada; I know what they pay when they buy the Disney or Paramount slates. A hundred times, a thousand times more than for Canadian content. They pay multiple millions for a 2-hour moviebecause it's a hit. A Canadian producer would be happy to get $\$ 50,000$. Multiply that by a library of 10,000 titles and you are talking about real infrastructure, real business. (Respondent, CEO, Canadian TV drama firm)

The informants' analyses shed light on nuanced questions about the structure of the Canadian TV drama value chain. They suggest the question of why a Canadian producer should need to rely on a broadcast partner, who has little authentic risk and whose vested interests are not aligned? How might financial triggers be adjusted, such that financial and creative pressure is felt throughout the value chain as a cascade of risk/reward from the first moment of development through monetization? How to accomplish such adjustment, without damaging existing strength in production? Should ownership be defined in a more modern way, for example, by distribution on any platform, including online? Should Canadian broadcasters be allowed to take on a studio/ownership/financier function, as was re-asserted in Hollywood in 1993, with the repeal of Fin Syn? This would involve a change in current interpretation of The Act's stipulation regarding the "independent production sector," which might be just as justifiably interpreted to have meant a strong story-telling sector, given the assumptions of the era.

Such questions are implied by the powerful anecdote below. The story confirms the necessity to follow the money and pulls together creative and financial elements. It's a mini case study about the development phase of the Canadian TV drama value chain, how a weak link to monetization rippled backwards to impact development, including scripts, casting, and opportunity for ROI:

When the [U.S. network] was ready to order [the series] to production, they needed a studio partner. They went to six different companies, including us. It could have been a U.S. studio. The project was expensive and they wanted a lot of money from the studio partner. Plus, they needed a studio partner that knew how to produce, could manage production, could help with casting, and who could continue the development because the scripts were still being written - everything a studio does. The producers would make their fees, but if they need more money on extras or extra days, the studio would have to say yes and it would come out of our pocket. And if the show works, we would make the money. They were looking for a very traditional studio relationship.

In our pitch, we suggested Canada as a location option and did a whole dog and pony show for how we could make it work. One of the things we said in our pitch was "Have you thought about doing Canadian content because we can get you more tax credits. You have to hire a Canadian director, because the writer is American; also first and second highest paid actors have to be Canadian - and we can save all this money." They responded: "We don't want to do that. We'd rather put up more money and get the show we want then spend less money and then not get the show we want. We're building an asset. This is our first big event mini-series and we need this to work." 
We were chosen, so we went forward and owned the show. We were the final decision makers. The buck stopped with us. We spent all the money and paid for overages. We made a decision to spend a million dollars more to make the show better. We had the right to hire and fire everyone.

We did our analysis beforehand: if it was Canadian content, we'd get this; non-content we'd get that. But we were wrong. Even we didn't value the value of good content. At the end of the day, they offered so much more money to do it non-content, than we'd ever get doing it content. And moreover, when we sold it Canada we got four times what we would have gotten!

Compare this to treaty co-productions where Canadians are service producers. They'll never make any profit from the show other than their fee.

We're losing opportunities. How great would it be if the rules were flexible enough so our show could have qualified as Canadian content? The show was based on a Canadian novel. It is a Canadian story. It didn't have the first or second highest paid actor but had a ton of Canadian actors, a great cast that helped drive the value of the show internationally. Just because it didn't have a Canadian director or actor. That's just two jobs and the result is: it's not Canadian.

Sorry, I didn't have Christopher Plummer. I had Australians, Brits, Americans, and Canadians. It's a global business, but didn't qualify as Canadian content. Because it didn't qualify as Canadian content, I didn't even have to shoot in Canada. I could have shot in Romania or Alaska. But a show shot in Ireland or Romania is Canadian? The rules make no sense anymore. (Respondent, CEO, Canadian TV drama firm)

The story above might suggest a value chain adjustment, such that Canadian networks are allowed to purchase global rights, or acquire companies with such capability, thus establishing Canadian TV studios. This type of VCE might empower Canadian networks to seek global attention for Canadian TV drama. Following the money in the Canadian English-language TV drama value chain has led to the analysis that the chain might be strengthened by adjusting its goal, from investment to return on investment.

\subsection{Role of Canadian development executives}

While Canadian co-venture creators and producers report experiencing the impact of a weak link to monetization of Canadian TV drama, Canadian development executives are charged with the role of managing the "bridge to nowhere." As the network's customer-facing professional, the development executive's responsibilities range from taking pitches to overseeing the final drafts of scripts, casting, financial structure, and giving the green light to production. Their expertise is highly valued: "The executives in these positions care. They want to be involved in television. They love the process. They're not in it to sabotage or cause problems" (Respondent, A-list Hollywood showrunner).

Similar to the other stakeholders, this group of informants was extremely generous with their time and deeply thoughtful about the development phase of Canadian English-language TV drama.

Collectively analyzed, they suggest a role which appears to be complex and conflicted. As the customerfacing touch point for creators and producers, they are spokespersons for the network' indistinct, conjoined broadcaster/studio role. Development executives must balance their employer's priorities (which prioritize investment so as to retain a broadcast licence) and that of creators/producers (who risk 
time, talent, money, and reputation to prioritize development of the best possible asset so as to optimize return on investment). Here is how creators and producers perceive Canadian development executives:

I do believe the Canadian network executives are very good people, but they're powerless to make any choices that matter. (Respondent, Canadian, A-list Hollywood showrunner)

I think they all do try. They have to do it, because it's a tax. But once they're in it, they truly are trying to make it the best it could be. I have no doubt about that. (Respondent, CEO, Canadian TV drama firm)

While clearly respected, their powerlessness was also observed, particularly compared to the role of their Hollywood counterparts:

The Canadian development people, they want good shows. It's more about regulatory, because it's more about the content rules. The Canadian original programming executives, they love what they do. They're passionate about the stuff they're developing, but that's it. They don't make money. They're not seen as superstars. If you look at who are the superstars with the Canadian broadcasters, it's the people buying the shows, the distribution people. In the U.S., it's the opposite; the superstars are the original programming people. The superstars there are the people that know how to develop content. Those are the people that run the networks. (Respondent, CEO, Canadian TV drama firm)

Nor were the development executives unaware of their role in the system, but spun it more positively:

I think the executives up here are just as desperate to make hit shows as the executives in L.A. There's perhaps less financial risk riding on it for the networks here but nobody wants to make a bad show. If you make a successful show it sells internationally, you syndicate. It has huge financial benefits if you make a show that runs five seasons for everybody. The executives at the different networks up here if they turn out a string of bad shows they'll lose their job. I think everyone is keen to make the best show they can. I don't know what I would change because we're doing everything we can. The industry, both on the production side and the broadcaster side, has matured to the point where it's "you stay in Canada if you can't make it in L.A." Today there are people who want to make their careers here or in both places. We have people coming to us all the time we want to do a show. It's not, "we'd rather do it in the States." It feels like a really good time in the industry. (Respondent, Canadian TV network development executive)

A struggle with the system also seems visible, as well as a certain acceptance that Canadian TV drama is inherently doomed to financial failure. Acceptance of the status-quo seems the complacency of which the Canadian networks are often accused, but this appears to be a result of a larger context than that of Canadian TV drama, since the corporate revenue, which does count, is derived from the aggregation of mobile, broadband, and cable/legacy broadcast revenues, boosted by simultaneous substitution. While development executives are aware of the dynamics, they are not empowered to change the game. The contemplative remark below indicates a reluctant reliance on what a producer called the networks" "selffulfilling prophecy of failure." Notice the use of the word "if" in the third sentence, confirming that, without public funds, the network appears to have no interest in the original content business: 
Our audiences love Canadian content. It doesn't make money necessarily as fast as a U.S. show, but it makes it over time. If we could enlarge our CMF envelope, we would just make more and more and more of it. The problem is a very practical one. Canadian dramas are anywhere between \$2.1 and \$2.3 million an hour. To fund that you often do need significant funding from the international market. Also you need to have tax credits, and somewhere, you still need $\$ 6$ to $\$ 7$ million to cover off the total budget of about $\$ 30$ million. The problem is a CMF envelope of about $\$ 32$ million, and you put in about $\$ 7$ million on one series, you can see support may be poor. That $\$ 7$ million we just have to take as equity and hope for the best. But corporate looks at this and says 'when we say return on investment, we just don't mean getting our initial investment back, we mean profit. That's where I start to look a little pale, because there are very few Canadian shows that have ever gone into profit. (Respondent, Canadian TV network development executive, [my italics])

One executive identified a key difference in the Hollywood and Canadian TV drama system, perhaps inadvertently suggesting a strategy for the Canadian networks to be able to own studios, so as to be able to monetize home-grown hits: "The U.S. networks own their own studios. And have spent millions and millions investing in the development of the shows they've created. If we had a studio that spent millions of dollars creating shows, we would have a vested interest" (Respondent, Canadian TV network development executive). In comments such as the following, the inherent ironies reflect the complex job, which requires working hard on a project which doesn't matter to your employer:

Financially there is something attractive about buying a show that's produced outside the country by someone else, but you don't feel the same investment in it. Because it's cheap to you, you also feel quite careless about it. So it doesn't get the same level of promotion. It's not valued to the same degree by the U.S. networks. (Respondent, Canadian TV network development executive)

While the executive projects that the U.S. network doesn't value Canadian TV drama because it is cheaply acquired, an irony may be that the Canadian network does value the U.S. shows purchased for a relatively low, market-driven price. A second irony, also poignant, is that Canadian TV drama is actually cheap to the Canadian network, because there are limited performance expectations, and little real risk. Canadian TV drama is simply the cost of doing business, i.e. monetizing Hollywood hits.

While Canadian development executives seems to have adapted to their role in the Canadian TV drama value chain, this may not include a confidence to deal from strength. For example, the remarkable Canadian record of Canadian creative strength in comedy, from Second City to Saturday Night Live to

Ghostbusters, from Lorne Michaels, Bill Murray, Dan Aykroyd, Martin Short, and dozens more

household names, seems to contrast with the tentative tone of the following remark. Such insecurity may further underscore the sense that the value chain weaknesses have handicapped development:

We would like to take some more risks in terms of some of the dramas we're doing, I think that will start to show itself. In our comedies we would like to be a little bolder and a little edgier. We have to be prepared to fail and take some risks before we hit the sweet spot. But it's a challenge. The financing issue is a huge one for us but we do not believe in compromising the creative. If we don' take risks, the more we continue to do shows for regulatory decisions, the fewer opportunities 
to evolve that other kind of programming. I think we need to hold the bar very, very high. I feel like it's a gradual process in comedy. That's one of the reasons I'm so excited because I feel like top comedy talent is back here doing the show. (Respondent, Canadian TV network development executive)

Hope is suggested as a business strategy to combat a sense of defeatism regarding Canadian TV drama, actualized by passive outreach for projects, rather than pro-active active search:

Development is always a crap shoot, right? You go in with the best of intentions, but it's just, sort of, however it turns out. It's a kind of alchemy that needs to take place. We just have to keep looking for the best. It comes down to the creative... but you never know what going to land on your desk until it lands on your desk. But if the show isn't a hit, there are all kinds of things that filter in: the marketing, the time slot. When it does do well, we don't think about it a lot. It's "Yay, it's done well." But Canadian drama is not an ROI business because it's incredibly expensive. Of course it's better when they do well than when they don't do well, but it's a very difficult business proposition in a country this size. A lot of people criticize the Canadian networks for creative complacency because you know the risk is less. I've heard that a lot but it hasn't been my experience. But I'm a fairly optimistic person so I think I'm not really looking for that either. (Respondent, Canadian TV network development executive)

Almost every phrase in the above remark seems to confirm the analysis of a missing link in the Canadian TV drama value chain. Complacency and hope as a business strategy are clearly evident. Marketing and scheduling strategies seem a step-behind the current system, where the linear TV schedule has been busted, and shows like Breaking Bad or Silicon Valley are discovered by the audience, regardless of when or where they are broadcast. Moreover, the commonly heralded excuse for commercial failure of Canadian TV drama, a small domestic market, might also be positioned as a symptom of a faulty goal, not the reason that Canadian TV drama is not an ROI business. TV drama is an expensive product, no matter where it originates. This research suggests that the reason that Canadian TV drama is not an ROI business is that the value chain is weakly linked to the third phase, monetization, which ripples back to impact development. Compare the above remark with the following description of the job of a Hollywood development executive, defined by necessity to follow the money:

People here in L.A. are terrified of failure. In Canada I feel people are tenured. They don't feel like they're going to lose their jobs. Here in L.A., you're the big exec who makes the wrong decision on a show: you're gone. You'll get another job somewhere else down the street. There's a joke here, but it's actually true. You can pitch to a guy at Fox on Monday. He gets fired on Tuesday. You pitch at NBC on Friday and that same guy is there. That's happened to me. He said: "Yeah I made the move." (Respondent, Canadian A-list Hollywood showrunner)

Notwithstanding all of the above, for some Canadian development executives, passion for their work seems indistinguishable from that of a U.S. counterpart, whose job, and the corporate survival of their employer, might be conditional on the fate of a given project: 
We walk around with our hearts in our mouths the premiere night of any show we do. And some of them are stronger than others. Some of them sometimes surprise you. Ones you feel are really not quite as strong sometimes really take off with an audience, which is great and inexplicable. Other shows that are creatively really great just don't hit a wide appeal mark. So it's very scary. And elusive. Every show you try and set up for success by making sure you've got the very best people you can assemble, the best talent that you can assemble, and that they've got enough money to do what they need to do, that the scripts are as strong as possible, things are in place. We even look at wardrobe and makeup, beyond all the casting we've already contributed our thoughts to. Everything is scoured and primed for as much success as possible. And because it involves a collaboration of, you know, 200 people, when you add in all the crews and everything, it takes on a life of its own, and a series becomes whatever it's going to be. You can't control the outcome. Sometimes it's wonderful, and sometimes, despite everybody's best efforts, it's a disappointing outcome. You have to have a very strong stomach to work in this. (Respondent, Canadian TV network development executive)

\subsection{A need to change}

Even accepting the analysis of a weak link in the value chain of Canadian English-language TV drama, the question remains as to whether the architecture of the chain needs to change. If so, why? While the Canadian development executives in this study were relatively complacent about the status quo, other informants were passionate about the system's urgent need to transform to one characterized by a need to succeed in attracting global attention and delivering ROI. The reasons spoke to the global changes in media, particularly that the shift to online distribution, long anticipated, threatens the current fundamentals of the Canadian system, and its ability to cross-subsidize Canadian content with profits from linear broadcasting. Creators and co-venture producers, who are familiar with the Hollywood environment, are aware these transformations have resulted in unprecedented opportunities for creators everywhere to capture global attention. As the global shifts continue, it appears that all national TV regimes may need to transform into local-global media systems. With respect to TV drama, the global business model will be content monetization, as it has always been for Hollywood drama. Hit content will remain king.

It would seem that a competitive advantage unique to Canada, if a goal is undertaken to upgrade the Canadian TV drama cluster from production to design excellence, may be an indication, evidenced in this research, of a new need for U.S. studios to partner on financing, due to the increased competition for both financial and creative resources, a result of global demand for TV. This financial need has reportedly led to a greater willingness, on the part of U.S. studios, to share in creative aspects of development. There is also a need for more studios, which implies potential opportunity for Canadian production companies to evolve into full service studios. Theoretically, this could imply opportunity for Canadian networks to also evolve their content development functions into real, risk-taking studios. Given all these factors, some informants perceived the current moment as an urgent time to adjust the Canadian English-language TV drama value chain, so it aligns organically from development to monetization, and so that touch 
points along its value chain align with those of U.S. partners. Following is a compelling argument regarding the need for structural change:

The system was working until relatively recently because it was forcing massive corporations to spend money on Canadians to help them hone their crafts: writers, directors, camera operators, all the rest. The combination of shelters and tax credits and CMF benefits was actually working. Today we have a big problem - broadcasters aren't making enough money doing what they traditionally did before. So they are turning their sights on the success of the shows that resulted from the system and squeezing producers to the point where it's not lucrative for us to make television any more. So they should just become a studio, or you're just going to run out of good producers. Smart producers like us aren't going to do this anymore. Some others will make your shows for little to no money because they've got no alternative. It used to be that you can make a good living making content because the broadcaster took the broadcast window let you exploit the rest of the world. Now that they are not making any money on traditional advertising they are stripping rights from producers, all the merchandising, second, third, fourth windows, VOD. But guess what, no one's going to make television anymore. There won't be an infrastructure to produce it.

Historically, for some policy reason, we decided were going to block Americans from being allowed to control our airwaves and instead, we gave monopolies to a bunch of Canadian rich people to control Canadian airwaves. Interestingly, the way they controlled them was buying American shows and simulcasting them. Holy: that didn't work very well. So for further cultural and policy reasons, we let them continue to do this, but imposed on them a bunch of requirements that make them make Canadian content to service cultural agenda. Of course they resent this. They're like "this really great gig you gave me to buy and sell is way better than having to make Canadian content." But back when Seinfeld was on, they didn't care, because it was just a little blip. Now, there's no money in traditional 'television [distribution] and they're turning to all their potential profit centres. They look at their independent production team and say "Who are you? What do you guys do exactly? What part of the building do you work in? Oh, you actually make stuff? Ok, that doesn't make us any money. It's actually costing us money! Since we're not making it anywhere else, you now have to start making money." So all of sudden, Canadian TV drama matters. But guess what happens when you matter? They want to take all your money away. (Respondent, CEO, Canadian TV drama firm)

A U.S. studio executive, who manages Canadian TV drama, confirmed there is current opportunity

for Canadian companies, with a note of strong caution, a need for limitless focus on creative:

The traditional TV model is getting tougher and tougher; these shows are $\$ 3.5$ million per episode and they often fail. Networks are okay because they have advertiser money. But studios can be hemorrhaging money until they finally get a hit, like House or NCIS. Hits are shows that can feed your studio for seasons and seasons to develop new shows....

In the current environment, it doesn't behoove us to shoot in Los Angeles because that's money off the screen. It doesn't behoove us to often do post in Los Angeles because that's also money off the screen. It doesn't behoove any of us to have a project that's you know got eight executive producers attached because that's money off the screen. So we want to look for creative ways of places to shoot, places to do post. We shot in [Europe] for 10 episodes, which wasn't ideal because it was so far away and we didn't have like a showrunner on the ground there who was you know communicating with us in a timely fashion so that wasn't the greatest way to do businessbut we are outsourcing more and more things. It would have been lovely to go up to Toronto or Montreal or Vancouver. We do want to ramp up and diversify our slate, we want to get more stuff going in cable and also in broadcast. We want to build the studio; it's a very entrepreneurial spirit 
here. We want to create something and diversify our slate, we want to have eggs in many baskets. Wherever we can find smart, creative ways to do something at a lower cost without eating away at the integrity of the vision we are open to those discussions with people. But we won't sacrifice creative for cost. (Respondent, Hollywood studio development executive, [my italics])

This informant expressed increasing interest to work with the Canadian system, specifically mentioning the development phase, however, specifically assuming a shared financial risk/reward model. Even in development, and maybe especially in development, because it is so risky, and so challenging, money talks:

Development partnership would be the most organic way to do it, because everyone is looking to decrease risk. I'm talking financial risk, so if everyone can come together and get excited about a creative idea, as opposed to "oh we have this script written by a Canadian" and then us trying to shape it more to our liking. The ideal way is determining "here's a great writer with a great idea" and let's develop this together, share the risk and figure out the best platform or home for it" (Respondent, Hollywood studio development executive).

\subsection{Chapter summary}

Chapter 6 has presented a central finding of the field research. Close reading of informants' remarks identified Canadian English-language TV drama value chain appears to have a systemic flaw, which is an unintended consequence of its production priority. The effects of a weak link to monetization ripple backwards and are evidenced at the first moments of development. One result is that talented, wellintentioned executives run around like "chickens with their heads cut off," a reason perhaps being that the work of developing original prime time drama is not an important revenue stream for the large Canadian media companies. The development phase of the value chain was characterized as a "bridge to nowhere," with "nowhere" defined as a place where the "numbers don't matter-so why compete?"

This chapter also demonstrated that informants perceive new opportunities for Canada's TV drama system. Declining profitability in the legacy broadcast system, coupled with increased demand for content, has intensified competition for creative services in Hollywood; informants reported a new receptiveness for development partnership. Yet, Hollywood partnerships tend to include an implicit condition that creative should not be compromised, because the Hollywood TV imperative, as reflected in the structure of the value chain, is to optimize the asset, and thus increase a slim chance of a hit.

The shift to online TV distribution could be framed as a potential repair to the chronic problem of Canada's 20th-century broadcast system: a small domestic market. This research suggests the Canadian TV drama sector could realign its goals with the progress of technology, by transforming from a system which 'demands domestic supply' to one which 'supplies global demand.' However, as the findings of this chapter underscore, TV drama success is so daunting a challenge, unless the fear of financial failure is omnipresent, the creative process might be "warped," from the first moment of development. 


\section{CHAPTER 7 \\ FINDINGS, PART 3 \\ BRAIN DRAIN TO BRAIN GAIN: \\ ROLE OF LOCAL-GLOBAL LINKAGES IN CANADIAN TV DRAMA}

The irony was, coming to Hollywood [after creating and producing a Canadian TV drama series], everyone was excited about what we had done. No one was excited in Canada. No one pursued us. No one called us. No network called. It was like it never happened. Here they were all interested. Everyone wanted to develop something with us. (Respondent, Canadian, A-list Hollywood showrunner)

I get why writers go to the states to get training. I love it when they come back. It's a win/win for us. But I'm interested in our younger writers; what are they being taught and who are their role models? Do they understand what's being done internationally to make a great script? As much as I love the CMF and we need it - are we rewarding mediocrity? It's ironic because if we fail to put stringent creative controls on the system that supports us and allows us to do so much television, then we're going to end up with mediocre television. Whereas, in fact, it's a gift of funding which should allow us to do something really amazing. (Respondent, Canadian TV network development executive)

\subsection{Introduction}

The previous chapter established that absent financial risk, the creative work of the development phase of TV drama does not function effectively to maximize the quality of the asset being developed. In this chapter, weakness in local-global (Canada-Hollywood) development linkages can also be positioned as a direct result of a process characterized by muted financial imperative. Given a business endeavor which is, above all, creator-driven, and given that the globally dominant cluster for of drama creation is Hollywood, a long established destination for Canadian creators, issues of Canada-Hollywood linkages were found to be top-of-mind for the informants in this study. These remarks demanded close analysis.

Research in the ways in which local-global linkages impact the upgrading of media clusters, from production to design capability, has been previously reviewed in Chapter 2. It has been suggested that informal social linkages are an important foundation for formal industry linkages. In Chapter 3, the unique relationship of Canada and Hollywood, proposed as 3Ps, suggests a rationale for reframing Canada-Hollywood linkages as win-win competitive advantage in the arena of Canadian Englishlanguage TV drama. In this chapter, remarks by informants extend these insights with on-the-ground perspectives on the role of local-global linkages. The argument positions weak local-global linkages as symptomatic of the structural glitch in the Canadian TV drama value chain, wherein the development phase lacks inexorable connection to monetization.

Section 7.1 establishes the informants' perspectives on brain drain and their view of the current level of connectivity between the Canadian and Hollywood creative clusters. This section will also 
explore whether Canadian creators in Hollywood are receptive to increased connection to the Canadian TV drama system.

Section 7.2 proposes that the reason why Canadian creators seek career acceleration in Hollywood is driven by the need for relationships, within a development community that is tightly clustered. As the informants confirm, taking meetings is a critical aspect of a creatives' work. The findings of this section depart from the expected, and follow the money. The main linkage problem may not be that Canadian creators in Hollywood are not linked to Canada. Instead, a systemic handicap may be that Canadian networks have no have no presence in Hollywood. This finding reframes the challenge of local-global linkages, and suggests a relatively simple, inexpensive firm-level strategy which may strengthen Canadian English-language TV drama.

Section 7.3 explores the informants' consensus of a need to strengthen Canadian writer training.

Section 7.4 examines the impact of the rules and regulations regarding writers, on the development phase of Canadian English-language TV drama.

Section 7.5 honours the great generosity of informants who contributed to this research, by acknowledging that, despite differences in risk, competition, and compensation, that Canadian creators, whether in Hollywood or Canada, expressed surprising similarity in their preferences for the work, including hiring practices and writing rooms. Creators on both sides of the border confirmed a timeless linkage: joy in the creation of TV drama.

\subsection{Brain drain to brain gain?}

The long-acknowledged migration of creative talent, from Canada to Hollywood, the planet's "centre of creativity," was confirmed by informants. As told in Chapter 5, the lure of Hollywood includes compensation, competition, and a chance to reach a huge audience. These are powerful motivators for creators working in a field that is so high risk. Moreover, in Hollywood, TV writers who do become successful, become powerful. A Canadian who become an A-list showrunner explained why writers have elite status:

Here's my theory on the reason writers got power on TV. It's not because of any creative decision, not because of any policy decision; it's a simple reality of the production schedule. It's a wonderful thing that has happened and it's the only way to get any really good stuff out. If you're doing a show every seven or eight days, you need somebody who can crank out really good shows - if you want it to work. (Respondent, Canadian, A-list Hollywood showrunner)

Canadian producers observed that increased opportunities for writers, driven by increased global demand for TV drama, may be accelerating brain drain to Hollywood: 
We've got the talent but half of it has moved down to L.A. and more and more people are continuing to move down to L.A. Why, because there are more jobs. There are more shows. (Respondent, CEO, Canadian TV drama firm)

The really talented writers move to the United because they want to work in the U.S. marketplace. It's not surprising. Nothing against Canada. They want to do it because it's a way bigger playing field, you can make way more money. Your show can be watched by way more people and you have a potential to have a global hit, which you know, has not happened in Canada. (Respondent, CEO, Canadian TV drama firm)

In a career which runs on reputation (Caves, 2000), a stint in Hollywood accelerates both skill and brand:

Canada has been very successful in creating really good crews and people don't hesitate to go to Canada to produce. But in terms of the creative end of things, the writers, frankly, I think the perception is that the really good Canadian writers come here. (Respondent M, Canadian, A-list Hollywood showrunner)

A Canadian showrunner based in Hollywood, considers it essential for Canadians to learn the business in its epicenter, since Canadian English-language TV dramas attempt to compete with Hollywood content:

I do think people should be coming out here and working in the American system for that experience and to see that level of production value, then they can go back. If the executives were involved in these conversations too-so writers are not held to just a Canadian standard. Because there's a universal standard. But it depends on what the goal is for the Canadian industry. Do they want their writers to go to the U.S.? It probably would be good; they could learn the business here and come back to Canada and develop original series. That's probably not a bad way for them to get their own hits is send their writers here. (Respondent, Canadian, Hollywood showrunner, [my italics])

The phrase above, "if the executives were involved in these conversations too," provided a clue regarding a fissure in the local-global linkages, which will be further explored in Section 7.4 below, and led to a surprising contrast in perception regarding the level of current linkages, as expressed by creators and development executives. As per the remarks below, Canadian development executives, in this study, indicated an intentional program of outreach to Canadian creators in Hollywood:

We reach out to them, they reach out to us. By no means are they off the radar because they've moved down south. A lot of them do go back and forth. But I think the difficulty is for many of them, the salaries they can make there are miles beyond what they can ever earn here in Canada, so there's not a lot of financial reason to want to come home to work. There are sometimes personal reasons. Or business reasons, like ownership of the back end. We do have some advantages that are enticing to people when they reach a certain stage in their career. But by and large, it's hard to get them back because they're all busy working and making hundreds of thousands of dollars more there than they would here. (Respondent, Canadian TV network development executive)

I think there's a responsibility on us broadcasters to reach out to people who might not otherwise think of us and say we want to support something that means something to you that could work for us. And keep that dialogue going. If you get that project into development, and the passion is behind it, then the rest will follow-because they're going to need a writing team in Canada. We would like to bring in a new writer to shadow - there are things like that can be put in place that we 
should do more of, but you have to start with an idea that is a passion. (Respondent, Canadian TV network development executive)

The structure in my conversations with Canadians based in L.A., that's a very attractive selling point for them to come back. They want to be the owner. So I think that's the opportunity, to be able to produce something outside of that studio system and retain some of the rights and being able to reap the rewards themselves rather than being a gun for hire. (Respondent, Canadian TV network development executive)

In contrast to the perception of the executives, creators in this study did not report high levels of pro-active connectivity with Canada, qualified by the very small sample of informants in this study. Nevertheless, as one informant put it, once Canadian creators "leave Canadian borders, they kind of disappear" (Respondent, Executive, TV drama firm), which seems consistent with Canada's official position not to track emigration. A Canadian showrunner, based in Hollywood, reported what happened on the day his series got renewed for its third season, which coincidentally occurred during the same week as the interview for this study:

The news we got renewed came yesterday and 20 different companies sent congratulations. "When can you come in? When can we talk?" No Canadian networks have ever approached me. American companies approach me, so I've been happily, gainfully employed. I've been so busy that I haven't had to reach out and they're not. It is crazy that no one's ever reached out. (Respondent, Canadian, Hollywood showrunner)

An A-list showrunner had a similar tale, which appears to extend a thematic log line of the story of Canadian TV drama, which is that no need to succeed causes no need to link with talent:

It's funny. I haven't been contacted directly by Canadians. I thought the reason was I had no profile up there. No network has contacted me and said "Why don't you come in for a meeting?" Here, the head of ABC would read an article in New Yorker, call and say "Come in. Create a show for me." Up there you don't seem to get that. There's no courting. Here, the agents are all over you. If you have a profile, people come at you. You have 200 people come at every which way. The reasons might be a couple of factors. One, it's just not the Canadian way, Two, they might think we're unavailable. I always hear "If he's available-I doubt he's available, but if he is, can he do x?" When I've been approached through my agent by Canadians, it always begins with "I'm guessing he's not available." Canadians apologize for everything. Stop apologizing. Call me and say you have a great fucking project. I use the curse word because that's what my agent would say: "Great fucking project. You want to do it?" Don't be Canadian. Come at me hard. Sell me. Court me. (Respondent, Canadian, A-list Hollywood showrunner)

A story about linkage failure came from a Canadian who got a start in the industry by creating a Canadian TV drama is so compelling that it functions as a mini case study of local-global linkages in Canadian English-language TV drama:

I had done something most people never do which is get a show on the air, in a country which barely makes any television. It wasn't the greatest hit on television, but when it was over, no one called. It was unbelievable. Not a single network. I didn't want to leave Canada. I had no intention 
of coming to L.A. I wanted desperately to do more things in Canada. But after doing 40 or 50 episodes of my drama, I was thinking "I' $m$ in the business."

I swear I went back to my house and the phone never rang. No one pursued me. No network called. I'd phone my agent and say "What's next?" They said "There's not really anything next." I had imagined in my mind that people would say "Let's do some deals." There was no ringing. Six months later there's nothing. I was like "What am I going to do?"

They forced me to L.A. because there was no work. I packed up my little car and drove here without a work permit — without anything. I just drove in. I said I was on vacation. The giveaway should have been my car packed to the ceiling. I'm a kid from Canada. I arrive here. I see palm trees.

I hustled my way into meetings with major agencies. The irony was I walked in the door and they had heard of my show. They had done their research. They had done their due diligence. Everyone was excited. They knew how to turn it on. There were six of them behind a table. They all had my material. I didn't even know where they got it. Everyone wanted to develop something with me. They were saying to themselves, "How do we know if this guy will be the next David Kelly?" They weren't about to let me walk out the door. They said, "We'll get you everywhere."

We'll package you, team you up. They wooed me in a way I've never been wooed. Then more things happened. Another agency hears about the meeting, so they called: "Come see us." Then another one. I met all the major agencies and got offers from every one. My first writing gig was on [Hollywood hit TV drama].

I wanted to be in Canada, but I felt like it was a desert in Canada in terms of my industry. It was like the show, the work never happened. There was an energy here that blew my brains. You felt loved. You felt wanted. I've been here 14 years. I'm still Canadian. I've not given up citizenship. I have no intention to. Nevertheless, when I went back there to create my own show, they had still never contacted me. I contacted them. (Respondent, Canadian, A-list Hollywood showrunner)

In another variant on the role of local-global linkages, some Hollywood-based informants weighed in the question whether they would consider participation in the Canadian TV drama system, and if so, under what conditions. In contrast to the informants in Chapter 6, who had decided not to further engage with the system, some Hollywood-based creators who had not yet participated in the Canadian TV drama system, expressed a theoretical willingness to work on a Canadian show. While some of the enthusiasm may be linked to the myth regarding the structural advantage of owning a show, three high-level Canadians who are Hollywood A-list showrunners expressed similarly pragmatic perspectives regarding whether they would engage in the Canadian TV drama system:

Would I work on a Canadian show? The answer is absolutely. For a few reasons. One, I think it will afford me more creative freedom than I would have here. Two, somebody said to me once, I've always remembered this, "the Canadian ethos is you haven't made it in Canada until you've made it in the U.S. If you're a Canadian with show credits, you can write your own ticket." It was an exaggeration. This individual was a bit of a cynic but I'm fortunate to have good credits. So yes, people have approached me to develop. I would, but the factors are number 1, clearly I would have to pick up and move to run a show. It's hard to do from a distance. I live here and my family is here. I have three kids. So the financial and the creative incentive would have to be big enough to physically lure me from Los Angeles. (Respondent, Canadian A-list Hollywood showrunner)

Am I driven by money? A little bit but not completely. The extra money allows you to attract really talented people and do great things. And you also reach a larger audience and that is significant. There's no point in telling a story to nobody. Plus if I develop a show here I know it's going to be 
on Canada too. ... The fact is I don't really care where my show is produced as long as I can do the show I want to do. It's all about creativity. If they came to me and said 'we would let you do whatever you want to do' which is too much to expect but that's what it would take. Great shows happen because somebody did that. Breaking Bad is a great show. Vince Gilligan had a vision. His studio and network let him do exactly what he wanted. (Respondent, Canadian, A-list Hollywood showrunner)

The most obvious one is money and the second is creative satisfaction. As long as they're getting more of at least one of those here, it's going to be very hard to counteract that. But I've met with Canadian companies to develop something and the talks go very well and then when I see their offer, I'm like "You don't get it, you're not even in the ballpark. Are you expecting patriotism, because your offer is certainly not based on economics." The other tough thing is creative satisfaction, which could be something I could see happening the more that Canadian producers can accept this new model of giving writers more creative freedom in developing new shows, then people are going to flock back and want to be involved in that. These are very pragmatic issues, but it's again what are the creative issues, what sort of career things am I getting out of this job? Do I perceive this to be a dead end? It really is just about the way anyone would look at two job offers and weigh all the options and make the best choice. But I don't feel any inherent prejudice against choosing a Canadian project. I would be very, very open to it. (Respondent, Canadian, A-list Hollywood showrunner)

The above perspectives suggest a question regarding insufficient financial offers from Canadian networks, to Canadians in Hollywood. If there were a need to succeed, on the part of Canadian networks, would such a need eliminate a perceived hurdle to a financially competitive offer? If there were an imperative for success in the business arena of content, might it follow that creator compensation might represent a small $R \& D$ investment, compared to the upside of a hit? If content were a profit centre in Canada's large media companies, such as broadband or wireless, might the need for investment in R\&D, and in particular, the best possible creators, be perceived as the small cost of doing business?

\subsection{Role of relationships in the development phase}

A common theme of informants was the critical importance of relationships. When these remarks are filtered through the lenses of global value chains, cluster upgrading, and local-global linkages, new insights emerge, regarding Canada-Hollywood relationships in the development phase of Canadian TV drama.

Showrunners' daily work involves taking and making meetings in order to pitch projects, respond to buyers' needs, evaluate and hire the best writers for the writers' room, just a few of the management responsibilities of the lead TV drama job. The theme of these tasks is relationship management:

You do have to be physically present, not because of the specific content of meetings, but because developing personal relationships with studios and with producers in Hollywood is a big deal. Especially in television, because there's so much contact between writers, producers, and the showrunner. It's critical for the showrunner to feel they know and/or like you and can tolerate being in a room with you for eight hours a day. So certainly, the TV industry is one where you have to be physically present. (Respondent, Canadian, A-list Hollywood showrunner)

When I'm hiring a writer, I don't just read a script. Much more important than their spec, because they could have taken a year to write it, is a personal recommendation. If someone I respect says, 
"You will love this person." Having been in writers' rooms for so many years, you also have your own personal relationships, so you hear about a lot of writers. For example, our writers' assistant last year wrote a script this season. People want to help other people. It's relationships.

(Respondent, Canadian, Hollywood showrunner)

Not every Canadian co-venture showrunner in the study reported a need to live in L.A.; however, a Canada-based informant reported that a stint in Hollywood proved to be important for career acceleration, including securing the right agent relationship:

I was living in L.A. for a while, working entirely on Canadian projects. Everybody had been asking if I would be willing to move to L.A. and I thought I don't really know how to answer that question until I try it so I went down to see if I would be willing to move. I just haven't needed to move there yet. While down there I signed with a manager who came after me and he set up a meeting with a top agency, and this has been really important. It's been an amazing relationship.

(Respondent, Canadian, TV drama showrunner)

Relationships were not only reported as critical for creatives; they were also seen to drive the business strategies of Canadian TV drama firms. One informant spoke explicitly about the need to hire the right relationships in order to succeed in assembling strong development elements, which would result in a green light to production. The informant included an observation about how a stint in a Hollywood writing room accelerates the skills of a junior writer, and as a result, upgrades the asset being developed:

We didn't hire a business person for our Hollywood office. We hired a very strong creative executive who is very, very good at development and has really terrific relationships with some of the best showrunners here. Oh yes, the buzz factor-we're working with a Canadian writer right now who just because of the spec script he wrote, got hired and had a season in the writing room. I'm sure he's learned a ton. If you take a young writer and you put them in an American writing room, they're going to learn a whole bunch of great, new fabulous things. I don't know whether being five miles away makes a difference, but it might. I can pick up the phone and say come in and have a coffee-I want to brainstorm with you. Versus doing a Skype call or having to fly to L.A. Proximity does help. (Respondent, CEO Canadian TV drama firm)

Close reading of the following remark by a producer, nicknamed by his agent "the undercover Canadian" (because no Canadian network had ever reached out) led to an unexpected insight regarding the role of local-global, Canada-Hollywood relationships in the Canadian TV drama value chain:

The TV industry is in Los Angeles. You need to come out here and forge those relationships with other writers and executives. The relationships are here. No one in the Canadian networks has reached out to me. The relationships should be fostered because a lot of times, you know how ideas work; it's let's have a drink and talk, where's your head at, what are you thinking about lately? Outside of my show in production, I've never had a creative conversation with a Canadian executive. If some Canadian exec was out here, we would have coffee or drinks. I'm always excited to discuss ideas and would not say no to any meeting or drink. Anyone can have an idea. (Respondent, Canadian, Hollywood showrunner [my italics])

By noting that no "Canadian network had ever reached out [but] if a Canadian executive" were 
present in Hollywood, this informant unveiled a nuance regarding weakness in the local-global linkages in the development phase of Canadian TV drama. Similarly to close readings of the remarks by the Canadian network development executives, the above remarks reinforce the positioning of the Canadian networks as the weakest link in the value chain and suggest the role of local-global linkages, in the development phase, might be reframed as a need for the Canadian networks to link pro-actively to the Hollywood development community. This initiative would seem relatively simple to accomplish, assuming a corporate need to succeed with Canadian English-language TV drama.

Just as Chapter 6 identified a central finding to be a weak link to monetization, this section confirms another key finding, regarding weakness in the related arena of local-global (Canada-Hollywood) linkages in the Canadian English-language TV drama system. The informants' remarks regarding the importance of development relationships suggest a reversal of the expected analysis. The core problem may not be brain drain. Emigration to Hollywood is how Canadian creators survive and thrive in their careers. The net impact of brain migration could be positive for Canadian TV drama, given Canada's unique geo-cultural proximity to Hollywood. Brain drain could be positioned as a unique competitive advantage, as brain gain. However, the data suggest that problematic local-global linkage, which may negatively impact development, might be a lack of presence in Hollywood by Canadian networks, in their role as content studios. The Canadian networks appear to operate as relatively passive outsiders to the prime time TV drama business, while informants emphasized that development success depends upon relationships, and those relationships are in Hollywood.

The informants' perspective on the value of relationships in Hollywood's tightly clustered development community is consistent with the cluster knowledge spillover concepts of social capital, as discussed in Chapter 2 and that physical presence in a knowledge cluster is more important in the digital era. Recent strategies to decrease local-global linkages may be symptomatic of a deeper Canadian issue, the lack of the need to succeed in the arena of content development. As long as the required amounts of money are spent commissioning programs, forfeiting the opportunity cost of presence in Hollywood, even if it may negatively impact the outcome of Canadian TV drama, does not impact the network's survival. Such analysis is found, not only by following the creators to Hollywood, but by following the money in the Canadian English-language prime time TV drama value chain.

\subsection{Reframing writer supply and training as a local-global linkage opportunity}

Moving from the central finding about local-global linkages towards peripheral, but still important development phase issues, this section will focus on two common concerns of informants, supply and training of Canadian writers, in a quintessentially, writer-driven business arena. There was consensus among all groups that there are too few qualified Canadian TV drama creators, including showrunners 
and episode writers. Quantity and quality of creators emerged as issues, as informants struggled with how to increase numbers of trained writers for Canadian English-language TV drama, and how to upgrade creatives from junior writers to showrunners. Considering the findings of the previous section, strengthening Hollywood linkages seems imperative.

Compared to such initiatives as the U.K.'s "Welcome to LA" program, there appears to be institutional resistance to framing the issue of upgrading Canadian writers as a local-global linkage opportunity. While Hollywood continues to be a career destination for an untracked number of junior creators, they remain "undercover," given the absence of a Telefilm office and a talent directory. When Canadian junior creators, who have relocated in Hollywood, rise up the ranks to elite status, new pools of Hollywood-trained Canadian talent, appears to be institutionally overlooked as strategic advantage.

An informant noted resistance to reframing the problem as a local-global linkage opportunity:

For whatever reason, Canada has not been able to train writers in English Canada. Here NYU has me give classes. I've given classes at Columbia Film School. I gave a full course at UCLA film school. No one in Canada has ever asked me to do anything. (Respondent, Canadian, Hollywood TV drama executive)

Several informants noted a need to include the theatre as a feeder system to train Canadian creator talent:

If you are not nurturing the pool and the feeder system isn't there, the [TV drama] business won't work. Our writers aren't great yet. We don't have a brilliant screenwriting nucleus. Our writing linkages have failed. CBC has abdicated. The feeder system has to be changed so it includes theatre, a traditional feeder to TV and Film. We need to further amplify development. There's no money being spent in writer training. There should be huge money invested in teaching the creative process. Bring someone in. We can't have our people teach our people yet. We're not there. (Respondent, CEO, Canadian TV drama firm)

In the current environment, as increased quantity of buyers of creative services in Hollywood translates to more opportunities for junior talent, thus impetus for emigration would appear to increase.

There, so does the urgency of training Canadian TV drama writers:

There is a challenge in Canada on the writing side where there are not enough shows to actually teach the next group of showrunners and train them. I firmly believe the way writers become better writers and become successful showrunners is that they train under experienced people. And there aren't enough experienced people. There aren't enough good shows in Canada. There are a small number. With over 50 outlets producing original scripted content and I think that's number's now gone up, there are such opportunities in the U.S. There's a brain drain where a lot of Canadian writers leave Canada because there aren't enough places for them to learn. And because they want to work on top shows. [Junior writer] has now staffed the [high profile Hollywood TV series]. Last year, he was on [another Hollywood TV series]. What an amazing experience. [A different junior Canadian writer] came down and worked on [Hollywood hit]. Another incredible writer out of Canada spent three years on [Hollywood hit] and then three years on [Hollywood hit].That kind of training exists in very limited ways in Canada. (Respondent, CEO, Canadian TV drama firm) 
Canadian development executives shared a similar analysis, reporting a shortage of junior, mid-

level, and showrunner level writers:

An ongoing challenge is you find a great project but the writer may not have the experience to bring it home. Unless you have a strong showrunner attached at a very early stage it's going to be hard to see that series realized. There's certain experience that you have as a showrunner in terms of shaping a series, the ability to give it longevity when you're doing the blueprint. An ongoing challenge is making sure we're training new writers to eventually be showrunners. There's a limited number of showrunners in the country and a lot of them leave to go to the states. It's important when you're developing new talent to surround them with really experienced showrunners and give them opportunities to grow within a story department so that one day they can showrun themselves. (Respondent, Canadian TV network development executive)

It's difficult in the last year or two to find sufficient number of really strong writers to populate the rooms we need. And that has been hurting our shows, for sure. (Respondent, Canadian TV network development executive)

The bigger our production slates get and the number of shows that are produced, the harder it is to find great writing talent, because it all gets sucked up. That goes back to training and bringing people up through the ranks. (Respondent, Canadian TV network development executive)

There was consensus that best practices for upgrading writers are apprenticeship and mentoring initiatives, also confirmed by a U.S. studio executive who manages Canadian drama development:

So much [writing] is about learning, being mentored. There is a great program here by WGA called Showrunner in Training. These types of seminars can be incredibly beneficial for people who are at mid-level, like the next class of Canadian showrunners that you want to make sure are groomed properly and taught properly and mentored properly. ... It's not that you can't get a hit from a newbie writer but it's not common. It's so difficult, so hard to create a hit show. You need someone, for the most part, who is a little seasoned or at least partner them with a younger writer, not age, but somebody who has the wisdom and the experience and has done it before. ... To be a great showrunner, first and foremost, you've got to be a great writer. But there are so many other skillsets that come into play to be able to successfully shepherd a show week in and week out for three, four, five seasons. You have to have your creative hat and your business hat and there are a lot of people to manage. (Respondent, Hollywood studio development executive)

A number of informants noted Canadian writer-training initiatives, which stand-out because they feature apprenticeship and Canada-Hollywood linkage strategies. Ryerson University's annual two week program in Hollywood, RTA in L.A., ${ }^{25}$ provides young creators "a window to the largest media market in the world, the Hollywood studio system" (RTA School of Media, n.d.). The Canadian Film Centre's Bell Media Prime Time TV Program ${ }^{26}$ is an educational pipeline, which has improved employment and compensation of junior creators (Davis et al., 2014). A question remains whether education-led initiatives are enough to strengthen the Canadian English-language TV drama sector, a challenging type of upgrade, said to require systematic coordination between government, industry, and lobby organizations.

\footnotetext{
${ }^{25}$ See: http://www.ryersonrta.ca/opportunities/rta-la

${ }^{26}$ See: http://www.cfccreates.com/programs/15-bell-media-prime-time-tv-program
} 
In this respect, the comments of a Canadian development executive, who worries about the impact of missing pressure on creative excellence in the system, are poignant:

One of the things I see, and this may seem minor, but it's not, is lack of research, a lack of effort in our writing community. We are working with [a Hollywood writer]; she's read 50 books on the topic. She traveled to see the area. I feel like our writers don't have the authenticity. Let's say you're writing a period drama or somewhere remote. A U.S. writer would travel half way around the world to research. Are we guiding them enough to understand what they could be capable of? Or are we accepting less than the best - and then there's no incentive to reach the best? Or do they not have the training? (Respondent, Canadian TV network development executive)

In contrast, Hollywood creators extolled the benefits of working in the world's high-pressure cluster, not only for unmatchable quantity of opportunities, but also for unparalleled opportunity for apprenticeship:

I have been fortunate to work with a number of incredibly talented people. I have a rolodex of incredible people who refer me to somebody who will hire me. So I've been able to develop a skill set learning under these great people. (Respondent, Canadian, A-list Hollywood showrunner)

There is something about the writers' room here. It doesn't always work. It's not always perfect. But I had the opportunity to sit in a room with great, great writers and watch them work and contribute and learn my own voice. Because it takes years, in my opinion, to develop your own voice properly. (Respondent, Canadian, A-list Hollywood showrunner)

A moderating factor, to the Hollywood advantage, appears to be consistency between writers' rooms in Canada and Hollywood. With writers' rooms on Canadian TV dramas increasingly structured exactly like Hollywood writers' rooms, and also featuring promotion from within, this may suggest an emerging advantage for Canadian writer training. Note the similarity of perspectives of the following Canadian coventure showrunners, the first leading a writing room in Hollywood and the second, in Canada:

The writers' assistant job is a great starting job. You are in the writers' room where they break stories. You start at 10:00 a.m. and you go to 6:00 p.m., taking notes about all the ideas, the day's work. At the end of the day, all the notes go to the writers. The writers' assistant hears how people come up with stories, what goes on the board. It's writing boot camp. It's the best grad school. And they are allowed to pitch ideas. Most times if they do a good job, we give the writers' assistant a script to write and they get a produced episode. (Respondent, Canadian, Hollywood showrunner)

We do have a writers' assistant job and we have a story coordinator job and in all cases on the show, our show the writer's assistant and the coordinator have become writers on the show. We have moved everybody up. My story coordinator from last year is a writer; my coordinator this year is writing one of the episodes. So I work really hard to promote people from those jobs. (Respondent, Canadian TV drama showrunner)

Showrunners themselves reported career trajectories informed by apprenticeship and mentoring:

I started at the bottom, as everybody does, as a story editor and slowly worked my way up on a bunch of different movies of the week, mini-series and here is what I'm doing - 5 years of the show. (Respondent, Canadian TV drama showrunner)

I moved to L.A. to write. I got an agent here and by chance, although not really-I think the fact that I was Canadian factored in their decision so I've been a beneficiary of the program. They hired 
me on [a Canadian co-venture] and I moved back to Toronto for a year. My plan was always "when this is done I'm going back to L.A," but they offered me the head writing position, which stunned me because I had exactly one year of professional writing experience under my belt. I remember thinking, even after consulting with my agent: 'This is insane and very wrong. I don't know what I'm doing.' If they're handing me the head writer position in Canada, and I'm the boss, who am I going to learn from? I took the job for one year because I figured I'd throw myself in the deep end of the pool. I learned a lot about production and what I was capable of. But I wanted to come back to continue my growth as a writer and that's what I did. (Respondent, Canadian, A-list Hollywood showrunner)

In contrast to Canadian development dynamics which lead "nowhere," creators praised the effects of the Hollywood pressure-cooker:

This entire 10 miles is full of people who stay up till 3:00 in the morning thinking about creative. And it can be a very fulfilling relationship. I love our executives. It's what it's about - creative. It feels fun. I'm a writer, but my part has contributed to the end product. Both shows I've been on have been super fulfilling experiences. (Respondent, Canadian, Hollywood showrunner)

\subsection{Impact of Canadian rules and regulations on local-global linkages}

When the conversation around linkages turned to the process of hiring writers on Canadian TV dramas, the Canadian content rules and regulations emerged as a concern. The systemic flaw in the Canadian TV drama value chain, the lack of a monetization imperative, lurked as a foreboding context to issues around the rules.

The suggestion was made that the Writers' Guild of Canada appears to be sensitive about jobs for its membership, perhaps valuing jobs over quality results, such that an award-winning producer who had made public remarks about the writer shortage, received a critical backlash: "I sat on a panel and made comments about how Canadian writers don't have enough places to be trained and was really attacked for that comment" (Respondent, CEO, Canadian TV drama firm).

Another informant explained that reframing writer training as opportunity to activate unique global-local linkages between Canada and the U.S., in the context of upgrading prime time drama capability, may not be received well by parties with a vested interest in the status quo:

We have to focus on who is being successful. The [focus on] writers in L.A. is very good, because they are successful. Because they are in a culture that supports the development of those skills. Can we let the barrier down for the moment and just talk about the development of talent and exposure? But the lobby organizations feel very threatened. You have to help them let the threat go and just think about development of their talent or their betterment. WGC and ACTRA will have their issues unless they get something out of it. I think there are things that are not expensive to put in place. Just find a way to make them acceptable. (Respondent, Executive, Canadian TV drama firm)

The story below, from a Canadian TV drama CEO, functions as a mini case study of the impact of the rules on co-venture development, suggests that rules regarding the one job that counts more than any other, in premium TV drama development, may prioritize job supply over development and audience outcomes: 
There's a CAVCO rule that says if a Canadian writes a script, but the writers' room is run by an American, even though that Canadian gets a credit for the script, CAVCO will ignore that credit. They say it doesn't matter because the way it works in the writers' room is that the American head writer touched the script. So therefore you need to hire a Canadian director on that episode because the Canadian writer doesn't count. This is very short-term thinking.

The result is the rules are not providing any incentive to put a Canadian in a writers' room on a Canadian show. I might as well have an American. I talked to the Writers Guild of Canada and asked: "Do you realize that long-term your writers are not learning how to run a show?" They replied: "We care about jobs for our writers. As soon as you break down the rule we know what happens. You guys will hire a bunch of American writers." They are so short-sighted.

So we talk to our American broadcaster and explained the rules require that you either have to have a Canadian writer or a director. They say: "Great, let's get some Canadian directors and some American." But I have to say, "No you can't do that because we have an American showrunner in our writers' room so all the Canadians we hire won't be able to get credit. So you can't hire an American director on the episode by the Canadian, because the Canadian writer won't count."

So the U.S. network executive who approves the writers realizes: "We don't need to hire any Canadian writers at all, because it doesn't help with the rules." So the result of the rules is if there's a Canadian in the writers' room, it's only by accident. Not because we orchestrated it. It's because there happens to be a good writer who we didn't realize was Canadian. (Respondent, CEO, Canadian TV drama firm)

\subsection{For the joy of creation}

This final section of the findings, before Chapter 8 , where informants consider the future, is a pause to express awe of the participants in this study, and gratitude for their generosity of time and spirit, in providing a rare glimpse into a mostly hidden, little understood arena. Despite the immense complexity of the job, omnipresent risk, differences in opportunities, competition, budgets, corporate cultures, and the rules, remarks by creators were united in the joy of building a career in TV drama development:

If there's a way to make it work and be part of what I feel is a growing wave of Canadian writers and producer and makers of television, that would be important to me not just on a personal level but on a philosophical level. I feel more and more that is a possibility, which is exciting. For sure, you feel risk. It's very hard to shake, even when you've been working steadily for 16 years. You always think, I better take this job because you never know. I feel a little more confident now, that I can kind of pause and try to be specific about projects I take on. I feel a little safer saying that at this point, but I'll probably be insecure about it till the day I die. (Respondent, Canadian TV drama showrunner)

It's a real roller coaster ride. When I'm working it's the best job in the world. I love the industry. I love that the industry is here. I love that the old Jews who built Hollywood came here and not Cleveland. So it was really a combination of "This is where I want to make my career and I like the lifestyle." I still, to some extent, think I'm on vacation, even though I live here. I've got three kids. One thing I'm very lucky about is my wife, how tolerant a person she is, how she has always rolled with the punches. We've had really great years and really bad years and often you don't know why one comes and why the other one comes. All of a sudden you're getting lots of offers then those offers dry up; you're not today's flavour and it just goes away. Then you usually have to generate some of your own spec work and try to recreate it. It's tough. But here's the good news. Right now I've been fortunate enough to be on a nice run. I recognize a writing career - any career in Hollywood, certainly a TV writing career - is a sine wave. Right now I'm above the X axis. (Respondent, Canadian, A-list Hollywood showrunner) 


\subsection{Chapter summary}

This chapter presented the third of four chapters that report on the field research. In Chapter 5, the informants set the stage by defining the role of development, comparing development in Canada and Hollywood, and confirming that development is the weakest node in the Canadian English-language TV drama value chain. In Chapter 6 informants considered the structure of the Canadian TV drama system; a weak link to monetization was found to ripple all the way back to the first pitch of the development phase.

This chapter added further depth to the analysis of development dynamics, with a consideration of the closely related role of local-global linkages. Upgrading local-global linkages is acknowledged to be an important strategy in upgrading domestic clusters, in industrial sectors characterized by global value chains.

Section 7.1 established informants' perspectives on connectivity between the Canadian and Hollywood development communities, and explored receptivity of Canadian, Hollywood-based A-list showrunners to increased involvement with the Canadian TV drama system.

Section 7.2 delved into the pivotal role of relationships in the development phase. The need to sustain a myriad of complex relationships was put forward as a critical driver of brain migration. However, the unexpected insight, which resulted is that the weakest link in the Canada-Hollywood connection may not be the absence of Hollywood creators in Canada, but the absence of Canadian networks in Hollywood. By contrast, other stakeholders in Canadian TV drama are present in Hollywood, including writers, producers, and Hollywood studios. The deepest analysis of local-global linkages is found by following the money in the development phase.

Section 7.3 reframed the shortage of qualified writers and writer-training opportunities as local-global linkage issues, with the qualification that these issues are eminently repairable, assuming an imperative for optimizing the asset being developed.

Section 7.4 explored the informants' assessment of the impact of the Canadian content rules on Canadian TV drama, during the development phase.

Section 7.5 found that, despite the challenges of a complex job and the omnipresence of risk, Canadian creators expressed joy in building a career in the development phase of TV drama.

With the extant status of Canadian development dynamics development explored, the discussion moves to Chapter 8, the informants' expert contemplation of the future of Canadian English-language prime time TV drama. 


\section{CHAPTER 8 \\ FINDINGS, PART 4 \\ THE WAY FORWARD: INVESTMENT TO RETURN ON INVESTMENT}

Canadians aren't taking risks. Putting risk back in the system could be an answer. (Respondent, Canadian, Hollywood TV drama executive)

How can we work to bring people together? We should start getting way more strategic, and I include the Canadian broadcasters, because television is getting better and better and better. How do we maintain our ability to be strong Canadian creators? There have been some wonderful ways of ensuring Canadians get money to produce, but as we move forward, only the best shows are going to survive. Canada can recognize we have this unique place and take advantage of it and figure out a smart way to improve on what we're doing. There must be policy changes. (Respondent, CEO Canadian TV drama firm)

Someone said to me, "They need to throw more money at it." I said, "No, the more money they throw, the less incentive to make great stuff." Everyone from Canada says "you don't have to pay it back, it's free money." What happens if Canadian broadcasters still have licenses, but the government says "You still have to do Canadian content, but we're not going to give you a penny-your loss if it's no good." Suddenly they'd search high and wide to make the shows great. They would have a hit. Can you imagine what that would do? (Respondent, Canadian, A-list Hollywood showrunner)

\subsection{Introduction}

Close reading of the interview data, in Chapters 5-7, uncovered insights regarding the current state of the development phase of Canadian English-language TV drama. Structural value chain issues appear to have had a negative impact development, and kept Canadian English-language TV drama at least "a half-step behind" (Respondent, Canadian, A-list Hollywood showrunner). In Chapter 8, we turn to the way forward.

The perception of informants in this study is that, in the current environment, characterized by more global demand for original TV drama than ever before, Canada appears to be losing status in Hollywood, rather than stepping up to new opportunity. This may be so, not only relative to Hollywood competitors, but relative to other national producers, from around the world, who are competing in Hollywood for partnership with Hollywood studios. Development is “more than important than ever," and Hollywood partners are not primarily seeking production discounts, reported as a common mistake made by Canadians pitching projects in Hollywood. To protect investment and optimize chances of monetizing a risky asset, Hollywood partners assert they "will not sacrifice creative for cost."

In this chapter, informants respond to a number of suggested strategies to strengthen the development phase of Canadian English-language TV drama, in Sections 8.1-8.6, which can be found in Appendix BB. These original ideas about the future were informally presented 10 minutes before the close of each interview. They are not a formal survey; they functioned to deepen insight on the 
development phase, and guide informants to focus on future-oriented strategies. In this respect, the original policy suggestions functioned, in the field research, as a policy pre-feasibility instrument. An unexpected outcome was that orientation towards the future permitted the deepest candor from participants. Therefore, in Sections 8.7 and 8.8, informants contribute on their own valuable ideas of how to future-proof the Canadian TV drama value chain for the digital age.

Informants perceive a decline in the efficacy of the legacy Canadian TV content system as a "ticking clock" of which producers, the key locus of risk in the system, are acutely aware:

There's no question our industry is as strong as it is because of subsidy. But if you never give them [the government] back their money, at some point they're going to say "I've been giving for 15 years and I've received 5\% of my money back-enough." So there is a ticking clock. We worry about it all the time. So I think the industry has done a very good job with both the federal and provincial governments. But at some point... (Respondent, CEO, Canadian TV drama firm)

Yet, producers perceive emergent opportunity for Canadian English-language TV drama, in the context of the global demise of legacy broadcasting:

There have been some wonderful ways of ensuring Canadians get money to produce, but as we move forward, only the best shows are going to survive. Canada can recognize that we have this unique place and take advantage of it and figure out a smart way to improve on what we're doing. There do have to be policy changes. (Respondent, CEO, Canadian TV drama firm)

As will be seen in this chapter, a consensus is that change is urgent. Informants recommended what might be summarized as a brand audit, in order to reposition Canadian TV drama for the online era. This would involve taking a candid view of the current situation, letting protective barriers down, trusting worldclass strengths which have been built, and building on the strengths (Kahn, 2013; Thomas \& Kohli, 2009), so as to forge a new strategic goal, to make content which competes well on the world stage:

We need to let our idea of protection go. We spend so much time protecting our little world"don't come in, you can't do that" - and not be afraid we will be abused or lose focus. The protection doesn't work anymore, because of the Internet. It's open. Really, we have to learn to compete, because otherwise I can see the whole model breaking down. It is breaking down. Television volume is down. The system is starting to fail, and nobody knows what's going to replace it. (Respondent, Executive, Canadian TV drama firm)

\subsection{Responses to $L E A F$, a trial ROI instrument}

As explored in Chapter 2, the rules for Canadian prime time TV drama have been revised numerous times. However, even audience performance metrics, via CMF envelopes, have not delivered an unequivocal, prime time hit. Canadian rules appear to be perceived as inhibiting creative excellence. Canada's regulatory regime for TV drama has been accused of delivering a beleaguered Canadian English-language TV drama brand, which has a reputation in Hollywood as "inexpensive filler." In strategizing how to strengthen audience attention and its result, the financial outcome of 
Canadian English-language, prime time TV drama, I conceived a further simplification of Canadian content rules, inspired by Canadian content rules for music, MAPL. As iterated in Chapter 2, MAPL rules require two of the following four requirements be met:

- $\mathrm{M}$ (music): music is composed entirely by a Canadian

- A (artist): music or lyrics are performed principally by a Canadian

- $\mathrm{P}$ (performance): musical selection consists of a performance that is either (a) recorded wholly in Canada or (b) performed and broadcast live in Canada

- L (lyrics): lyrics are written entirely by a Canadian

Observing that MAPL prioritizes the creation of content, while working in conjunction with Canadian content radio broadcasting requirements, I designed LEAF to describe a new category of Canadian created content for TV drama, emphasizing the pivotal role of development. Acknowledging a key difference between music and TV drama is cost, particularly in development and production, I proposed a Canadian TV drama would qualify for LEAF status, if E plus one other requirement is met:

- L: Location of production-in Canada

- E: Executive producer-TV drama firm or creator/showrunner is Canadian

- A: Actors-main performers are Canadian

- F: Finish-post-production in Canada

Consultations with informants helped clarify the purpose of flexibility in $\mathrm{E}$ is to acknowledge risk undertaken by two parties to development, creators and producers. Networks enter into development agreements with both types of entities; LEAF honours the importance of creative and financial risk. Per previous chapters of this dissertation, achieving excellence in the development phase requires that financial and creative interest are integrated. The definition of $E$ has been proposed, following discussions with informants, given the passionate comments around the pressures of financial and creative risk. A goal was to invent an incentive which might strengthen prime time TV development, but would not negatively impact production phase incentives, which continue to deliver infrastructure and jobs to the Canadian economy. Phase 2 value chain capability appears to be functioning well, even in the rapidly transforming TV drama ecosystem, and should not be sacrificed. It should be noted that the efficacy of LEAF, or similarly purposed instruments, would depend, similarly to radio broadcasting requirements, on the continuance of TV program exhibition requirements for Canadian content.

For a majority of informants, in this study, the suggestion to simplify and loosen restrictions in the development stage for prime time drama resonated as positive and strategic:

That's super-smart. That's genius. It would change the industry if you could do that. If I could give one message to the CRTC, I'd say "if you want to make TV that is on par with European and American TV, you have to evolve" - and this is evolution. (Respondent, Canadian, A-list Hollywood showrunner) 
Amazing. Anything that makes the process more streamlined and easier to understand and fewer obstacles works. (Respondent, Canadian, Hollywood showrunner)

I swear that would change things dramatically, because there are so many creative restrictions. That would change so much. (Respondent, Hollywood studio executive)

An interesting idea. I'm grateful for the 10 out of 10 system, but it is very limiting. (Respondent, Canadian TV drama showrunner)

The idea of creating more flexibility in the rules is absolutely necessary. (Respondent, CEO, Canadian TV drama firm)

With typically muted enthusiasm, Canadian development executives also perceived a potential benefit to a simplifying instrument such as LEAF. An interesting wrinkle was resistance, by these informants, to including the production firms in E. Close readings enabled this to be understood as indicating a previously hidden hostility between the independent production community and the Canadian networks. The emergence of this hostility will be further addressed in this chapter, as a series of final nuances to this dissertation's analysis of the development of Canadian English-language TV drama:

Simplifying systems is always interesting. The emphasis on the creator is something that could help push it, make it stronger. (Respondent, Canadian TV network development executive)

Maybe all the restrictions do make it too tight. You're trying to hit too many external targets then what are you compromising as a result? You can't compromise on the $E$ but this could really open things up in terms of the kinds of stories you could tell, the locations. In principle it's really interesting. (Respondent, Canadian TV network development executive)

For our shows, that would allow us a little bit of extra breathing room as we push for creative excellence, so would be to be able to use a non-Canadian writer. We have too many shows going for the available writers that we have who are senior enough to be a showrunner or even a senior writer in the room. It's put a natural limit on the number of shows that can go forward, because everybody's really aggressively going after their Canadian. I know people would be anxious that we would abandon our community of writers, which we wouldn't because they're superb, but there are moments when there's no one available to work on an idea. Then that would be awesome. (Respondent, Canadian TV network development executive)

Some TV drama producers had a wary response to LEAF, explaining that, while they need to please Hollywood partners with creative excellence, these firms also need to protect their hard-won position as recipients of public funds. Some of the same stakeholders, who worry the system is broken, also worry that changing it, by loosening broadcaster requirements, in the development phase might result in a reduced need for services provided by their companies. This is indicative of tension between the Canadian independent production community and Canadian TV networks, as linear broadcasting comes under increasing financial pressure from online delivery. Producers struggle with a partner empowered to lay off a substantive portion of risk, not only on public funds, but also on producers:

If you loosen the Can-Con definition for the broadcaster, what will happen is they'll be able to buy American shows from American studios that satisfy the LEAF requirement and have it satisfy the Can-Con requirements without having to buy from Canadian producers. In order for us to make TV 
shows, we need to own rights and we need access to the subsidy system. In order to have that access, we need to jump through 1,000 different hoops. If you loosen up the Can-Con requirements with the Canadian broadcasters that don't tie into the subsidy system, the first thing they're going to do is figure out how to satisfy their licensing requirement without worrying about Canadian producers at all. Our need is for money. It comes back to the question of if you went to a different model, what funding would that trigger? I don't care whether my show satisfies Canadian broadcasters' Can Con requirements. I care about can we raise the \$2 million to get it made. (Respondent, CEO Canadian TV drama firm)

The rules are a protection that I as a Canadian producer want. I don't want it to get a lot more flexible because the bottom line is everybody and their brother will be here and it will all be pretend. I believe our writers and directors are as good as other people's. Do we have the breadth? No we don't. I haven't thought about whether we need another regulatory thing. I'll think about it. (Respondent, CEO Canadian TV drama firm)

\subsection{Responses to digital directory of Canadian creators in Hollywood}

During the first wave of Canadian TV dramas which had U.S. network presence, in the late 1980s, there was a directory of Canadian Talent in Hollywood, administered by the Canadian Consulate in L.A., used by Canadian development executives and TV drama producers. As described in Section 2.3.3, it went defunct in the mid-2000s, and was never digitized or updated.

In the current environment, characterized by increased demand for creative services and greater opportunities at entry levels in Hollywood writers' rooms, brain drain from Canada to Hollywood has continued, but there exists no straightforward way to contact Canadian brain migrators. For the highest profile creators, this presents no problem, as their agents can be contacted through IMDbPro, the professional level of the Internet Movie Database, ${ }^{27}$ which has replaced the Hollywood Creative Directory as the industry phone book. For mid-level and entry-level creatives, who are seeking career acceleration in the global hot-spot, there is no way to search "Canadian writers" or national creators from 50+ countries which have national media regulations, as indicated by the number of co-production treaties with Canada. Per Chapter 7, absence of such a local-global linkage tool seems symptomatic of how "no need to succeed" translates to "no need to connect."

I proposed a directory of Canadian creators could be designed as a modern information tool. Informants were asked about whether such a directory would be valuable, even simply operationalized as a small, voluntary icon, such as a national flag in a corner of the IMDbPro page, which could be clicked to enable searches. Embedding such an app in the IMDbPro directory would seem to benefit IMDbPro membership, by increasing employment opportunities for creators in Hollywood, from all nations with content regimes. Although this idea seemed minor, because it did not address the structural issue, the response was positive. All stakeholders in the development process perceived this local-global linkage tool as a necessity, in an industry where information and relationships are key currencies.

\footnotetext{
${ }^{27} \mathrm{IMDbPro}$, found at https://pro-labs.imdb.com/login, offers a free trial. IMDb is owned by Amazon Inc.
} 
Here is how two mid-level showrunners of Canadian TV drama, one based in Hollywood and one based in Canada, responded to a proposed directory. Notice how the Hollywood-based showrunner conceives of it as a necessary two-way communication tool, since this same informant had never received any inquiries from Canadian networks. Also note that both creators share a sense, that there is a cache of untapped Canadian talent in Hollywood:

I love the idea of a Canadian directory. It would also be fun for me to know who the Canadian executives are and what the opportunities are. One day I'd love to come back and write and direct a Canadian something. It's in my life plan. Canadians are proud, like I am. (Respondent, Canadian, Hollywood showrunner)

That would for sure be useful. I feel there's hidden Canadians that would be perfect to write [Canadian TV dramas] that would be willing to come up who I would never know are Canadian. Would be very helpful. (Respondent, Canadian TV drama showrunner)

Another observation, by a Canadian who is a Hollywood A-list showrunner, counters the perception that Canadians in Hollywood all know each other, and confirms a local need to know about new arrivals, attempting to upgrade their skills: "What happens is somebody creates a show and asks me: 'Do you know any Canadian writers?' I say 'No, I know my two friends and that's about it.' I would love to have a directory of whoever's down here" (Respondent, Canadian, A-list Hollywood showrunner). Some of the more experienced informants remembered the old directory, and welcomed a rejuvenation of a basic industry tool: "That would be great. I always used the old one when it was around. I used to know everybody who stopped in Saskatoon for a ham sandwich long enough to qualify as Canadian” (Respondent, CEO, Canadian TV drama firm).

A CEO of a TV drama firm, which is willing to pay the price for the best creator as a strategic investment in the project's outcome, finds the Canadian TV drama reputation a hurdle to hiring Canadian creators in Hollywood. This is because agents and managers, who are building careers for ascending talent, do not necessarily want their client to be identified with a Canadian production. This informant perceives that a user-generated directory could strengthen this firm's development business, by sidestepping the Canadian TV drama brand problem:

Yes, it would help us because we have to hire Canadians. The reality is we're constantly trying to figure that out. Chances are the agents don't want their clients to come up and work in Canada. One particular writer, his agency did everything they could to stop him from developing a show with us. A little red flag on IMDb would be good for us. We wouldn't have to worry about any of that. (Respondent, CEO, Canadian TV drama firm)

A Canadian development executive gave the directory a more distanced endorsement. Consistent with the analysis of Canadian networks' self-perception as outsiders to the process to which they are gatekeepers, a close reading of the following response, appears to confirm a cynical, and perhaps erroneous, approach to finding the best talent and exploiting new financing opportunities: 
It's become a bit of a business strategy for American agencies, where they're combing their lists to see who's the secret Canadian. They know the American networks are kind of interested in this alternative financing model, because it makes good business sense to them. So they may not want all that information out there because it's proprietary in a way. We have our own lists of Canadians in L.A. I'm sure it's not exhaustive, but it's useful. (Respondent, Canadian TV network development executive)

Not only is the above comment lacking passionate interest in creative excellence, but it also misconstrues the potentially win/win/win value of easy information, which could benefit creators, financiers, and the Canadian English-language TV drama brand. In a nuanced way, it may reinforce the story told in the previous chapters, that Canadian TV networks' weak financial imperative affects a corporate drive for excellence in the development phase of Canadian English-language TV drama.

\subsection{Responses to harmonizing TV drama development terms and schedules}

Hollywood TV development processes have been honed since the beginning of the industry. Great writers and great scripts remain the quintessential ingredients in the recipe for TV drama success. The rules of the Hollywood development system, in its schedules, credits, and expected trajectories of career advancement are known to insiders, but rarely formalized, and can be misunderstood by newcomers and outsiders. Differences in credits and schedules can cause misunderstanding and/or friction between U.S. and Canadian partners. Given that high-budget Canadian TV dramas operate in the Hollywood system, informants were asked to weigh in on the value of harmonizing Canadian development credits and schedules with Hollywood, which might confer an advantage of aligning interests in the development phase.

The proposal to harmonize credits (for example, Executive Producer on a TV series) and job descriptions (for example, the role of the showrunner) was endorsed:

I think that'd be really helpful. All those executive producers on the Simpsons, probably more than half of them are writers. (Respondent, Canadian, Executive, TV drama firm)

It's just so important to have everyone talking the same language. (Respondent, Hollywood studio executive)

When you talk about showrunners in Canada, they talk about being on set. I said "You guys don't understand the meaning of showrunner. The showrunner doesn't have to be on set; they come when they need to. A showrunner takes care of everything visual, from the writing to the acting, to who's hired. As a showrunner on a [U.S. hit series] there wasn't a decision I didn't make about what you saw on screen." But a Canadian executive said to me "You need to live here when we shoot because you need to be on set." I said "That's not what the showrunner does. A directing producer is on set for 18 hours watching tapes. I send my writers to cover the episodes. Showrunners keep one vision going." That's back to development, where you start with one vision and take it through. My job as a showrunner is to make sure the voice stays the same. (Respondent, Canadian, Hollywood A-list showrunner)

A CEO of an award-winning TV drama company acknowledges the dissonance which can be caused by credit confusion in development phase jobs: 
We try to follow the American hierarchy with the rooms and we try to look for precedents and try to promote people within rooms, when deserved. But we're not going to tank a deal because some bozo Canadian agent doesn't know the credit system. The American agents are schooled in the system. It's much more institutionalized there. You learn the system and you don't rail against it. We had a situation on a show where a head of a Canadian network refused to allow us to give our line producer a 'produced by' credit on a television series, insisting it was the wrong credit and had never been done before. Within 10 minutes, we wrote a list of 10 shows with the line producer getting the "produced by" credit, not the producer credit, which is the writer. (Respondent, CEO, Canadian TV drama firm)

Consistent with the argument which suggests the Canadian network's role is the most powerful financial gatekeeper, yet the weakest link in the Canadian TV drama value chain, the above remark regarding credit discrepancies on a co-venture, suggests a lack of understanding of Hollywood by a Canadian network TV drama executive, perhaps symptomatic of a weak local-global linkage, as noted earlier.

When the question turned to the proposal to harmonize development schedules with the Hollywood system, most informants did not support this idea. A number of informants pointed out that Hollywood development schedules are already changing, to accommodate larger numbers of productions, and as well the transformations in program scheduling and audience viewing habits, such as binge viewing, which require a release pattern of a full season at one time. Changes in distribution are driving changes in development schedules. One example given was that, as shelf space expands, a function of online distribution, the exorbitant cost of pilots, and thus, the traditional pilot season can be replaced by using equivalent dollars to risk production of a full series. Unlike a pilot, a full season can be globally monetized, over time, by releasing it directly online:

The model that's changing is rather than making 12 pilots and throwing eight in the trash, they make one whole series of 12 episodes and have some faith in the talent involved and let that series develop and breathe. In one sense they're taking a bigger risk on a series, but they're reducing risk in terms of pilot outlay. And they also tend to be shrinking orders from 24 or 22 to 12 or 13. (Respondent, Canadian, A-list Hollywood showrunner)

With Hollywood development practices in transition, and demand for creators on an upward trend, most informants did not see an advantage to harmonizing Canadian development schedules with a moving target in Hollywood. Having a different schedule was even mentioned as a development advantage, in terms of securing creative talent. Moreover, the Canadian schedule was reported as functionally tied to both the public funding year-end cycle, and the immutable outdoor production season:

We don't want to be starting our shows at the same time as all the big American shows. And moreover, now, development goes all year round. (Respondent, Canadian TV network development executive)

It's not a great system in Hollywood. It forces a huge competition for writers July to September. But in our country it does happen around March-April, because of weather and CMF. (Respondent, CEO, Canadian TV drama firm) 
I don't love the Hollywood system because I think it should be more organic. If anything, U.S. broadcasters and obviously the cable networks are moving away from that kind of harmonization. Everyone is saying it is not working because we're all competing for the same talent at the same time. (Respondent, CEO, Canadian TV drama firm)

A Canadian TV development executive left coordination with Hollywood to others, indicative of an outsider perspective and a weak financial imperative to strengthen the outcome of Canadian TV drama:

You either have time or money and we don't have money so we take the time to do things. But it's always great to have transparency and maybe somebody needs to write a great blog about it or a handbook. [Interviewer mentions WGA has one on their website] Maybe WGC needs to look at doing something like that, especially because it is not as standardized here as it is down there. That could be really valuable to young writers. (Respondent, Canadian TV network development executive)

Notice above, in this answer regarding development schedules, an assumption of insufficient development funds, which appears to imply that available financing would be public funds. Profits from other revenue streams of the company do not seem to be contemplated, perhaps due to a corporate ethos, which does not consider original content as a business which creates value, but as a cost. Another informant spoke candidly, positioning credits and schedules as tiny tweaks, which do not address a challenge in the Canadian system, which is that gatekeepers have a weak motivation to succeed in the content business:

Yes it could help to harmonize terms and schedules but that's chicken-shit; it's not going to solve the problem. If people are that oblivious, with all the access there is today, they should get out of the business. It's not a business for the lazy or weak hearted. (Respondent, CEO Canadian TV drama firm)

\subsection{Responses to a creator incentive}

Since 1969, Ireland has deployed a strategy to upgrade its creative cluster and counteract brain drain, by allowing Irish residents the tax-free sale of creative IP (Chrisafis, 2005; Citizens Information, 2015). Informants were asked to consider whether a similar initiative might incentivize Canadian creators living in Hollywood to re-establish temporary residence in Canada. Spill-over benefit to the Canadian TV drama system would appear to include the upgrading of development and writer-training. As with responses to the talent directory, response to this proposal was uncontroversial and positive, such as "It's a financial incentive so it can't hurt" (Respondent, CEO, Canadian TV drama firm) and "That seems to make a lot of sense. Ultimately, you want anything that leads to creators" (Respondent, Canadian A-list Hollywood showrunner). Responses teased out the ever-present risk in a career as a creator:

As a writer you're always looking for your next project, even if you're in the middle of one, because it's never going to last forever. It's always about keeping a lot of irons in the fire. Any given project is usually $10 \%$ it will go or last more than a year. So it's very important to be able to keep your options open, and not be exclusive in pursuing other jobs or opportunities. So to the extent that you're able to keep another facet of your professional career, that would be great. (Respondent, Canadian, A-list Hollywood showrunner) 


\subsection{Responses to network incentive}

Informants were asked about ways to tweak the system at the site of the Canadian network, without damaging other strengths in the Canadian English-language TV drama value chain.

One proposed incentive was a bonus for securing development deals. Development deals, in Hollywood, are mutually beneficial for sellers and buyers. For creators, who are the sellers, development deals are considered badges of success in Hollywood, because they reduce risk by guaranteeing income. For the buyer, in a market which is intensely competitive for creative services, such deals ensure an exclusive supply of product by preferred creators.

Development deals take various forms, known as housekeeping deals, blind deals, first look deals, or combinations thereof. Housekeeping refers to providing a creator with paid offices expenses. A blind deal refers to the fact that the buyer/studio doesn't know what projects will result from the arrangement with a trusted creator. First look deal refers to the creator's obligation, in return for the above affordances, to provide a buyer with a first right of refusal on a set of projects. If the buyer passes, typically the project would be released for pitching elsewhere, often with the condition that turnaround will ensure payback of the original studio's development expenses if the project goes forward. Various arrangements include guaranteed pick-ups for one or more pilots or series, known as output deals. Details are negotiated based on the relative strength of buyer and seller of the creative services.

Not unexpectedly, showrunners, in this study, tended to endorse a proposal for Canadian networks receiving some sort of systemic bonus against Canadian content requirements, for striking development deals with creators. Benefits were seen as creating pathways to cultivate relationships, and as well, guaranteed compensation, in the most risky phase of the risky business of TV drama manufacturing:

As I've had more experience in the industry, I understand the first thing you want is to work on a network show, then a hit show that's respected. As it goes on, you're like "what's next?" Wherever that opportunity comes from, I'm open to it. I think everyone is. (Respondent, Canadian A list Hollywood showrunner)

Yes, if you're trying to lure somebody from here, it would be nice to know there's some guaranteed money, and it's substantial, because there's an opportunity cost. (Respondent, Canadian A-list Hollywood showrunner)

If a Canadian company came to me and said "We want your next show. We don't care what it is. Whatever you want." Maybe that is too much to expect, but that is exactly what it takes. Great shows happen because somebody did that. Breaking Bad is a great show. Vince Gilligan had a vision and his network let him do exactly what he wanted to do. (Respondent, Canadian A-list showrunner)

Canadian producers and networks, buy-side stakeholders, were wary of the benefits of development deals:

We're trying to get into business with some of those very senior guys. But the risk is that, ultimately you've paid for a show that you have no say in. (Respondent, CEO, Canadian TV drama firm) 
I do think we have to be more pro-active and target them and say "what's your passion?" Find the right project and they'll come. But I want it to be something real. I don't want to lock them in and have it be vague. This has never worked. (Respondent, Canadian development executive)

Consistent with the argument that Canadian networks position themselves as outsiders to co-venture TV drama business, for which they are gatekeepers, there were some telling responses to the suggestion of instruments to increase network risk, and the possibility of reward, via strengthening creator relationships:

I'm not sure anyone's going to be able to afford a housekeeping deal with [A-list creator], so maybe we would need the CMF. But there's only a handful and I'm not sure we'd get them. Or we'd have a deal and may or may not like what they did because they may or may not put their back into it. (Respondent, Canadian TV network development executive)

Close reading of the above response, filtered through the lens of the value chain analysis, reveals that each of the three sentences appear to misunderstand the purpose of a proposed broadcaster incentive. The first sentence presumes government funding would be used to finance development deals, rather than an $R \& D$ investment, which might be undertaken, for example, to upgrade a fiber optic network, with an imperative to commercialize. The second sentence speaks to the observation, as previously noted, that top creators are happy to be available to Canadian networks, but for a competitive offer. The third sentence appears to express a self-fulfilling prophecy of creative and financial failure.

Another Canadian development executive responded with a similarly defeatist tone:

In theory that could be useful. I practice I don't think it would work because the senior Canadian writers are under contract to one of the major studios. Also, I think they're not looking at a relationship with a Canadian broadcaster as a career maker (Respondent, Canadian TV network executive).

Notwithstanding that the above remark directly conflicts with informants who indicated they would welcome competitive offers from Canadian networks, the statement also may reflect the systemic flaw in the value chain. The first sentence reflects the outsider mentality, presuming Canadian networks could not be competitive players in the development process. The second implicitly confirms a corporate culture which lacks an imperative for a hit. In the Hollywood TV drama system, hits are not merely careermakers for creators, but they are company makers for broadcasters and studios. In Hollywood, all stakeholders are aligned to the same goal: a hit.

The proposal for network incentives may have exposed the most tender spot in the Canadian English-language TV drama value chain, misalignment of interests between TV drama producers, who undertake great risk, and their partners and gatekeepers, the Canadian networks, who do not fully share in either risk or goal. The last sentence of the remark below seems significant, because it indicates frustration with a partner who does not share vested interest in optimizing the asset being developed: 
The truth is [Canadian] broadcasters are not people who worry about how a show gets made. Broadcasters worry about whether a show is good and how do they program it. The only people who really worry about how a show is going to get made [in Canada] are the producers. How will it be financed? How will it sell internationally? How will it stay on the air for 5, 6 years? It's the producer's job to worry about that. If there was money [in the system] I would plough it into broadcasters doing first look deals with writers or producers. (Respondent, CEO, Canadian TV drama firm)

An informant proposed a structural fix, allowing Canadian networks to become studios, that is, to own the right to distribute original content, in exchange for production financing: "[Canadian networks] would have to become full-fledged studios, then they could do housekeeping. But they don't have a studio component. They don't make television and they don't distribute television" (Respondent, CEO, Canadian TV drama firm). Another producer summarily bluntly responded to whether a Canadian network could benefit from a public policy incentive to make hit content: "Why don't they do it on their own? The Canadian networks have risk averseness" (Respondent, CEO, Canadian TV drama firm).

Joining the story on Canadian network incentives to Hollywood, an A-list creator expressed instinctive reticence about developing with a Canadian network. This showrunner worried about initiating a project into Canadian development, then being left alone to complete the necessary financial partnerships. This concern lands on a weakness in local-global linkages, as revealed in Chapter 7, missing Canadian network presence in Hollywood:

Yes, but I wouldn't want to do it on my own. If there was somebody to help me sell it here. I wouldn't want to have to create the show and then turn around and call my agent and say, "I just sold this in Canada, can you set up meetings at NBC and CBS to help sell it here? (Respondent, Canadian, A-list showrunner).

To conclude this section, responses to development incentives to Canadian TV networks began with positive responses by creators. However, the A-list creator above, implicitly expressed comfort with the aligned sharing of risk, creative and financial, in Hollywood development. In contrast, danger appeared to be instinctively sensed by a high-performing creative, absent financial risk in the development phase.

\subsection{Other responses: Other countries' competitive advantage}

In addition to responding to original policy suggestions to strengthen the way forward, a number of informants offered comments which indicated that Canadian TV drama seems to be losing status in Hollywood, compared to a visible record of other nations, and attributed this to weak development.

As noted, increased numbers of buyers of TV drama has translated to increased competition and opportunity along several paradigms. There is increased need for creative services, which has reinforced a pattern of brain drain from Canada to Hollywood. There is also an increased need for skilled production crews, thus, increased competition for production contracts among jurisdictions around North America and the world. The Netflix hit, House of Cards made use of subsidies from the state of Maryland 
(Johnson, 2014). Breaking Bad benefitted from Arizona subsidies, changing its setting part way into production to take advantage of incentives (Brennan, 2013). Ironically, Canadian production discounts may have delivered a learning curve to Hollywood, on outsourcing:

Shows like Rookie Blue and Flashpoint are changing how the networks down here behave because they're asking, "Why am I paying $\$ 4$ million licence fee for a show, while another is being made for \$2 million and still has high quality and good audience?” That's not restricted to Canada. If it's an Israeli program or any kind of international co-financing deal, it's really making the networks sit up and take notice. It's not a direct result of Canadian shows but just a direct result of how the industry is changing. (Respondent, CEO, Canadian TV drama firm)

Nevertheless, in the current climate, production discounts do not appear be the determining factor in partnership. On a level playing field, where there are many potential locations to shoot, there appears to be a disadvantage to Canada's reputation for discount TV drama. Downward pressure on budgets, which increases production outsourcing from Los Angeles, is accompanied by upward pressure on development, and therefore, to minimize creative restrictions. As reported earlier, a Hollywood studio executive reports that rules caused a series to bypass Canada as a location.

Informants also remarked on another aspect of competitive advantage in TV drama, specifically related to development, observing that Canadian networks are not stepping up to unprecedented opportunity to co-develop:

They're trying to do some development from the beginning, but you know who's driving it? It's not the Canadians. It's the Americans. The Canadians are being called by the Americans and saying "Do you have anything interesting? What do you have going in development?" If there's anything that excites these people, they'll buy it. You've got studios coming and saying they want to buy the rights to content. And networks coming and saying we would like to license with you as a team. Let's find the right studio to make it for us. Or a third version is the minute you make it $100 \%$ Canadian, we want to be the ones to air it in America. We'll have an exclusive license. (Respondent, Canadian, Hollywood, A-list showrunner)

The Canadian network's perspective on this recent opportunity appears more detached:

We are fortunate because increasingly around the world, including the U.S., broadcasters and producers are recognizing the value of sharing costs on creative output in a way that is encouraging. Canadians have always been very good at international co-pros and we have a good reputation for being terrific partners who are able to make stuff work. If we can show our television industry has matured so much in the last 5 years, that gives confidence to some countries who have a rich tradition in television who, till now, may have felt a little hesitant about co-ventures ${ }^{28}$ For instance, in Britain they're very comfortable doing co-productions like The Tudors, where it's their own history being explored. I'm still hoping for the day where we manage to get something going that is not a period drama, but a compelling contemporary drama that set wherever it's set. But I

\footnotetext{
${ }^{28}$ This is an instance of the term "co-venture" being used colloquially by a Canadian TV network development executive, to reference, not only a formally defined CRTC Co-venture, but more simply, any type of partnership with Canadian producers.
} 
think we still have a little bit of a ways to go to get there. (Respondent, Canadian TV network development executive)

The slowness of Canadian networks to capitalize on trends in Hollywood TV drama has not gone unnoticed by a prominent media journalist; as discussed in Chapter 7, this may be related to absence from the cluster, which may lead to missing industry buzz:

There's a prevailing sentiment in the culture that we're more than a decade into a new Golden Age of television. The starting point was the arrival of The Sopranos in 1999 and the most recent marker in the ongoing evolution of excellent TV was the series finale of Breaking Bad. What has Canada contributed to this? Pretty much nothing. Look at the last 14 years of Canadian TV and what you see is almost complete creative failure. (Doyle, 2013, para. 2)

Informants also suggested another development opportunity being missed, the sale of TV drama format adaptions. For example, Homeland, Showtime's hit series, is based on an Israeli series. Secrets and Lies (in development with $\mathrm{ABC}$ ) and Rake (U.S. network FOX) are based on Australian series. The Killing (AMC and Netflix) is based on a Danish TV series. Broadchurch, a British series from ITV, is being adapted by Fox. As well known, the Netflix hit, House of Cards, is based on BBC mini-series. Informants suggested this trend signals financial opportunity based on development excellence:

The Americans have suddenly discovered foreign content. Every format in every country now is being bought. Just to give you an example, from a development point of view, Secrets and Lies is a new show $\mathrm{ABC}$ is on the verge of picking up. It's an Australian show that had not even aired in Australia before everyone in the world bid on it. There are so many successful formants now that are being bought. Homeland is Israeli. There's a whole bunch of Belgium Dutch shows. The Killing has been hugely successful. House of Cards is a British format. Sometimes they're giving not just the format, but also the scripts. These shows are being purchased before they're even airing. (Respondent, Canadian A-list showrunner)

It can be very difficult to compete with the networks but you can with cable, like the shows that are coming out of Israel and Denmark and Norway and things like that. There are all these interesting shows and limited series. You want to encourage writers to do something good. (Respondent, Canadian A-list showrunner)

To date, it appears that the only format rights sold by a Canadian series were those of Little Mosque on the Prairie (CBC, 2007-2012), acquired by Fox, but a U.S. version of the show has never been produced (Floyd, 2011). Canada's English-language TV drama sector, theoretically well positioned to capitalize on Hollywood trends, does not appear to be doing so:

Australia, New Zealand, the UK, France, even Quebec - all these countries [sic] have more formats coming into the U.S. than English speaking Canada. (Respondent, CEO, Canadian TV drama firm)

Look at House of Cards which was in England first then became an American version. Then this series called The Killing which was Danish first, then British, then American. It was these interesting ideas that developed in one country and re-formatted in another. Those are all money makers. Nothing is preventing us from selling format ideas, we have to come up with format that are sellable, that other people want. (Respondent, CEO, Canadian TV drama firm) 
I don't know why but it seems like the BBC has succeeded where the Canadian market has not. Not just the BBC, also other European markets. (Respondent, Canadian, Hollywood A-list showrunner) ${ }^{29}$

Broadchurch was something the assistants were talking about I immediately went to Netflix and check it out, because they have their finger on the pulse. Next thing you know Fox does a big deal where they're going to do the American version. It's case by case, but predominantly the history has been "Oh it's Canadian," more of a filler than something you're going to get creatively excited about because it's going to feel fresh and original. (Respondent, Hollywood studio development executive)

To conclude this section, the data suggests the development phase of TV drama may be more valuable than ever. With development phase activities increasingly visible, it may be more noticeable that the Canadian English-language TV drama development process has been "warped" by missing a strong link to financial results.

\subsection{Final answer: Strongest player to weakest link}

At the close of each interview, informants were asked for any further thoughts regarding the way forward for Canadian English-language TV drama system. Frustration gave way to excitement about the future, by creators and producers:

It's such a golden age of television right now. There are so many good shows and people have to embrace that and figure out why that is happening. The reason it is happening is because the writers have powers, and Canada's a half-step behind in that. (Respondent, Canadian, A-list Hollywood showrunner)

Netflix, God bless them, they're changing the face of television, how we watch and how it's made. It's really encouraging as a writer to seem more of what I hope is a renewed faith in the creative process. (Respondent, Canadian, A-list Hollywood showrunner)

Sixty networks in the U.S. are commissioning original programming. It's a great opportunity because demand is outpacing supply and the U.S. market has become more open to non-Americans. (Respondent, CEO, Canadian TV drama firm)

Given the sea change in how TV drama is consumed, response by the Canadian system is seen as urgent:

The protection has helped develop the industry, but now we need to stop focusing so much on protecting and trust we're strong enough to be able to compete. ... We all have to figure this out and stop whining and complaining and just get on with it. We're going to have to change, so let's start the process. (Respondent, Canadian Executive, Canadian TV dramafirm)

Yet, there was concern about the motivation of Canadian networks to change. The following remark suggests a reversal of roles, with the Canadian TV networks shifting from strongest players to weakest link in the English-language TV drama value chain: "What's the motivation for the Canadian networks to try to fix this problem? The money [they trigger and invest] is not theirs. They're losing only a small

\footnotetext{
${ }^{29}$ This informant means the TV drama production industries, rather than the markets of the respective countries.
} 
percentage of their own money. They write it off on their taxes" (Respondent, Canadian Hollywood A-list showrunner).

In the current ecosystem, "content is valuable/any content you can own" (Respondent, CEO, Canadian TV drama firm). The data, in this dissertation, suggests the historic nexus of strength in the Canadian system, the networks, may have devolved to a nexus of weakness. A value chain fault, which delivers a weak development phase, which may be inhibiting Canadian TV drama from meeting the online era with strength and purpose:

It's a systemic structural problem. Canadian broadcasters make their money by buying U.S. shows and simulcasting them. They make Canadian shows because it's a requirement and it goes to the whole culture of how they approach Canadian content. The problem we have today and it's a big problem, is the big media companies are not making enough money doing what they traditionally did. So they're turning their sights to the success of the shows being created. So your mind turns to "OK, if you're going to do that, just become a studio, rather than squeeze producers to the point where it's no longer lucrative to make television." (Respondent, CEO, Canadian TV drama firm).

The broadcasters who exist because of regulation are now being handcuffed because of regulation. It's a very interesting phase. If you look at Netflix coming to Canada, the hatred the Canadian broadcasters have for Netflix doesn't exist in the U.S. Netflix is a competitor, so you don't always love your competitors. But they're also part of the value chain - because broadcasters in the U.S. own their own programming. Today, the rules are not supporting the opportunity to have a real hit. There has to be change. I know there are a lot of competing voices that are, in my opinion, very short sighted. (Respondent, CEO, Canadian TV drama firm)

I hope there is a point where these shows [Canadian content] become self-sustainable. (Respondent, CEO, Canadian TV drama firm)

An impassioned analysis underscores that upgrading cannot be accomplished without connecting phase 1, creation of the asset, to phase 3, monetization of asset. Value chain evolution seems imperative:

You can see the end; it's just around the corner. The Canadian broadcasters, especially in drama, to compete have to do bigger budget shows, which they can't afford. So Canadian producers are now burdened with these huge deficits. There was a period of time when Canadian drama was fully funded in Canada. In the old days, you could get a show ordered, and a small deficit would be taken on by a distributor. If you sold in a few territories, you'd be fine. Now, for these big dramas, if you don't get a U.S. sale, it's impossible to get them financed. And all of a sudden, Canadian broadcasters are saying we want these shows to compete, because we need to make money on these Canadian shows, and in order to do that we need bigger budgets, bigger talent. And, they want these shows to be relatively procedural and closed ended, because where they have a chance to make money is by repeating them. But, the serialized dramas, which help build brands for networks because they are the cool shows that people talk about, they don't repeat.

But I see what's going on in the rest of the world. Everywhere else the broadcasters and producers are partnering. They're sharing rights because they need each other. The U.S. doesn't have terms of trade. You work out deals based on "if you have a great show, there will be a bidding war for it." In Canada it's still political.

They need to figure out new rules, because the really good shows in Canada that have big deficits are using all the CMF money. Then, the U.S. studios are coming in and taking world-wide rights to those shows, and hiding behind Canadian production companies. So all the money that 
CMF financed, all the upside is going to be owned, not by a large Canadian media company, but by a large U.S. media conglomerate (Respondent, CEO, Canadian TV drama firm).

The data suggests that Canada's TV drama producers are the stakeholders who undertake the most risk in Canadian English-language premium TV drama value chain, and consequently, appear to feel the most urgency to change development dynamics, with the priority being to address the financial structure in the development phase. The implication is that fixing structural issues may organically lead to creative upgrading. Development cannot be strengthened without addressing monetization:

You've got to open up the rules and look at what's really important-which is ownership and control of the shows. Soon as you say it can only work with Canadian writers, it's too limiting. Why can't a British or French or American develop a great project as long as the intention of that project ultimately shoots in Canada? And even if the project doesn't shoot in Canada, it would help if the Canadian broadcaster owns the project, so even if the show ends up shooting in Germany, if it's a hit, the Canadian company gets the profits. When a U.S. broadcaster funds development, they own it. It depends on what the Canadian mandate is. If one of the mandates is making sure Canadian culture is maintained, that's what the CBC is for. CTV and Bell and Shaw, they're private enterprises. They're supposed to make money. (Respondent, CEO, Canadian TV drama firm)

When pressed for a way forward, some informants engaged in "thought experiments," which included sweeping away the current regulatory regime and starting over, including a deep question about the justification for rules about the writer, which is just one job, but the most important one:

We're now in a very disrupted time. The old model is not going to work. The biggest problem is the funding model, which goes from the broadcasters to the CMF and then dispersed to the production industry. We have to acknowledge the internet is going to become the broadcaster. My generation is cutting the cord. When it was just kids, it was different. I think the whole thing should be blown open. We have to figure this out and stop whining and complaining and just get on with it. We have to change so let's start the process. Ok, let's start from zero. Take all the subsidies off the table. See what's working, and how it could work differently. See where that leads us. Aren't we masters of our own destiny? If we made the regulations, we can change them. (Respondent, Executive, Canadian TV drama firm, [my italics])

"We have to step back and look at the Canadian system from first principles and say "OK, these rules came into place in the 60s and 70s - then they evolved over time and may have made sense back then, but to they still make sense now?" The whole system needs an overhaul. It's now a business where development is more important than it's ever been. Assuming you want some regulatory framework in Canada, you've got to focus on development. If you wanted to just produce jobs, why have all these creative rules? That will create six jobs. Versus a hit show in Canada that stays on for eight seasons and makes millions or even hundreds of millions of dollars for the Canadian infrastructure that will create way more jobs. (Respondent, CEO, Canadian coventure firm, [my italics] $)^{30}$

Historical perspective, as reviewed in Chapter 2, shows that it is not surprising that Canada's Broadcasting Act strategized the way to build an industry was to lean on the strongest players, the TV

\footnotetext{
${ }^{30}$ For clarification, the informant's reference to the "whole system" means the whole Canadian prime time TV drama system, which was the abiding context and specific focus of the interview.
} 
networks, to build a story-telling sector. And it worked. Nevertheless, so unguarded is the informant below, despite status as an award-winning Canadian TV drama CEO, the recommendation is to allow Canadian TV networks to operate as studios:

I believe in subsidizing industry to make great content, but large aspects of the Canadian system are deeply and irreparably flawed. There will be bandages, but at the end of the day, none of it makes any sense, so we're fighting against the tide.

Production subsidies are valuable, for the same reason the UK has them, why Hungary has them, why multiple U.S. states have them. Not cultural subsidies, but industrial subsidies designed to create a place of making content. Those should stay in place.

My view is the rest should all be done away with. All regulations for broadcasters should be wiped out and all other subsidies should be wiped out and it should be survival of the fittest. If someone wants to be a producer, fight on the merits of your content and raise capital and become a studio and underwrite content - as a result have the right to own and distribute it.

You have to skip ahead 30 years and see whether that experiment would work; that's the point. It would wipe out the industry, but when everyone starts fresh, you would see this ground swell of young Canadian talent, starting to create stuff. You can bet it will speak to them in a Canadian way. Whatever is getting them going creatively would be influenced by their upbringing and where they were born, which would be Canada. If the regulations went away, and there were three broadcasters left, and they would have the ability to start a studio, start distributing content in a real business-like manner, you would have more great shows by Canadian writers. They would do it because it would be good.

I'm trying to think about another industry. I'll pick clothing. There are two or three internationally renowned Canadian clothing companies. There are not 400 Lululemons. But there are 400 Canadian production companies. If instead of 400 companies, we' $d$ have five- that would be $\mathrm{OK}$ in my view.

The problem is systemic. It's gone on for so long the broadcasters in this country are incapable of looking at the creative community the way they should.

Maybe the simple fix is, if you don't want to undo it all, if you don't want to pull on the thread and undo the whole sweater - why can't Canadian broadcasters also be producers? Why are there restrictions in their license agreements that require that they buy Can-con from third-party producers, as opposed to buying it for themselves? Why they can't access the CMF envelopes themselves? If the rationale for these restrictions is simply to create 400 production companies across the country, this might be the weakest link in the whole system. Break that down, let the broadcasters build studios, just like the Americans have now, where there are very few independents. Work with really strong creative producers and still keep the Canadian production subsidies in place. Now you could still make Canadian stories with Canadian creators but you've got bigger, stronger entities making the content. And you won't have the dynamic of the broadcaster resenting and squeezing the Canadian production community. And the Canadian production community throwing up their arms going "I need to stay alive. I have 30 people here. I have to pay my mortgage. I have to feed my kids."

The American model has evolved. The Canadian business model makes absolutely no sense today. If you try to mandate fixes to a policy that has its origin in the era in which it was created, you have a massive problem on your hands. You know what's the most ironic thing? The most successful Canadian content company of all time, Alliance Atlantis, almost went bankrupt using the Canadian system. What saved them? Buying a show using the American model, paying $50 \%$ of the cost of the content and selling it around the world. CSI was the biggest, most successful drama in the history of television. Today, content is more valuable than ever. Content, any content you can possibly own. (Respondent, CEO, Canadian TV drama firm, [my italics]) 
The informant's analysis suggests that in a global, online distribution system, TV drama business models of all countries, regulated or not, may evolve towards a Hollywood model: make great content which competes internationally, and monetize it over the largest possible audience. In such an environment, potential benefits of finding a way to build well-financed Canadian studios might be an important component of a value chain evolution. A result could be that if a global hit were created, using substantial public funds, the profits, instead of flowing to a U.S. media conglomerate, would flow back to Canada. Theoretically, profits might be used to further strengthen development and infrastructure, lessen dependence on public funds, and move the prime time TV drama sector towards sustainability.

Yet, there may be a catch. Trina McQueen's report, Dramatic Choices, as referenced in Chapter 2, brilliantly observed that Canadian TV drama, in the 20th century, existed purely due to political will (McQueen, 2003). Even assuming, as an informant suggested, that risk could be built into the value chain, the catch, as noted by informants, may be whether Canadian networks would choose to enter a new, risky business arena, whereby Canadian drama would exist due to financial will. Canadian TV drama could be positioned as one business activity, embedded with other robust revenue streams, including wireless and broadband. While the other revenue streams are characterized by a need for substantive R\&D investment, informants were wary as to whether, these same players might be incentivized to enter an arena in which they have little history of success, and in the case of global distribution, little in-house capability: “I don't know if there's a way to train the Canadian networks to actually be in the television business. I don't think they want to be in the commissioning business" (Respondent, CEO, Canadian TV drama firm).

As also noted, the cost of not upgrading Canadian TV drama capability could include the decline of the hard-won production sector:

Revenue is down. They're cutting back on Canadian programming. Where's the CMF money going to come from if they are not contributing what they used to? Programming is already down in terms of what they're greenlighting. More production companies are going to voluntarily reduce themselves or close their doors, because everything's changed. It's like the music business; we ignore it at our peril. We have to be active in searching out next steps. The real jeopardy is we let all of it disintegrate. Nothing has happened drastically yet, but it's coming. (Respondent, Executive, Canadian TV drama firm)

Unless the value chain is adjusted, the decline of legacy cable and linear broadcasting may cause a decline in public funds available to the system, given the current cross-subsidy model. In the words of an informant, the time to mature is now, and the door seems open wider for Canada than ever before:

Shelf space in the U.S. is growing; shelf space in Canada is diminishing, and I am referring specifically to Canadian content. We have this interesting situation where a bunch of networks in the U.S. are now looking to Canada as a potential supplier. (Respondent, CEO, Canadian TV drama firm) 
If you tweak the rights holding rules, that would change the dynamic. (Respondent, CEO, Canadian TV drama firm)

The consistent message was that development, the creative and financial arena that has historically been both hidden and overlooked, must be urgently addressed:

If you impose quotas on development, it would help tremendously. (Respondent, CEO, Canadian TV drama firm)

We're never going to spend $\$ 4$ million on a show so we have to tell the greatest stories, the darkest stories, the edgiest, the coolest, the smartest. (Respondent, Canadian, A-list Hollywood showrunner)

It's highly competitive now. What it's going to take in my opinion is lightning in a bottle. Is there a way we can take development up a notch? (Respondent, CEO, Canadian TV drama firm)

Some informants weighed on the idea that, since the production phase involves the majority of jobs, development may not be controversial. A tricky part may be adjusting long entrenched protections, which may have contributed to an entitlement mentality of lobby organizations, ${ }^{31}$ whose memberships do not represent the majority of TV drama jobs, but those jobs which do critically impact development:

Can we let the protection barrier down for the moment and just talk about the development of talent? They feel very threatened in these conversations. It's the same with DGC and ACTRA. It's easy for them to feel the threat first. So you have to help them let the threat go and think about their betterment. Could it be done in installments, so nobody gets too scared? There are all kinds of transitions that could be put in place. (Respondent, Executive, Canadian TV drama firm)

Organizations, which were mentioned by informants, included Writers' Guild of Canada/WGC, Directors Guild of Canada/DGC, Actors Guild/ACTRA, and Canadian Media Production Association/CMPA:

There's a challenge because there's an old guard and a new guard, both at the producers' level and the Writers' Guild level. (Respondent, CEO, Canadian TV drama firm)

You've got so many interest groups. You've got the writers' guild and all the guilds saying "This sounds like a recipe for jobs being lost to Americans." Yes, maybe in the short run they're right. But think about the long term play you can create. Because our production structure is great. People are producing in Toronto, Vancouver, Montreal, Halifax, Calgary. American shows are still coming in. The major jobs are below-the-line jobs. The writer jobs are obviously crucial, but that is like, six jobs. It doesn't necessarily make a Canadian show just because you have a Canadian writer. And don't force a first or second highest paid actor. Again, you've created one job. Why does the first or second most prominent actor have to be Canadian? I'll tell you why, ACTRA. If you want to maintain and build a Canadian infrastructure besides a below-the-line infrastructure, you've got to open the creative rules a little so you're not so short-sighted that it's all about creating 10 jobs. Open it up, focus more on real ownership and control. (Respondent, CEO, Canadian TV drama firm)

\footnotetext{
${ }^{31}$ The transcript of the Let's Talk TV hearing, which can be found at http://www.crtc.gc.ca/eng/transcripts/2014/index.htm, indicates that the CRTC Chairman questioned the WGC about "entitlements."
} 
What is the perspective on the future from the Canadian networks? An informant relayed a thirdhand anecdote, perhaps indicative of the Canadian TV networks' mindset. At a 2014 conference, when the discussion turned to the global transition in consumer viewing habits, the informant reports " $\mathrm{A}$ Canadian network VP stood and said, 'Our audience really likes to watch one episode a week.' We were all stunned. But that's what he said" (Respondent, Executive, Canadian TV drama firm). When pressed for specifics on a way forward for Canadian TV drama, notice how, in the remark below, the situation is problematized, by a network executive, as a need for more public assistance. Other than positioning public funding as a way to "offset the costs of production," the strongest idea of how to fix the current situation appears to be a suggestion for more product-placement. A content monetization model of Canadian TV drama does not appear to be contemplated, notwithstanding an obvious irony that monetization of Hollywood content has been the long-standing ROI model of Canadian TV broadcasters:

The feds have been putting in a hundred million for 10 or 15 years, and we're very grateful to the $\mathrm{CMF}$, but that's been a static amount. Yet production costs and everything else has gone up, and the private side of the revenues are going down. Do they need to think about it? I know it sounds like I'm just going back to the old system, but I think that's a piece of whatever needs to be considered. Increasingly, if we can get sponsors who will come on board with integrations into drama in ways that are unobtrusive and organic, that might be an additional way for us to offset some of the costs of production. (Respondent, Canadian TV network development executive)

Contrast the above analysis with a U.S. studio development executive's assessment of the need for change in response to ongoing transformations:

We are trying to think outside the box, because the business is constantly changing all around us. The traditional TV model is getting tougher and tougher.... Wherever we can find smart ways to do something at a lower cost, without eating away at the integrity of the vision, we are open to discussions. (Respondent, Hollywood studio development executive)

As the informants closed out their comments on development dynamics, a simple, top-down strategic recommendation emerged. A start-point for change might be the overall goal of the Canadian, Englishlanguage prime time TV drama value chain:

Maybe a better way to do it is to first say what we do want to accomplish and set a goal. And then say, let's look at the whole system and what works towards that goal, and what doesn't. It will be too late when it lands, the train will have left the station. We need to be asking these questions now. (Respondent, Executive, Canadian TV drama firm, [my italics])

\subsection{Chapter summary}

This chapter reported on informants' responses to suggestions for development strategies. In a departure from Chapters 5-7, informants were asked to focus on the future of Canadian English-language TV drama, and as well, to weigh in on any other thoughts they might have, which had not been discussed. 
Section 8.1 reported on informants' responses to LEAF, a trial instrument to shift the goal of Canadian drama from domestic supply to global demand, and its outcome from investment to return on investment. Inspired by the music policy, MAPL, LEAF for TV drama might loosen creative restrictions in the development stage, to better align interests in Canadian TV drama with Hollywood counterparts.

Section 8.2 reported on informants' responses to a volunteer digital directory of Canadian development talent. Such a directory could help development stakeholders connect and deliver a win/win benefit of increasing employment and at the same time, strengthen development of Canadian TV drama. It could benefit the many nations with content regulations, whose nationals are present in Hollywood.

Section 8.3 reported responses to the potential impact of a tax free sale of creative IP; a benefit could be the presence of accomplished creators in Canada, which could have spillover training benefits, which would meet the expressed need to continuously upgrade domestic TV drama writing skills.

Section 8.4 reported on informants' responses to the idea of harmonizing Canadian TV drama development terms and schedules with those of Hollywood. While the consensus on harmonizing terms was positive, responses to a benefit to harmonizing development schedules was mixed. An unexpected value of the question was to tease out the ways that Hollywood development practices are changing to adapt to the current environment.

Section 8.5 reported on informants' responses to mechanisms geared to incentivize Canadian TV networks to participate more fully in the content business. These proposals prompted informants to express candid frustrations and recommendations regarding an urgent need for change.

Section 8.6 reported on a common theme in the data, that despite unique geo-cultural proximity, Canada seems to be losing competitive advantage in TV drama, and this weakness seems most visible in development, i.e. creative output. Three arenas of weakness were identified by informants: (a) loss of TV drama production deals due to Canadian development phase restrictions; (b) missed opportunities to codevelop for the same reasons; and (c) missed opportunities in the growing market for format rights.

Section 8.7 focused on informants' most candid recommendations on how to strengthen Canadian TV drama going forward. Several consider the system to be irreparably flawed, and suggested rules should be swept away and re-written with a modern understanding of the TV drama business. Informants asserted that development is of unprecedented importance, as online distribution unbundles the protection of cable subscriptions and channels, and more than ever before, renders the content consumer facing. A number of informants were clear that change is needed urgently, that a consequence of doing nothing about the development phase might be the decline of hard-won industry strength in the production phases of the Canadian English-language premium TV drama value chain. 


\section{CHAPTER 9}

\section{DOMESTIC SUPPLY TO GLOBAL DEMAND: FUTURE-PROOFING CANADIAN ENGLISH-LANGUAGE TV DRAMA}

How can we work to bring people together? We should start by getting way more strategic, and I include the Canadian broadcasters, because television is getting better and better and better. How do we maintain our ability to be strong Canadian creators? What I would say is a much more strategic approach. There have been some wonderful ways of ensuring that Canadians get money to develop and produce, but as we move forward, the best shows are going to survive. And so Canada can recognize that we have this unique place and take advantage of it and figure out a smart way to improve on what we're doing. (Respondent, CEO, Canadian TV drama firm)

Irene Berkowitz of Ryerson University... discussed the importance of rebranding Canada as an exporter of global hits (CRTC, 2015f, para. 55).... Ms. Berkowitz proposed ... turning Canada's proximity to the U.S. into a competitive advantage by changing the points system. ... "Canadian created stories," in Berkowitz's view, would recapture the value of Canadian expatriates working in Hollywood and make the "brain drain" into a "brain chain." She proposed a new points system which can be found in her written submission. (CRTC, 2015f, para. 110)

\subsection{Introduction}

This dissertation has been a case study, for the purpose of providing evidence informed policy research. Consistent with recommended case study methodology, data from a wide variety of sources was sourced and utilized, including industrial history, policy history, and theoretical frameworks, which were then joined with original analysis and field data. The case of development dynamics of Canadian Englishlanguage prime time TV drama has been examined, and compared to development dynamics of Hollywood TV drama, against the background of profound global upheaval in the TV industry, in content delivery technology, revenue models, and consumer practices. Widening the perspective on the ongoing disruption, production phase jobs in diverse sectors are being hollowed out by technology, while the importance of IP appears to be ascending. It has been predicted that, in the near future, nearly half of existing jobs may be taken by technology, and as observed, by futurist Ray Kurzweil, the global economy may be driven "almost exclusively by intellectual property" (Efron, 2015, Brawn to brain, para. 3).

Why does this dissertation matter? It matters because the Canadian TV industry is subject to these unprecedented, global changes, which are accelerating. This research suggests that the Canadian Englishlanguage premium TV drama sector must change, if it is to thrive in the era of online TV program delivery. In contrast to predictions that the Internet would cause the end of TV drama, and as proof that competition breeds strength, TV Hollywood creators have responded with content so good at capturing attention that this transformative era is being called the newest golden age of TV. More than ever before, hit content is king. At this writing, Huffington Post, a 10-year old digital native company, has announced an original TV and movie division, with the goal to position themselves as a "global video brand" to 
compete with Netflix, saying "it's no secret how successful they've been. They're proving the content model is working" (Charlton, 2015, paras. 1, 9). While digital delivery has already irreversibly transformed other media sectors, the unbundling work of the Internet on linear TV is in full swing. Unprecedented competition for consumer attention is further complicated, as platforms and geographic boundaries blur, making discoverability of all content, not just Canadian content, a key issue for the global TV industry, as the disruption accelerates (O’Brien, 2015).

For Canada, the argument of this dissertation suggests that a competitive content business model, which prioritizes a value chain designed to deliver globally popular content, may be important, if the philosophical imperatives of Canada's Broadcasting Act are to be achieved, in an era of online TV delivery. If implemented carefully, such an IP focused model might be accretive to the current value chain, which appears to prioritize value derived from the production phase. Most simply put, The Act has a dual requirement for our system to have strong story-telling sector and to remain technologically current. It can be deduced, from informants' remarks in the foregoing chapters, that re-interpreting The $A c t$, for the 21 st century, may require adjusting our value chain to forge a tighter connection between at phase 1 (create) and phase 3 (exploit). At this writing, Canadian English-language TV drama is not in a golden age; it continues to be domestically and globally unpopular.

This research set out to discover the reasons why the Canadian content business model is not strong, with the purpose to inform the suggestion of new TV drama policies, which might effectively respond to global disruption and rapid value migration, and suggest policy innovation, which might help to bring on a golden age of Canadian English-language TV drama. The foregoing value chain analysis and field study data suggest a new explanation for weak market traction: weak development, an unintended consequence of the Canadian English-language TV drama value chain. A finding suggests that development appears to be the key ingredient in the market performance of a TV drama, yet this phase appears to have been largely overlooked in policy, regulation, industry practice, and in the substantive public conversation around Canadian English-language TV drama.

Five reasons pointed to the strategy to explore development. Firstly, notwithstanding the exploding use of big data to inform development decisions, business practices in the development phase have remained relatively stable since the origins of the TV industry. Secondly, brain drain to Hollywood: Canada has never lacked world-class TV creators, but has lacked a record of exporting world-class creations. Thirdly, strengthening the development phase may be a strategy, which might future-proof the Canadian TV drama system for the digital age. As platforms and program origins blur, the development phase remains distribution agnostic; the audience doesn't care how a program gets to a screen, but only about what's on it. 
The last two rationales for the focus on development bring the story of this dissertation full circle. Fourthly, development is where the asset is created and optimized. As asserted in the opening pages, story-telling, whether around a campfire or a digital screen, is an archetypical human need. More than ever, stories appear to be an increasingly welcome anchor in an era of dizzying information overload, an expression of our identity and spirit (Sachs, 2012). Finally, there is the reframing of this historic creative destruction (Abernathy \& Clark, 1985) of the TV industry, from threat to opportunity for Canadian English-language TV drama. The global mediaquake demands response, and value chain evolution is a potent response strategy (Christensen et al., 2013). The online era might be reframed as bringing to English Canada, a solution to the problem it has struggled with most, since the beginning of the TV industry, a small domestic market. Digital delivery might allow a reframing of the goal of Canadian English-language TV drama, from its 20th century domestic focus, to a 21 st century goal to connect with the English-language North American audience, and more, with the world's seven billion potential viewers. All that is needed is to grab their attention:

I think the goal is to continue storytelling, allowing Canadian talent, wherever it is, to develop and practice, and I think we should be encouraging that. We have the means to encourage it in many different ways - either in training or in regulation of what we consider to be most valuable. We have the means-we just have to decide what we are looking for-what our goal is. (Respondent, CEO, Canadian TV drama firm)

A global audience may not have been imagined by the creators of Canada's Broadcasting Act, because digital TV distribution had not yet been conceived. Yet, what might be more synchronous with the spirit of The Act, given its requirement for a strong story-telling sector, than popularity for Canadian stories? As all TV models converge towards Hollywood's, commercialization of content via popularity; domestic and global applause for Canada's stories may not just be good business, it could be great culture (Berkowitz, 2014g). The reasons why global popularity might be great culture are multiple.

Firstly, a strong content business model for prime time TV drama, which globally, has always been the most popular and profitable TV genre (and as such, became CMF's priority, as directed by DCH), might result in economic strength, which might lessen dependence on public assistance to entertainment. This might free up funds for other media being impacted by online delivery, such as news and documentaries, and or even other national

Secondly, global applause for Canadian English-language TV drama might cause positive spillover effects on the Canadian content brand. An exemplary case seems BAFTA's special award to Downton Abbey (2010-to date, ITV, PBS) for "flying the flag of Britain." Calling the series a "national treasure" and a "global phenomenon," Downton producer's says: "Not only is Downton Abbey a much loved show in Britain, it has had huge success in the U.S. and right around the world, waving the flag for Britain and our creative content" (as cited in Debnath, 2015, para. 4). 
Lastly, positive spillover might extend beyond pride in Canadian content, to other industries. Waving the flag for Canadian drama might stimulate tourism and global interest in our marvelous country. Global attention for Canadian created stories could implicitly export, not trivial cultural markers like street signs or kilometers, but deeper, core values, such as tolerance, peace, gun prohibition, and universal health care. At the very least, as the joke goes, success can't hurt.

\subsection{Review of original contributions of this dissertation}

This dissertation employed three methodologies to study the dynamics of Canadian Englishlanguage prime time TV drama development, and compare them to development dynamics in Hollywood prime time TV drama. Chapter 2 assembled four arenas of background information. Chapter 3 presented a value chain analysis of the Canadian English-language TV drama sector. Chapters 4-8 reported on a field study of elite informants in the development phase. The results have included a number of original contributions. Overall, the finding is that, while the Canadian English-language TV drama value chain has been well built for national profits on global content (i.e., Hollywood drama), this might be backwards for the online era. To succeed at an original content model, there appears to be an urgency to adjust the Canadian English-language TV value chain, so as to deliver global profits on national content.

As a whole, the contributions offer a reframing of the challenges of the Canadian, English-language TV drama sector. The findings extend and deepen some previous analyses about why Canadian TV drama has not matured into a popular sector:

- Development, phase 1 of the value chain, must emerge as a priority. Further focus on production incentives will continue to deliver results in production, already a world-class capability. To preserve employment in TV production, specifically the half which represents Canadian content, the focus should be development.

- Previous analyses of the weakness of Canadian English-language TV drama, chiefly insufficient audiences and insufficient financing, are reframed as symptomatic of development weakness.

- Strengthening development does not mean defining development only in terms of creative excellence. Financial excellence is the determinant. This dissertation found that the Canadian English-language TV drama value chain tends to fade at the conclusion of production, phase 2, and is characterized by a weak link is to monetization, phase 3 . This weakness ripples backwards to result in a poor alignment of financially vested interests in the development phase, which, in turn, results in insufficient pressure to optimize the asset. Even in development, for which the main outcome must be creative excellence, it is critical to follow the money.

- Local-global linkages, Canada-Hollywood, are not most strategically framed as linkages between creative communities. An imperative to follow the money suggests an important reframing of 
local-global linkages as the absence in Hollywood, of the broadcasters, the gatekeepers to Canadian English-language premium TV drama, who appear to perceive their role as outsiders. Their easily achieved presence in Hollywood might result in numerous affordances.

- A common refrain regarding the challenge of strengthening the development of Canadian Englishlanguage prime time TV drama is that Canadians, who have attained the status of A-list Hollywood showrunners, are too expensive. While this might be true, if the only financing considered is public financing. This perspective might be considered limited, considering that all businesses need to spend money to make money. In comparison to the level of R\&D exhibited by the other business activities by Canada's large media companies, the cost of script development, in the hundreds of thousands, does not appear to be a hurdle, compared to the costs of upgrading wireless or broadband R \& D. Great writers are expensive, but the reason they are not hired appears to be attributable to a systemic fault in the Canadian TV drama value chain, such that Canadian broadcasters have a weak imperative to succeed in the original content business. Canadian development executives are found to be earnest, talented pawns in a broken development phase. This dissertation finds role reversal, suggesting that the strongest players in the 20th century value chain, the Canadian broadcasters, might be the weakest link to a successful outcome for Canadian English-language, prime time TV drama, in the 21st century.

- An often mentioned advantage to the structural difference between the Canadian and the Hollywood development phase, is the agreement, per the Terms of Trade between the Canadian producers and the Canadian broadcasters, which prevents Canadian networks from purchasing exCanada distribution rights, even though they function as a quasi-studio, providing governance for the investment of public funds (CMPA, 2011). This structure appears to be outdated, as it similar to the prohibitions in the U.S. Financial Syndications rules, which were repealed in 1993. The powerful Hollywood studios have been the contemporary result, are entities with the necessary deep pockets to withstand the risk to deliver TV drama which can compete for attention in the most competitive conditions in history. Moreover, from a practical perspective, this so-called advantage is questionable, because Canadian producers trade ownership to a U.S. studio in exchange for production financing and global distribution. Another outcome of this structure appears to be that Canadian public funds flow towards foreign studios.

\subsection{Implications of this dissertation for policy and industry}

For policy makers in the Canadian English-language TV drama sector, this study might appear to lead to a dilemma of how to operationalize the insights, as policy innovation for the online era. In this section, a three part, strategic plan is proposed to strengthen Canadian English-language TV drama: private sector strategies, public sector strategies, and a separate focus on IP innovation. These suggestions 
are not positioned as findings. In accordance with best practices in policy-making, operationalizing the insights requires a consultative process, which exceeds the scope of this dissertation, which has focused on the identification and analysis of vulnerabilities, work which might be situated within the mission of policy research, and as well, of the Ryerson-York Communication and Culture PhD program: "research in public policy reveal[s] that creativity consists of finding a problem about which something can and ought to be done" (Wildavsky, 2007, p. 3).

The three upcoming sections, 9.2.1-9.2.3, are, at best, proposed as a place to begin the "social process" of policy design (Wildavsky, 2007, p. 404). They are proposed as a draft policy "tool kit" (Grant \& Wood, 2004, p. 137) for the online TV era, in homage to tool kits proposed in previous studies of Canadian English-language TV drama (Grant, 2008; Grand \& Wood, 2004).

Given the outcomes of the music and book industry disruptions, it seems feasible that a global, online TV delivery system, dominated by the new media web empires, may be prevalent when TV disruption settles (Strangelove, 2015). A question is what type of policy instruments might comprise an effective response to such disruption, given that policy-makers have only two ways of spurring change: impacting either the "motivation or ability" of industry participants (Christensen et al, 2013, p. 290). Moreover, it is not unusual for policy-makers, in a rapidly disrupting sector, to be conceptually ahead of industry; participants may be entrenched in protecting established practices (Porter, 1990):

One of the most common, and often the most fatal, causes of lost national advantage is the ebbing of domestic rivalry, since pressure to improve and adjust is also lost with it. While some local industry consolidation is often part of the process of gaining or sustaining competitive advantage, consolidation often proceeds too far ... market sharing, informal agreements or widespread cooperation can turn a group of aggressive rivals into a club. ... A diminished taste for rivalry is also sometime reflected in efforts to enlist government support or intervention. ... Successful national industries often gain some political power, and the temptation is great to exercise it. ... There is also a natural and sometimes fatal tendency for successive generations of managers to want to eliminate "excessive" competition in order to make life more predictable. (Porter, 1990, pp. 169-171)

In such an atmosphere, public policy is correctly positioned as leading the way forward: "Government's proper role is to push and challenge its industry to advance, not provide 'help' so industry can avoid it" (Porter, 1990, p. 30). Given a choice between affecting motivation or ability, instruments of motivation might be more effective in the current media ecosystem, which is characterized by declining national boundaries and an ascending global marketplace. In the case of Canadian English-language TV drama, no policy could force an industry player to acquire new capabilities. This may suggest the efficacy of an overall policy shift, in the online era, from requirements to incentives (i.e., from sticks to carrots). 


\subsubsection{Private sector}

A finding of this dissertation has been to identify an unintended consequence of Canada's worldclass strength in TV production, manifested as a structural fault in the Canadian English-language TV drama value chain, which appears to impact development. The TV drama value chain appears to be currently characterized by uneven financial interests in development and overall, a weak link to market performance. This research has suggested the importance of a new goal: globally popular TV drama.

A new goal might imply three success factors, suggested by the research, which might characterize a strong content business model in the online era, for Canadian English-language premium TV drama: (a) strong development; (b) strong distribution; and (c) special attention to their necessary co-dependence in the value chain. How might such goals be operationalized as policy initiatives? Three approaches are suggested below: (a) VCE: Value chain evolution; (b) Cluster upgrading: Canada-Hollywood linkages; and (c) RPV: Resources, processes and values adjustments.

\subsubsection{VCE: Value chain evolution}

As elaborated in Chapter 3, VCE has been proposed as a key response to disruptive innovation (Christensen et al., 2013). VCE begins with assessment of whether the extant chain enables successful competition and proceeds to improve "what is not good enough" (Christensen et al., 2013, p. 18), by shifting value to where it may be migrating. Evolving the Canadian TV drama value chain, towards a strong content model, may involve adjustments in the source of public funds, as well as their allocation, triggers and governance, for the purposes of strengthening development and ideally, stimulating private investment in it. The following VCE initiatives may have potential to ripple backwards to re-align financial interests in the development phase towards a new goal, Canadian English-language premium TV drama with national and global market traction (Berkowitz, 2015f):

(1) ADJUST TRIGGER FOR PUBLIC FUNDS: As discussed in Chapter 3, considering that legacy broadcasters appear to have undergone a role reversal, from strongest to weakest players, there might be a consideration to remove a requirement for a legacy broadcast licence, in order to trigger public funds. Funds might be awarded to Canadian producers of Canadian English-language TV drama, who have a distribution deal for Canada, with any TV drama delivery technology. This might also help to incentivize the formation of additional Canadian distributors for North American and/or global rights to Canadian English-language premium TV drama, currently a limited pool of sector capability. Such a value chain adjustment might allow broadcasters, distributors, or new parties to step into the role of studios. CRTC appears to have initiated this type of process, with its intention to cease governance over CMPA's Terms of Trade agreement (Berkowitz, 2015f; CRTC, 2015f). 
(2) ADJUST SOURCE OF PUBLIC FUNDS: As discussed in Chapter 3, given that legacy broadcasters are part of integrated media companies with four distribution businesses (Internet, wireless, cable, and legacy broadcast), the source of public funds might be adjusted to include all four TV drama delivery technologies. This might insure a source of public funds, as cable and legacy decline, while Internet and wireless continue to surge. Thinking further "outside the box," as elaborated below in Section 9.2.2 below, a new, "follow the money" approach might result in plentiful financing for Canadian content system, in the form of an S.A.T. (Screen Access Tax) and/or S.D.T. (Screen Device Tax).

(3) INCENTIVIZE GLOBAL RIGHTS ON ORIGINAL CONTENT: Incentivize Canadian media organizations to acquire North American and/or global distribution rights to original Canadian English-language TV drama content. Please see Section 9.2.1.3 for elaboration, as accomplishing this might involve revising the current point system, such that global distribution rights, coupled with strong audience results, might increase access to public funds for Canadian English-language TV drama.

(4) MAINTAIN LEGACY QUOTAS: A nuance to the above suggestions might be to maintain Canadian content quotas in prime time, for the natural life span of linear broadcasting. The rationale would be that the benefit of simultaneous substitution, and the cost of Canadian content, each about $30 \%$, seem to balance; this would appear to put Canadian legacy broadcasters on a level playing field of competition with other distribution technologies.

The above VCE policy initiatives might result in what has been called a "sustaining innovation," meaning the creation of an opportunity for incumbents to improve their competitive position, amidst new market realties: "Launching a radical sustaining innovation is akin to throwing down the gauntlet, saying if you want to play in the game, you have to pay the price and upgrade" (Christensen et al., 2013, p. 285).

\subsubsection{Cluster upgrading: Canada-Hollywood linkages}

A theme in this dissertation has been a need to upgrade the Canadian English-language TV drama development community, which might be accomplished via strategies to strengthen Canada-Hollywood linkages. Upgrading a remote cluster by strengthening linkages to a primary cluster has been identified as a common upgrading strategy. The following institutional and policy initiatives are suggested, qualified by the idea that creative linkages have been positioned, by this research, as corollary to financial linkages:

(1) RE-ESTABLISH CANADIAN CREATIVE DIRECTORY: As discussed in Chapters 2, 7, and 8, there was support for a voluntary, digital directory, an industry tool for linkages. Enthusiasm was further evidenced by tweets from organizations, such as Playback during my CRTC testimony 
(Berkowitz, 2014h). Such an industry tool might conceivably be a joint undertaking with Canadian Consulate (former Canadian Talent Directory), CMF, Telefilm, WG, and WGA. This would appear to be a win for creators, financiers, and the Canadian public. It might strengthen the brand and increase employment opportunities. Currently, there is no institutional path to contact a young Canadian creator who lands a job in a Hollywood writing room. Potential value of Hollywood learning, to Canadian English-language TV drama, may be lost. Such a directory might potentially be scalable to all countries with national content regimes.

(2) RE-ESTABLISH FUNDING AGENCY PRESENCE IN HOLLYWOOD: As discussed in Chapters 2 and 8, given the status of Hollywood as the dominant cluster for TV drama development, and home to a record number of Canadian creatives, it may be advisable to re-open a Telefilm or other office in L.A., in a similar spirit to the U.K's "Welcome to L.A." program.

(3) INCENTIVIZE CANADIAN PRIVATE FINANCIER PRESENCE IN HOLLYWOOD: As analyzed in Chapter 3, an absence of Canadian broadcasters in Hollywood, entities who appear to perceive themselves as outsiders, may be a weak local-global linkage. The maintenance of a yearround development office in L.A. might be considered as a condition of licence renewal.

(4) INCENTIVIZE WRITER AND SHOWRUNNER TRAINING: All three categories of informants identified a need for writer training. Educational initiatives, such as RTA and CFC seem vital to training of entry-level creators. WGC might be encouraged to undertake a leadership role, regarding continuous upgrading. Initiatives, such as bringing in Canadian A-list creators for workshops, might be considered for public funding.

(5) INCREASE APPRENTICESHIP OPPORTUNITIES FOR JUNIOR CREATIVES BY HIRING A-LIST CANADIANS AS SHOWRUNNERS: VCE initiatives above, which tighten the relationship between risk and reward might organically increase the presence of Canadian A-list creators on Canadian English-language TV dramas. This is so, because the cost of hiring A-list talent, currently perceived as a hurdle, might potentially migrate to the cost of R\&D.

(6) INCENTIVIZE OPEN COMPETITION: Many informants observed that skill upgrading is best achieved by competition, which appears to imply the removal of job protection mechanisms for Canadian writers. Also supported by the business management and cluster theory, competition is analyzed to be the key to cluster upgrading, such as the Hollywood environment. See Section 9.2.1.3, below, for further discussion of this recommendation. 


\subsubsection{RPV: Resources, processes, and values}

Resources, processes, and values (RPV), as discussed in Chapter 2, might be considered a corollary strategy, once broad strokes of value chain evolution have been identified and addressed. RPV implies a close assessment of how to re-allocate financial availabilities in the system, so as to meet new goals (Christensen et al., 2013). The following RPV policy suggestions are somewhat speculative. They are consistent with, and suggested by findings herein, principally, a need to tighten the relationship of script to audience. Confirming their feasibility would appear to require additional study, including a more complex quantitative analysis of audience results, than is publicly available.

The LEAF proposal, elaborated in Chapter 8.1, was designed to be purposed to this type of effort, with its intention to loosen arbitrary development restrictions to better align Canadian producers with the "limitless creative" required by U.S. studio development executives. CRTC's new pilot project for Canadian English-language TV drama appears to reflect such a strategy (CRTC, 2015).

A comprehensive RPV approach might go further towards tightening the relationship of script to audience, even so far, as to replace the current point system. As discussed in Chapter 2.3.1, the current point system roughly equivocates the importance of TV producers, writers, directors, performers, designers, directors of photography, music composers, and picture editors. The field study data appears to suggest that this extant point system may reflect a priority to stimulate production. The findings of this dissertation suggest a consideration that the extant point system might be replaced with a new rubric. A draft rubric, proposed below, might have potential to isolate, incentivize, and reward TV drama market performance, by tightening the relationship between script and audience. In this spirit, this draft rubric might extend the CMF's current audience focus, and render it even more rigorous.

An aspect of this rubric, which may be most controversial, is a change suggested by a number of informants, that there is one job, which should not be protected, the TV drama writer. Canada is rich with writing talent. Protecting the job which appears to make a critical difference in market performance may be a disservice to the potential value proposition of public funds; to producers, who may be prevented from hiring the best talent for the job; and to the pool of Canadian talent, who are protected from competing on an open market, and thus, from benefitting from the best upgrading strategy known, which is competition. The opportunity to compete has lured Canadian creators to Hollywood for nearly 100 years. Competition has delivered, amidst unprecedented disruption, the latest golden age of TV.

In consideration of audience reports by CMF (CMF, 2015g), a pilot rubric for access to public funds for Canadian English-language TV drama might be set, with a high bar of Canadian audience at 1.5 million, which might be raised after a few years. While perhaps controversial, a suggestion might be to include the U.S. audience in a new algorithm for audience calculation, since the target market (consumption) of premium Canadian English-language TV drama includes the U.S.; moreover, its 
competitive set (creation) is also Hollywood drama. As suggested by this dissertation, a Canadian audience of two million might be a threshold predictive of North American market traction, but confirmation requires further quantitative analysis.

The eight-tier rubric below suggests a revision of the extant point system. Informants in this field study suggested that the extant point system may reflect market realities of the mid twentieth century, and may have been inspired by a film, rather than TV model. The purpose of the draft below is to tighten a critical relationship identified in this dissertation, between development and distribution. Moreover, the rubric reflects current transformations, including the decline of linear broadcasting, the ascent of content as a value driver, and the importance of global rights, to the process of commercialization.

- CATEGORY A: AT OR ABOVE CANADIAN AUDIENCE BAR OF 1.5M:

(1) CANADIAN PRODUCER + CANADIAN SHOWRUNNER who have each achieved a maximum audience at/over the bar + CANADIAN DISTRIBUTOR for Canada and U.S.;

(2) CANADIAN PRODUCER + CANADIAN SHOWRUNNER who have each achieved a maximum audience at/over the bar + ANY DISTRIBUTOR for Canada and the U.S.;

(3) CANADIAN PRODUCER + ANY SHOWRUNNER who have each achieved a maximum audience at/over the bar + CANADIAN DISTRIBUTOR for Canada and the U.S.;

(4) CANADIAN PRODUCER + ANY SHOWRUNNER who have each achieved a maximum audience at/over the bar + ANY DISTRIBUTOR for Canada and the U.S.;

- CATEGORY B: BELOW CANADIAN AUDIENCE BAR OF 1.5M:

(5) CANADIAN PRODUCER + CANADIAN SHOWRUNNER, who have each achieved a maximum audience below the bar + CANADIAN DISTRIBUTOR for Canada and U.S.;

(6) CANADIAN PRODUCER + CANADIAN SHOWRUNNER, who have each achieved a maximum audience below the bar + ANY DISTRIBUTOR for Canada and the U.S.;

(7) CANADIAN PRODUCER + ANY SHOWRUNNER who have each achieved a maximum audience below the bar + CANADIAN DISTRIBUTOR for Canada and the U.S.;

(8) CANADIAN PRODUCER + ANY SHOWRUNNER who have each achieved a maximum audience below the bar + ANY DISTRIBUTOR for Canada and the U.S.

Protecting Canada's hard-won strength in production should continue to be a priority. This might be addressed by extending the requirements for a minimum of Canadian costs to include any above-the-line categories not mentioned above, such as directors and performers. An observation, suggested by this research, appears to be that some above-the-line elements may not be directly related to market traction in today's media ecosystem. Tiered access to public funds might strengthen torque between development and distribution, by positioning script as the best possible proxy for market performance. 
Another advantage of such a rubric may be to incentivize organic upgrading of Canada's development community, by strengthening an apprenticeship process, similarly to that of the marketdriven Hollywood dynamics. In order to access greater levels of public financing, producers or creators with unproven market success, would be required to team up with producers with proven market success.

In concluding this section, I would like to underscore that these suggestions implicitly acknowledge the complexity of effective policy innovation, and a goal to strengthen development, without sacrificing existing strengths in the system, which continue to deliver important results. It has been noted: "policies, once promulgated, exist independently of their origins. Long after their causes fade away, their consequences carry on unless intervention alters them" (Wildavsky, 2007, p. 405). These suggestions have been put forth in the spirit of kick-starters. Much consultation and collaboration, with key policy stakeholders including DCH, CMF, Telefilm, CMPA, CAB, WGC, and others, seems essential to achieve a policy path towards a content model for Canadian English-language premium TV drama.

\subsubsection{Public sector}

What do the analyses in this dissertation imply for Canada's public broadcaster in the digital era? The Canadian Broadcasting Corporation (CBC) emerged, spontaneously, in many discussions with informants. Its fate appears to be a widely and strongly felt concern. As such, a few comments on the $\mathrm{CBC}$ will be included in these final thoughts, understanding they are largely speculative.

A number of informants expressed a belief that CBC should be re-invented as an all-Canadian, commercial-free global portal. A strategic advantage might be, as discussed in Chapter 1, that clearly defined brands are a necessary strategy in the current era of unprecedented screen competition. Moreover, purposeful definition may give $\mathrm{CBC}$ the best chance at achieving global hits, as well as becoming a strong global brand, similar to BBC.

Such a change might imply numerous changes, such as an all Canadian linear broadcast schedule. During prime-access, why not promote Canada's global reputation in the evergreen family genre? As CMF audience results show, Canadian content family dramas can attract up to $40 \%$ of the Canadian audience (CMF, 2015g). There has been an expressed need for Canadian theatrical films to be distributed; this too could be $\mathrm{CBC}$ 's role. As a studio, $\mathrm{CBC}$ could be the place for producers to sell a project clearly national in reference, which does not imply limited in creative excellence, or that its reception would limited to domestic audience, only that its best development home might be the public broadcaster.

As an international distributor, a profit-seeking CBC America, or CBC Global, could monetize original content, similarly to BBC America. Recently in New York, I was surprised to be unable to access a CBC documentary. What if I sent it to ten friends in the U.S.? What if it went viral and got a million views? Viewers are not a lot. They are everything. 
What about a digital age funding model for CBC? An idea grew from my MBA students, as presented to Let's Talk TV (Berkowitz, 2014c, 2014d, 2014g). A solution may be to follow the money, which appears to be migrating, from content to access. A Screen Access Tax (S.A.T.) and/or a Screen Device Tax (S.D.T.) might provide CBC with funding for the foreseeable future.

I would also suggest that $\mathrm{CBC}$ dramas, in contrast to the draft rubric for the private sector, as presented in Section 9.2.1.3, might be required to have in addition to a Canadian producer, both a Canadian writer and a Canadian distributor.

If the $\mathrm{CBC}$ were commercial-free, given the findings of this dissertation, what need to succeed would pressure its content to be excellent? To answer this question, I suggest a return to the discussion of popularity in Chapter 2. Shows not receiving a certain threshold of audience, algorithmically assessed to include domestic and international viewers, might be cancelled.

\subsubsection{Innovation}

A fundamental of this dissertation is that TV drama development is the innovation phase of the value chain. R\&D weakness may be generally related to Canada's overall low ranking in innovation, 13th of 16 peer countries (Conference Board of Canada, 2015). Upgrading the value chain of Canadian English-language TV drama, from production to innovation excellence might begin with great scripts.

Following the field study, I did some preliminary research on the problem of incentivizing innovation (Berkowitz, 2014g). There is a 300-year history of governments and industry deploying a rather simple, cost-effective strategy to jump-start innovation and spur excellence: prizes. In 1714, Britain solved the problem of sea location with The Longitude Prize, (O'Conner \& Robertson, 1997). Fastforwarding to the 21 st century, The Goldcorp Challenge used the Internet to literally strike gold in a dormant Canadian gold mine (Goldcorp, 2001). The driverless car originated with a challenge prize (Markoff, 2007). Netflix solved discoverability with a prize (Netflix, 2009). Since 2010, more than 350 prize competitions have been used in the U.S. to spur innovation, an advantage being that compensation is only awarded for good results (Goldhammer, Mitchell, Parker, Anderson, \& Joshi, 2014).

A suggestion is that a substantial sum, on the order of one million dollars, less than $1 \%$ of the annual public assistance to Canadian TV, might be deployed for an annual Canada Prize for Creative Excellence. Two-hundred and fifty entries could deliver $\$ 10$ million of R\&D value, or 10 times the initial investment, if each submitted script is valued at $\$ 40,000$ dollars. Similar equations seem to make a compelling case for why prizes, like Nobel and Pulitzer, and entertainment icons, such as American Idol, have persisted in the risky arena of $R \& D$.

\subsection{Review of chapters in this dissertation}

Chapter 1 introduced the study, described the motivation for this thesis; clarified important 
definitions and exclusions, gaps in the literature, and questions to be investigated. It described the research methodology, and listed some original contributions of this dissertation.

Chapter 2 introduced three foundational concepts (hits, popularity, brand) and surrounded the investigation of TV drama development with a review of four arenas of relevant knowledge: a TV industry overview in Canada and in Hollywood; a review of Canadian TV policy, as a response to Hollywood dominance and as a reflection of the larger Canada-U.S. relationship; business research on value chains and global value chains; and research in the closely related arena of cluster upgrading, local-global linkages, and economic diasporas.

Chapter 3 proposed a theorization of the TV drama value chain, beginning with a simple depiction demonstrating three segments with unique dynamics and unique supply chains: development, production, distribution. Iteratively complex value-chain depictions suggested new locus of weakness in Canadian English-language drama: the development phase, analogous to R\&D or IP creation in other industries. Moreover, the theorization suggested that the Canadian TV value chain tends to fade at the conclusion of phase 2 (production), wherein success metrics are tallied. The value chain analysis suggests that, while TV drama is "writer-driven," strengthening development stage may not be primarily about the creative or about strengthening local-global linkages, an important aspect of the effort. The data suggests the driver of development-phase weakness may be a poor alignment of vested financial interests in the development phase. An outcome of this theorization is that development weakness can be reframed as a systemic fault in the Canadian TV drama value chain, which ripples backwards from the monetization phase, to affect the development phase, rendering it a "bridge to nowhere."

Chapter 4 described the methodology of the field research, including the qualitative interview approach, the choice of informants, interview design, and data analysis.

Chapter 5, the first of four chapters on the findings of the field study, introduced development, defined its role in the TV drama value chain, compared TV drama development dynamics in Canada and Hollywood, including respondents' remarks on the Canadian TV brand, and set the stage for deeper analyses in the next chapters.

Chapter 6 presented a core finding in this story of Canadian TV drama. Compelling remarks by informants suggested that strengthening the development phase of Canadian TV drama may require following the money, to the missing link to monetization. Successful transformation may require re-aligning the vested interests of stakeholders in development phase around a mutual need to optimize and monetize the asset.

Chapter 7 reported findings regarding the deeply intertwined connections in development between Canada and Hollywood. This chapter included informants' perspectives on current levels of connectivity between the Canada and Hollywood development communities, showrunner and junior writer shortages, and the need for writer training. The chapter concluded by reframing a role for local-global linkages, as 
suggested by the data, a possibility that Canadian TV networks, in their role as TV drama commissioners, could have closer linkages with the Hollywood development community.

In Chapter 8, informants responded to original strategies to strengthen the development phase of Canadian TV drama and as well, offered their own most candid perceptions on what must be done to future-proof the Canadian TV drama system for the digital age.

Chapter 9 concludes the discussion, reviews findings and original contributions of the dissertation, discusses limitations of this study, suggests further research on Canadian English-language TV drama, and policy and industry implications of this thesis. A closing epilogue connects this study with the 20142015 CRTC Let's Talk TV inquiry into the future of Canadian TV.

\subsection{Limitations of this study and suggestions for future research}

An obvious limitation of this study is sample size. In keeping with this data limitation, the results aimed at deep insight, rather than quantitative findings.

The study combined a value chain analysis with the field research. The VCE theory, value chain adjustment (Christensen et al., 2013) was used to construct a strategic response to global TV market disruption. A related theory, RPV, resources, processes and values (Christensen et al., 2013) might subsequently be engaged to extend these results and advance a nuanced understanding of strategies which might result in a strong, original content model for Canadian English-language TV prime time drama. Along the way, ideas for further research suggested themselves. They include the following:

- A study of how other countries organize their TV drama development phase seems imperative. As explored in Chapter 8, informants noted that TV dramas and TV drama formats from many other small countries, such as Israel, Denmark, Australia, and of course, the U.K., are visible in Hollywood, as the basis of TV hits. How and why are these countries excelling at development capabilities?

- As this study was an in-depth exploration of development, a companion study might be a comprehensive study of Canada's distribution sector, and how it impacts the value chain, which also seems imperative. Since the value chain is currently characterized by weak linkages to governance of creative elements, unpacking the influence of international distribution, also seems an important follow up, which might contribute to a critical path towards value chain adjustment.

- Case studies, which follow emerging Canadian English-language premium TV drama models, from development through distribution, in the online era seem important. An example might be the TV drama series, Between (2015 - to date), a 2015 partnership by Rogers Media, Shomi, and Netflix, partially funded by CMF. The series is internationally distributed by a new distribution company, previously mentioned in this dissertation, Elevation Pictures. Early reviews have focused on weak writing: "Between ... is Netflix money, north-of-the-border talent and formulas" (Hale, 2015, 
para. 1). Small audiences on Netflix have been predicted, for this "low grade placeholder" (Uhlich, 2015, para. 1). However, the story of Between's fate is not over, as it has been renewed for six more episodes. Netflix's need for global market traction may force an imperative to upgrade the creative, which might be consistent with the findings of this dissertation.

- A study, which follows the careers of junior Canadian writers over a period of years, could be useful in designing strategies for writer training and supply. As mentioned in the dissertation, the U.K. has a "welcome to L.A." program for young creators. While the informants of this study were mostly A-list TV drama showrunners, many mentioned the unknown numbers of junior creators seeking career acceleration in Hollywood. It seems important to gather their perspectives and follow the careers of Canada's junior TV drama development workers.

\subsection{Epilogue: Connecting to the 2014-2015 CRTC public process, Let's Talk TV}

The CRTC's Let's Talk TV launched in September 2013, by calling for participation by the Canadian public (CRTC, 2013) and a theme, which remained consistent through its eight decisions (Appendix CC), to future-proof Canadian TV for the era of online distribution: "The world is evolving and we must prepare for the future before it is too late" (CRTC, 2015e, Conclusion, para. 2).

One connection, of this dissertation to Let's Talk TV, is the cache of more than 2,600 written submissions (CRTC, 2014f) to the 2014 hearing, and the record of live presentations from nearly every stakeholder in Canadian English-language TV drama, including networks, government entities, lobby organizations, and some U.S. media services. While this data did not form part of the research for this dissertation, which had previously been completed, it has helped to inform its conclusions. Throughout the hearing, there was palpable tension between the status quo and the future. A minority of participants, including me, positioned the current transformations as opportunity.

My participation in Let's Talk TV hearing turned out to be an unexpected epilogue to this dissertation; a list of this research's public impact can be found in Appendix DD. Based on publicizing the research, which had already been completed, I became an unexpectedly visible participant in the Let's Talk $T V$ process. My decision to enter this research into public debate, and in particular, sustained encouragement for this time-consuming initiative, by the Ryerson University Communication and Culture $\mathrm{PhD}$ program, is greatly appreciated. Such support might be contextualized by a note suggesting how unusual it is for such initiatives to be institutionally encouraged: "Reframing research in an accessible, nonpartisan, and timely manner that policy makers prefer is an important skill, yet one that few professionals learn in their academic training” (Bogenschneider, 2010, Preface, para. 2). On March 12, 2015, it was surprisingly confirmed that I was personally recognized, as was my affiliation with Ryerson University, in the decision concerning Canadian content, The Way Forward (CRTC, 2015f). 
Participation began with a written submission in response to CRTC's notice of the upcoming hearing (CRTC, 2014a). My report of June 27, 2014, Brain Drain to Brain Chain | Can Con to Can Brand-Reframing the Challenge of English Language Canadian TV Drama (Berkowitz, 2014a), previewed perspectives in this dissertation, mainly that future-proofing Canadian TV drama might require a systemic goal shift, from one purposed for domestic supply to one purposed to respond to global demand. This turned out to be the first of many public presentations in the next months.

Of more than 30,000 comments from the public on Let's Talk TV, including more than 2,600 written submissions, I was one of 118 invitations to appear personally at the September 2014 CRTC hearing, including about 10 individuals, the remainder being representatives of virtually all corporate stakeholders in the Canadian TV system. I was invited to lead off Day 2, and did so, with a presentation entitled Can Con to Can Brand-Let's Pivot Our Goal from Domestic Supply to Global Demand (Berkowitz, 2014c, 2014d), which appeared to be well received:

Ms. Berkowitz provided a unique perspective on the content issue, stating Canada has never had a lack of talent for content creation, but rather the lack of risk taking and the focus on domestic promotion of Canadian content has held back the Canadian system as a whole. The issue can be summed up in her statement: "content is not king, hit content is king." In order for Canada to successfully harness the changes in media consumption and production, Canada must look to taking greater risks with new content, invest in the production of hit Canadian content, and make this content available to a global audience. (Public Interest Advocacy Centre, 2014)

My remarks were subsequently mentioned a number of times during the hearing. At CRTC's request, I submitted a final report, Future Proofing Canada's Media System-From Investment to Return on Investment: Global Applause Is not Just Good Business -It's Great Culture (Berkowitz, 2014g). I wrote two newspaper articles related to this dissertation, "Is It Time to Re-brand Canadian TV?" (Berkowitz, 2014b) and "Canadians Want Good Programs, not 300 Channels" (Berkowitz, 2014e), and was interviewed by TV, radio, and online media.

The CRTC's decision on content was announced March 12, 2015 (CRTC 2015f), positioned as a "fundamental shift" (CRTCe, Fundamental Shift, para. 2) and framed as "tearing down barriers to innovation that have hampered broadcasters and producers" (CRTCe, Age of Abundance, para. 5). Similarly to the suggestion, in this dissertation, to reframe Canadian content as Canadian created content (Berkowitz, 2014a, 2014c, 2014d), it was asserted:

As long as the story is told by a Canadian, let's get the best talent working on it and make something that will conquer the world. Forget about the "made in Canada." We want content that is made BY Canada. (CRTC, 2015e, Today’s Decision section, para. 13)

Similarly to my discussion of brand (Berkowitz, 2014a, 2014c, 2014d), it was noted: "We have yet to establish a wining and sustainable Canadian brand" (CRTCe, Preparing for the Future, para. 3). 
The personal mentions on March 12, 2015, cited below, created fresh interest in my perspective, including a newspaper article, "CRTC Gets It, Time to Make Hits, not Shows” (Berkowitz, 2015a) and other media:

55. Both Irene Berkowitz of Ryerson University and Entertainment One (eOne) discussed the importance of rebranding Canada as an exporter of global hits, to make Canada's brand known as a creative brand. In their view, Canada is currently known primarily as a country with strong production crews and good financial incentives, but with no track record of producing real global hits. At the hearing, eOne stated that it would welcome the opportunity to participate in a roundtable discussion to share its data and discuss case studies with interested industry stakeholders in order to further discussion. In her final submission, Ms. Berkowitz stated that she had spoken with eOne since the hearing and together they would support a working group to implement strategies to achieve the goal of global hits. (CRTC, 2015f, para. 55)

108. Similarly, Ms. Berkowitz proposed bringing Canadians back from Hollywood and turning Canada's proximity to the U.S. into a competitive advantage rather than disadvantage by changing the points system so that Canadians do not have to be residing in Canada. "Canadian-created stories," in Berkowitz's view, would recapture the value of Canadian expatriates working in Hollywood and make the "brain drain" into a "brain chain." She proposed a new points system which can be found in her written submission. (CRTC, 2015f, para 108)

The "new points system," (CRTC 2015f, para. 128) appears to have similarities to LEAF, as presented in Chapter 8 of this dissertation.

Let's Talk TV appears to have taken steps to pivot the goal, of Canadian English-language TV drama, towards a content business model for the global market, which implies success at home:

Some may balk at the suggestion that Canadian programming can reach the same heights as shows created in other major global markets. Not me. I know it can succeed. (CRTC, 2015e, Canadian Content for the World Stage, para. 1)

Let's Talk TV delivered a surprise ending to this dissertation. I am honoured by recognition of my efforts to contribute to a golden age of Canadian English-language premium TV drama. I concluded my presentation at Let's Talk TV, saying our 5-year goal might be "a string of global hits" (Berkowitz, 2014c, p. 8). It is my hope the ending of this dissertation is just the beginning of many more contributions to the future of Canadian English-language premium TV drama. There is much work to be done. 
Appendix A

TV budget, above and below the line

(Source: www.coronetpublications.net)

\begin{tabular}{|c|c|c|}
\hline A & $\mathrm{C}$ & t \\
\hline 10 & Category Des & Page \\
\hline 00 & STORY/WRITING & \\
\hline 00 & PRODUCER UNIT & \\
\hline 00 & DIRECTOR'S UNIT & \\
\hline 00 & CAST/TALENT/VOCAL & \\
\hline & TOTAL FOR ABOVE & \\
\hline 00 & EXTRAS/CROWD & \\
\hline 00 & PRODUCTION STAFF & \\
\hline 00 & ART DEPARTMENT & \\
\hline 00 & GRIP OPERATIONS & \\
\hline 00 & SET DRESSING & \\
\hline 00 & PROPERTY & \\
\hline 00 & PICTURE VEHICLES & \\
\hline 00 & LIGHTING & \\
\hline 00 & CAMERA & \\
\hline 00 & PRODUCTION SOUND & \\
\hline $\mathrm{n} n$ & INIADODORF & \\
\hline
\end{tabular}




\section{Appendix B}

\section{U.S.: Top 50 TV programs, 2013-2014,}

(Note: $71 \%$ are dramas, in bold)

(Sources: Schneider, 2015; Statista, 2015)

\begin{tabular}{|c|c|c|c|}
\hline No. & Title & Network & $\begin{array}{l}\text { Viewers } \\
\text { (millions) }\end{array}$ \\
\hline 1 & The Big Bang Theory & CBS & 23.1 \\
\hline 2 & NCIS & CBS & 22.4 \\
\hline 3 & Sunday Night Football & NBC & 21.7 \\
\hline 4 & The Walking Dead & AMC & 18.3 \\
\hline 5 & NCIS: Los Angeles & CBS & 17.9 \\
\hline 6 & The Blacklist & NBC & 16.9 \\
\hline 7 & Person of Interest & CBS & 16.2 \\
\hline 8 & Dancing With the Stars & $A B C$ & 15.5 \\
\hline 9 & Blue Bloods & CBS & 15.2 \\
\hline 10 & The Voice (Monday) & NBC & 14.7 \\
\hline 11 & Criminal Minds & CBS & 14.4 \\
\hline 12 & Castle & $A B C$ & 14.3 \\
\hline 13 & Modern Family & $A B C$ & 14.1 \\
\hline 14 & The Voice (Tuesday) & NBC & 14.0 \\
\hline 15 & Monday Night Football & ESPN & 13.7 \\
\hline $16(\mathrm{~T})$ & $\begin{array}{l}\text { - CSI: Crime Scene Investigation } \\
\text { - Elementary }\end{array}$ & $\begin{array}{l}\text { CBS } \\
\text { CBS }\end{array}$ & 13.4 \\
\hline 18 & Downton Abbey & PBS & 13.2 \\
\hline $19(\mathrm{~T})$ & $\begin{array}{l}\text { - Scandal } \\
\text { - Resurrection }\end{array}$ & $\begin{array}{l}A B C \\
A B C\end{array}$ & 13.0 \\
\hline 21 & Hawaii Five-0 & CBS & 12.9 \\
\hline 22 & Grey's Anatomy & $A B C$ & 12.4 \\
\hline 23 & The Mentalist & CBS & 12.3 \\
\hline $24(T)$ & $\begin{array}{l}\text { - The Millers } \\
\text { - } 60 \text { Minutes }\end{array}$ & $\begin{array}{l}\text { CBS } \\
\text { CBS }\end{array}$ & 12.2 \\
\hline 26 & American Idol (Wednesday) & Fox & 12.1 \\
\hline 27 & The Good Wife & CBS & 11.9 \\
\hline
\end{tabular}




\begin{tabular}{|c|c|c|c|}
\hline \multirow[t]{2}{*}{$28(T)$} & - American Idol (Thursday) & Fox & 11.5 \\
\hline & - Sleepy Hollow & Fox & \\
\hline \multirow[t]{2}{*}{$30(\mathrm{~T})$} & - Survivor & CBS & 11.4 \\
\hline & - Two and a Half Men & CBS & \\
\hline 32 & How I Met Your Mother & CBS & 11.3 \\
\hline 33 & Duck Dynasty & $A \& E$ & 11.1 \\
\hline 34 & Chicago Fire & NBC & 10.7 \\
\hline 35 & The Crazy Ones & CBS & 10.5 \\
\hline 36 & Marvel's Agents of S.H.I.E.L.D. & $A B C$ & 10.4 \\
\hline \multirow[t]{2}{*}{$37(\mathrm{~T})$} & - Mike \& Molly & CBS & 10.2 \\
\hline & - Intelligence & CBS & \\
\hline 39 & 2 Broke Girls & CBS & 10.0 \\
\hline \multirow[t]{4}{*}{$40(T)$} & - Once Upon a Time & $A B C$ & 9.6 \\
\hline & - The Bachelor & $A B C$ & \\
\hline & - The Amazing Race & CBS & \\
\hline & - 24: Live Another Day & Fox & \\
\hline \multirow[t]{2}{*}{$44(T)$} & - Unforgettable & CBS & 9.3 \\
\hline & - Bones (Friday) & Fox & \\
\hline \multirow[t]{3}{*}{$46(T)$} & - Mom & CBS & 9.2 \\
\hline & - Chicago PD & NBC & \\
\hline & - The Middle & $A B C$ & \\
\hline \multirow[t]{2}{*}{$49(T)$} & - Law \& Order: SVU & NBC & 9.1 \\
\hline & - Undercover Boss & CBS & \\
\hline
\end{tabular}




\section{Appendix C}

U.S.: Top TV programs through the decades, 1950s -2000s

(Sources: TVIV, 2008 and Classictvhits.com, n.d.)

\section{> 1954 - 1955 (Households with TV: 30,700,000)}

\begin{tabular}{|clcc} 
Rank & \multicolumn{1}{c}{ Show } & Network & Estimated Audience \\
\hline 1. & I Love Lucy & CBS & $15,135,100$ \\
\hline 2. & The Jackie Gleason Show & CBS & $13,016,800$ \\
\hline 3. & Dragnet & NBC & $12,924,700$ \\
\hline 4. & You Bet Your Life & NBC & $12,587,000$ \\
\hline 5. & The Toast of the Town & CBS & $12,157,200$ \\
\hline 6. & Disneyland & ABC & $12,003,700$ \\
\hline 7. & The Jack Benny Show & CBS & $11,758,100$ \\
\hline 8. & The George Gobel Show & NBC & $10,806,400$ \\
\hline 9. & Ford Theatre & NBC & $10,714,300$ \\
\hline 10. & December Bride & CBS & $10,652,900$ \\
\hline
\end{tabular}

\section{$>1964$ - 1965 (Households with TV: 52,700,000)}

\begin{tabular}{clcc} 
Rank & Show & Network & Estimated Audience \\
\hline 1. & Bonanza & NBC & $19,130,100$ \\
\hline 2. & Bewitched & ABC & $16,337,000$ \\
\hline 3. & Gomer Pyle, U.S.M.C. & CBS & $16,178,900$ \\
\hline 4. & The Andy Griffith Show & CBS & $14,914,100$ \\
\hline 5. & The Fugitive & ABC & $14,703,300$ \\
\hline 6. & The Red Skelton Show & CBS & $14,439,800$ \\
\hline 7. & The Dick Van Dyke Show & CBS & $14,281,700$ \\
\hline 8. & The Lucy Show & CBS & $14,018,200$ \\
\hline 9. & Peyton Place II & ABC & $13,912,800$ \\
\hline 10. & Combat & ABC & $13,754,700$ \\
\hline
\end{tabular}




\section{> 1974 - 1975 (Households with TV: 68,500,000)}

\begin{tabular}{cllc} 
Rank & Show & Network & Estimated Audience \\
1. & All in the Family & CBS & $28,687,100$ \\
2. & Sanford and Son & NBC & $20,276,000$ \\
3. & Chico and the Man & NBC & $19,522,500$ \\
4. & The Jeffersons & CBS & $18,906,000$ \\
5. & M*A*S*H & CBS & $18,769,000$ \\
6. & Rhoda & CBS & $18,015,500$ \\
7. & Good Times & CBS & $17,673,000$ \\
8. & The Waltons & CBS & $17,467,500$ \\
\hline 9. & Maude & CBS & $17,056,500$ \\
10. & Hawaii Five-O & CBS & $16,988,00$
\end{tabular}

\section{$>1984$ - 1985 (Households with TV: 84,900,000)}

\begin{tabular}{|clcr|}
\hline Rank & Show & Network & Estimated Audience \\
\hline 1. & Dynasty & ABC & $21,225,000$ \\
\hline 2. & Dallas & CBS & $20,970,300$ \\
\hline 3. & The Cosby Show & NBC & $20,545,800$ \\
\hline 4. & 60 Minutes & CBS & $18,847,800$ \\
\hline 5. & Family Ties & NBC & $18,847,800$ \\
\hline 6. & The A-Team & NBC & $18,593,100$ \\
\hline 7. & Simon \& Simon & CBS & $18,508,200$ \\
\hline 8. & Murder, She Wrote & CBS & $17,064,900$ \\
\hline 9. & Knots Landing & CBS & $16,980,000$ \\
\hline 10. & Cagney \& Lacey & CBS & $17,514,200$ \\
\hline
\end{tabular}




\section{> 1994 - 1995 (Households with TV: 95,400,000)}

\begin{tabular}{rlrc} 
Rank & Show & Network & Estimated Audience \\
\hline 1. & Seinfeld & NBC & $19,622,400$ \\
\hline 2. & ER & NBC & $19,080,000$ \\
\hline 3. & Home Improvement & ABC & $18,603,000$ \\
\hline 4. & Grace Under Fire & ABC & $17,744,400$ \\
\hline 5. & Monday Night Football & ABC & $16,885,800$ \\
\hline 6. & 60 Minutes & CBS & $16,408,800$ \\
\hline 7. & N.Y.P.D. Blue & ABC & $15,741,000$ \\
\hline 8. & Murder, She Wrote & CBS & $14,882,400$ \\
\hline 9. & Friends & NBC & $14,882,400$ \\
\hline 10. & Roseanne & ABC & $14,787,000$ \\
\hline & & & \\
\hline
\end{tabular}

\section{> 2004 (Households with TV: 108,000,000)}

\begin{tabular}{clll} 
Rank & Show & Network & Estimated Audience \\
1. & American Idol & FOX & (not drama) \\
\hline 2. & CSI & CBS & $26,000,000$ \\
\hline 3. & Survivor & CBS & (not drama) \\
\hline 4. & Desperate Housewives & ABC & 24,000,000 \\
\hline 5. & CSI Miami & CBS & $19,000,000$ \\
\hline 6. & Dancing with the Stars & ABC & (not drama) \\
\hline 7. & Monday Night Football & ABC & (not drama) \\
\hline 8. & Without a Trace & CBS & $18,700,000$ \\
\hline 9. & Everybody Loves Raymond & CBS & $17,400,000$ \\
\hline 10. & Two and a Half Men & CBS & $16,500,000$
\end{tabular}




\section{Appendix D}

\section{U.S.: Broadcast ratings 1989-2010}

(Source: Eastman \& Ferguson, 2013, p. 49)

\subsection{Graph of Network Ratings}

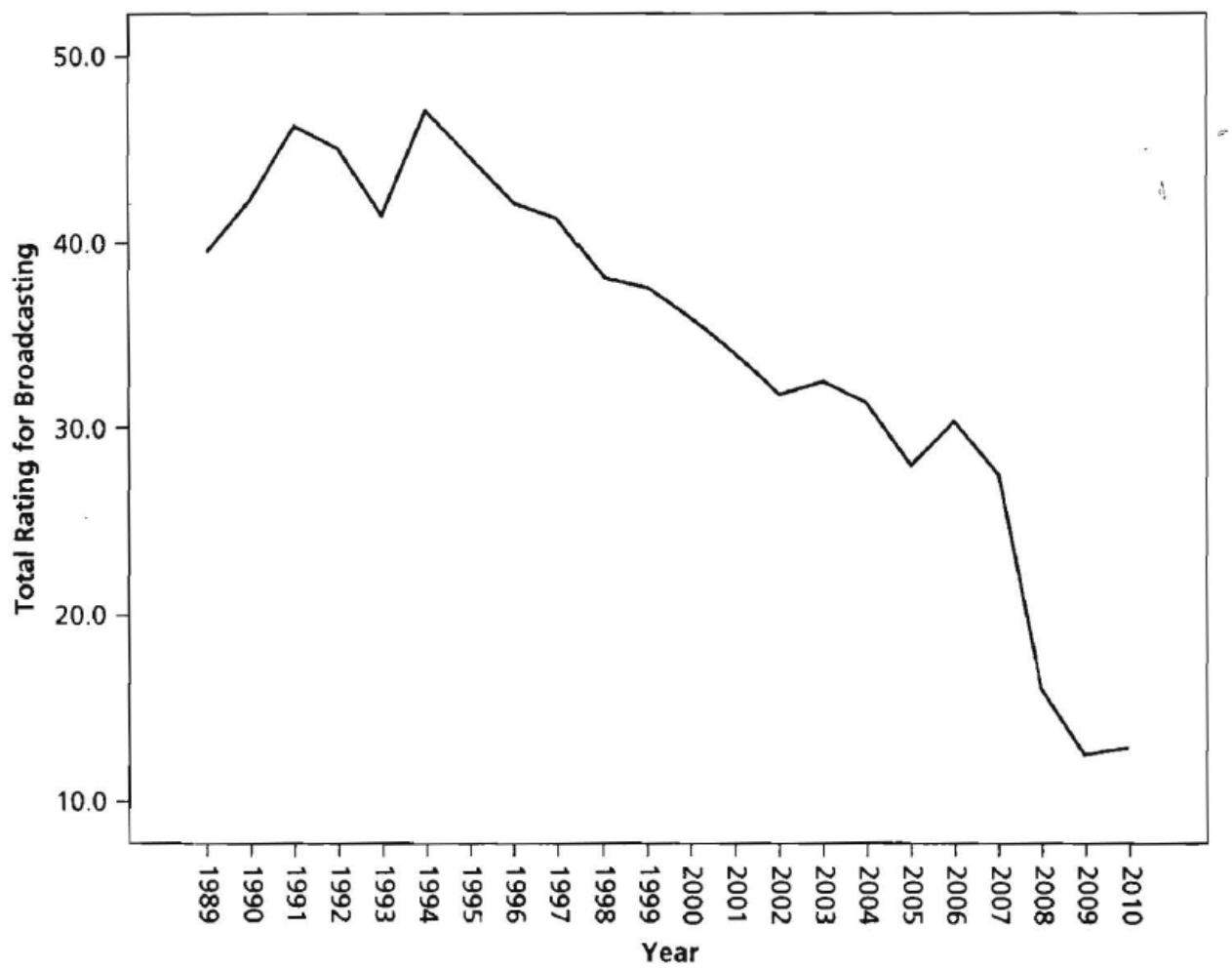

This graph shows the total ratings for all broadcast networks from 1989-90 to 2010-11. FOX was added in 1990-91. UPN and WB were added in 1994-95 and the Spanish language networks were added in 2006-07. For ratings by network see lable 2.4 . 


\section{Appendix E}

U.S.: Nielsen, audience viewing trends

(The Nielsen Company, 2014, p. 4)

\section{A CONSUMER'S JOURNEY TO CONTENT DISCOVERY}

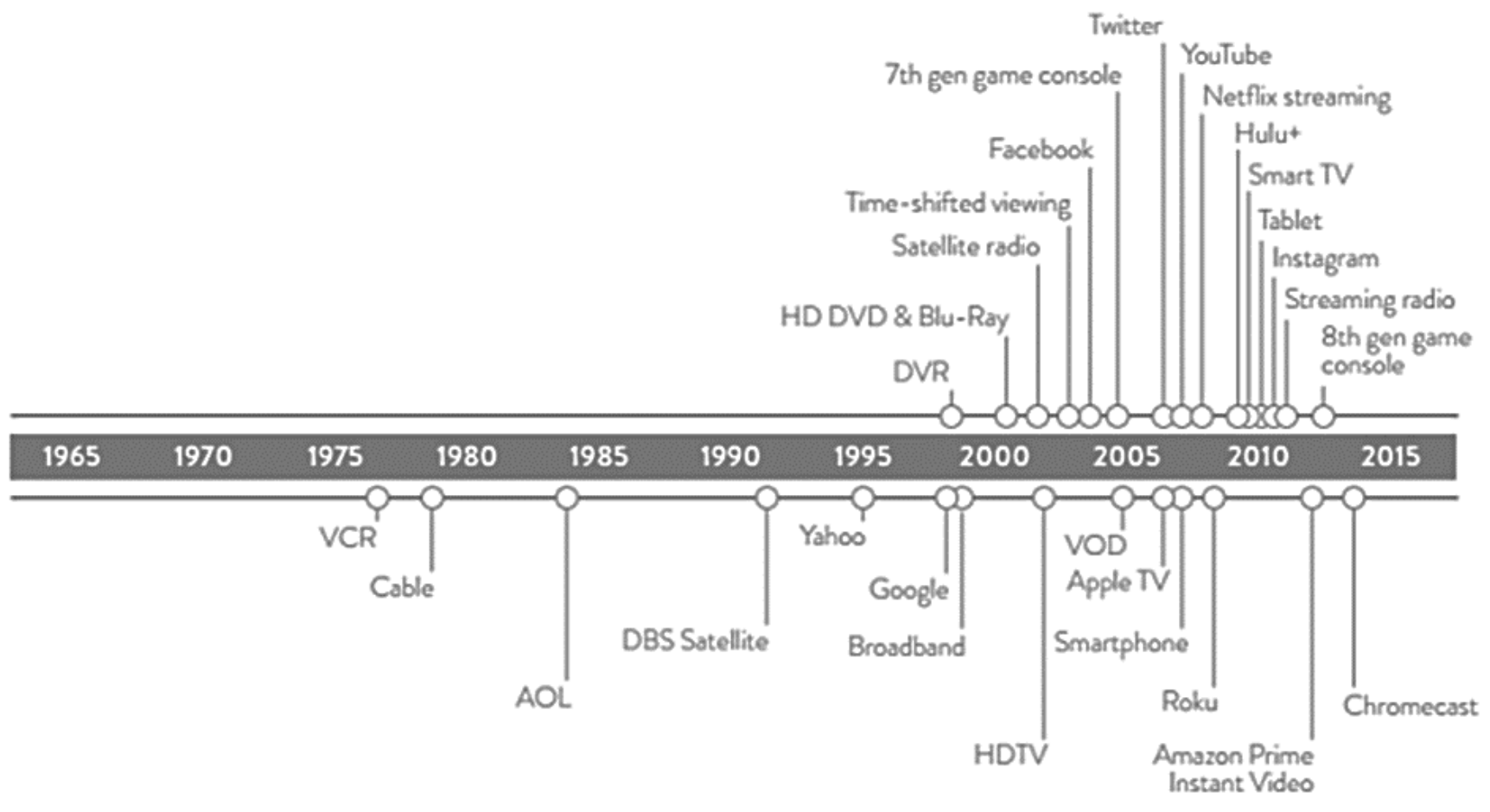




\section{Appendix F}

Hollywood: TV drama development process

(Source: Eastman \& Ferguson, 2013, p. 77)

Process begins with the review of new ideas submitted in the form of pitch sessions, requested submissions, open submissions, or company-developed proposals.

Step 1: Possibilities

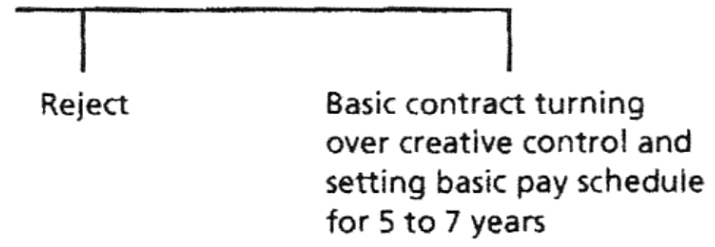

Step 2: Possibilities

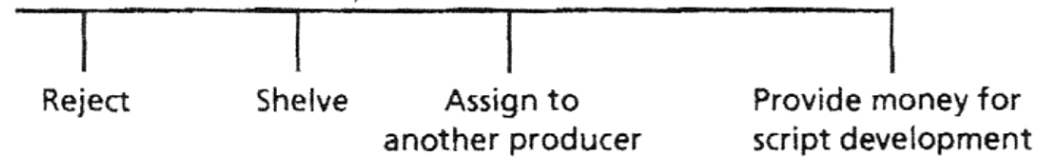

Step 3: Possibilities

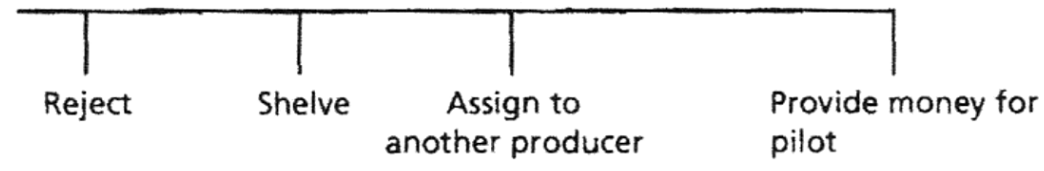

Step 4: Possibilities

\begin{tabular}{l|l|l|l|}
\hline & & & \\
Reject & Assign to & $\begin{array}{l}\text { Set aside for possible } \\
\text { mid-season replacement }\end{array}$ & $\begin{array}{l}\text { Provide a limited } \\
\text { episode order }\end{array}$
\end{tabular}




\section{Appendix G}

\section{Hollywood: Geographic clustering, WGA-W}

(Source: Scott, 2005, p. 125)

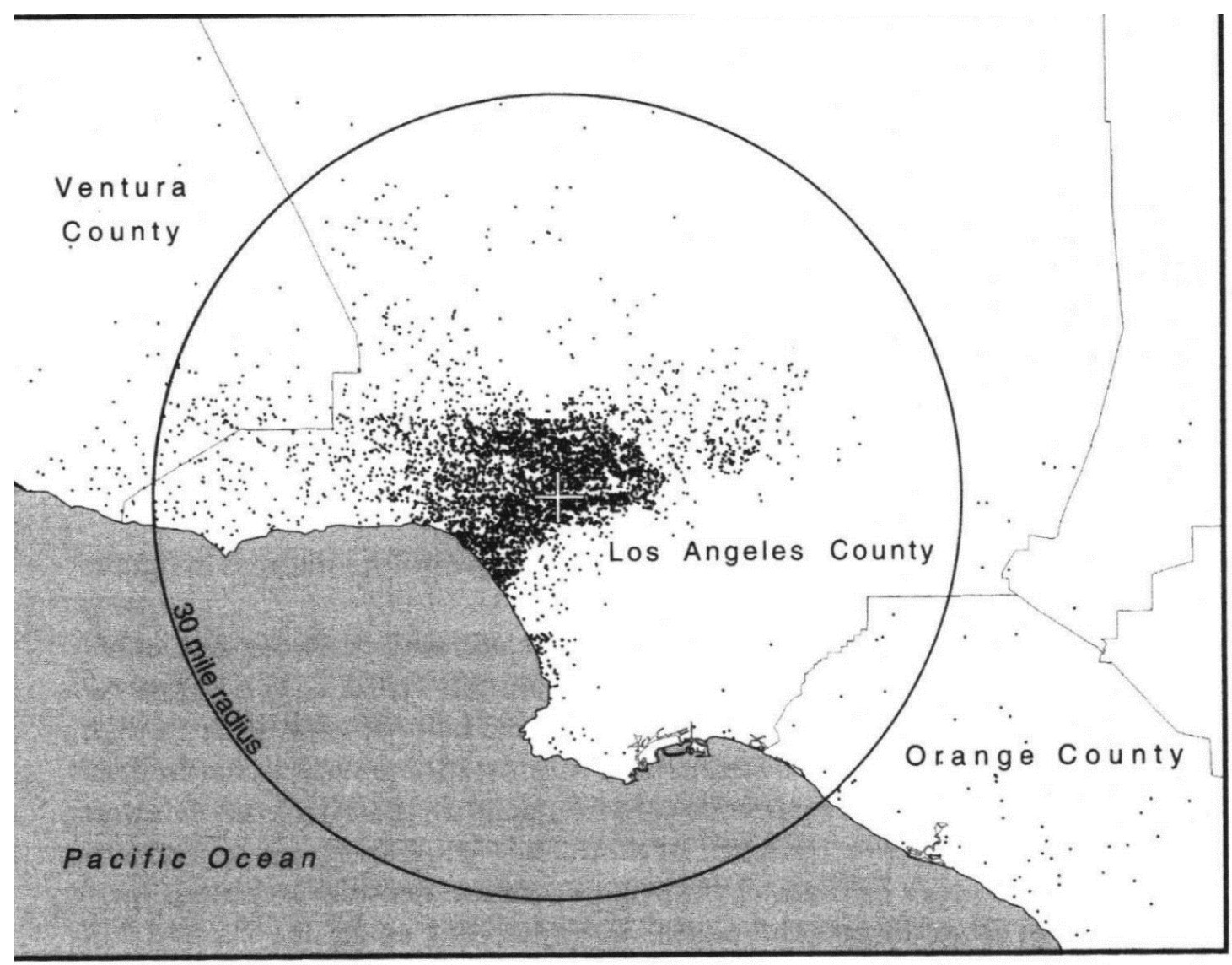

Figure 7.3. Residential locations of members of the Writers Guild in Southern California. The center of the Hollywood labor market (as defined in union and guild contracts) is represented by a cross marking the intersection of Beverly and La Cienega Boulevards, and the thirty-mile circle around this point is shown. The map is based on zip code data provided by the Guild. 


\section{Appendix H}

Hollywood: Entities commissioning original TV drama

(Sources: Eastman \& Ferguson, pp. 275, 306-308; personal communication with informant, June 2015)

1. ABC Disney

2. ABC Family Channel

3. A \& E

4. Amazon

5. $\mathrm{AMC}$

6. BBC America

7. $\mathrm{CBS}$

8. Channel Four

9. Comedy Central

10. Crackle

11. $\mathrm{CW}$

12. Disney Channel

13. Discovery

14. E! Entertainment

15. Encore

16. Epix

17. Facebook

18. Flix

19. FOX

20. FX Network

21. Golf Channel

22. Google/YouTube

23. $\mathrm{HBO}$

24. History Channel

25. Huffington Post

26. ION

27. Lifetime

28. Max

29. Movie Channel

30. MTV

31. NBCU

32. Netflix

33. Nickolodeon/NICK

34. Nine (Australia)

35. Seven (Australia)

36. Ten (Australia)

37. Showtime

38. Spike TV

39. Starz

40. Sundance Channel

41. TBS

42. NT

43. Turner Classic Movies

44. TV Land

45. Travel

46. USA Network

47. Yahoo 


\section{Appendix I}

Canada: Prime time audience viewing patterns 1979-2014

(Sources: as cited below)

1979 viewing pattern, English-language TV in Canada (Source: Canadian Media Research, 2013, p. 2)

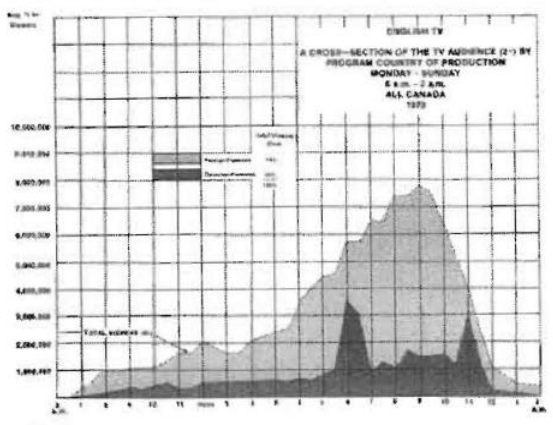

(Source: Standing Committee on Canadian Heritage, 2003, p. 81)

Figure 4.8 Viewing curve of English-language television by program source, All persons 2+, Sept. 2000 to Aug. 2001

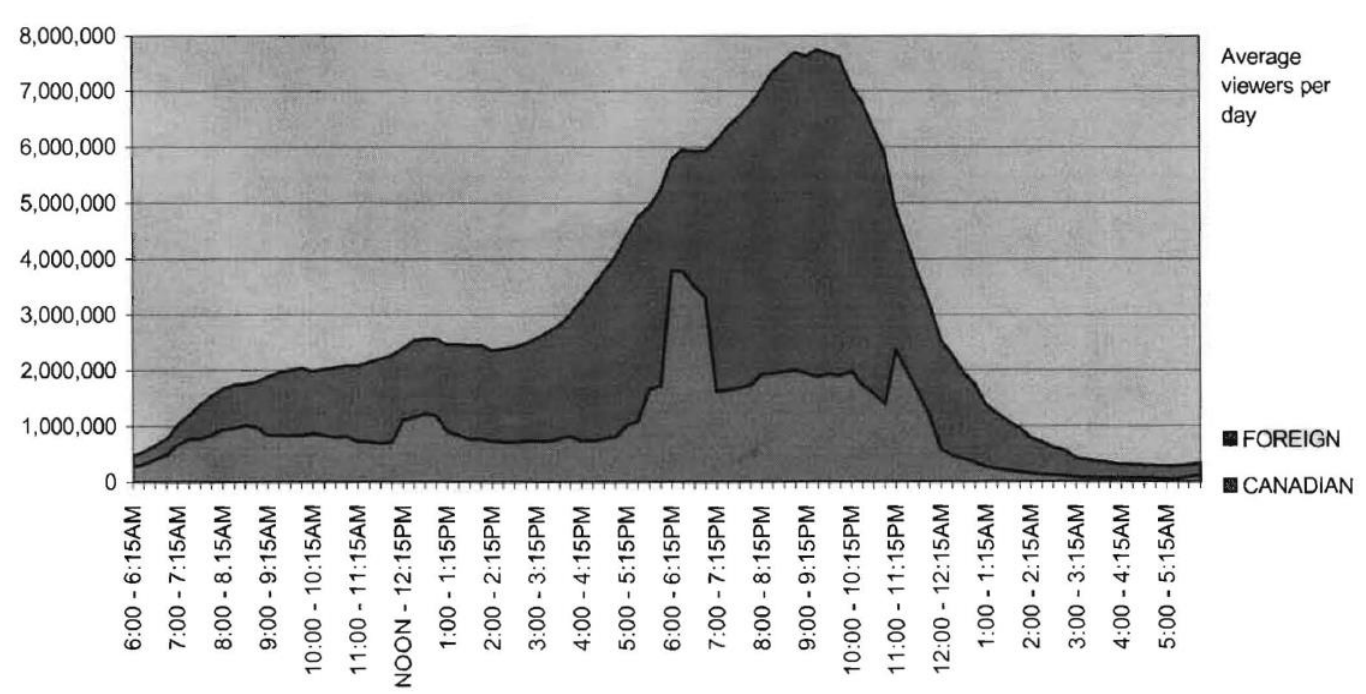

2014 (Source: CMF, Annual Report 2013-2014, p. 35)

CMF-funded vs. Other Canadian vs. Foreign Programs by Genre Peak Hours - English

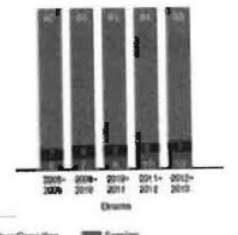


Appendix $\mathbf{J}$

Canada: CRTC, Audience viewing trends

(Source: CRTC, 2014c, Figure 4.2.16 Average weekly viewing hours)
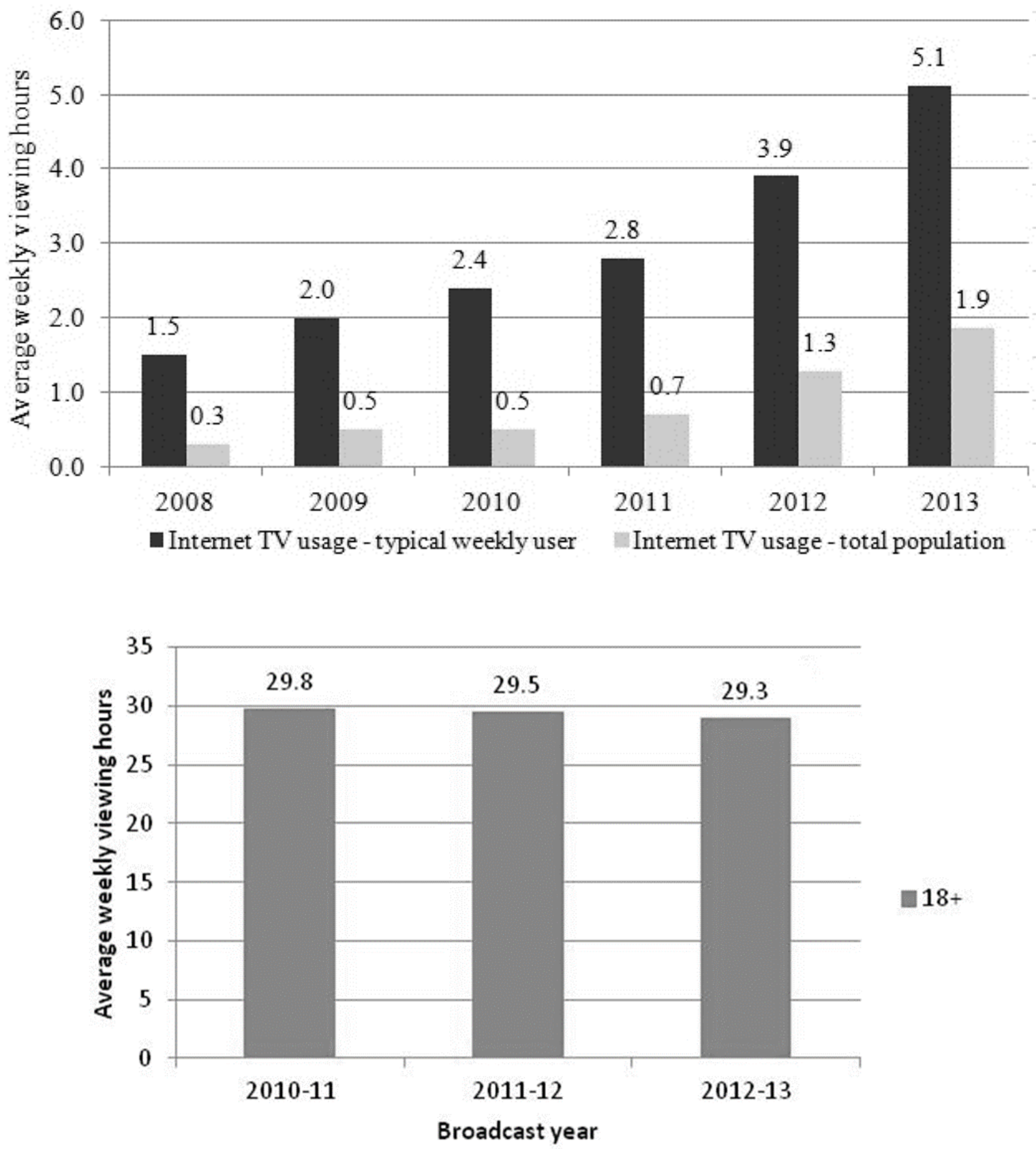


\section{Appendix K}

Top ten TV series in Canada, 2014

(Source: CMPA, 2015, p. 74, Exhibit 2-68)

Program (country of origin)

1. Big Bang Theory (U.S.)

2. La Voix (Canada-French)

3. NCIS (U.S.)

4. Under the Dome (U.S.)

5. Grey's Anatomy (U.S.)

6. NCIS: Los Angeles (U.S.)

7. Criminal Minds (U.S.)

8. Unite 9 (Canada - French)

9. C.S.I. (U.S.)

10. Marvel's Agents of S.H.I.E.L.D. (U.S.)
Average Minute Audience (000's)

$\mathbf{3 , 3 3 7}$

2,715

2,453

2,410

2,261

2,168

2,121

2,100

2,097

2,024 
Appendix L

Canada: Top ten Canadian TV series, English and French, 2014

(Source, CMPA, 2015, p. 74, Exhibit 2-69)*

Program

1. La Voix (French)

2. Unite 9 (French)

3. Les Beaux Malaise (French)

4. Rookie Blue (English)

5. Les jeunes loup (French)

6. Saving Hope (English)

7. Yamaska (French)

8. LOL :) (French)

9. Toute La Verite (French)

10. Motive (English)
Average Minute Audience 000's

2,715

2,100

1,900

1,634

1,622

1,491

1,372

1,337

1,327

1,291

*Note: English Canada population is approximately $\mathbf{2 5}$ million. French Canada is about 10 million. (Government of Canada, 2013). 


\section{Appendix M}

\section{Canada: Top ten Canadian English-language TV series, 2014 broadcast year}

(Source: CMPA, 2015, p. 74, Exhibit 2-71)

Program

1. Rookie Blue

2. Saving Hope

3. Motive

4. Murdoch Mysteries

5. The Listener

6. Battle of the Blades

7. Remedy

8. Vikings

9. Rick Mercer Report

10. Played
Average Minute Audience (000's)

1,634

1,491

1,291

1,147

1,114

1,043

966

904

836

736

*Source listed by CMPA: CMF Research (Numeris 2014) 


\section{Appendix N-1}

Canada: Top ten CMF-funded English-language programs, 2012-2013

(Source: CMF, 2014c, Successes, Audience results section)

\begin{tabular}{|c|c|c|c|c|c|c|}
\hline Broadcaster & Program Title & Day & Time & CMF Genre & \#Telecasts & $\begin{array}{l}\text { Average Minute } \\
\text { Audience }(000)\end{array}$ \\
\hline CTV & Flashpoint & Thursday & $\begin{array}{l}10: 00 \text { pm- } \\
11: 00 \text { pm }\end{array}$ & Drama & 13 & 1,824 \\
\hline CTV & Saving Hope & Thursday & $\begin{array}{l}10: 00 \text { pm- } \\
11: 00 \text { pm }\end{array}$ & Drama & 12 & 1,492 \\
\hline GLOBAL & Rookie Blue & Thursday & $\begin{array}{l}10: 00 \text { pm- } \\
11: 00 \text { pm }\end{array}$ & Drama & 12 & 1,439 \\
\hline $\mathrm{CBC}$ & $\begin{array}{l}\text { Air Farce New Year's } \\
\text { Eve Special } 2012\end{array}$ & Monday & $\begin{array}{l}\text { 8:00 pm- } \\
\text { 9:00 pm }\end{array}$ & $\begin{array}{l}\text { Variety \& } \\
\text { Performing Arts }\end{array}$ & 1 & 1,264 \\
\hline CBC & Murdoch Mysteries & Monday & $\begin{array}{l}9: 00 \mathrm{pm}- \\
10: 00 \mathrm{pm}\end{array}$ & Drama & 13 & 1,238 \\
\hline CTV & The Listener & Wednesday & $\begin{array}{l}10: 00 \mathrm{pm}- \\
11: 00 \mathrm{pm}\end{array}$ & Drama & 15 & 1,189 \\
\hline CTV & Motive & Thurs, Sun & $\begin{array}{l}10: 00 \text { pm- } \\
11: 00 \text { pm }\end{array}$ & Drama & 8 & 1,055 \\
\hline $\mathrm{CBC}$ & Rick Mercer Report & Tuesday & $\begin{array}{l}8: 00 \mathrm{pm}- \\
8: 30 \mathrm{pm}\end{array}$ & Drama & 20 & 1,038 \\
\hline HISTORY & Vikings & Sunday & $\begin{array}{l}\text { 10:00 pm- } \\
11: 00 \mathrm{pm}\end{array}$ & Drama & 9 & 928 \\
\hline GLOBAL & Bomb Girls & Mon, Wed & $\begin{array}{l}\text { 8/9:00 PM- } \\
\text { 9/10:00 pm }\end{array}$ & Drama & 12 & 908 \\
\hline
\end{tabular}

Source: CMF Research (Numeris) 2012-2013 Broadcast Year

Notes: Top 10 data was derived from the Original First Run (OFR) audience data submitted for CMF Performance Envelope calculations. 


\section{Appendix N-2}

Canada: Top ten CMF funded English-language programs, 2011-2012

(Source: CMF, 2013a, Successes, Audience results section)

\begin{tabular}{|c|c|c|c|c|c|c|}
\hline Broadcaster & Program Title & Day & Time & CMF Genre & \#Telecasts & $\begin{array}{l}\text { Average Minute } \\
\text { Audience }(000)\end{array}$ \\
\hline Global & Combat Hospital & Tuesday & $\begin{array}{l}\text { 10:00pm- } \\
11: 00 p m\end{array}$ & Drama & 2 & 1,705 \\
\hline CTV & Saving Hope & Thursday & $\begin{array}{l}9: 00 \mathrm{pm}- \\
10: 00 \mathrm{pm}\end{array}$ & Drama & 10 & 1,683 \\
\hline Global & Rookie Blue & Thursday & $\begin{array}{l}\text { 10:00pm- } \\
11: 00 p m\end{array}$ & Drama & 14 & 1,506 \\
\hline CTV & Flashpoint & $\begin{array}{l}\text { Mon, Tues, } \\
\text { Fri }\end{array}$ & $\begin{array}{l}\text { 8:00pm- } \\
\text { 9:00pm }\end{array}$ & Drama & 13 & $-20121,427$ \\
\hline $\mathrm{CBC}$ & $\begin{array}{l}\text { Royal Canadian } \\
\text { Air Farce }\end{array}$ & Sunday & $\begin{array}{l}\text { 8:00pm- } \\
\text { 9:00pm }\end{array}$ & Drama & 1 & 1,256 \\
\hline $\mathrm{CBC}$ & $\begin{array}{l}\text { Battle of the } \\
\text { Blades }\end{array}$ & Sunday & $\begin{array}{l}\text { 8:00pm- } \\
\text { 9:00pm }\end{array}$ & $\begin{array}{l}\text { Variety \& } \\
\text { Performing Arts }\end{array}$ & 9 & 1,252 \\
\hline Global & Bomb Girls & Wednesday & $\begin{array}{l}\text { 8:00pm- } \\
\text { 9:00pm }\end{array}$ & Drama & 6 & 1,252 \\
\hline CTV & The Listener & Wednesday & $\begin{array}{l}\text { 10:00pm- } \\
11: 00 p m\end{array}$ & Drama & 13 & 1,114 \\
\hline $\mathrm{CBC}$ & $\begin{array}{l}\text { This Hour Has } 22 \\
\text { Minutes }\end{array}$ & Tuesday & $\begin{array}{l}\text { 8:00pm- } \\
\text { 9:00pm }\end{array}$ & Drama & 1 & 1,055 \\
\hline $\mathrm{CBC}$ & Republic of Doyle & Wednesday & $\begin{array}{l}\text { 9:00pm- } \\
\text { 10:00pm }\end{array}$ & Drama & 17 & 1,013 \\
\hline
\end{tabular}

Source: BBM Canada PPM 2011-2012 Broadcast Year 


\section{Appendix N-3}

\section{Canada: Top ten CMF funded English-language programs, 2010-2011}

(Source: CMF, 2012a, Successes, Audience results section)

\begin{tabular}{|c|c|c|c|c|c|c|c|}
\hline Broadcaster & Program Title & Duration & Genre & $\begin{array}{l}\text { Funded } \\
\text { Year }\end{array}$ & $\begin{array}{l}\text { Episodes } \\
\text { Funded }\end{array}$ & $\begin{array}{l}\text { Episodes } \\
\text { Aired }\end{array}$ & $\begin{array}{l}\text { Average } \\
\text { Minute } \\
\text { Audience }\end{array}$ \\
\hline Global & Combat Hospital I & 60 & Drama & $\begin{array}{l}2011- \\
2012\end{array}$ & 13 & 10 & $1,767,600$ \\
\hline $\mathrm{CBC}$ & $\begin{array}{l}\text { Battle of the Blades: } \\
\text { Game ON }\end{array}$ & 60 & Documentary & $2010-$ & 1 & 1 & $1,528,600$ \\
\hline CTV & Flashpoint IV & 60 & Drama & $\begin{array}{l}2010- \\
2011\end{array}$ & 18 & 7 & $1,513,700$ \\
\hline CTV & Flashpoint III & 60 & Drama & $\begin{array}{l}2009- \\
2010\end{array}$ & 13 & 29 & $1,497,800$ \\
\hline $\mathrm{CBC}$ & $\begin{array}{l}\text { Heartland Christmas } \\
\text { (A) }\end{array}$ & 120 & Drama & $\begin{array}{l}2009- \\
2010\end{array}$ & 1 & 2 & $1,372,100$ \\
\hline Global & Rookie Blue II & 60 & Drama & $2010-$ & 13 & 14 & $1,307,100$ \\
\hline $\mathrm{CBC}$ & $\begin{array}{l}\text { Rick Mercer Report } \\
\text { (The) VIII }\end{array}$ & 30 & Drama & $\begin{array}{l}2010- \\
2011\end{array}$ & 19 & 64 & $1,196,700$ \\
\hline $\mathrm{CBC}$ & $\begin{array}{l}\text { Air Farce New Year's } \\
\text { Eve } 2010\end{array}$ & 60 & $\begin{array}{l}\text { Variety \& } \\
\text { Performing Arts }\end{array}$ & $\begin{array}{l}2010- \\
2011\end{array}$ & 1 & 2 & $1,097,800$ \\
\hline Global & Rookie Blue I & 60 & Drama & $\begin{array}{l}2008- \\
2009\end{array}$ & 13 & 5 & $1,071,400$ \\
\hline CTV & Listener (The) II & 60 & Drama & $2010-$ & 13 & 32 & $1,005,300$ \\
\hline
\end{tabular}




\section{Appendix N-4}

Canada: Top ten CMF funded English-language programs, 2009-2010

(Source: CMF, 2011, Successes, Audience results section)

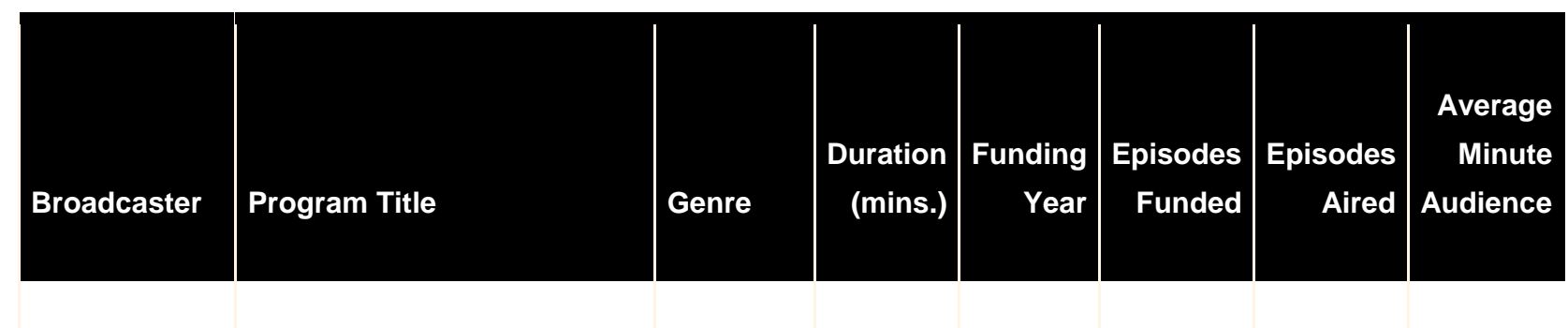

2008-

$\begin{array}{llllllll}\text { CTV } & \text { Hiccups I (Pilot) } & \text { Drama } & 30 & 2009 & 1 & 1 & 2,059,000\end{array}$

\begin{tabular}{l|rrrrr|r} 
CTV Dan for Mayor I (Pilot) & Drama & 30 & $2008-$ & 1 & 1 & $1,995,000$
\end{tabular}

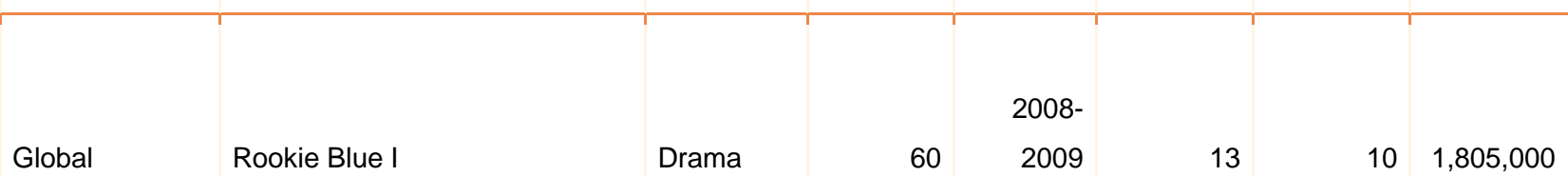

$\Gamma_{\mid}$

\begin{tabular}{|c|c|c|c|c|c|c|c|}
\hline CTV & Flashpoint III & Drama & 60 & $\begin{array}{r}2009- \\
2010\end{array}$ & 13 & 4 & $1,472,000$ \\
\hline CTV & Flashpoint II & Drama & 60 & $\begin{array}{r}2008- \\
2009\end{array}$ & 18 & 18 & $1,449,000$ \\
\hline
\end{tabular}

Keep Your Head Up, Kid: The

$\mathrm{CBC}$

Don Cherry Story

Drama

120
2009-

2010

2

$21,357,000$

\begin{tabular}{|c|c|c|c|c|c|c|c|}
\hline CTV & Bridge (The) & Drama & 120 & $\begin{array}{r}2007- \\
2008\end{array}$ & 1 & 1 & $1,223,000$ \\
\hline & & & & & & & \\
\hline
\end{tabular}


2009-

$\begin{array}{llllrrr}\text { CBC } & \text { Rick Mercer Report VII } & \text { Drama } & 30 & 2010 & 19 & 19\end{array}$

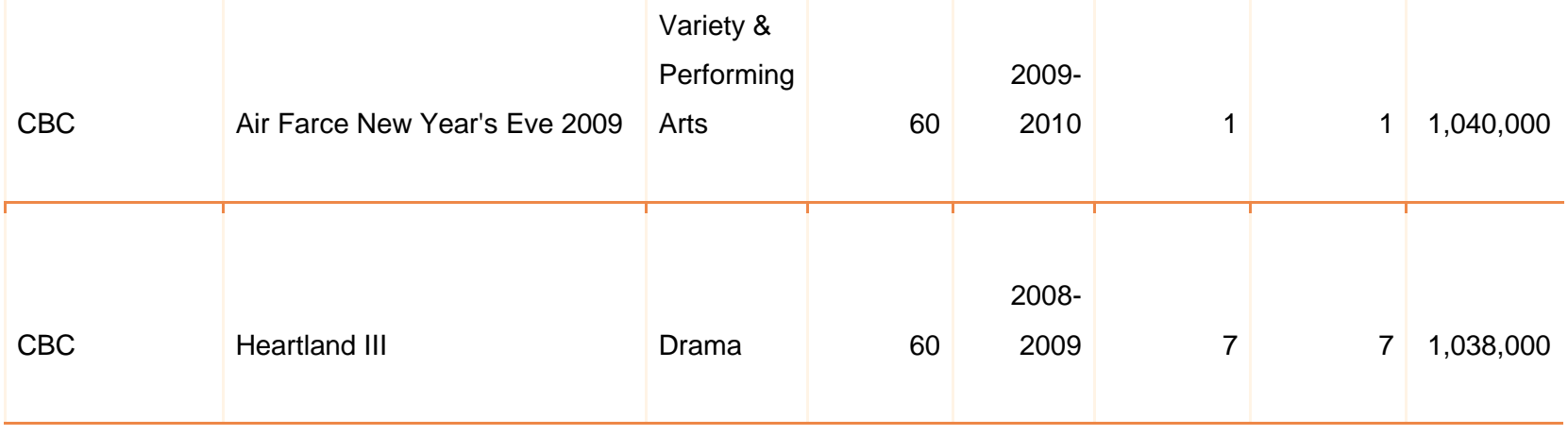

NOTE: aired during the 2009-2010 broadcast year 


\section{Appendix 0 \\ Canada: English-language premium TV dramas, U.S. presence* \\ (Source: lists compiled from Appendices N1-4 and R)}

\section{(The following shows are available by ecommerce on Amazon.com and/or iTunes.com, but may not be}

available on amazon.ca or iTunes.ca.)

Beauty and the Beast [CRTC co-venture] CW, 2012-to date, Showcase, 2012-to date)

Bomb Girls (Reelz Channel, 2012; Global 2012)

The Border (Ion, Hulu Plus, CBC)

Borgias (Canada-Ireland-Hungary co-prod), 2011-2013, Showtime; Bravo and CTV 2011-2013

Call Me Fitz (HBO Canada, Movie Network \& Movie Central, 2011-2013)

Combat Hospital (ABC 2011; Shaw, 2011)

Flashpoint (CBS 2008-2009; CBS International, 2009-2011, ION, 2011-2012; CTV, 2008-2012)

InSecurity: (CBC 2011)

King (Showcase, 2011-2012, no U.S. sale)

The Listener (Fox International Channels, 2010-2014; CTV, 2010-2014)

Lost Girl (Showcase and Shaw Media, 2010-2014; Syfy 2012)

Motive (ABC 2013-2014; CTV 2013-to date)

Murdoch Mysteries (Ovation, American Public Television, Hulu, Acorn; Bravo-CBC 2008- to date)

Orphan Black (BBC America; 2013-to date; Bell Media Space, 2013-to date)

ReGenesis (CW Plus, Hulu.com; Movie Network and Movie Central, 2004-2008)

Rookie Blue (ABC, 2010-to date; Global, 2010-to date)

Saving Hope (NBC partial season one; CTV 2012 - to date)

Schitt's Creek (Pop; CBC, 2015-to date)

Seed (CW, City, 2013-2014)

Tudors (UK-Ireland-Canada co-prod, Showtime, CBC, BBC Two, TV3 Ireland)

Vikings [Canada-Ireland co-production] History U.S. and Canada, 2013-to date

Working the Engels (NBC, July-Aug 2014, remaining episodes pulled; Globa 


\begin{abstract}
Appendix P
Canada: Financial structure, Canadian English-language premium TV dramas
\end{abstract}

(Source: Personal communication with informant, June 26, 2015)

\title{
CANADIAN ENGLISH TV DRAMA SERIES
}

Production Finance Plan

$10 \times 60$ minutes

10/10 CAVCO Points

TOTAL BUDGET

SOURCE

Broadcaster

CMF

Private Equity

Tax Credits

Distribution Advance

TOTAL
TOTAL AMOUNT

$3,150,000$

$5,545,786$

250,000

4,593,907

$\mathbf{5 , 4 6 0 , 3 0 7}$

19,000,000
PER EPISODE \% BUDGET

315,000

$16.58 \%$

$\mathbf{5 5 4 , 5 7 9}$

$29.19 \%$

25,000

$1.32 \%$

459,391

$24.18 \%$

546,031

$28.74 \%$

1,900,000

$100.00 \%$ 


\section{Appendix Q}

Canada: Canadian Media Fund, percent of funding spent on English-language drama 2005-2015

(Source: personal communication with CMF, April 29, 2015)

\begin{tabular}{lccc} 
Year & $\mathbf{\$ M}$ & $\mathbf{\%}$ & of Total \$M \\
$2005-2006$ & 101.9 & $62 \%$ & 165.4 \\
$2006-2007$ & 99.7 & $60 \%$ & 164.8 \\
$2007-2008$ & 88.0 & $56 \%$ & 156.7 \\
$2008-2009$ & 113.0 & $62 \%$ & 182.5 \\
$2009-2010$ & 128.3 & $62 \%$ & 203.1 \\
$2010-2011$ & 111.8 & $61 \%$ & 182.6 \\
$2011-2012$ & 112.1 & $56 \%$ & 188.9 \\
$2013-2014$ & 104.4 & $58 \%$ & 184.6 \\
$2014-2015$ & 107.1 & $58 \%$ & \\
\hline
\end{tabular}




\section{Appendix R}

Canada: Exports of Canadian Media Fund TV dramas

(Canadian Media Fund, 2014c. International Sales Section, Drama*)

*Retrieved from http://ar-ra13-14.cmf-fmc.ca/audience/international_prominence/

\section{Drama}

\section{Title}

\section{Country/Region}

\begin{tabular}{|c|c|}
\hline Saving Hope & 7 \\
\hline Cracked & 5 \\
\hline Adam et Ève & 4 \\
\hline Picnicface & 4 \\
\hline Little Mosque on the Prairie & 2 \\
\hline Michael: Tuesdays \& Thursdays & 2 \\
\hline Sanctuary & 2 \\
\hline InSecurity & 1 \\
\hline Les Parent & 1 \\
\hline Republic of Doyle & 1 \\
\hline Rookie Blue & 1 \\
\hline Seed & 1 \\
\hline Working the Engels & 1 \\
\hline \# of Drama projects sold & 13 \\
\hline \# of unique countries/regions & 19 \\
\hline
\end{tabular}




\section{Appendix S}

\section{Canada: International distributor, CMF English-language premium TV dramas, 2010-2014}

\section{(Source: personal communication with informant, June 26, 2105, not comprehensive)}

2013-2014:

Flashpoint - Foreign

Saving Hope - Canadian

Rookie Blue - Canadian

Murdoch - Foreign

The Listener - Foreign

Motive - Foreign

Vikings - Foreign

Bomb Girls - Canadian

Michael, Tuesdays and Thursdays - Canadian

Sanctuary - Canadian

InSecurity - Canadian

Republic of Doyle - Foreign

Seed - Canadian

Working the Engels - Foreign

2012-2013:

Combat Hospital - Foreign

Saving Hope - Canadian

Rookie Blue - Canadian

Flashpoint - Foreign

Bomb Girls - Canadian

The Listener - Foreign

Motive - Foreign

Mr. D - Canadian

Orphan Black - Foreign

ReGenesis - Canadian

Michael: Tuesdays and Thursdays - Canadian

Cracked - Foreign

Sanctuary - Canadian

\section{1-2012}

Combat Hospital -Foreign

Flashpoint III and IV - Foreign

Rookie Blue I and II - Canadian

Listener - Foreign

Murdoch Mysteries - Foreign

Republic of Doyle - Foreign

The Tudors - Foreign

Bomb Girls - Canadian

Borgias - Foreign

Sanctuary - Canadian

King - Foreign

Call me Fitz - Canadian

Lost Girl - Foreign

ReGenesis - Canadian

The Border - Canadian then foreign

\section{0-2011:}

Rookie Blue - Canadian

Flashpoint - Foreign

Republic of Doyle - Foreign

Heartland - Foreign then Canadian later

Call me Fitz - Canadian

Midnight's Children -

Being Erica (includes 2 format buys) - Foreign

Murdoch Mysteries - Foreign

Combat Hospital - Foreign

Flashpoint - Foreign

Republic of Doyle - Foreign

Heartland - Foreign then Canadian 


\author{
Appendix T \\ Canada: CRTC co-ventures, TV dramas, 2010-2014 \\ (Source: CRTC, 2014g)
}

Search terms:

Dates: April 1, 2010 to March 31, 2014

Category SR number and Drama 7A, 7B, 7C, 7D per below

7A, ongoing dramatic series and 7B, ongoing comedy series

Skins

Beauty and the Beast

Reign

Hard Rock Medical

When Calls the Heart

High Moon

Ascension

7C, mini-series and made for TV feature films and 7D, feature films

Night of Terror

Penpals

Slapshot: The junior league

Skins (pilot)

Radio Rebel

Nicky Deuce

Hannah's Law

Out of Reach

Sink Hole

Defending Santa

Avalanche Sharks

Crimes of the Minds

Pop Star Puppy

Wishes

Voeux 


\title{
Appendix U
}

\section{Canada: Financial structure, CRTC co-venture}

\author{
(Source: Goodmans LLP, 2012, p. 14)
}

CANADA

\begin{tabular}{l} 
CANADIAN CITIZEN \\
$\qquad 100 \%$ \\
\hline Canadian Controlled Company \\
(“Can. Co.") \\
- entered into Co-Venture \\
Agreement with U.S. Co. \\
- with U.S. Co., jointly engaged \\
Can. Prod. Co. under the \\
Production Services Agreement \\
to produce the Production \\
- responsible for contributing 50\% \\
of financing of Production and \\
has right to receive 50\% of \\
"profits" from the Production \\
- licence fee per episode \\
attributed to Can. Co.'s 50\% \\
financing contribution to the \\
Production Canadian distribution \\
rights \\
- jointly controls with U.S. Co. \\
worldwide distribution right \\
(excluding Canada) \\
\hline
\end{tabular}

CO-VENTURE STRUCTURE

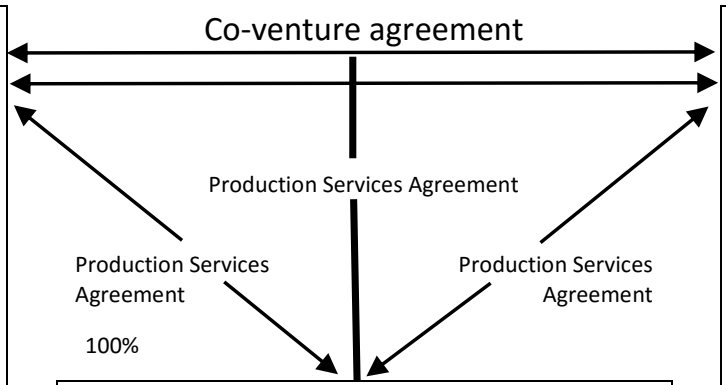

Canadian Production Company ("Can. Prod. Co.")

- single purpose production company owned $100 \%$ by Can. Co. and jointly engaged by Can. Co. and U.S. Co. to produce the Production

- responsible for claiming all production services tax credits ("Tax Credits")

- Tax Credits attributed to Can. Co.'s 50\%

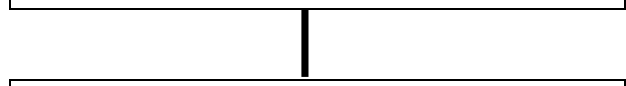

\section{U.S. Distributor Company (“U.S. Dist.”)}

- Owned $100 \%$ by U.S. Co. and appointed by U.S. Co. and Can. Co. as worldwide distributor (excluding Canada)

- distribution advance attributed and allocated to Can Co.'s and U.S. Co.'s respective $50 \%$ financing contribution to the Production, as required to ensure ultimate $50 \% / 50 \%$ contribution split

- recoups distribution advance, maximum fees, costs and expenses with remaining "net profits"

\section{$+2$}

\section{Broadcasting Arrangements}

- granted worldwide (excluding (i) U.S. broadcast rights and (ii) Canadian broadcast rights) distribution rights by U.S. Dist.; distribution advance per episode payable to U.S. Dist.

- granted U.S. broadcast rights by U.S. Dist.; licence fee payable to U.S. Dist.
U.S.

\section{CANADIAN CITIZEN/}

AMERICAN CITIZEN

$100 \%$

American Controlled Company (“U.S.

Co.")

- entered into Co-Venture Agreement with Can. Co.

- with Can. Co., jointly engaged Can. Prod. Co. under the Production Services Agreement to produce the Production

- responsible for contributing $50 \%$ of financing of Production and has right to receive $50 \%$ of "profits" from the Production

- controls Canadian distribution rights

- jointly controls with Can. Co. worldwide distribution right (excluding Canada) 


\section{Appendix V}

\section{Canada: International co-production treaties}

(Source: Telefilm Canada, 2015, co-productions)

\section{Audiovisual Coproduction Treaties and MOUs}

Audiovisual coproduction treaties and MOUs are negotiated between two countries to outline their respective obligations with regard to an audiovisual coproduction.

Canada is a party to bilateral treaties and MOUs with more than 50 countries. Telefilm Canada administers those treaties and MOUs on behalf of the Government of Canada.

You can read the details of each of the applicable treaty or MOU below.

\begin{tabular}{ll} 
Algeria & Italy \\
Argentina & Japan \\
Australia & Latvia \\
Austria & Luxembourg \\
Belgium & Macedonia \\
Bosnia-Herzegovina & Malta \\
Brazil & Mexico \\
Bulgaria & Morocco \\
Chile & Netherlands \\
China & New Zealand \\
Colombia & Norway \\
Croatia & Republic of the Philippines \\
Cuba & Poland \\
Czech Republic & Romania \\
Denmark & Russian Federation \\
Estonia & Senegal \\
Finland & Singapore \\
France (Cinema) & Slovak Republic \\
France (Television) & Slovenia \\
France (Mini-treaties) & South Africa \\
Germany & South Korea \\
Greece & Spain \\
Hong Kong & Sweden \\
Hungary & Switzerland \\
Iceland & United Kingdom \\
India & Uruguay \\
Ireland & Venezuela \\
Israel & Yugoslavia (Serbia and Montenegro) \\
& \\
\hline &
\end{tabular}




\section{Appendix W}

Canada: Policy history, Royal Commission on radio broadcasting (Aird Commission)

(Source, Royal Commission on radio broadcasting, 1929, p. 17)

RADIO BROADCASTING

\section{BWEDEN}

Broadcasting is in the hands of an organization known as Aktiebolaget Rsdiotjänot in which the press of the country is largely interested. The transmitters are owned and oper shed by the State. They are about 30 in number, including one of $40 \mathrm{k}$. antenns input at Motals working on a long wave. Radiotjängt has about 4,000 miles of telephonie cincurts connecting its Stockholm studio with the various stations. The revenue comes exclusively form 50 per cent being available for the programs onganisation. The number of licensed listeners on December 31, 1928, was 380,863 or one receivet for esch 16 persons

\section{SWITZERLAND}

Five separate organisations have been granted licenses to transmit, the State holding a place on each Board of Directors. The stations are the property of the companies. A fusion of interests is taking place which will probably result in the establishment of two high-power stations one for French-opeaking Switserland and the other for Germsarspeaking Switzeriand. The only source of revenue is the license fees (14 Swite francs per annum).

The number of licensed listeners at the end of December, 1928, was 70,183.

\section{TURKEY}

One company has been given a monopoly for both Turkey in Europe and Turkey in Asia. Two high-power etations have been built, one at Angora, the other st Stamboul. The source of revenue is not known to us, nor the number of listeners. The growth of interest is believed, however, to be but amall.

\section{UNION OF SOUTH AFRICA}

Broadcasting in the Union of Bouth Africa is a regional monopoly, esch station being licensed to operate exclusively within a oertain territory for a period of five yeans Thero sre four stations. Receiving set owners are required to pay both license fees and brosdcast eubacriptions. The licenses cost five shillings per year, while the subecriptions vary from six shillings, sixpence to thirty-five shillings, depending upon the distance from the broadcasting stations. Higher scales are in in effect for sets to be used for commercisl purposes.

\section{UNITED STATES OF AMERICA}

Broadcasting in the United Statea in carried on by private enterprise under license of the Federal Itadio Commission. There are 604 stations so dicensed. There is no license fee for listecers. 


\section{Appendix X}

Canada: Policy history, CRTC, origin of simultaneous substitution

(Source: CRTC, 1971)

Decision $79-460$ to $79-495$; Aug. 6,$1979 ; 8,3-4$

S.E.T.T.E. indicated its intention to offer a three and houfcastiny priority to Canodian oroadcasters mere applicable and expressexd llu. hope that cable opetors and oroadcasters would fora a joint rommitter. to identify prograns requiring such prierity protecion. As a condition of licence, participating coble television licenoes are restired to ensare prierity to Conadian broadcasters in the annmer outlined in this announcement.

IMLTAMEUS PROGRAM SUBSTITUTIEN

Decision 70-93; Apr. 10, 1970; p. Z

The non-Canadian prograns brosdcast by Canedian breadcasting stations serving the area shall not be duplicated on a cable systea siaulfaneously or during the neek prior to and the meek subsequent to the date of airing on the Canadian stations unless specifically autherized by the Comission.

) Public Announcenent, Feb, 26, 1971, Part II, p, 17?

) Peter Grant's Index; Table B; 205-78

Several objections have been raised against the proposal suggested in Decision $70-93$ resulring cable systeas to black out all prograes provided by distant stations wich deplicate prograns provided by the local station withix a peried of me meek. The Conaission therefore suggests that the cable systea should carry the local station's version of any progran deplicated sieultaneously by distant station. The Conaission also suggested that other progran substitution aethods night also be considered.

Petar Grant's Index; Table B; 205-84 


\section{Appendix Y}

Canada: Policy history, FCC article on signal substitution

(Source: personal communication, Ken Goldstein, March 25, 2015;

article noted as from New York Times and reprinted in The Globe and Mail, May 18, 1970)

bsidies for ETV: FCC votes to drop limits on cable TV

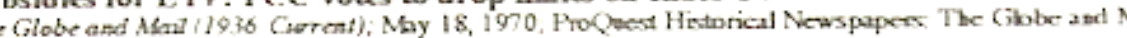

20

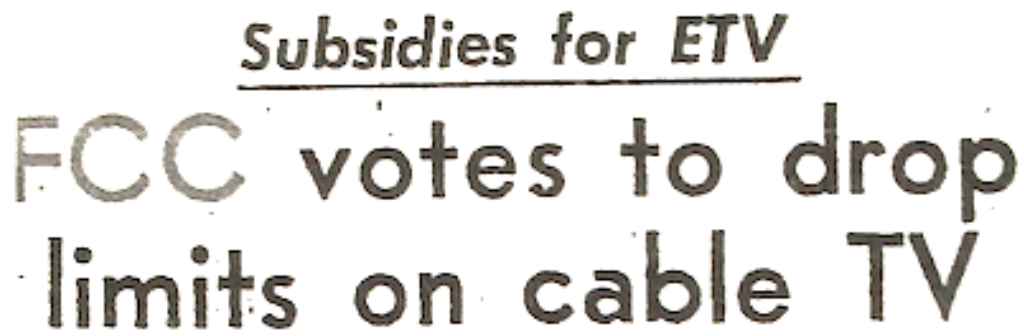

(C) New York Times Servicie

The Burch proposal -is still

WASHINGTON - In a pol- in outline form and may face y shift that could radically - the concerted opposition of the pand the program choices

U.S. television, the Federal immunications Commissjon is voted tentativaly to perit virtually unlimited importion of oul-ol-town programing on cable television sysms.

The new plan, lifting the ost burdensome restrictions CATV's development, was onsored by FCC chairman zan Burch and endorsed by 4-to-3 commission majority a preliminary vote Frlday. Although the plan would ve the CATV industry a werful boost, it would also vert 5 per cent of cable mpanies; income into a ge now subsidy for educainal television. established TV networks and some local stations. Yet it is already being cautiously described as a historic breakthrough in the liberation of cable technology.

Burch's solution, conceived with the help of Henry Geller, the FCC's general counsel, is to let CATV systems import out-of-town programming but require the substitution of locally sold advertising for the commerclal breaks on the imported signal. 'Revenue from the substituted commercials would go directily to local ultra-high frequency stations whose audience would be expected to shrink as the CATV alternative grew popular. 
Appendix Z

Ryerson University: Research Ethics Board approval through 2015

APPROVAL THROUGH JULY 4, 2014:

From: "rebchair@ryerson.ca"<rebchair@ryerson.ca>

To: isberkowitz@yahoo.com

Sent: Thursday, July 4, 2013 10:21 AM

Subject: REB 2013-120 Status

REB 2013-120

Project Title: Brain Drain to Brain Chain; Re-framing the Challenge of Canadian English-language Television Drama

Dear Irene Berkowitz,

The Research Ethics Board has completed the review of your submission. Your research project is now approved for a one year period as of Jul 4, 2013. The approval letter is attached in Adobe Acrobat (PDF) format.

Congratulations and best of luck with the project.

Please note that this approval is for one year only and will expire on July 4, 2014. Shortly before the expiry date a request to complete an annual report will be automatically sent to you. Completion of the annual report takes only a few minutes, enables the collection of information required by federal guidelines and when processed will allow the protocol to remain active for another year.

Please quote your REB file number (REB 2013-120) on future correspondence.

If you have any questions regarding your submission or the review process, please do not hesitate to get in touch with the Research Ethics Board (contact information below).

No research involving humans shall begin without the prior approval of the Research Ethics Board. Record respecting or associated with a research ethics application submitted to Ryerson University.

Yours sincerely,

Toni Fletcher, MA Research Ethics Co-Ordinator on behalf of

Lynn Lavallée, Ph.D. Chair, Research Ethics Board Associate Professor

Ryerson University EPH-241 350 Victoria St., Toronto, ON (416)979-5000 ext. 4791 lavallee@ryerson.ca rebchair@ryerson.ca

http://www.ryerson.ca/research

Toni Fletcher, MA Research Ethics Co-Ordinator Office of Research Services Ryerson University(416)979-5000 ext. 7112

toni.fletcher@ryerson.cahttp://www.ryerson.ca/research

\section{RENEWAL OF APPROVAL THROUGH JULY 6, 2015:}

From: "rebchair@ryerson.ca"<rebchair@ryerson.ca>

To: isberkowitz@yahoo.com

Sent: Sunday, July 6, 2014 11:15 PM

Subject: REB 2013-120 Status

Project Title: Brain Drain to Brain Chain; Re-framing the Challenge of Canadian English-language Television Drama

Dear Irene Berkowitz,

Your research project is now approved for renewal for an additional year as of Jul 06, 2014.

This is a renewal for REB file \# 2013-120. The approval letter is attached in Adobe Acrobat (PDF) format.

Congratulations and best of luck with the project.

Please quote your REB file number (2013-120) on future correspondence.

If you have any questions regarding your submission or the review process, please do not hesitate to get in touch with the Research Ethics Board (contact information below).

No research involving humans shall begin without the prior approval of the Research Ethics Board.

Record respecting or associated with a research ethics application submitted to Ryerson University.

Yours sincerely,

Lynn Lavallée, Ph.D. Chair, Research Ethics Board Associate Professor Ryerson University EPH-200C

350 Victoria St., Toronto, ON (416)979-5000 ext. 4791

lavallee@ryerson.ca rebchair@ryerson.ca http://www.ryerson.ca/research

Toni Fletcher, MA Research Ethics Co-Ordinator Office of Research Services Ryerson University (416)979-5000 ext. 7112 toni.fletcher@ryerson.ca http://www.ryerson.ca/research 


\section{Appendix AA \\ Ryerson University: Informant release for field study \\ Brain drain to brain chain: \\ Re-framing the challenge of Canadian English-language television \\ Interview Consent Form}

This research investigates the impact of global-linkages (Hollywood-Canada) on the development of Canadian English-language television series. The study is based on the premise that the manufacturing of television series can be accurately represented by a three-phase value-chain including development, production and distribution - and moreover, that weakness originates in the development phase, rather than in production, which is the phase more commonly addressed by policy and regulation. Given the acknowledged brain drain of Canadian creators to the Hollywood entertainment cluster (the established global mecca for television development), the study attempts to uncover the complexity of development dynamics by speaking with development professionals working on series which are official Canada-US co-ventures or Canadian creators/writer/producers working on US television series.

While there will be no immediate benefit to you for participating in this study, the goal of this research is to gain insights which may be applicable to firm strategies and policy avenues that can be applied to strengthen global-local linkages (Hollywood-Canada) which could help strengthen the development of Canadian, English-language television series. I would be pleased to provide you with a copy of the resulting paper from this research, including my $\mathrm{PhD}$ thesis.

I am asking for your help by consenting to an interview. This interview, which has been designed to minimize the amount of time required by you, typically lasts one half-hour.

Additionally, with your permission below, the interview will be recorded with a voice recorder.

Please note that all information gathered from you will be treated as strictly confidential. The confidentiality will be assured by assigning code numbers to each interviewee. We also assure you that neither your identity nor any details of your organization will be revealed in any presentations or publications that result from this research, without your express written permission. Should specific information on your organization be desired, or attribution of quotes, consent will be sought prior to use. Your participation in this study is strictly voluntary and you are, of course, free to choose not to answer any questions and may terminate the interview at any time with no consequences or effect on your relationships with Ryerson University. If you have any questions regarding the study and your participation in it, please feel free to inquire at the contacts below.

\section{LEAD INVESTIGATOR:}

Irene Berkowitz

PhD Candidate,

Ryerson/York University, Program in Communication and Culture

isberkowitz@yahoo.com or 416-433-8758

\section{RESEARCH ADVISOR:}

Professor Charles H. Davis,

Edward S. Rogers Sr. Research Chair, Media Management and Entrepreneurship and

Associate Dean, Scholarly Research and Creative Activities,

Faculty of Communication \& Design, Ryerson University

(416) 979-5000 ext 7145 or c5davis@ ryerson.caI.

(Name/Title/Organization - Please Print Clearly)

agree to participate in the study as outlined above. My participation in this study is voluntary and I understand that I may withdraw at any time.

Participant's signature

Date

Researcher's signature

Date

II.

I acknowledge and offer my consent to have this interview recorded with a voice recorder.

Participant's Signature

Date

Researcher's Signature

Date 


\section{Appendix BB}

\section{Ryerson University: Semi-structured interview questions and original policies}

THANK YOU very much for agreeing to this interview. The structure will be to request your insights on development, and finish with your response to some trial policies to strengthen Canadian TV drama development.

At any point, please feel welcome to contribute any additional thoughts or ask any questions:

1. Would you describe the development path of $x x x x$, from concept through network pitch, green-lit script, pilot, to series order?

2. You began your career in Canada. Were you privy to the series development process? If so, can you describe the Canadian TV drama development process, from concept through network pitch, green-lit script to series order?

3. Can you describe any key difference(s) between development in Canada and Hollywood? Feel welcome to include all sides of the story: financial/creative, network/creator, series/episode. How do development processes in LA and Canada affect the trajectory of the resultant shows?

4. I'm sure you are aware of shows like Flashpoint, Rookie Blue, Saving Hope, and Working the Engels. How are these series perceived in Hollywood, both by individual creators, and by major network/studios such as NBC, CBS, ABC, HBO?

5. How would you describe the Canadian TV 'brand'? Should it/could it change and why? If so, what would it take?

6. Would someone like yourself would re-engage in the Canadian TV system in a creative capacity? If so, what under what circumstances? If not, why?

7. What would it take for the Canadian system to deliver a true global 'hit'?

8. Are there any stories about Canada or Canadians that might not sell in Hollywood that you would like to tell?

9. Would you take a few moments to comment on some proposed policies which could strengthen HollywoodCanada development linkages?

A. Could it be useful to have an incentive for a Canadian network to offer a 'housekeeping' or 'first look' deal to senior Canadian creators in Hollywood, like yourself, which could enhance industrial opportunity and potentially upgrade educational opportunities for junior Canadian creators? Why/why not?

B. Could it be useful to offer tax-free sale of IP for Canadian residents, which might incentivize Canadian creators in LA to periodically work in Canada, with training spillovers? Why/why not?

C. Could it be useful to harmonize Canadian TV development schedules, practices and even terms (such as 'executive producer') with LA, so Canadian creators and network execs could better access opportunities to compete and partner with US networks? Why/why not?

D. Could it help to simplify Canadian content regulations with a category called C3/Canadian Created Content, emphasizing the pivotal role of creators/development? Inspired by music's simple and successful MAPL policy, what is your response to $\mathbf{L E A F}$ (like MAPL, content would qualify if only 2 of 4 conditions are met)?

Location of production: in Canada

Executive Producer/Creator/Writer: Canadian citizen

Actors, main performers: Canadian citizens

Finish: post production in Canada

10. Before we end, any other observations which could help Canada strengthen development and/or achieve the long-articulated goal of a nationally and globally embraced, profitable TV series hit? THANK YOU! 


\section{Appendix CC}

\section{Canada: CRTC, Let's Talk TV, key documents}

Canadian Radio-television and Telecommunications Commission (2013, October 24). Speech by JeanPierre Blais, Chairman and CEO, to launch Let's Talk TV: A conversation with Canadians at Université Laval. Retrieved from http://www.crtc.gc.ca/eng/com200/2013/s131024.htm

Canadian Radio-television and Telecommunications Commission. (2014e, August 21). Broadcasting Notice of Consultation 2014-190-3 (Working document for discussion: Let's Talk TV). Retrieved from http://www.crtc.gc.ca/eng/archive/2014/2014-190-3.htm

Canadian Radio-television and Telecommunications Commission. (2014f). Interventions (Public process number: 2014-190). Retrieved from https://services.crtc.gc.ca/pub/ListeInterventionList/DefaultDefaut.aspx?en=2014-190\&dt=i\&lang=e

Canadian Radio-television and Telecommunications Commission. (2015a, January 29). CRTC continues to set the course for the future of television with Let's Talk TV decisions. Retrieved from http://news.gc.ca/web/article-en.do?nid=926529

Canadian Radio-television and Telecommunications Commission. (2015b, January 29). Broadcasting and Telecom Decision 2015-26: Complaint against Bell Mobility Inc. and Quebecor Media Inc., Videotron Ltd. and Videotron G.P. alleging undue and unreasonable preference and disadvantage in regard to the billing practices for their mobile TV services Bell Mobile TV and illico.tv. Retrieved from http://www.crtc.gc.ca/eng/archive/2015/2015-26.htm.

Canadian Radio-television and Telecommunications Commission. (2015c, January 29). Broadcasting Regulatory Policy 2015-24: Over-the-air transmission of television signals and local programming. Retrieved from http://www.crtc.gc.ca/eng/archive/2015/2015-24.htm

Canadian Radio-television and Telecommunications Commission. (2015d, January 29). Broadcasting Regulatory Policy 2015-25: Measures to address issues related to simultaneous substitution. Retrieved from http://www.crtc.gc.ca/eng/archive/2015/2015-24.htm

Canadian Radio-television and Telecommunications Commission. (2015e, March 12). Jean-Pierre Blais to the Canadian Club of Ottawa on Let's Talk TV and the future of content made by Canadians. Retrieved from http://news.gc.ca/web/article-en.do?nid=947239

Canadian Radio-television and Telecommunications Commission. (2015f, March 12). Broadcasting Regulatory Policy 2015-86: The way forward-Creating compelling and diverse Canadian programming. Retrieved from http://crtc.gc.ca/eng/archive2015/2015-86.htm

Canadian Radio-television and Telecommunications Commission. (2015g, March 19). Statement from Jean-Pierre Blais, Chairman and CEO of the CRTC, on maximizing choice and affordability for Canadians. Retrieved from http://news.gc.ca/web/article-en.do?nid=953129

Canadian Radio-television and Telecommunications Commission. (2015h, March 19). Broadcasting Regulatory Policy 2015-96: Let's Talk TV, A world of choice-A roadmap to maximizing choice for $T V$ viewers and to foster a healthy, dynamic market. Retrieved from http://www.crtc.gc.ca/eng/archive/2015/2015-96.htm

Canadian Radio-television and Television Telecommunications Commission (2015i, March 26). CRTC proposes measures to empower Canadian TV viewers. Retrieved from http://news.gc.ca/web/article-en.do?nid=955539

Canadian Radio-television and Telecommunications Commission. (2015j, March 26). Broadcasting Regulatory Policy 2015-104: Let's Talk TV, navigating the road ahead-Making informed choices about television providers and improving accessibility to television programming. Retrieved from http://www.crtc.gc.ca/eng/archive/2015/2015-104.htm

Canada Radio-television and Telecommunications Commission. (2015k, March 26). Let's Talk TV decisions at a glance. Retrieved from http://www.crtc.gc.ca/eng/com300/infograph1.htm 


\section{Appendix DD}

\section{Media presence: Public impact of this research [chronological]}

Berkowitz, I. (2014, June 27). Brain Drain to Brain Chain | Can Con to Can Brand -- re-framing the challenge of English language Canadian TV drama, submission to CRTC Let's Talk TV, June 27. Retrieved from https://services.crtc.gc.ca/pub/ListeInterventionList/Documents.aspx?ID=218358\&Lang=e.

Berkowitz, I. (2014, July 7). Is it time to re-brand Canadian TV? Playback Magazine, July 7. Retrieved from http://playbackonline.ca/2014/07/07/oped-is-it-time-to-re-brand-canadian-tv/\#ixzz36oOrqGOX

Berkowitz, I. (2014, September 9). Can Con to Can Brand-Let's pivot our goal from domestic supply to global demand, text of live presentation. Retrieved from

https://services.crtc.gc.ca/pub/ListeInterventionList/Documents.aspx?ID=218358\&Lang=e

CPAC (2014, September 9). Can Con to Can Brand - Let's pivot our goal from domestic supply to global demand. Live testimony at Let's Talk $T V$. [video file]. Retrieved from http://www.cpac.ca/en/digitalarchives/?search=Let\%27s+Talk+TV

Public Interest Advocacy Center/PIAC (2014, September 9). Let's Talk TV, Day 2, Retrieved from http://www.piac.ca/telecom/let_s_talk_tv_day_2/

Berkowitz, I. (2014, September 15). Canadians want good programs, not 300 channels, The Globe and Mail. Retrieved from http://www.theglobeandmail.com/globe-debate/canadians-want-good-programs-not300-channels/article20600050/

BNN-TV (2014, September 19). Fireworks at CRTC hearing: Netflix clashes on data delivery, Business AM with Frances Horodelski [video file]. Retrieved from http://www.bnn.ca/Video/player.aspx?vid=445243

CFRB Radio (2014, September 23). Netflix and the Let's Talk TV hearing. Interview with Rob Snow [audio file].

Berkowitz, I. (2014, October 3). Future Proofing Canada's Media System-From investment to return on investment. Retrieved from https://services.crtc.gc.ca/pub/ListeInterventionList/Documents.aspx?ID=218358\&Lang=e:

Abma, D. (2014, October 30), Canada on the verge of 'new era' of online TV. The Wire Report [phone interview]. Retrieved from http://www.thewirereport.ca/news/2014/10/30/canada-on-verge-of-new-eraof-online-tv/28919

Canadian Radio-television and Telecommunications Commission (2015, March 12). The Way Forward. CRTC Broadcast Regulatory Policy 2015-86. Retrieved from http://crtc.gc.ca/eng/archive/2015/201586.htm

55. Both Irene Berkowitz of Ryerson University and Entertainment One (eOne) discussed the importance of rebranding Canada as an exporter of global hits, to make Canada's brand known as a creative brand. In their view, Canada is currently known primarily as a country with strong production crews and good financial incentives, but with no track record of producing real global hits. At the hearing, eOne stated that it would welcome the opportunity to participate in a roundtable discussion to share its data and discuss case studies with interested industry stakeholders in order to further discussion. In her final submission, Ms. Berkowitz stated that she had spoken with eOne since the hearing and together they would support a working group to implement strategies to achieve the goal of global hits. 
108. Similarly, Ms. Berkowitz proposed bringing Canadians back from Hollywood and turning Canada's proximity to the U.S. into a competitive advantage rather than disadvantage by changing the points system so that Canadians do not have to be residing in Canada. "Canadian-created stories," in Berkowitz's view, would recapture the value of Canadian expatriates working in Hollywood and make the "brain drain" into a "brain chain." She proposed a new points system, which can be found in her written submission.

Zanette, C. (2015, March 13). New Poll Suggests streaming services are future of TV [phone interview]. Retrieved from http://j-press.fcad.ryerson.ca/carlozanette/2015/03/13/new-poll-suggests-streamingservices-are-future-of-tv/

Berkowitz, I. (2015, March 13). Time to make hits, not shows, The Globe and Mail. Retrieved from http://www.theglobeandmail.com/globe-debate/crtc-gets-it-time-to-make-hits-notshows/article23449134/.

Noakes, S. (2015, March 18). CRTC quest for quality set to shake up Canadian production [phone interview]. Retrieved from http://www.cbc.ca/news/business/crtc-quest-for-quality-set-to-shake-upcanadian-production-1.2998419

BNN-TV (2015, March 20). The future of Canadian TV: Will pick and pay matter by 2016? Business News AM with Frances Horodelski [video file] Retrieved from http://www.bnn.ca/Video/player.aspx?vid=574451.

CBC Radio (2015, April 7). Canadian content. Maritime Noon with Norma MacLeod [audio file] Retrieved from http://www.cbc.ca/maritimenoon/2015/04/07/duffy-trial-sick-days-canadian-content-peielection-rink-support-1/

Berkowitz, I (2015, June 10). In TV's new golden age, consumers are already online. Industry must follow. The Globe and Mail. Retrieved from http://theglobeandmail.com/report-on-business/robcommentary/in-tvs-new-golden-age-onsumers-have-the-gold-we-should-follow-their-lead/article 24879478

Berkowitz, I. (2015, July 6). Yanking the value chain: How to make global hits. Playback. Retrieved from http://playbackonline.ca/2015/07/06/yanking-the-value-chain-how-to-make-global-hits/ 


\section{References}

ABC nabs upcoming Canadian police series Copper. (2009, April 22). CBC News. Retrieved from http://www.cbc.ca/news/arts/abc-nabs-upcoming-canadian-police-series-copper-1.775680

Abernathy, W. J., \& Clark, K. B. (1985). Innovation: Mapping the winds of creative destruction. Research Policy, 14(1), 3-22.

Abma, D. (2014, October 30). Canada on the verge of "new era" of online TV. The Wire Report. Retrieved from http://www.thewirereport.ca/news/2014/10/30/canada-on-verge-of-new-era-ofonline-tv/28919

Acheson, K., \& Maule, C. J. (1994). Understanding Hollywood's organization and continuing success. Journal of Cultural Economics, 18(4), 271-300. doi:10.1007/BF01079760

Acheson, K. \& Maule, C. (1997). Canada's cultural policies - you can't have it both ways. Canadian Foreign Policy Journal. 4 (3), p. 65-81.

Adams, J. (2009, January 8). Mamma Mia! We love U.S. fare. The Globe and Mail. Retrieved from http://www.theglobeandmail.com/arts/mamma-mia-we-love-us-fare/article1145798/

Adams, J. (2014, August 17). “The Listener" cancelled: Series finale to air after 5 seasons. Huffington Post. Retrieved from http://www.huffingtonpost.ca/2014/08/17/the-listener-cancelled-seriesfinale_n_5685707.html

Adorno, T. (1991). The culture industry: selected essays on mass culture. London: Routledge.

The Affair, season one ratings. (2014, December 23). TV Series Finale. Retrieved from http://tvseriesfinale.com/tv-show/the-affair-season-one-ratings-34530/

All the right connections: a new world of opportunity for broadcasters with digital TV, connected screens and high-speed broadband (2014, April 3). Accenture. Retrieved from http://m.accenture.com/usen/Pages/insight-right-connections-new-world-opportunity-broadcasters-digital.aspx

Anderson, C. (2006). The long tail: Why the future of business is selling less of more. New York, NY: Hyperion.

Anderson, S. P., \& Gabszewicz, J. J. (2005). The media and advertising: A tale of two-sided markets (Discussion paper 5223). London, UK: Centre for Economic Policy Research.

Andreeva, N. (2015, May 14). The vertically integrated upfronts: Nets big push for program ownership on independent studios, viewers. Deadline Hollywood. Retrieved from http://deadline.com/2015/05/vertically-integrated-upfronts-network-program-ownership-impactstudios-viewers-1201425404/

Apple Inc. in talks to offer online TV service for iPhone, iPad and set-top box, report says. (2015, March 17). Financial Post. Retrieved from http://business.financialpost.com/2015/03/17/apple-inc-intalks-to-offer-online-tv-service-for-iphone-ipad-and-set-top-box-report-says/?__lsa=921e-2b7 
Ariens, C. (2015, June 15). "Catastrophe” makes its American debut on Facebook, not Amazon Prime. Adweek. Retrieved from http://www.adweek.com/news/television/uk-comedy-catastrophe-makesits-american-debut-facebook-not-amazon-prime-165354

Armstrong Consulting. (2014, June 25). The economic value of simultaneous signal substitution for English-language private television broadcasters (Appendix 5, Bell submission to Let's Talk TV by Bibic, Miko, Intervention 2641, Related Documents). Retrieved from https://services.crtc.gc.ca/pub/ListeInterventionList/Default-Defaut.aspx?en=2014$190 \& \mathrm{dt}=\mathrm{i} \&$ lang $=\mathrm{e} \& \mathrm{~S}=\mathrm{C} \& \mathrm{PA}=\mathrm{b} \& \mathrm{PT}=\mathrm{nc} \& \mathrm{PST}=\mathrm{a}$

Asheim, B., Cooke, P., \& Martin, R. (Eds.). (2006). Clusters and regional development: Critical reflections, regional development and public policy. New York, NY: Routledge.

Asia Pacific Foundation of Canada. (2011). Canadians abroad: Canada's global asset. Vancouver, BC: Author. Retrieved from http://www.asiapacific.ca/research-report/canadians-abroad-canadasglobal-asset-capstone-report

Auerswald, P. E., \& Branscomb, L. M. (2003). Valleys of death and Darwinian seas: Financing the invention to innovation transition in the United States. The Journal of Technology Transfer, 28(34), 227-239.

Ault, S. (2014, August 5). Survey: YouTube starts more popular than main stream celebs among U.S. teens. Variety. Retrieved from http://variety.com/2014/digital/news/survey-youtube-stars-morepopular-than-mainstream-celebs-among-u-s-teens-1201275245/

Austen, I. (2012, February 23). Pierre Juneau, champion of Canada's pop music industry, dies at 89. The New York Times. Retrieved from http://www.nytimes.com/2012/02/24/arts/music/pierre-juneauchampion-of-canadas-pop-music-industry-dies-at-89.html?emc=eta1

Babe, R. E. (2000). Canadian communication thought: Ten foundational writers. Toronto, ON: University of Toronto Press.

Barnett, M. N. (1996). Israel in comparative perspective (SUNY series in Israeli studies). Albany, NY: State University of New York.

Barraclough, L. (2013). Kevin Spacey's memo to TV execs: Trust the talent. Variety. Retrieved from http://variety.com/2013/tv/news/kevin-spacey-mactaggart-memorial-lecture-edinburgh$1200586355 /$

Bathelt, H., Malmberg, A., \& Maskell, P. (2004). Clusters and knowledge: Local buzz, global pipelines and the process of knowledge creation. Progress in Human Geography, 28(1), 31-56. doi:10.1191/0309132504ph469oa

Baxter, P. \& Jack, S. (2008). Qualitative case study methodology: Study, design and implementation for novice researchers. The Qualitative Report, vol. 13, no. 4, p. 544-559. 
Bellandi, M., \& Caloffi, A. (2010). Towards a framework for the evaluation of policies of cluster upgrading and innovation. Revue d'Économie Industrielle, 2010/1-2(129/130), 259-276.

Bennett, T. (2014). Showrunners: The art of running a TV show. London, UK: Titan.

Bergsten, F.C. \& Choi, I. (Eds.). (2003). Korean diaspora in the world economy. Washington, DC: Institute for International Economics.

Berkowitz, I. (2005a, December 14). Simultaneous substitution, “AmCon for CanCon”: Origin, impact, issues in Canadian broadcasting. Unpublished manuscript. Archived at https://drive.google.com/drive/folders/0B0MRD5ktRGemZURVUlVRbDZjbDQ

Berkowitz, I. (2005b, December 18). Let's dance. Canadian drama: Where we've been, where we are, what next? Unpublished manuscript. Archived at https://drive.google.com/drive/folders/0B0MRD5ktRGemZURVUlVRbDZjbDQ

Berkowitz, I. (2006a). Dance with the elephant (Ryerson graduate student research article competition). Retrieved from www.ryerson.ca/ORS

Berkowitz, I. (2006b, December 5). Dance with the elephant. Paper presented at the Institute for International Communications-Canada, Ottawa, ON. Retrieved from http://www.iiccanada.ca/userfiles/file/english/2006_Program_E.pdf

Berkowitz, I. (2006c April 5). Canada's television drama production firms: Market orientation parameters. Unpublished manuscript. Archived at https://drive.google.com/drive/folders/0B0MRD5ktRGemZURVUlVRbDZjbDQ

Berkowitz, I. (2006d, June 19). Canadian story-telling in the digital age: CanCon, AdHoc, or CanBrand-A discussion paper. Unpublished manuscript. Archived at https://drive.google.com/drive/folders/0B0MRD5ktRGemZURVUIVRbDZjbDQ

Berkowitz, I. (2006e, June 19). Canadian story-telling in the digital age, a policy framework. Unpublished manuscript. Archived at https://drive.google.com/drive/folders/0B0MRD5ktRGemZURVUlVRbDZjbDQ

Berkowitz, I. (2006f, November 14). Canadian story-telling in the digital age: New realities, new rules, new responses. Unpublished manuscript. Archived at https://drive.google.com/drive/folders/0B0MRD5ktRGemZURVUlVRbDZjbDQ

Berkowitz, I. (2009a). From hockeywood to Googlewood. Unpublished manuscript. Archived at https://drive.google.com/drive/folders/0B0MRD5ktRGemZURVUlVRbDZjbDQ

Berkowitz, I. (2009b). Good stories well told vs. good policies well implemented. Unpublished manuscript. Archived at https://drive.google.com/drive/folders/0B0MRD5ktRGemZURVUlVRbDZjbDQ 
Berkowitz, I. (2009c). Show vs. business. Unpublished manuscript. Archived at https://docs.google.com/document/d/1U9LE4oafUr002QGUYgFoBsBdR3jvkUz0N2DDx7HLv4/edit

Berkowitz, I. (2014a, June 27). Submission to Canada Radio-television and Telecommunications Commission: Comments regarding Let's Talk TV, CRTC notice of consultation, 2014-190 (and 190-2). Brain Drain to Brain Chain | Can Con to Can Brand-Reframing the Challenge of English Language Canadian TV Drama. Retrieved from https://services.crtc.gc.ca/pub/ListeInterventionList/Documents.aspx?ID=218358\&Lang=e:

Berkowitz, I. (2014b, July 7). Op/Ed: Is it time to re-brand Canadian TV? Playback. Retrieved from http://playbackonline.ca/2014/07/07/oped-is-it-time-to-re-brand-canadian-tv/\#ixzz36oOrqGOX

Berkowitz, I. (2014c, September 9). Can Con to Can Brand - Let's pivot our goal from domestic supply to global demand. (Written version of live presentation at CRTC hearing Let's talk TV). Retrieved from https://services.crtc.gc.ca/pub/ListeInterventionList/Documents.aspx?ID=218358\&Lang=e:

Berkowitz, I. (2014d, September 9). Can Con to Can Brand-Let's pivot our goal from domestic supply to global demand (Live presentation of full testimony at CRTC hearing, Let's Talk TV) [Video file]. Retrieved from http://www.cpac.ca/en/digital-archives/?search=Let\%27s+Talk+TV

Berkowitz, I. (2014e, September 15). Canadians want good programs, not 300 channels. The Globe and Mail. Retrieved from http://www.theglobeandmail.com/globe-debate/canadians-want-goodprograms-not-300-channels/article20600050/

Berkowitz, I. (2014f, September 19). Fireworks at CRTC hearing: Netflix clashes on data delivery [Video file]. Business News Network. Retrieved from http://www.bnn.ca/Video/player.aspx?vid=445243

Berkowitz, I. (2014g, October 3). Future proofing Canada's media system-From investment to return on investment-Global applause is not just good business: it's great culture. Final submission to Let's Talk TV. Retrieved from

https://services.crtc.gc.ca/pub/ListeInterventionList/Documents.aspx?ID=218358\&Lang=e:

Berkowitz, I. (2014h, September 9). @irenesberkowitz \#talktv @CRTCeng @WGCtweet JPB you asked story of CAN TV? How's this: PROTECT CORRECT (20th cent market) to SEND RECEIVE (21st cent world)?! [Twitter feed]. Retrieved from https://twitter.com/irenesberkowitz/status/510410104445743106

Berkowitz, I. (2015a, March 13). CRTC: Time to make hits, not shows. The Globe and Mail. Retrieved from http://www.theglobeandmail.com/globe-debate/crtc-gets-it-time-to-make-hits-notshows/article23449134/

Berkowitz, I. (2015b, March 20). The future of Canadian TV: Will pick and pay matter in 2016? [Video file]. Business News Network. Retrieved from http://www.bnn.ca/Video/player.aspx?vid=574451 
Berkowitz, I. (2015c, April 7). Canadian content after the decisions. CBC's Maritime Noon [Audio file]. Retrieved from http://www.cbc.ca/maritimenoon/2015/04/07/duffy-trial-sick-days-canadiancontent-pei-election-rink-support/

Berkowitz, I. (2015d, June 3). Where is Canada in the golden age of TV? Invited presenter, special CRTC panel at Canadian Communications Association Conference 2015. University of Ottawa. Unpublished manuscript and slide presentation. Archived at https://drive.google.com/drive/mydrive

Berkowitz, I. (2015e, June 10). In TV's new golden age, consumers are already online. Industry must follow. The Globe and Mail. Retrieved from http://www.theglobeandmail.com/report-onbusiness/rob-commentary/in-tvs-new-golden-age-consumers-have-the-gold-we-should-followtheir-lead/article24879478/

Berkowitz, I. (2015f, July 6). Yanking the value chain: how to make global hits. Playback. http://playbackonline.ca/2015/07/06/yanking-the-value-chain-how-to-make-global-hits/

Berkowitz, I., Davis, C.H., \& Florin, V. (2008). Business capabilities of small entrepreneurial firms: Independent production children's television in Canada. Journal of Media Business Studies, 5(1), 9-39.

Bielby, W. T., \& Bielby, D. D. (1992). Cumulative versus continuous disadvantage in an unstructured labor market: Gender differences in careers of television writers. Work and Occupations, 19(4), 366-386. doi:10.1177/0730888492019004003

Bielby, W. T., \& Bielby, D. D. (1994). “All hits are flukes”: Institutionalized decision making and the rhetoric of network prime-time program development. American Journal of Sociology, 99(5), 12871313. doi: $10.1086 / 230412$

Bielby, W. T., \& Bielby, D. D. (1999). Organizational mediation of project-based labor markets: Talent agencies and the careers of screenwriters. American Sociological Review, 64(1), 64-85.

Bielby, W. T., \& Bielby, D. D. (2002). Hollywood dreams, harsh realities: Writing for film and television. Contexts, 1(4), 21-27. doi:10.1525/ctx.2002.1.4.21

Birnbaum, D. (2014, June 4). Q \& A: "Shameless" and “Orphan Black” stars Emmy Rossum and Tatiana Maslany. Variety. Retrieved from variety.com/2014/tv/awards/qa-emmy-rossum-and-tatianamaslany-1201213370/

Bogenschneider, K.E. \& Corbet, T.J. (2010). Evidence-based policy making. New York, NY: Taylor \& Francis.

Bradshaw, J. (2014, October 6). Rogers Hockey Night in Canada will be a whole new game for viewers. The Globe and Mail. Retrieved from http://www.theglobeandmail.com/sports/hockey/canadiansprepare-for-more-game-coverage-storytelling-with-new-nhl-season/article20930976/?page=all 
Brennan, E. (2013, August 6). Albuquerque's role in "Breaking Bad." NY Times. Retrieved from http://www.nytimes.com/2013/08/11/travel/albuquerques-role-on-breaking-bad.html?_r=0

Breschi, S., \& Malerba, F. (2005). Clusters, networks and innovation. Oxford, UK: Oxford University Press.

British Academy of Film and Television (BAFTA-LA). (n.d.). Newcomers program. Retrieved from http://www.bafta.org/los-angeles/events-initiatives/supporting-talent/newcomers-program

Brookers. (n.d.), The YouTube Wiki. Retrieved from http://youtube.wikia.com/wiki/Brookers

Brown, D. (2015, June 30). Press release: A record 3.2 million viewers watch Canada's heartbreaking quarter-final loss on CTV and RDS. Retrieved from http://dexterbrown.ca/2015/06/30/press-releasea-record-3-2-million-viewers-watch-canadas-heartbreaking-quarter-final-loss-on-ctv-and-rds/

Brunet, J. (2004). The social production of creative products in the television and film industry. International Journal of Arts Management, 6(2), 4-10.

Cable Public Affairs Channel. (n.d.). Let's talk TV digital archive [Video file]. Retrieved from http://www.cpac.ca/en/digital-archives/?search=Let\%27s+Talk+TV

Canadian Association of Broadcasters (CAB) (2002, November 29). Simultaneous substitution and described video programming. Letter from CAB to CRTC. Originally retrieved from www.cabacr.ca; however this reference is no longer available online.

Canadian Country Music Association. (2015). Stan Klees. Retrieved from http://www.ccma.org/cgi/page.cgi/hall_of_fame_inductees.html?log=view\&log_id=49

Canadian Forex. (2015, June 29). Yearly average exchange rate for currencies. Retrieved from http://www.canadianforex.ca/forex-tools/historical-rate-tools/yearly-average-rates

Canadian Heritage. (2009, March 9). Canada Media Fund. Retrieved from http://www.pch.gc.ca/eng/1294329166335/1294329166338

Canadian Heritage. (2014, March 21). Canadian films share of box office revenues. Market share of Canadian films, 2001-2013. Retrieved from http://www.pch.gc.ca/eng/1358534428946

Canadian Media Fund. (n.d.a). CMF history. Retrieved from http://www.cmf-fmc.ca/aboutcmf/overview/cmf-history/

Canadian Media Fund. (n.d.b). Performance envelopes. Retrieved from http://www.cmf-fmc.ca/envelopeadministration/calculations/

Canada Media Fund. (2011). 2010-2011 annual report. Retrieved from http://ar-ra1011.cmf-fmc.ca/ Canada Media Fund. (2012a). 2011-2012 annual report. Retrieved from http://ar-ra11-12.cmf-fmc.ca/ Canadian Media Fund. (2012b). PE calculation process. Audience success and original first run performance (2011-2012). Retrieved from http://www.cmf-fmc.ca/documents/files/archives/envadmin/PE_Calc_Aud_Sccs_Orig_1st_Run.pdf 
Canada Media Fund. (2013a). 2012-2013 annual report. Retrieved from http://ar-ra12-13.cmf-fmc.ca/

Canada Media Fund. (2013b). CMF business policies, appendix B, 2013-2014. Retrieved from http://www.cmf-fmc.ca/documents/files/programs/2013-14/guidelines/appendix_b_2013_2014.pdf

Canada Media Fund. (2014a). 2014-2015 program budget. Retrieved from http://www.cmffmc.ca/documents/files/programs/2014-15/guidelines/2014-15-cmf-program-budget.pdf

Canada Media Fund. (2014b March 26). Digital Media Performance Measurement Advisory Committee. Retrieved from http://www.cmf-fmc.ca/documents/files/about/ind-outreach/2013-14/digital-mediaperformance-measurement-ac.pdf

Canada Media Fund. (2014c). 2013-2014 annual report. Retrieved from http://ar-ra13-14.cmf-fmc.ca/

Canadian Media Fund. (2014d April). CMF/FMC development envelope manual. Retrieved from http://www.cmf-fmc.ca/documents/files/env-admin/manuals/dev_env_manual_2014-15.pdf

Canadian Media Fund. (2015a). Funding streams. Retrieved from http://www.cmf-fmc.ca/fundingprograms/overview/

Canadian Media Fund. (2015b). Keytrends report 2015: The big blur challenge. Retrieved from http://trends.cmf-fmc.ca/research-reports/keytrends-report-2015-the-big-blur-challenge

Canadian Media Fund. (2015c). Appendix A, 2015-2016-Definitions and essential requirements. Retrieved from http://www.cmf-fmc.ca/documents/files/programs/201516/guidelines/appendix_a_2015_2016.pdf

Canadian Media Fund. (2015d). Performance envelope program guidelines 2015-2016. Retrieved from http://www.cmf-fmc.ca/documents/files/programs/2015-16/guidelines/201516_perf_env_guidelines.pdf

Canadian Media Fund. (2015e, April 15). 2015-2016 performance envelope allocations. Retrieved from http://www.cmf-fmc.ca/documents/files/env-admin/allocations/2015-16-pep-allocations.pdf

Canada Media Fund. (2015f, April 15). 2015-2016 CMF broadcast ownership groups with envelopes. Retrieved from http://www.cmf-fmc.ca/documents/files/env-admin/allocations/2015-16_corpgrps.pdf

Canada Media Fund. (2015g). Canada Media Fund annual report, 2013-2014. Retrieved from http://arra13-14.cmf-fmc.ca/

Canadian Media Fund. (2015h, April 24). 2015-2016 development envelope allocations. Retrieved from http://www.cmf-fmc.ca/documents/files/env-admin/allocations/2015-16-dev-allocations.pdf

Canada Media Fund. (2015i). 2015-2016 program commitment allocation. Retrieved from http://www.cmf-fmc.ca/documents/files/programs/2015-16/guidelines/2015-16-cmf-programbudget.pdf 
Canadian Media Fund. (2015j, April 29). Percentage of funds spent on English-language dramas and list of English-language TV dramas, 2005-2006 to 2014-2015 [Provided to me for this research, as a courtesy of CMF].

Canadian Media Fund. (2015k). Summary of changes, 2015-2016. Retrieved from http://www.cmffmc.ca/documents/files/programs/2015-16/guidelines/2015-

16_summary_technical_changes_guidelines.pdf

Canadian Media Production Association. (2011a). Profile 2011: An economic report on the screen-based production industry in Canada. Ottawa, ON: Author.

Canadian Media Production Association. (2011b, April 26). Terms of trade. Retrieved from http://www.cmpa.ca/business-affairs-production-tools/terms-trade

Canadian Media Production Association. (2014, November). CMPA terms of trade handbook (3rd ed.). Retrieved from http://www.cmpa.ca/sites/default/files/documents/terms-oftrade/CMPA\%20Terms\%20of\%20Trade\%20Handbook\%20-\%20Third\%20edition\%20$\% 20$ Nov\%202014.pdf

Canadian Media Production Association. (2015). Profile 2014: Economic report on the screen-based media production industry in Canada. Retrieved from http://cmpa.ca/sites/default/files/documents/industry-information/profile/CMPA_2014_eng.pdf Canadian Radio-Television Commission. (1970, April 10). Simultaneous Program Substitution. Decision 70-93. Archived papers, courtesy of Margaret Kennedy, CRTC employee, December 2005.

Canadian Radio-Television Commission. (1971, February 26). Public Announcement, Part II, p. 17. Archived papers, courtesy of Margaret Kennedy, CRTC employee, December 2005.

Canadian Radio-television and Telecommunications Commission. (1999a). Building on success-A policy framework for Canadian television (Public Notice CRTC 1999-97). Retrieved from http://www.crtc.gc.ca/eng/archive/1999/pb99-97.htm

Canadian Radio-television and Telecommunications Commission. (1999b). Exemption order for new media broadcasting undertakings (Public Notice CRTC 1999-197). Retrieved from http://www.crtc.gc.ca/eng/archive/1999/PB99-197.htm

Canadian Radio-television and Telecommunications Commission. (1999c). New media (Public Notice CRTC Broadcasting PN 1999-84, Telecom PN 99-14). Retrieved from http://www.crtc.gc.ca/eng/archive/1999/pb99-84.htm

Canadian Radio-television and Telecommunications Commission. (2000, March 17). Certification for Canadian Programs - A revised approach (Archived Public Notice CRTC 2000-42). Retrieved from http://www.crtc.gc.ca/eng/archive/2000/pb2000-42.htm 
Canadian Radio-television and Telecommunications Commission. (2004). Incentives for Englishlanguage Canadian television drama (Broadcasting Public Notice CRTC 2004-93). Retrieved from http://www.crtc.gc.ca/eng/archive/2004/pb2004-93.htm

Canadian Radio-television and Telecommunications Commission. (2006, December 15). Commercial Radio Policy 2006 (Broadcast Public Notice CRTC 2006-158.) Retrieved from http://www.crtc.gc.ca/eng/archive/2006/pb2006-158.htm

Canadian Radio-television and Telecommunications Commission. (2009). The MAPL system: Defining a Canadian song. Retrieved from http://www.crtc.gc.ca/eng/info_sht/r1.htm

Canadian Radio-television and Telecommunications Commission (2010a, March 22). A group-based approach to the licensing of private television services (Broadcast Regulatory Policy 2010-167). Retrieved from http://www.crtc.gc.ca/eng/archive/2010/2010-167.htm

Canadian Radio-television and Telecommunications Commission (2010b, November 1). Definitions for television program categories (Broadcasting Regulatory Policy CRTC 2010-808). Retrieved from http://www.crtc.gc.ca/eng/archive/2010/2010-808.htm

Canadian Radio-television and Telecommunications Commission (2010c, December 3). Revision of the definition of a Canadian program to include Canadian programs that have been dubbed in Canada and outside Canada (Broadcasting Regulatory Policy CRTC 2010-905). Retrieved from http://www.crtc.gc.ca/eng/archive/2010/2010-905.htm

Canadian Radio-television and Telecommunications Commission. (2010d). Communications monitoring report (GC catalogue no. BC9-9/2010E-PDF). Retrieved from http://www.crtc.gc.ca/eng/publications/reports/PolicyMonitoring/2010/cmr41.htm\#n24

Canadian Radio-television and Telecommunications Commission. (2011a). Conventional television, statistical and financial summaries, 2006-2010 (GC catalogue no. BC9-18E-PDF). Retrieved from http://publications.gc.ca/site/eng/475024/publication.html

Canadian Radio-television and Telecommunications Commission. (2011b). Group-based licence renewals for English-language television groups-Introductory decision (Broadcasting Decision CRTC 2011-441). Retrieved from http://www.crtc.gc.ca/eng/archive/2011/2011-441.htm Canadian Radio-television and Telecommunications Commission (2011c, December 11). Complaint by Telus Communications against BCE Inc., Bell Canada and Bell Mobility, alleging undue preference and disadvantage, contrary to the provisions of the New Media Exemption Order (Broadcasting Decision CRTC 2011-765). Retrieved from http://www.crtc.gc.ca/eng/archive/2011/2011-765.htm 
Canadian Radio-television and Telecommunications Commission. (2013, October 24). Speech by JeanPierre Blais, Chairman and CEO, to launch Let's Talk TV: A conversation with Canadians at Université Laval. Retrieved from http://www.crtc.gc.ca/eng/com200/2013/s131024.htm

Canadian Radio-television and Telecommunications Commission. (2014a). Broadcasting Notice of Consultation 2014-190 (Notice of Hearing, Let's Talk TV). Retrieved from http://crtc.gc.ca/eng/archive/2014/2014-190.htm

Canadian Radio-television and Telecommunications Commission. (2014b). Communications monitoring report (GC catalogue no. BC9-9/2014E-PDF). Retrieved from http://www.crtc.gc.ca/eng/publications/reports/PolicyMonitoring/2014/cmr.htm

Canadian Radio-television and Telecommunications Commission. (2014c). Financial summaries—Private broadcasting. Retrieved from http://www.crtc.gc.ca/eng/publications/reports/BrAnalysis/tv2013/1.htm

Canadian Radio-television and Telecommunications Commission. (2014d). Financial summaries-Cable. Retrieved from http://www.crtc.gc.ca/eng/publications/reports/BrAnalysis/dist2013/bdu1.htm Canadian Radio-television and Telecommunications Commission. (2014e). Broadcasting Notice of Consultation 2014-190-3 (Working document for discussion, Let's Talk TV). Retrieved from http://www.crtc.gc.ca/eng/archive/2014/2014-190-3.htm

Canadian Radio-television and Telecommunications Commission. (2014f). Interventions (Public process no. 2014-190). Retrieved from https://services.crtc.gc.ca/pub/ListeInterventionList/DefaultDefaut.aspx?en=2014-190\&dt=i\&lang=e

Canadian Radio-television and Telecommunications Commission. (2014g, March 18). List of CRTC Canadian program recognition numbers. Retrieved from https://services.crtc.gc.ca/pub/CanrecList/Report04Rapport04.aspx?_ga=1.266658694.944346413.1422544645

Canadian Radio-television and Telecommunications Commission. (2015, January 19). Guide to the CRTC Canadian program certification application process. Retrieved from http://www.crtc.gc.ca/canrec/eng/guide1.htm\#s9k

Canadian Radio-television and Telecommunications Commission. (2015a, January 29). CRTC continues to set the course for the future of television with Let's Talk TV decisions (Press release). Retrieved from http://news.gc.ca/web/article-en.do?nid=926529

Canadian Radio-television and Telecommunications Commission. (2015b, January 29). Broadcasting and Telecom Decision 2015-26: Complaint against Bell Mobility Inc. and Quebecor Media Inc., Videotron Ltd. and Videotron G.P. alleging undue and unreasonable preference and disadvantage in regard to the billing practices for their mobile TV services Bell Mobile TV and illico.tv.

Retrieved from http://www.crtc.gc.ca/eng/archive/2015/2015-26.htm 
Canadian Radio-television and Telecommunications Commission. (2015c, January 29). Broadcasting Regulatory Policy 2015-24: Over-the-air transmission of television signals and local programming. Retrieved from http://www.crtc.gc.ca/eng/archive/2015/2015-24.htm

Canadian Radio-television and Telecommunications Commission. (2015d, January 29). Broadcasting Regulatory Policy 2015-25: Measures to address issues related to simultaneous substitution. Retrieved from http://www.crtc.gc.ca/eng/archive/2015/2015-24.htm

Canadian Radio-television and Telecommunications Commission. (2015e, March 12). Jean-Pierre Blais to the Canadian Club of Ottawa on Let's Talk TV and the future of content made by Canadians (Press release). Retrieved from http://news.gc.ca/web/article-en.do?nid=947239

Canadian Radio-television and Telecommunications Commission. (2015f, March 12). Broadcasting Regulatory Policy 2015-86: The way forward-Creating compelling and diverse Canadian programming. Retrieved from http://crtc.gc.ca/eng/archive2015/2015-86.htm

Canadian Radio-television and Telecommunications Commission. (2015g, March 19). Statement from Jean-Pierre Blais, Chairman and CEO of the CRTC, on maximizing choice and affordability for Canadians (Press release). Retrieved from http://news.gc.ca/web/article-en.do?nid=953129

Canadian Radio-television and Telecommunications Commission. (2015h, March 19). Broadcasting Regulatory Policy 2015-96: Let's Talk TV, a world of choice-A roadmap to maximizing choice for $T V$ viewers and to foster a healthy, dynamic market. Retrieved from http://www.crtc.gc.ca/eng/archive/2015/2015-96.htm

Canadian Radio-television and Telecommunications Commission. (2015i, March 26). CRTC proposes measures to empower Canadian TV viewers (Press release). Retrieved from http://news.gc.ca/web/article-en.do?nid=955539

Canadian Radio-television and Telecommunications Commission. (2015j, March 26). Broadcasting Regulatory Policy 2015-104: Let's Talk TV, navigating the road ahead-Making informed choices about television providers and improving accessibility to television programming. Retrieved from http://www.crtc.gc.ca/eng/archive/2015/2015-104.htm

Canadian Radio-television and Telecommunications Commission. (2015k, March 26). Let's Talk TV decisions at a glance. Retrieved from http://www.crtc.gc.ca/eng/com300/infograph1.htm

Canadian Radio-television and Telecommunications Commission. (20151, May 4). Programming and production expenses (private television) - Canada. Retrieved from http://www.crtc.gc.ca/eng/publications/reports/branalysis/tv2014/7.htm

The Canadian Trade Commissioner Service. (2015, March 13). Podcast transcript-California: A golden state of opportunity. Retrieved from http://www.tradecommissioner.gc.ca/eng/canadexport/document.jsp?did=139716 
Caplan, G. L., \& Sauvageau, F. (1986). Report of the Task Force on Broadcasting Policy. Ottawa, ON: Minister of Supply and Services Canada.

Carr, D. (2013, February 24). Giving viewers what they want. The New York Times. Retrieved from http://www.nytimes.com/2013/02/25/business/media/for-house-of-cards-using-big-data-toguarantee-its-popularity.html?_r=0

Carr, N. (2010). The shallows: What the Internet is doing to our brains. New York, NY: Norton.

Caves, R. E. (2000). Creative industries: Contracts between art and commerce. Cambridge, MA: Harvard University Press.

Cervantes, M., \& Guellac, D. (2002). The "brain drain": Old myths, new realities. OECD Observer. Retrieved from http://www.oecdobserver.org/news/archivestory.php/aid/673/The_brain_drain:_Old_myths,_new_r ealities.html

Charlton, J. (2015, June 25). Huffington Post to launch 24-hour online video network TV and movie divisions. The Wrap-Covering Hollywood. Retrieved from http://www.thewrap.com/huffingtonpost-to-launch-24-hour-online-video-network/

Chou, T. L., Ching, C-H., Fan, S-M., \& Chang, J-Y. (2011). Global linkages, the Chinese high-tech community and industrial cluster development: The semiconductor industry in Wuxi, Jingsu. Urban Studies, 48(14), 3019-3042. doi:10.1177/0042098010396237

Chrisafis, A. (2005, June 18). Ireland may abandon tax exemption scheme for creative writers. The Guardian. Retrieved from http://www.theguardian.com/uk/2005/jun/18/booksnews.artsnews Christensen, C. (2000). The Innovator's Dilemma. Boston, MA: Harvard Business School Publishing.

Christensen, C., Anthony, S., \& Roth, E. A. (2013). Seeing what's next: Using the theories of innovation to predict industry change. Boston, MA: Harvard Business School Publishing.

Christensen, C. M., Cook, S., \& Hall, T. (2005). Marketing malpractice: The cause and the cure. Harvard Business Review, 83(12), 74-83.

Christensen, C. M., \& Raynor, M. E. (2003). The innovator's solution: Creating and sustaining successful growth. Boston, MA: Harvard Business School Publishing.

Christensen, C. M., Raynor, M., \& Verlinden, M. (2001). Skate to where the money will be. Harvard Business Review, 79(10), 72-83.

Christopherson, S. (2009). Beyond the self-expressive creative worker: An industry perspective on entertainment media. Theory, Culture \& Society, 25(7-8), 73-95. doi:10.1177/0263276408097797

Citizens Information. (2015, March 26). Artist's exemption from income tax. Retrieved from http://www.citizensinformation.ie/en/money_and_tax/tax/income_tax/artists_exemption_from_inco me_tax.html 
Classictvhits.com. (n.d.). TV ratings: Top 30 shows for each year, from 1950 to 2000. Retrieved from http://www.classictvhits.com/tvratings/

Coalition of Canadian Audio-Visual Unions. (2003, November 28). Addressing the crisis in Canadian English-language drama: A submission to the CRTC from the Coalition of Canadian audio-visual unions (CCAU). Retrieved from http://www.writersguildofcanada.com/files/ccau-dramabrief.pdf

Combat Hospital: ABC-TV series cancelled. No season two. (2012, February 1). TV Series Finale. Retrieved from http://tvseriesfinale.com/tv-show/combat-hospital-canceled-season-two-21154/

Conference Board of Canada. (2015a). How Canada performs: Connectivity. Retrieved from http://www.conferenceboard.ca/hcp/details/innovation/connectivity.aspx

Conference Board of Canada. (2015b). Labour productivity growth. Retrieved from http://www.conferenceboard.ca/hcp/details/economy/measuring-productivity-canada.aspx

Cunningham, S., \& Silver, J. (2013). Screen distribution and the new King Kongs of the online world. London, UK: Palgrave Macmillan.

Davis, C. H. (2010). New firms in the screen-based media industry: Startups, self-employment, and standing reserve. In M. Deuze (Ed.), Managing media work (pp. 165-178). Thousand Oaks, CA: Sage.

Davis, C. H. (2011a). Media industry clusters and public policy. In C. Karlsson \& R. Picard (Eds.), Media clusters across the globe: Developing, expanding, and reinvigorating content capabilities (pp. 7298). Cheltenham, UK: Edward Elgar.

Davis, C. H. (2011b). The Toronto media cluster: Between culture and commerce. In C. Karlsson \& R. Picard (Eds.), Media clusters across the globe: Developing, expanding, and reinvigorating content capabilities (pp. 223-250). Cheltenham, UK: Edward Elgar.

Davis, C. H., Berkowitz, I., \& Mills, N. (2012). Getting on the global playlist: The innovation scorecard for new product development in screen media. Toronto, ON: RTA Transmedia Centre.

Davis, C. H., Creutzberg, T., \& Arthurs, D. (2009). Applying an innovation cluster framework to a creative industry: The case of screen-based media in Ontario. Innovation: Management, Policy \& Practice, 11(2), 201-214.

Davis, C. H., \& Kaye, J. (2010a). "If it ain't on the page, it ain't on the stage": Screenwriting, national specificity and the English-Canadian feature film. Journal of Screenwriting, 2(1), 61-83. doi:10.1386/josc.2.1.61_1

Davis, C. H., \& Kaye, J. (2010b). International production outsourcing and the development of indigenous film and television capabilities: The case of Canada. In G. Elmer, C. Davis, J. McCullough, \& J. Marchessault (Eds.), Locating migrating media (pp. 57-78). Lanham, MD: Lexington Books. 
Davis, C. H., \& Nadler, J. (2009). International television co-productions and the cultural discount: The case of Family Biz, a comedy. In I. Bernhard (Ed.), Uddevalla symposium: The geography of innovation and entrepreneurship (pp. 359-378). Trollhattan, Sweden: University West.

Davis, C. H., Shtern, J., Coutanche, M., \& Godo, E. (2014). Screenwriters in Toronto: Centre, periphery, and exclusionary networks in Canadian screen storytelling. In J. Grant (Ed.), Seeking talent for creative cities: The social dynamics of innovation (pp. 77-98). Toronto, ON: University of Toronto Press.

Davis, C. H., Vladica, F., \& Berkowitz, I. (2008). Business capabilities of small entrepreneurial media firms: Independent production of children's television in Canada. Journal of Media Business Studies, 5(1), 9-39.

Davis, C. H., Wolfe, D., \& Cassidy, E. (2009). Indicators to support innovation cluster policy. International Journal of Technology Management, 46(3/4), 263-279.

Debnath, N. (2015, June 13). Downton Abbey to be given special BAFTA award for flying the flag for British drama. Express. Retrieved from http://www.express.co.uk/entertainment/tvradio/584231/Downton-Abbey-Bafta-award-Hugh-Bonneville-Julian-Fellowes

Deighton, J., \& Kornfield, L. (2013). Amazon, Apple, Facebook, and Google. Case \#9-513-060. Boston, MA: Harvard Business School Publishing.

Delgado, M., Porter, M. E., \& Stern, S. (2014). Clusters, convergence, and economic performance. Research Policy, 43(10), 1785-1799. Retrieved from http://papers.ssrn.com/sol3/papers.cfm?abstract_id=1695011

Department of Foreign Affairs and International Trade. (1998). Multi-lateral agreement on investment (MAI). Ottawa, ON: Author. Retrieved from www.dfait-maeci.gc.ca/english/trade/backgr-e.htm

DeVany, A. (2004). Hollywood economics: How extreme uncertainty shapes the film industry. New York, NY: Routledge.

Dingham, S., \& Gray, J. (2015, January 8). What's a VPN, are they legal, and does Netflix care Canadians use them? The Globe and Mail. Retrieved from http://www.theglobeandmail.com/technology/what-is-a-vpn-are-they-legal-and-whos-not-happycanadians-are-using-them/article22363040/

Doyle, J. (2009, October 7). Canadians like their Dr. House. Pastor Mansbridge, not so much. The Globe and Mail. Retrieved from http://www.theglobeandmail.com/arts/canadians-like-their-dr-housepastor-mansbridge-not-so-much/article791100/

Doyle, J. (2013, October 10). Where is Canada in the golden age of TV? The Globe and Mail. Retrieved from http://www.theglobeandmail.com/arts/television/where-is-canada-in-the-golden-age-oftv/article14753279/ 
Doyle, J. (2015, March 3). CBC needs to make room for original, ambitious TV dramas. The Globe and Mail. Retrieved from http://www.theglobeandmail.com/arts/television/john-doyle-cbc-needs-tomake-room-for-orginal-ambitious-tv-dramas/article23267901/

Eastman, S. T., \& Ferguson, D. A. (2013). Media programming: Strategies and practices. Boston, MA: Wadsworth.

Edwardson, R. (2008). Canadian content, culture and the quest for nationhood. Toronto, ON: University of Toronto Press.

Efron, L. (2015, October 28). Technology may take your job, but you'll still be able to protect your income. Forbes. Retrieved from http://www.forbes.com/sites/louisefron/2015/10/28/technologymay-take-your-job-but-youll-still-be-able-to-protect-your-income/

Eisenhardt, K.M. (1989). Building theories from case study research. Academy of management review, 14(4), 532-550.

Eisenhardt, K.M. \& Graebner, M.E. (2007). Theory building from cases: opportunities and challenges. Academy of management journal, 50(1), 25-32.

Elberse, A. (2013). Blockbusters: Hit-making, risk-taking, and the big business of entertainment. New York, NY: Henry Holt and Company.

Elmer, G., Davis C. H., Marchessault, J., \& McCullough, J. (Eds.). (2010). Locating migrating media. Lanham, MD: Lexington Books.

Elmer, G., \& Gasher, M. (Eds). (2005). Contracting out Hollywood: Runaway productions and foreign location shooting. Lanham, MD: Rowman \& Littlefield.

Elo, S., \& Kyngäs, H. (2008). The qualitative content analysis process. Journal of Advanced Nursing, 62(1), 107-115. doi:10.1111/j.1365-2648.2007.04569.x

Entertainment Software Association of Canada. (2013). Essential facts about the Canadian video game industry. Retrieved from http://theesa.ca/wp-content/uploads/2013/10/Essential-Facts-English.pdf

Epstein, E. J. (2005). The big picture: The new logic of money and power in Hollywood. New York, NY: Random House.

Evans, P. (2015, February 4). Nielsen ratings data shows big TV decline due to streaming video. $C B C$ News. Retrieved from http://www.cbc.ca/news/business/nielsen-ratings-data-shows-big-tv-declinedue-to-streaming-video-1.2944432

Fang, C., \& Bei, H. (2010). Research on incubation mechanism of entrepreneurs in the industrial cluster. Proceedings of the Computer Sciences and Convergence Information Technology international conference, 302-307. doi:10.1109/ICCIT.2010.5711075 
Federal Policy Review Committee. (1982). Report of the Federal Cultural Policy Review Committee. Ottawa, ON: Minister of Supply and Services Canada. Retrieved from http://archivists.ca/content/key-reports-and-publications-canadian-archival-history

Fédération Internationale des Coalitions Pour la Diversité Culturelle. (n.d.). The "trade and culture" issue, at the origin of the Convention on the Protection and Promotion of the Diversity of Cultural Expressions. Retrieved from http://www.cdc-ccd.org/IMG/pdf/Culture-trade_history_Eng.pdf

Feinberg, S. E., \& Gupta, A. K. (2004). Knowledge spillovers and the assignment of R\&D responsibilities to foreign subsidiaries. Strategic Management Journal, 25(8-9), 823-845.

Feir, J. (2008). The U.S.: The number one bet for innovative Canadians. Retrieved from http:/www.dfaitmaeci.gc.ca/canadaexport/articles

Ferrall, V. E. (1989). The impact of television deregulation on private and public interests. Journal of Communication, 39(1), 8-38.

Flew, T. (2011, June). Culture and creative industries in Australia. Paper presented at the 3rd China Trade in Services congress, Beijing, China. Retrieved from http://eprints.qut.edu.au/41835/

Florida, R. (2002). The rise of the creative class: and how it is transforming work, leisure, community and everyday life. New York: Basic Books.

Florida, R. (2007). The flight of the creative class: The new global competition for talent. New York, NY: Hyperion.

Florida, R. (2008). Who's your city? How the creative economy is making where to live the most important decision of your life. Toronto, ON: Random House.

Florida, R., Mellander, C., \& Stolarick, K. (2009). That's entertainment: Scale and scope economies in the location and clustering of the entertainment economy (MPI Working Paper Series: Music \& the Entertainment Economy). Retrieved from http://martinprosperity.org/2009/04/23/thatsentertainment-scale-and-scope-economies-in-the-location-and-clustering-of-the-entertainmenteconomy/

Floyd, T. (2011, September 7). Does "Little Mosque on the Prairie" have a future in the U.S. to ease fears? Retrieved from https://ca.news.yahoo.com/blogs/dailybrew/does-little-mosque-prairiefuture-u-ease-fears-192414048.html

Foreign Affairs, Trade, and Development Canada. (1988). Canada-United States Free Trade Agreement. Retrieved from http://www.international.gc.ca/trade-agreements-accordscommerciaux/agr-acc/us-eu.aspx?lang=eng

Fransko, P. (2014, August 27). Upside down thinking. Window Film Mag. Retrieved from http://www.windowfilmmag.com/2014/08/that-company-is- 
Fraser Institute. (1998). Appendix A: Highlights in the evolution of Canadian content regulations. Retrieved from http://oldfraser.lexi.net/publications/forum/1998/august/appendix1.html

Freeman, S. (2013). CanCon in the Netflix age: Just don’t mention it's Canadian. Huffington Post. Retrieved from http://www.huffingtonpost.ca/2013/11/29/canadian-contentnetflix_n_4358272.html

Freeman, S. (2014, September 8). Ontario to CRTC: Regulate Netflix like it's a TV channel. Huffington Post. Retrieved from http://www.huffingtonpost.ca/2014/09/08/ontario-crtc-netflix-regulationcancon_n_5786334.html

Friend, D. (2007, January 10). CanWest buys Alliance Atlantis. Toronto Star. Retreived from http://www.thestar.com/business/2007/01/10/canwest_buys_alliance_atlantis.html

Friesen, J. (2011, June 27). As nation of immigrants, Canada must now confront its emigrants. The Globe and Mail, Retrieved from http://www.theglobeandmail.com/news/national/time-to-lead/as-nationof-immigrants-canada-must-now-confront-its-emigrants/article588140/

Frye, N. (1971). The bush garden: Essays on the Canadian imagination. Toronto, ON: House of Anansi. Fulford, R. (1986, March). Blaming the Yanks. Saturday Night, pp. 7-9.

Fulford, R. (2001, December 22). The Massey Report: Did it send us the wrong way? The National Post. Retrieved from www.robertfulford.com/MasseyReport.html

Garnham, N. (2005). From cultural to creative industries: An analysis of the implications of the "creative industries" approach to arts and media policy making in the United Kingdom. International journal of cultural policy, 11(1), 15-29.

Geist, M. (2015a, January 5). New Year offers chance to hit reset button on digital policies. Michael Geist. Retrieved from http://www.michaelgeist.ca/2015/01/new-year-offers-chance-hit-resetbutton-digital-policies-2/

Geist, M. (2015b, June 8). Sorry Bell, accessing U.S. Netflix is not theft. Michael Geist. Retrieved from http://www.michaelgeist.ca/2015/06/sorry-bell-accessing-u-s-netflix-is-not-theft/

Gelman, V. (2014, August 20). NBC cancels "Working the Engels." TV Line. Retrieved from http://tvline.com/2014/08/20/working-the-engels-cancelled-nbc/

Gereffi, G. (2011). Global value chains and international competition. Antitrust Bulletin, 56(1), 37-56.

Gereffi, G., Humphrey, J., \& Sturgeon, T. (2005). The governance of global value chains. Review of International Political Economy, 12(1), 78-104. doi:10.1080/09692290500049805

Gerring, J. (2007). Case study research: principles and practices. New York, NY: Cambridge University Press.

Gertler, M. S. (2003). Tacit knowledge and the economic geography of context, or the undefinable tacitness of being (there). Journal of Economic Geography, 3(1), 75-99. 
Gibson, C., \& Kong, L. (2005). Cultural economy: A critical review. Progress in Human Geography, 29(5), 541-561. doi:10.1191/0309132505ph567oa

Gilbert, J. (2011, October 10). Quixter goes quickly: A look back at a Netflix mistake. Huffington Post. http://www.huffingtonpost.com/2011/10/10/qwikster-netflix-mistake_n_1003367.html

Gitlin, T. (2000). Inside prime time. Berkeley, CA: University of California Press.

Giuliani, E., Pietrobelli, C., \& Rabellotti, R. (2005). Upgrading in global value chains: Lessons from Latin American clusters. World Development, 33(4), 549-573. doi:10.1016/j.worlddev.2005.01.002

Godfrey, S., \& Unger, F. (2004). The shifting foundations of modern nation-states: Realignments of belonging. Toronto, ON: University of Toronto Press.

Goldberg, L., \& Vlessing, E. (2014, August 20). NBC's "Working the Engels" canceled. Hollywood Reporter. Retrieved from http://www.hollywoodreporter.com/live-feed/nbcs-working-engelscanceled-726553

Goldcorp. (2001, March 12). US\$575,000 Goldcorp Challenge awards world's first 6 million ounce internet gold rush yields high grade results! (Press release). Retrieved from http://www.infomine.com/index/pr/Pa065434.PDF

Goldhammer, J. (2014). New insights into the craft of incentive prize design. Retrieved from http://monitorinstitute.com/blog/2014/06/24/new-insights-into-the-craft-of-incentive-prize-design/

Goldhammer, J., Mitchell, K., Parker, A., Anderson, B., \& Joshi, S. (2014, June 18). The craft of incentive prize design: Lessons from the public sector. Retrieved from http://dupress.com/articles/the-craft-of-incentive-prizedesign/?id=us:2el:3dp:dup819:eng:fed:mmddyy:prize

Gornostaeva, G., \& Brunet, J. (2009). Internationalization of the production process in the US film industry: The case of the United Kingdom. International Journal of Arts Management, 12(1), 21-30.

Government of Canada. (1991). Broadcasting Act. Retrieved from http://lawslois.justice.gc.ca/eng/acts/B-9.01/

Government of Canada. (1993). Telecommunications Act. Retrieved from http://lawslois.justice.gc.ca/eng/acts/t-3.4/

Government of Canada. (2013, September 9). International trade agreements: A summary guide for Canadian municipalities. Retrieved from http://www.parl.gc.ca/Content/LOP/ResearchPublications/prb9925-e.htm

Government of Canada. (2015, May 12). North American Free Trade Agreement (NAFTA). Retrieved from http://www.international.gc.ca/trade-agreements-accords-commerciaux/agr-acc/naftaalena/index.aspx ?lang=eng 
Government of Canada, Department of Canadian Heritage. (2003). Canadian content in the 21st century in film and television productions: A matter of cultural identity (Catalogue no. CH44-29/2003). Retrieved from publications.gc.ca/collections/Collection/CH44-29-2003E.pdf

Government of Canada, Department of Canadian Heritage. (2009). Canada Media Fund. Retrieved from http://www.pch.gc.ca/eng/1294329166335/1294330109930

Government of Canada, Federal Cultural Review Committee. (1982). Report of the Federal Cultural Review Committee. Ottawa, ON: Author.

Government of Canada, Foreign Affairs, Trade and Development Canada (2013, September 13). Canadian culture in a global world. Retrieved from http://www.international.gc.ca/tradeagreements-accords-commerciaux/topics-domaines/ip-pi/canculture.aspx ?lang=en

Granovetter, M. (1973). Strength of weak ties. American Journal of Sociology, 78(6), 1360-1380.

Grant, P. S. (2008). Stories under stress: The challenge of indigenous television drama in English language broadcast markets. Retrieved from http://www.mccarthy.ca/pubs/IAWG_DRAMA_REPORT_FINAL.pdf

Grant, P. S. (2012, January). Have we reached a flashpoint? New developments affecting independent TV production in Canada. Paper presented at the Policy Leaders Seminar, York University, Toronto, ON.

Grant, P. S., \& Buchanan, G. (Eds.). (2010a). Canadian broadcasting regulatory handbook (10th ed.). Toronto, ON: McCarthy Tétrault.

Grant, P. S., \& Buchanan, G. (Eds.). (2010b). Regulatory guide to Canadian television. Toronto, ON: McCarthy Tetrault.

Grant, P. S., \& Wood, C. (2004). Blockbusters and trade wars: Popular culture in a globalized world. Vancouver, BC: Douglas \& McIntyre.

Greenfield, R. (2013, February1). The economics of Netflix \$100 million new show. The Wire. Retrieved from http://www.thewire.com/technology/2013/02/economics-netflixs-100-million-newshow/61692/

Grieve, Horner and Associates Inc. (1983). A study of the U.S. market for television programs. Study prepared for the Department of Communications, Government of Canada. Toronto, ON: Author.

Guarino, F. (2015, September 17). Challenging Apple's call for the appification of TV. Canadian Media Fund: CMF Trends. Retrieved from http://trends.cmf-fmc.ca/blog/challenging-apples-call-for-theappification-of-tv

Guiliani, E., Pietrobelli, C. \& Rabellotti, R. (2005). Upgrading in global value chains: Lessons from Latin American clusters. World Development, 33(4), 549-573. 
Guinness Book of World Records. (2015). Highest box office films gross—Inflation adjusted. Retrieved from http://www.guinnessworldrecords.com/world-records/highest-box-office-film-gross-inflationadjusted/

Habaradas, R. (2008). SME development and technology upgrading in Malaysia: Lessons for the Phillippines. Journal of International Business Research, 1(7), 89-116.

Hagey, K., \& Ramachandran, S. (2015, June 16). Hulu steps up its fight against Netflix. The Wall Street Journal. Retrieved from http://www.wsj.com/articles/hulu-steps-up-its-fight-against-netflix1434497311

Hale, M. (2015, May 19). Review: Netflix's 'Between' puts a polite damper on growing old. The New York Times. Retrieved from http://www.nytimes.com/2015/05/20/arts/television/review-netflixsbetween-puts-a-polite-damper-on-growing-old.html?_r=0

Harris, J. (2010). Entertainment industry against the world [Web log post]. Retrieved from http://lostincomment.blogspot.ca/2010/08/entertainment-industry-against-world.html

Harris, S. (2015, March 13). Target closing 16 stores next week. CBC News. Retrieved from http://www.cbc.ca/news/business/target-canada-closing-16-stores-next-week-1.2992063

Havens, T., Lotz, A. D., \& Tinic, S. (2009). Critical media industry studies: A research approach. Communication, Culture \& Critique, 2(2), 234-253

Hearle, K. C., McHenry, G. C., Reitzes, J. D., Verlinda, J., \& Bazelon, C. (2014, May 2). Canadian wireless market performance and the potential effect of an additional performer. Huffington Post. Retrieved from http://www.huffingtonpost.com/bruce-kushnick/time-warner-cables-97pro_b_6591916.html

Hibberd, J. (2014, August 13). TV fight club: “The Sopranos” vs "Breaking Bad.” Entertainment Weekly. Retrieved from http://www.ew.com/article/2014/08/13/the-sopranos-vs-breaking-bad

Hickey, W. (2013, September 29). In one chart, here's how "Breaking Bad" was like no other show that came before it. Business Insider. Retrieved from http://www.businessinsider.com/chart-breakingbad-is-the-greatest-show-ever-made-2013-9

Hinckley, D. (2014, March 5). Average American watches 5 hours of TV per day, report shows. New York Daily News. Retrieved from http://www.nydailynews.com/life-style/average-americanwatches-5-hours-tv-day-article-1.1711954

Hollywood Creative Directory Staff. (2005). Hollywood creative directory (54th ed.). Santa Monica, CA: Author.

Hoskins, C., \& McFadyen, S. (1991). The U.S. competitive advantage in the global television market: Is it sustainable in the new broadcasting environment? Canadian Journal of Communications, 16(2). Retrieved from http://cjc-online.ca/index.php/journal/article/view/602/508 
Hoskins, C., McFadyen, S., \& Finn, A. (1994). The environment in which cultural industries operate and some implications. Canadian Journal of Communication, 19(3). Retrieved from http://cjconline.ca/index.php/journal/article/view/824/730

Hoskins, C., McFadyen, S., \& Finn, A. (2000a). Cultural industries from an economic/ business research perspective. Canadian Journal of Communication, 25(1). Retrieved from http://cjconline.ca/index.php/journal/article/viewArticle/1146

Hoskins, C., McFadyen, S. \& Finn, A. (2004). Media economics: Applying economics to new and traditional media. Thousand Oaks, CA: Sage.

Hoskins, C., McFadyen, S., \& Finn, A. (2008). Global television and film. New York, NY: Oxford University Press.

Hoskins, C., \& Mirus, R. (1988). Reasons for the U.S. dominance of the international trade in television programmes. Media, Culture and Society, 10(4), 499-515. doi:10.1177/016344388010004006

Hsieh, H. F., \& Shannon, S. E. (2005). Three approaches to qualitative content analysis. Qualitative health research, 15(9), 1277-1288. doi:10.1177/1049732305276687

Huang, Y., \& Khanna, T. (2003, July/August). Can India overtake China? Foreign Policy, 74-81.

Humphrey, J., \& Schmitz, H. (2000a). Governance and upgrading: Linking industrial cluster and global value chain research (IDS Working Paper 120). Retrieved from http://www.ids.ac.uk/publication/governance-and-upgrading-linking-industrial-cluster-and-globalvalue-chain-research

Humphrey, J. \& Schmitz, H. (2000b). Governance and upgrading in global value chains. Paper for the Bellagio value chain workshop. Institute of development studies, University of Sussex. Brighton: UK. Retrieved from http://www.ids.ac.uk/ids/global/pdfs/jhhs\%20Bellagio.pdf

Humphrey, J., \& Schmitz, H. (2002). How does insertion in global value chains affect upgrading in industrial clusters? Regional Studies, 36(9), 1017-1027. doi:10.1080/0034340022000022198

Idea Connection. (2015). Open innovation: Goldcorp challenge. Retrieved from http://www.ideaconnection.com/open-innovation-success/Open-Innovation-Goldcorp-Challenge00031.html

Inkpen, A. C., \& Tsang, E. W. (2005). Social capital, networks, and knowledge transfer. Academy of Management Review, 30(1), 146-165.

Institute for Strategy and Competitiveness. (n.d.). Cluster profiles. Retrieved from http://data.isc.hbs.edu/cp/

Institute for Strategy and Competiveness. (2015). Canadian cluster data. Retrieved from http://www.competeprosper.ca/index.php/clusters/data/ 
Internet Live Statistics. (n.d.). Google search statistics. Retrieved from

http://www.internetlivestats.com/google-search-statistics/

Internet virtually ubiquitous in Canada: Netflix has changed the way Internet TV service are used: MTM reports (2014, April 22). Cartt.ca. Retrieved from https://cartt.ca/article/internet-virtuallyubiquitous-canada-netflix-has-changed-way-internet-tv-services-are

Irish Film Board. (2015). Other fiscal incentives. Retrieved from http://www.irishfilmboard.ie/financing_your_film/Other_Fiscal_Incentives/6

Jean, A., Kern, B., Melvoin, J., Pettler, P., Prestwich, D., Veasey, P., Wirth, J., \& Yorkin, N. (2012). Writing for episodic TV: From freelance to showrunner. Retrieved from http://www.wga.org/content/default.aspx?id=156

Jenkins, H. (2004, March). The cultural logic of media convergence. International journal of cultural studies, 7 (1), p. 33-43.

Jenkins, H. (2006). Convergence culture: Where old and new media collide. New York, NY: New York University Press.

Johannsson, R. (2003). Case study methodology. Key note speech at the International Conference "Methodologies in Housing Research" organized by the Royal Institute of Technology in cooperationwith the International Association of People-Environment Studies. September 22-24, Stockholm, Sweden. Retrieved from http://www.psyking.net/HTMLobj3839/Case_Study_Methodology-_Rolf_Johansson_ver_2.pdf

Johnson, T. (2014, April 5). "House of Cards" receives Maryland tax credit. Variety. Retrieved from http://variety.com/2014/biz/news/house-of-cards-maryland-filming-1201164393/

Johnson-Yale, C. (2008). "So-called runaway film production": Countering Hollywood's outsourcing narrative in the Canadian press. Critical Studies in Media Communications, 25(2), 113-134. doi:10.1080/15295030802032259

Kahn, B. E. (2013). Global brand power: Leveraging branding for long-term growth. Philadelphia, PA: Wharton Digital Press.

Karlsson, C., \& Picard, R. G. (2011, March). Media clusters and media cluster policies (CESIS electronic working paper series, paper no. 246). Retrieved from https://static.sys.kth.se/itm/wp/cesis/cesiswp246.pdf

Karpel, A. (2013, July 18). Do Netflix Emmy nominations blur the line forever about what is television? Fast Company. Retrieved from http://www.fastcocreate.com/1683422/do-netflixs-emmynominations-blur-the-line-forever-about-what-is-television

Kawale, N. (2014, June). Keynote speech, Canadian Telecom Summit, Toronto, ON. 
Kiefl, B. (2008, April 14). Measuring TV audiences: Defining “audience success” (Report to the Canadian Radio-television and Telecommunications Commission). Retrieved from www.crtc.gc.ca/eng/publications/reports/cmri080605.htm

Kiefl, B. (2011, July). Trends in TV and Internet Use: The impact of Internet TV on Canadian programming, appendix 1: Joint submission of ACTRA, APFTQ, CMPA, DGC and WGC in response to B/TNOC 2011-34. Retrieved from http://www.omdc.on.ca/Assets/Research/Research+Reports/Trends+in+TV+and+Internet+Use/Tre nds+in+TV+and+Internet+Use_en.pdf

Kiefl, B. (2013, April 18). 60th Anniversary of Canadian TV: Why we don't have hit TV series.

Retrieved from http://mediatrends-research.blogspot.ca/2013/04/60th-anniversary-of-canadian-tvwhy-we.html

Kissell, R. (2014, August 6). Update: Emmy's draw second largest audience in eight years. Variety. Retrieved from http://variety.com/2015/data/ratings/golden-globes-ratings-on-nbc-down-vs-lastyear-still-strong-1201400878/

Kissell, R. (2015, January 12). Golden Globes ratings on NBC down vs. last year, still strong. Variety. Retrieved from http://variety.com/2015/data/ratings/golden-globes-ratings-on-nbc-down-vs-lastyear-still-strong-1201400878/

Kulish, N., \& Cieply, M. (2011, December 5). Around the world in one movie: Film financing's global future. The New York Times. Retrieved from http://www.nytimes.com/2011/12/06/business/media/around-world-in-one-movie-film-financingsglobal-future.html?pagewanted=all\&_r=0

Kushnick, B. (2015, February 2). Time Warner Cable's 97 percent profit margin on high speed internet service exposed. Huffington Post. Retrieved from http://www.huffingtonpost.com/brucekushnick/time-warner-cables-97-pro_b_6591916.html

Lamolinara, G. (1996, February 19). Wired for the future, President Clinton signs Telecommunications Act at LC. Library of Congress. Retrieved from http://www.loc.gov/loc/lcib/9603/telecom.html

Lampel, J., Lant, T. \& Shemise, J. (2000). Balancing act: Learning from organizing practices in cultural industries. Organization Science, 11(3), p. 263-269.

Larrea, T. (1997). Eliminate the cultural industries exemption from NAFTA. Santa Clara Review, 37(4), Article 7. p. 1107-1150. Retrieved from file:///Users/irene/Downloads/Larrea,\%20valenti\%20and\%20Eliminate\%20the\%20Cultural\%20Ind ustries\%20Exemption\%20from\%20NAFTA.pdf

Lasswell, H. D. (1970). The emerging conception of policy sciences. Policy Sciences, 1(1), 3-14. 
Lawson, R. (2012, July 13). The case for "Breaking Bad" as television's best show. The Wire. Retrieved from http://www.thewire.com/entertainment/2012/07/case-breaking-bad-televisions-bestshow/54565/

Le Goff, J-P., Brunet, J., Davis, C. H., Giroux, D., \& Sauveageau, F. (2011, December). Canada 's Independent Television Production : Funding, Supply and Audience. Sainte-Foy, QC: Centre d'études sur les medias, Université Laval.

Lemieux, R., \& Jackson, J. (1999, October 12). Cultural exemptions in Canada's major international trade agreements and investment relationships. Retrieved from http://www.parl.gc.ca/Content/LOP/researchpublications/prb9925-e.htm

Lester, J. (2013). Tax credits for foreign location shooting of films: No net benefit for Canada. Canadian Public Policy, 39(3), 451-472.

Levitt, T. (1960). Marketing myopia. Harvard Business Review, 38(4), 24-47.

Lewis, J. (2001). Constructing public opinion. New York, NY: Columbia University Press.

Libresco, L. (2015, June 24). Here's how Americans spend their working, relaxing and parenting time [Web log post]. Retrieved from http://fivethirtyeight.com/datalab/heres-how-americans-spendtheir-working-relaxing-and-parenting-time/

Litt, P. (1992). The muses, the masses and the Massey Commission. Toronto, ON: University of Toronto Press. Littleton, C. (2014, March 18). TV's new playing field. Variety. Retrieved from http://variety.com/2014/tv/news/its-a-new-playing-field-for-the-big-four-networks-1201136859

Lloyd, R. (2012, April 23). Television review: "The L.A. Complex" twists the familiar. The Los Angeles Times. Retrieved from http://articles.latimes.com/2012/apr/23/entertainment/la-et-la-complex20120423

Lorenzen, M., \& Mudambi, R. (2012). Clusters, connectivity and catch-up: Bollywood and Bangalore in the global economy. Journal of Economic Geography. Doi: 10.1093/jeg/lbs017

Lowry, B. (2015). TV review: “Schitt's Creek." Variety.com. Retrieved from http://variety.com/author/brian-lowry

Macaray, D. (2013, September 4). The 2007-08 writers' strike. Huffington Post. Retrieved from http://www.huffingtonpost.com/david-macaray/the-200708-writers-strike_b_3840681.html

MacDonald, G. (2007, February 24). A hand up in a tough town. The Globe and Mail. Retrieved from http://www.theglobeandmail.com/arts/a-hand-up-in-a-tough-town/article4094117/?page=all

Macerola, F. (2003, June). Canadian content in the $21^{\text {st }}$ century in film and television productions: A matter of cultural destiny (Cat. No. CH44-29/2003). Retrieved from https://www.sfu.ca/cmns/courses/230/Body\%20text.section/Canada/Canadian\%20Content2003E.pdf 
MacInnis, L. (2012, January 14). White House casts doubt over anti-piracy legislation. Reuters. Retrieved from http://www.reuters.com/article/2012/01/14/us-usa-internet-whitehouse-

idUSTRE80D0Q520120114

Madrigal, A. C. (2014, January 2). How Netflix reverse engineered Hollywood. The Atlantic. Retrieved from http://www.theatlantic.com/technology/archive/2014/01/how-netflix-reverse-engineeredhollywood/282679/

Mandel-Campbell, A. (2007). Why Mexicans don't drink Molson: Rescuing Canadian business from the suds of global obscurity. Vancouver, BC: Douglas \& McIntyre.

Markoff, J. (2007, November 5). Crashes and traffic jams in military test of robotic vehicles. The New York Times. Retrieved from http://www.nytimes.com/2007/11/05/technology/05robot.html?_r=0

Marshall, A. (1890). Principles of economics. London, UK: Macmillan.

Martin Prosperity Institute. (2009a). Ontario competes: Performance overview using the 3Ts of economic development. Toronto, ON: Author.

Martin Prosperity Institute. (2009b). Ontario in the creative age. Toronto, ON: Author. Retrieved from http://martinprosperity.org/2011/01/01/ontario-in-the-creative-age/

Martin Prosperity Institute. (2011). Prospects for Ontario's prosperity: Annual report 10. Toronto, ON: Author. Retrieved from http://www.competeprosper.ca/work/annual_reports

McAllister, M. (2015). The financial interest and syndication rules: U.S. broadcasting regulations. Retrieved from http://www.museum.tv/eotv/financialint.htm

McGrath, B. (2006, October 16). It should happen to you. The New Yorker. Retrieved from http://www.newyorker.com/magazine/2006/10/16/it-should-happen-to-you

McLuhan, M. (1970). Culture is our business. New York: McGraw-Hill.

McMillan, G. (2014, July 2). Online ads make more money for networks than traditional TV. Wired.com. Retrieved from http://www.wired.com/2014/07/digital-tv-ads/

McQueen, T. (2003). Dramatic choices: A report on Canadian English-language drama. Ottawa, ON: Canadian Radio-television and Telecommunications Commission. Retrieved from http://www.crtc.gc.ca/eng/Library/Detail/catalog5894

Meeker, M. (2015, May 27). Internet trends 2015-code conference. Kleinter Perkins Caufield Byers (KPCB). Retrieved from http://www.slideshare.net/kleinerperkins/internet-trends-v1

Miller, M. J. (1987). Turn up the contrast: CBC television drama since 1952. Vancouver, BC: University of British Columbia Press.

Miller, T. (2004). A view from a fossil: The new economy, creativity and consumption-Two or three things I don't believe in. International Journal of Cultural Studies, 7(1), 55-65. doi:10.1177/1367877904040605 
Miller, T., Govil, N., McMurrin, J., Maxwell, R., \& Wang, T. (2005). Global Hollywood 2. London, UK: British Film Institute.

Museum of Broadcast Communications. (n.d.). United States: Cable television. Retrieved from http://www.museum.tv/eotv/unitedstatesc.htm

Nadler, James \& Davis, C.H. (2012, April). The showrunner: Creative, economic and transmedia coordination of project-based production in the North American television industry. Paper presented at the International Symposium on Media Innovations, Oslo, Norway.

Nadler, J., Davis, C.H., \& Kaye, J. (2010, June). Who's running the show? Creative and economic showrunner models in the U.S. and Canada. Paper presented at the First Annual Popular Culture Association of Australian and New Zealand (PopCAANZ) conference, Sydney, Australia.

Nahapiet, J., \& Ghoshal, S. (1998). Social capital, intellectual capital, and the organizational advantage. Academy of Management Review, 23(2), 242-266.

National Aeronautics and Space Administration. (2014). NASA's 2015 sample return robot challenge open for registration. Retrieved from http://www.nasa.gov/press/2014/september/nasas-2015sample-return-robot-challenge-open-for-registration/\#.VRg1CjvF9fw

Nearly 1 in 10 English-speaking Canadians watch content online: Study. (2015, February 18). CTV News. Retrieved from http://www.ctvnews.ca/sci-tech/nearly-1-in-10-english-speaking-canadians-onlywatch-content-online-study-1.2242292

Netflix. (2009). Netflix prize. Retrieved from http://www.netflixprize.com/

New York City Economic Development Corporation. (2015). NYC next idea. Retrieved from http://www.nycedc.com/program/nyc-next-idea

New York Times Service. (1970, May). FCC votes to drop limits on cable TV. Noted as reprinted in The Globe and Mail, May 18, 1970. Article supplied by personal communication, Ken Goldstein, March 25, 2015.

Nielsen. (n.d.). Celebrating 90 years of innovation. Retrieved from http://sites.nielsen.com/90years/ Nielsen Company. (2014, December). The total audience report. Retrieved from http://www.nielsen.com/content/dam/corporate/us/en/reports-downloads/2014\%20Reports/totalaudience-report-december-2014.pdf

Nikitopoulos, C. (2015, July 9). Personal communication: Guest presentation to Ryerson University MBA class, MT8411 SS 2015, Media, Consumers \& Markets, which I teach.

Noakes, S. (2015, March 18). CRTC quest for quality set to shake up Canadian production. CBC News. Retrieved from http://www.cbc.ca/news/business/crtc-quest-for-quality-set-to-shake-up-canadianproduction-1.2998419 
Noam, E. M. (2008, July 11). TV or not TV: Three screens, one regulation? (Report to the Canadian Radio-television and Telecommunications Commission). Retrieved from http://www.crtc.gc.ca/eng/media/noam2008.htm

Noam, E. M. (2014). Cloud TV: Toward the next generation of network policy debates. Telecommunications Policy, 38(8), 684-692.

Nordicity. (2008). Canadian television: Why the subsidy? Retrieved from www.nordicity.com/media/20121112ccyguzuj.pdf

Nordicity. (2009a). Analysis of the economics of Canadian television programming. Retrieved from www.nordicity.com/media/20121112barxegyz.pdf

Nordicity. (2009b). Towards a national digital strategy, issues discussion paper, Release 1.0. Retrieved from http://www.nordicity.com/digitalstrategy/Towards-a-National-Digital-Strategy.pdf

Nordicity. (2013, July). Canada's video game industry in 2013, final report. Retrieved from heesa.ca/wpcontent/uploads/2013/10/ESAC-Video-Games-Profile-2013-FINAL-2013-10-21-CIRC.pdf

Nowak, P. (2013, March 18). The country most gouged by telecom companies. Huffington Post. Retrieved from http://www.huffingtonpost.ca/peter-nowak/telecom-canada_b_2902174.html

Noy, C. (2008). Sampling knowledge: The hermeneutics of snowball sampling in qualitative research. International Journal of Social Research Methodology, 11(4), 327-344.

O’Brien, G. (2015, April 15). NAB 2015: Content discoverability to be the top challenge for the TV biz and there's no number two [Web log post]. Retrieved from https://cartt.ca/user/8139/posts

O'Connell, M. (2014, February 19). Ratings mystery, the guessing game of who's watching Netflix originals. The Hollywood Reporter. Retrieved from http://www.hollywoodreporter.com/news/house-cards-ratings-mystery-guessing-681375

O’Conner, J. J., \& Robertson, E. F. (1997). Longitude and the Académie Royale. Retrieved from http://www-history.mcs.st-and.ac.uk/HistTopics/Longitude1.html

Office of the United States Trade Representative. (n.d.). Canada: U.S.-Canada trade facts. Retrieved from https://ustr.gov/countries-regions/americas/canada

Oliviera, M. (2014, February 4). Netflix subscribers nearly a third of English Canada. Huffington Post Canada. Retrieved from http://www.huffingtonpost.ca/2014/02/04/netflix-canadasubscribers_n_4724597.html

Oliveira, M. (2015, January 5). Netflix says "virtually crossing borders" not ok. CTV News. Retrieved from http://www.ctvnews.ca/sci-tech/netflix-says-virtually-crossing-borders-not-ok-1.2172688 Olson, S.R. (1999). Hollywood planet: Global media and the competitive advantage of narrative transparency. Mahwah, N.J.: Lawrence Erlbaum.

Onstad, K. (2009). Screenwriter and executive producer Tassie Cameron. Chatelaine, 202-203. 
Ontario Media Development Corporation. (2010). Canada's digital economy strategy: Response to Government of Canada consultation. Retrieved from https://www.ic.gc.ca/eic/site/028.nsf/eng/00285.html

Ontario Media Development Corporation. (2013). Annual report 2012-2013. Retrieved from http://www.omdc.on.ca/Assets/Communications/Annual+Report/Annual+Report+20122013_en.pdf

Ontario Media Development Corporation. (2014, March 10). Industry profiles. Film and TV. http://www.omdc.on.ca/collaboration/research_and_industry_information/industry_profiles/Film_ _TV_Industry_Profile.htm

Ontario Ministry of Tourism and Culture. (2010). Ontario's entertainment and creative cluster: A framework for growth. Toronto, ON: Queen's Printer for Ontario.

O'Regan, T., \& Goldsmith, B. (2006). Making cultural policy: Meeting cultural objectives in a digital environment. Television and New Media, 7(1), 68-91. doi:10.1177/1527476403253922

Ormanidhi, O., \& Stringa, O. (2008). Porter's model of generic competitive strategies: An insightful and convenient approach to firms' analysis. Business Economics, 43(3), 55-64. doi:10.2145/20080305

Palmer, P. (2015, January 23). Why broadcasting and telecoms belong in different legislation. Philip Palmer Law. Retrieved from http://philippalmerlaw.ca/broadcasting-telecoms-belong-differentlegislation/

Palmer, S. (2006). Television disrupted: The transition from network to networked TV. Burlington, MA: Focal Press/Elsevier.

Panthania-Jain, G. (2001). Global parents, local partners: A value-chain analysis of collaborative strategies of media firms in India. The Journal of Media Economics, 14(3), 169-187. doi:10.1207/S15327736ME1403_3

Parks Associates. (2015, January 22). Seventeen percent of U.S. broadband households are likely to subscribe to an OTT HBO service. Retrieved from http://www.parksassociates.com/blog/article/prjan2015-ott-hbo

Parliament of Canada. (1999). Cultural exemptions in Canada's major international trade agreements and investment relationships. Retrieved from http://www.parl.gc.ca/Content/LOP/researchpublications/prb9925-e.htm

Parsons, W. (2004, March). Not just steering, but weaving: relevant knowledge and the craft of building policy capacity and coherence. Australian Journal of Public Administration. 63 (1), p. 43-57.

Patterson, R. (2006). Transnationalism: Diaspora-homeland development. Social Forces, 84(4), 18911907. doi:10.1353/sof.2006.0103 
Pettigrew, A.M. (1990). Longitudinal field research on change: Theory and practice. Organization science, 1(3), 267-292.

Pisano, G. S. (2015, June). You need an innovation strategy. Harvard Business Review. Retrieved from file://localhost/Users/irene/Documents/phd2015MayMark/Pisano,\%20YOU\%20NEED\%20AN\%2 OINNOVATION\%20STRATEGY._\%20EBSCOhost.html

Playback. (2014, September 9). @irenesberkowitz proposes identifying Canada/countries on IMDB w "small flag" so Canadian talent/writers more easily found \#crtc \#letstalk [Twitter feed]. Retrieved from https://twitter.com/playbackonline/status/509334770384646144

Plunkett, J., \& Deans, J. (2013). Kevin Spacey: Television has entered a new golden age. The Guardian. Retrieved from http://www.theguardian.com/media/2013/aug/22/kevin-spacey-tv-golden-age

Porter, M.E. (1985). The competitive advantage: Creating and sustaining superior performance. New York: Simon and Schuster.

Porter, M. E. (1990). The competitive advantage of nations. New York, NY: Free Press.

Porter, M. E. (1996, November). What is strategy? Harvard Business Review, 61-78. Retrieved from https://hbr.org/1996/11/what-is-strategy/ar/1

Porter, M. E. (1998a). Competitive strategy: Techniques for analyzing industries and competitors. New York, NY: The Free Press. (Original work published 1980)

Porter, M. E. (1998b, November). Clusters and the new economics of competition. Harvard Business Review, 77-90. Retrieved from https://hbr.org/1998/11/clusters-and-the-new-economics-ofcompetition

Porter, M. E. (2008). On competition-Updated and expanded edition. Boston, MA: Harvard Business School.

Potts, J., Cunningham, S., Hartley, J., \& Ormerod, P. (2008). Social network markets: A new definition of the creative industries. Journal of Cultural Economics, 32(3), 167-185.

Prudom, L. (2014, June 13). “Orphan Black” creators talk Transgender Tony, Helena and Rachel's maternal instincts. Variety. Retrieved from http://variety.com/2014/tv/news/orphan-black-creatorstransgender-tony-helena-rachel-1201219983/

Public Interest Advocacy Center/PIAC (2014, September 9). Let's Talk TV, Day 2. Retrieved from http://www.piac.ca/telecom/let_s_talk_tv_day_2/

Punter, J. (2013, September 17). Toronto: New Canadian distribution shingle inks deal with Black Bear. Variety. Retrieved from http://trends.cmf-fmc.ca/blog/challenging-apples-call-for-the-appificationof-tv 
PwC. (2014). Global entertainment and media outlook. Retrieved from

http://www.pwc.com/gx/en/global-entertainment-media-outlook/segment-insights/internetadvertising.jhtml

QSR International. (2015). Products. Retrieved from http://www.qsrinternational.com/products.aspx Raboy, M. (1990). Missed opportunities: The story of Canada's broadcasting policy. Montreal, QC: McGill-Queen's University Press.

Reca, A. A. (2006). Issues in media product management. In A. B. Albarran, S. M. Chan-Olmstead, \& M. O. Wirth (Eds.), Handbook of media management and economics (pp. 181-201). Mahwah, NJ: Lawrence Erlbaum.

Reilly, T. (2014, December 9). Netflix plans to launch 20 new originals every year. The Wrap. Retrieved from http://www.thewrap.com/netflix-plans-to-launch-20-new-originals-every-year/

Revler, N. (2008). Shaw slams TV fund at CRTC hearing. The Hollywood Reporter. Retrieved from http://www.hollywoodreporter.com/news/shaw-slams-tv-fund-at-104321

Rideout, V., Foehr, U., \& Roberts, D. F. (2010). Generation $M^{2}$ : Media in the lives of 8-to-18-year-oldsA Kaiser Family Foundation study. Menlo Park: CA, Henry J. Kaiser Family Foundation. Retrieved from https://kaiserfamilyfoundation.files.wordpress.com/2013/04/8010.pdf

Robertson, G. (2009, October 28). The day Leonard Asper lost the Street. The Globe and Mail. Retrieved from http://www.theglobeandmail.com/report-on-business/rob-magazine/the-day-leonard-asperlost-the-street/article4320504/?page=all

Rody-Mantha, B. (2015, May 26). Netflix projected to top 100 million subscriers by 2020: Report. Retrieved from http://streamdaily.tv/2015/05/26/netflix-projected-to-top-100-million-subscribersby-2020-report/

Rosen, S. (2003). China goes Hollywood. Foreign Policy, 134, 94-98.

Rosenberg, H. (1994, September 15). No breakthroughs in three new dramas. Los Angeles Times. Retrieved from http://articles.latimes.com/1994-09-15/entertainment/ca-38644_1_tv-reviews

Royal Commission on National Development in the Arts, Letters, and Sciences. (1951). Report-Royal Commission on National Development in the Arts, Letters, and Sciences, 1949-1951. Ottawa, ON: Edmond Cloutier, Printer to the King's Most Excellent Majesty.

Royal Commission on Radio Broadcasting. (1929). Report of the Royal Commission on Radio Broadcasting. Ottawa, ON: F.A. Acland, Printer to the King.

RTA School of Media. (n.d.). RTA in LA. Retrieved from http://www.ryersonrta.ca/opportunities/rta-la Rust, R. T., Moorman, C., \& Bhalla, G. (2013). Rethinking marketing. In On strategic marketing: HBR's 10 must reads (pp. 1-14). Boston, MA: Harvard Business School Publishing. 
Ruttan, V. W. (1959). Usher and Schumpeter on invention, innovation, and technological change. The Quarterly Journal of Economics, 73(4), 596-606. doi:10.2307/1884305

Sachs, J. (2012). Winning the story wars: Why those who tell-and live-the best stories will rule the future. Boston, MA: Harvard Business Review Press.

Sadler, G. R., Lee, H. C., Lim, R. S. H., \& Fullerton, J. (2010). Recruitment of hard-to-reach population subgroups via adaptations of the snowball sampling strategy. Nursing \& Health Sciences, 12(3), 369-374.

Sandvoss, C. (2003). A game of two halves: Football, television and globalization. London, UK: Routledge.

Saving Hope: Cancelled series returns to U.S. television. (2014, September 11). TV Series Finale. Retrieved from http://tvseriesfinale.com/tv-show/saving-hope-cancelled-series-returning-to-ustelevision-33850/

Saxenian, A. (1994). Regional advantage: Culture and competition in Silicon Valley and Route 128. Boston, MA: Harvard University Press.

Schneider, M. (2014, June 6). America's most watched: The top 50 shows of the 2013-2014 season. TV Guide. Retrieved from http://www.tvguide.com/news/most-watched-shows-2013-2014-1082628/

Schulz, C. (2013, December 9). For and against: Is "Breaking Bad" the best TV show of all time? The New Zealand Herald. Retrieved from http://www.nzherald.co.nz/entertainment/news/article.cfm?c_id=1501119\&objectid=11174575

Scott, A. J. (1999). The cultural economy: Geography and the creative field. Media, Culture \& Society, 21(6), 807-817. doi:10.1177/016344399021006006

Scott, A. J. (2002). A new map of Hollywood: The production and distribution of American motion pictures. Regional Studies, 36(9), 957-975. doi:10.1080/0034340022000022215

Scott, A. J. (2005). On Hollywood: The place, the industry. Princeton, NJ: Princeton University Press.

Scott, A.J. (2006). Creative cities: conceptual issues and policy questions. Journal of urban affairs, 28(1), $1-17$.

Scott, A.J. \& Pope, N.E. (2007). Hollywood, Vancouver, and the world: employment relocation and the emergence of satellite production sectors in the motion picture industry. Environment and Planning A, 39(6), 1364.

Selznick, B. (2008). Global television: Co-producing culture. Philadelphia, PA: Temple University Press.

Schein, J. B. (2012). At Ford, turn around is job one (Kellogg School of Management, the Case Centre, Case \#5-211-250) Retrieved from http://www.thecasecentre.org/educators/

Simonton, D. K. (2002). Collaboration aesthetics in the feature film: Cinematic components predicting the differential impact of 2,323 Oscar-nominated movies. Empirical Studies of the Arts, 20, 115-125 
Skilton, P. F. (2008). Similarity, familiarity and access to elite work in Hollywood: Employer and employee characteristics in breakthrough employment. Human Relations, 61, 1743-1773.

Slywotzky, A.J. (1996). Value migration: How to think several moves ahead of the competition. Boston, MA: Harvard Business School Press.

Smart, A., \& Hsu, J-Y. (2004). The Chinese diaspora, foreign investment and economic development in China. The Review of International Affairs, 3(4), 544-566. doi:10.1080/1475355042000241511

Smith, A. (2014, December 9). Online video streaming up 60\%, TV consumption down but not out. Retrieved from http://www.reelseo.com/online-video-streaming-up-60-per-cent/

SOFA Entertainment. (2010). The Ed Sullivan Show-The official Ed Sullivan site. Retrieved from http://www.edsullivan.com/most-frequent-ed-sullivan-show-guests/

Spangler, R. (2015, October 23). The force awakens - but only in Canada. Variety. Retrieved from http://variety.com/2015/digital/news/star-wars-netflix-streaming-1201623566/

Standing Committee on Canadian Heritage. (2003). Our cultural sovereignty: The second century of Canadian broadcasting. Retrieved from http://www.parl.gc.ca/HousePublications/Publication.aspx?DocId=1032284

Statista. (n.d.a). TV advertising revenue in the United States 2015 to 2019 (in billion U.S. dollars). Retrieved from http://www.statista.com/statistics/259974/tv-advertising-revenue-in-the-us/ Statista. (n.d.b). Global television advertising revenues from 2015-2019 (in billion U.S. dollars). Retrieved from http://www.statista.com/statistics/237803/global-tv-advertising-revenue/ Statista. (2015). Number of TV households in the United States from season 2000-2001 to season 20142015 (in millions). Retrieved from http://www.statista.com/statistics/243789/number-of-tvhouseholds-in-the-us/

Statistics Canada. (2009). Study: GDP per capita and productivity in Canada and the United States. Retrieved from http://www.statcan.gc.ca/daily-quotidien/070326/dq070326a-eng.htm

Statistics Canada. (2013, February 13). Population by mother tongue, by province and territory, excluding institutional residents. 2011 census. Retrieved from http://www.statcan.gc.ca/tablestableaux/sum-som/101/cst01/demo11d-eng.htm

Stelter, B. (2008, January 29). O'Canada, where the writers aren't on strike. The New York Times. Retrieved from http://mediadecoder.blogs.nytimes.com/2008/01/29/o-canada-where-the-writersarent-on-strike/?_r=0

Stonehouse, G., \& Snowdon, B. (2007). Competitive advantage revisited: Michael Porter on strategy and competitiveness. Journal of Management Inquiry, 16(3), 256-273. doi:10.1177/1056492607306333

Storper, M. \& Scott, A.J. (2009). Rethinking human capital, creativity and urban growth. Journal of economic geography, Ibn052. 
Strangelove, M. (2015). Post-TV, piracy, cord-cutting and the future of television. Toronto, ON: University of Toronto Press.

Strauss, M. (2009, September 29). CTV, Global premieres soar, thanks to PPM. Playback. Retrieved from http://www.playbackonline.ca/articles/daily/20090929/ppm.html

Sturgeon, J. (2011, October 24). Where are TV viewers slipping away to? Financial Post. Retrieved from http://business.financialpost.com/2011/10/24/where-are-tv-viewers-slipping-away-to/?_lsa=a7e2c18a

Sunberg, J. (n.d.). Top ten personal branding quotes from people who made it. @ jorgensunberg. Retrieved from http://jorgensundberg.net/top-10-personal-branding-quotes-those-who-made-it/

Surridge, G. (2009, March 10). “The model is broken,” CRTC chief admits. Financial Post. Retrieved from https://www.reality-check.ca/archive/index.php/t-206663.html

Taylor, K. (2015, February 6). Numeris is calling, but Canadians need more information about TV ratings. The Globe and Mail. Retrieved from http://www.theglobeandmail.com/arts/television/numeris-is-calling-but-canadians-need-moreinformation-about-tv-ratings/article22838581/

Telefilm Canada. (n.d.). Partnering with Canada. Retrieved from http://www.telefilm.ca/canadausb/en/coventures/1\#/EN/COVENTURES/2

Telefilm Canada. (2015). History. Retrieved from http://www.telefilm.ca/en/telefilm/telefilm/history

Television Bureau of Canada. (n.d.). TVBasics 2014-2015. Retrieved from http://www.tvb.ca/page_files/pdf/InfoCentre/TVBasics.pdf

Thomas, S., \& Kohli, C. (2009). A brand is forever! A framework for revitalizing declining and dead brands. Business Horizons, 52(4), 377-386. doi:10.1016/j.bushor.2009.03.004

Tillson, T. (2003). Fireworks founder Firestone exits. Variety. Retrieved from http://variety.com/2003/film/markets-festivals/fireworks-founder-firestone-exits-1117885676/

Tinic, S. (2005). On location: Canada's television industry in a global market. Toronto, ON: University of Toronto Press.

Tortoriello, M., Reagans, R., \& McEvily, B. (2012). Bridging the knowledge gap: The influence of strong ties, network cohesion, and network range on the transfer of knowledge between organizational units. Organization Science, 23(4), 1024-1039.

Trudeau, P. E. (1969). Washington Press Club speech [Video file]. Retrieved from http://www.cbc.ca/player/Digital+Archives/Politics/Prime+Ministers/ID/1801879425/

Tucker, R. (2015, February 6). At the Canadian Screen Awards, it really is an honour just to be nominated. National Post. Retrieved from http://news.nationalpost.com/arts/television/at-thecanadian-screen-awards-it-really-is-an-honour-just-to-be-nominated 
TVIV. (2008, October 23). Nielsen/Ratings/Historic/Network Television by Seasons/2000s. Retrieved from http://tviv.org/Nielsen_Ratings/Historic/Network_Television_by_Season/2000s\#2004.E2.80.932005_S eason

Uhlich, K. (2015, May 19). 'Between': TV review. The Hollywood Reporter. Retrieved from http://www.hollywoodreporter.com/review/between-tv-review-796866

United Nations. (2008). Creative economy report 2008-The challenge of assessing the creative economy: Towards informed policy-making. Geneva, Switzerland, Author. Retrieved from http://www.unctad.org/en/docs/ditc20082cer_en.pdf

United States Department of Labor, Bureau of Labor Statistics. (DATE). Career guide to industries. Washington, DC: U.S. Government Printing Office.

University of Cambridge Digital Library. (n.d.). Papers of the Board of Longitude (RGO 14/1). Retrieved from http://cudl.lib.cam.ac.uk/view/MS-RGO-00014-00001/19

Van Den Steen, E. (2014). Tesla Motors (HBS case no. 9-714-413). Boston, MA: Harvard Business School Publishers.

Vanderbilt, T. (2013, August 7). The science behind the Netflix algorithms that decide what you'll watch next. Wired. Retrieved from http://www.wired.com/2013/08/qq_netflix-algorithm/

Vang, J., \& Chaminade, C. (2007a). Cultural clusters, global-local linkages and spillovers: Theoretical and empirical insights from an exploratory study of Toronto's film cluster. Industry \& Innovation, 14(4), 401-420. doi:10.1080/13662710701523942

Vang, J., \& Chaminade, C. (2007b). Spatial organization of the news industry: Questioning assumptions about knowledge externalities for clustering of creative industries. Innovation: Management, Policy \& Practice, 9(1), 14-27.

Vlessing, E. (2008, February 4). Canadians see sellers market. The Hollywood Reporter. Retrieved from http://www.hollywoodreporter.com/news/canadians-see-sellers-market-103985

Vlessing, E. (2009a, January 20). Homemade market share slips to 3\%. Playback. Retrieved from http://www.playbackonline.ca/articles/daily/20090120/box.html

Vlessing, E. (2009b, January 26). The small screen: Canadian content creep. Playback. Retrieved from http://www.playbackonline.ca/articles/magazine/29900126

Vlessing, E. (2014, May 13). Shaw Media's strategy at LA Screenings. Media in Canada. Retrieved from http://mediaincanada.com/2014/05/13/inside-shaw-medias-strategy-at-la-screenings/

Vlessing, E. (2015, May 12). LA screenings: Why it's getting tougher for Canadian broadcasters to buy online rights. Cartt.ca. Retrieved from https://cartt.ca/article/la-screenings-why-it\%E2\%80\%99sgetting-tougher-canadian-broadcasters-buy-online-rights 
Vlessing, E. (2015, July 8). Netflix's 'Between' renewed for second season. The Hollywood Reporter. Retrieved from http://www.hollywoodreporter.com/live-feed/netflixs-between-renewed-secondseason- 806920

Vogel, H. L. (2007). Entertainment industry economics: A guide for financial analysis (7th ed.). New York, NY: Cambridge University Press.

Watson, W. (2013, October 9). William Watson: Save \$470 illion today. Financial Post. Retrieved from http://business.financialpost.com/fp-comment/william-watson-save-470-million-today

Wharton, D. (1993, November 17). H'wood: Muy bueno, eh? Variety. Retrieved from http://variety.com/1993/biz/news/h-wood-muy-bueno-eh-115912/

Wildavsky, A. (2007). Speaking truth to power: The art and craft of policy analysis. (Twelfth printing). New Brunswick, NJ: Transaction Publishers.

Wohlsen, M. (2014, August 15). The Internet is officially more popular than cable in the U.S. Retrieved from http://www.wired.com/2014/08/the-internet-is-now-officially-more-popular-than-cable-inthe-u-s/

Wolf, M. J. (1999). Entertainment economy: How mega-media forces are transforming our lives. New York, NY: Three Rivers Press.

Wolff, M. (2015a). Television is the new television: The unexpected triumph of old media in the digital age. New York, NY: Portfolio/Penguin.

Wolff, M. (2015b, June 29). How television won the Internet. The New York Times. Retrieved from http://www.nytimes.com/2015/06/29/opinion/how-television-won-theinternet.html?emc=eta1\&_r=0

Writers Guild of America. (2015). Writing for episodic TV. Retrieved from http://www.wga.org/content/default.aspx?id=156

Wu, T. (2015, January 27). Netflix secret special algorithm is a human. The New Yorker. Retrieved from http://www.newyorker.com/business/currency/hollywoods-big-data-big-deal

Young, S.P. (ed.) (2013). Evidence-based policy-making in Canada: A multidisciplinary look at how evidence and knowledge shape Canadian public policy. Don Mills, ON: Oxford University Press.

Zhou, Y. (1996). Inter-firm linkages, ethnic networks, and territorial agglomeration of computer firms in Los Angeles. Papers in Regional Science, 75(3), 265-291. doi:10.1007/BF02406755

Zitzerman, D. (2012, March). Structuring an international treaty co-production or a CRTC co-venture: Insight 5th edition entertainment law: Best practice and lessons learned. Retrieved from www.goodmans.ca/files/file/docs/zitzerman.pdf

Zitzerman, D. (2014, January). Great White North. Update re: film and TV production in Canada. Los Angeles, CA. Goodmans LLP. 


\section{Glossary}

ACTRA - Alliance of Canadian Cinema, Television and Radio Artists

BAFTA - British Academy of Film and Television Arts

B2B - Business To Business

B2C - Business To Consumer

BDU - Broadcast Distribution Undertaking

CAGR - Compound Annual Growth Rate

CAVCO - Canadian Audio-Visual Certification Office

CFDC- Canadian Film Development Corporation

CMF - Canadian Media Fund

CMPA - Canadian Media Production Association

CPAC - Cable Public Affairs Channel

CPE - Canadian Program Expenditures

CRTC - Canadian Radio-television and Telecommunications Commission, The Commission

CTF - Canada Television Fund

CUSFTA - Canada United States Free Trade Agreement

DGC - Directors Guild of Canada

DCH - Department of Canadian Heritage

FCC - Federal Communications Commission

FICDC - Federation Internationale Des Coalitions Pour la Diversite Culturelle

FIN SYN - Financial Syndication Rules

FLS - Foreign Location Service productions, also known as "Service Productions"

FTA - Free Trade Agreement

FTE - Full Time Equivalent job

GATS - General Agreement on Trade in Services

GVC - Global Value Chain

HSP - Highly Skilled Professional

ICM - International Creative Management

ICT - Information and Communications Technology

IMDB - Internet Movie Data Base

IoE - Internet of Everything 
IOT - Internet of Things

IP - Intellectual Property

L.A. - Los Angeles

MAPL - Music, Artist, Performance, Lyrics

MOW - Movie of the Week

OMDC - Ontario Media Development Corporation

NAFTA - North American Free Trade Agreement

NASA - National Aeronautics Space Administration

OFR - Original First Run

OTT - Over The Top online content delivery

PBIT - Profit Before Interest and Taxes

PE - Performance Envelope

PNI - Programs of National Interest

R \& D - Research and Development

ROI - Return On Investment

RPV - Resources Processes \& Values

SAT - Screen Access Tax

SDT - Screen Device Tax

THT - Total Hours Tuned

UNESCO - United Nations Educational, Scientific, and Cultural Organization

U.S. - United States of America

VCE - Value Chain Evolution

VI - Vertically Integrated

VOD - Video On Demand

VPN - Virtual Private Network

WGA, WGA-W - Writers Guild of America, Writers Guild of America West

WGC - Writers Guild of Canada

WTO - World Trade Organization 